\author{
Monograph \\ urn:lsid:zoobank.org:pub:9CD3B2CD-F072-4994-8CA9-24145D343401
}

\title{
A revision of Cissidium Motschulsky (Coleoptera: Ptiliidae) with seventy seven new species
}

\author{
Michael DARBY \\ Department of Life Sciences, Natural History Museum, London, SW7 5BD, UK \\ Email: m.darby@nhm.ac.uk \\ urn:1sid:zoobank.org:author:FA87E30B-5023-4169-A47C-EB1EBC0A7EA1
}

\begin{abstract}
This paper examines the described species of Cissidium and adds 77 new ones based on a study of material in the Manchester Museum, UK, the Natural History Museum, London, UK and in the possession of Dr Yoshihiro Sawada, Japan. The new taxa are: Cissidium advena sp. nov., C. amazonicum sp. nov., C. amieuense sp. nov., C. angulatum sp. nov., C. angusi sp. nov., C. apterum sp. nov., C. arcuatum sp. nov., C. aristophanousi sp. nov., C. besucheti sp. nov., C. bifoveolatum sp. nov., C. bilineatum sp. nov., C. bomjesus sp. nov., C. brachypterum sp. nov., C. ceylonicum sp. nov., C. clareae sp. nov., C. cryptophagoides sp. nov., C. davaoense sp. nov., $C$. deanei sp. nov., C. delicatum sp. nov., C. dewhurst sp. nov., C. dividuum sp. nov., $C$. dybasi sp. nov., C. eciton sp. nov., C. ecuadoriense sp. nov., C. faustum sp. nov., C. flavum sp. nov., C. franzi sp. nov., C. fraternum sp. nov., C. glabratum sp. nov., C. greensladei sp. nov., C. houailou sp. nov., C. ibicarense sp. nov., C. impressum sp. nov., C. inexspectatum sp. nov., C. insulare sp. nov., $C$. kolombangaricum sp. nov., C. lamington sp. nov., C. lawrencei sp. nov., C. loebli sp. nov., C. logunovi sp. nov., C. losbanos sp. nov., C. lucidulum sp. nov., C. luctuosum sp. nov., C. mahleri sp. nov., C. mindanao sp. nov., C. misellum sp. nov., C. modestum sp. nov., C. montanum sp. nov., C. murphyi sp. nov., C. mussardi sp. nov., C. noumeae sp. nov., C. obscenum sp. nov., C. obscurum sp. nov., C. obsoletum sp. nov., C. opacum sp. nov., C. orami sp. nov., C. peruviense sp. nov., C. pilosellum sp. nov., C. pinense sp. nov., C. plaumanni sp. nov., C. puncticolle sp. nov., C. riparium sp. nov., C. robustum sp. nov., C. rogeri sp. nov., C. seditiosum sp. nov., C. semicalvum sp. nov., C. similatum sp. nov., C. steeli sp. nov., C. subangulatum sp. nov., C. subfaustum sp. nov., C. sueae sp. nov., C. trangse sp. nov., C. upiense sp. nov., C. visendum sp. nov., C. waginicum sp. nov., C. werneri sp. nov. and C. yoruba sp. nov. The division of the genus is discussed and five species groups are established. The majority of the new species are the first records of Cissidium for the 28 countries represented.
\end{abstract}

Keywords. Coleoptera, Ptiliidae, Cissidium, morphological review, new species.

Darby M. 2020. A revision of Cissidium Motschulsky (Coleoptera: Ptiliidae) with seventy seven new species. European Journal of Taxonomy 622: 1-188. https://doi.org/10.5852/ejt.2020.622

\section{Introduction}

Since its establishment by Motschulsky (1855) on the basis of the Panamanian species Cissidium basale Motschulsky, 1855, the genus Cissidium has undergone the addition of 28 new species and three generic revisions. 
In the same paper publishing C. basale, Motschulsky included C. rufulum Motschulsky, 1855 also from Panama (renamed C. rufescens in Motschulsky 1868). Neither species was included by Matthews (1872) because he had not seen any specimens, although he did include Camptodium Motschulsky, 1869, type species C. adustipenne Motschulsky, 1869, from Japan, later synonymised with Cissidium by Johnson who noted that Camptodium was a mis-spelling of Camplodium (I think this assumption was incorrect, the letter ' $t$ ' in the original type face has a very faint cross piece and is clearly shorter in height than the letter '1') (Johnson 1982). In the same paper, Johnson also synonymised the genus with Dimorphella Matthews, 1889, type species D. reitteri, Matthews, 1889, from Brazil, and with Epibaptus Deane, 1931, type species E. scutellaris Deane, 1931 from Australia, added C. foveolatum Johnson, 1982 and C. crowsoni Johnson, 1982 from New Zealand, and revised the generic description to include these species. He also remarked that some 70 species almost all undescribed were known to him from tropical and subtropical parts of the world and that, with the exception of a few distinctive species, the identification of most was difficult. I have examined specimens of Camptodium, Dimorphella Matthews, 1889 and Epibaptus Deane, 1931 to confirm the validity of Johnson's findings and species of all three former genera are included in this paper.

In 2008, Sawada described a further nine new species from Japan: C. ikeuchii Sawada, 2008; C. nomurai Sawada, 2008; C. itoi Sawada, 2008; C. latum Sawada, 2008; C. ishigakiense Sawada, 2008; C. nishikawai Sawada, 2008; C. elongatum Sawada, 2008, C. shibatai Sawada, 2008 and C. sakaii Sawada, 2008, and revised the generic description to include the Japanese species.

The move of the genus into the Discheramocephalini was made by Grebennikov at the time of establishing the tribe in 2009 and adding C. okuense Grebennikov, 2009 from Cameroon (Grebennikov 2009). His paper also included a revised generic description justifying the inclusion of the genus in Discheramocephalini on the basis of the possession of a perforated mesoventrite.

In 2010, Johnson completed a paper as the third part of a series on the ptiliid fauna of the Solomon Islands which included descriptions of ten new species of Cissidium, but this was never published as a result of the severe illness which brought a permanent curtailment to his entomological work. His family have kindly allowed me access to the manuscript which is referenced here as 'Johnson ms 2010'. The holotypes and several paratypes mentioned in this paper were deposited both in the Manchester Museum (MMUE) and in the Natural History Museum London (BMNH) with manuscript names, and these names have been retained when possible in the present paper.

In 2013, the present author described a single new species from Madagascar C. banari Darby, 2013 (Darby 2013); in 2015 six new species from Bolivia: C. amboroense Darby, 2015; C. globosum Darby, 2015; C. lisae Darby, 2015; C. petri Darby, 2015; C. sawadai Darby, 2015 and C. tigrum Darby, 2015 (Darby 2015) and in 2019 six new species from Sarawak: C. globulum Darby, 2019; C. longum Darby, 2019; C. marshallae Darby, 2019; C. pauxillum Darby, 2019; C. subfoveolatum Darby, 2019; C. triangulum Darby, 2019 (Darby 2019). The Bolivian paper (Darby 2015) also discussed the relationship of the genus to Dacrysoma Grebennikov, 2009, and problems encountered with earlier generic descriptions concerning in particular the possession of mesoventral perforations. It also provided a new generic description to include these factors. This is now revised again, below, to encompass the new species described in this paper.

\section{Material and methods}

Most of the specimens included in this study (223) were located pinned onto cards in two boxes in the Manchester Museum (MMUE), labelled respectively TN 7328, TN 7329, and, by Colin Johnson, 'Ptiliidae. Cissidium In Work'. No museum acquisition numbers are known except when mentioned. Because of his illness, these boxes were passed to me to work on and return. Many of the specimens 
were present either as singletons or in small groups with manuscript names attached. These names have been retained in the present work where possible and are identified as 'Johnson ms name'. Many of the attached labels giving habitat information etc. are in Johnson's hand and it is assumed that these data were on other specimens of the same species, which were returned to the collection of origin, so that these specimens represent retained specimens. The specimens were collected over a wide period by various collectors from across the world. During this study it became clear that 41 specimens belonged to Dacrysoma and these have been set aside for later work. A further 11 specimens were without information, or with insufficient information to merit study, and have also been set aside. No paperwork was located in MMUE referring to specific specimens, apart from a loan form from FMNH mentioning 22 specimens of Camptodium and letters between Johnson and Dr H. Franz which make clear that they arranged an exchange of holotypes to include specimens in those families on which each was working.

Further pinned specimens with ms names by Johnson were found in the collection of the Natural History Museum, London (BMNH). These names have also been retained. Specimens from Bolivia, Madagascar, Peru and the Philippines, resulting from the author's own publications and collections, are also located in the BMNH and in the Museo de Historia 'Noel Kempff Mercado', Santa Cruz de la Sierra, Bolivia (UASC), the Moravian Museum, Brno, Czech Republic (MMBC), the Snow Entomological Collection, USA (SEMC) and the University of San Marcos Museum of Natural History, Peru (MUSM). The specimens described by Sawada (2008) are distributed between the BMNH and in his own possession awaiting permanent deposition (YS). Where countries have acquired new names since the date of collection these have been applied. The stated depositories of types in this paper may be subject to further investigation and discussion between the various museums and stakeholders concerned. Eight specimens bear pink labels stating Manchester Museum Holotype and these are indicated in the type descriptions as MM holotype.

Research on this material was carried out using a Leica M165C stereo microscope, an Olympus BH2 compound microscope fitted with Phase Contrast, and a Phenom scanning electron microscope. Images and measurements were made using the inbuilt software and cameras of the Phenom, a Leica DFC450 digital camera and associated software attached to the stereo microscope, and a Canon EOS 1100D digital camera with associated software attached to the Olympus microscope. The images were prepared for publication using Helicon stacking software and Corel Paint Shop Pro software care being taken not to alter or obscure any features. Data analysis was carried out using an Excel Pivot Table.

The main focus of this paper is on the pronotum and the mesoventrite, but other features are also included when appropriate in particular the back of the head, the mentum, the elytra, the metaventrite and the genitalia. The antennae, the scutellum and abdominal features have not been included although some figures of the antennae and male terminal ventrites are given for information.

The following notes are intended to assist in interpreting the descriptions and figures.

\section{Diagrammatic figure of the ventral surface of the pterothorax}

(Terminology partly after Lawrence \& Ślipiński 2013) (Fig. 1).

\section{Skeletal features of the pronotum, head and mesoventrite (Figs 2-5)}

When foveae and foveolae are of a similar size the latter may quickly be determined by the presence of a single seta projecting from the anterior margin. The term 'distinct foveolae' refers to foveolae as in Fig. 2A and 'shallow foveolae' to foveolae as in Fig. 2C. When setae are associated with foveae they often emanate from the centre of the depression and not from the margin. 
The head between the eyes (Fig. 3A-G) show some morphological characters useful in separating species as do the menta and submenta (Fig. 4A-F). The form of the mesoventral keel as seen in dorsal view is relied on heavily in the descriptions, Fig. 5A-F illustrates lateral views of the principal types.

The term border is used to distinguish the border from the margin and is taken to include the area inside the margin.

\section{Genitalia (Fig. 6A-N)}

Although study of the genitalia in many genera of Ptiliidae is an important factor in determining species, the spermathecae and aedeagi in most species of Cissidium vary little in overall form and are so tiny as to make studying them difficult. Almost all the females examined displayed globular spermathecae differing only slightly in pump length and general outline (Fig. 6A-E), and almost all the males to have beaked aedeagi (Fig. 6Fa-b) differing mainly in their overall length. The exceptions regarding the latter are to be found particularly in the fauna of the Philippines and Solomon Islands where the aedeagi display a variety forms providing helpful characters in determining the morphologically rather similar species (Fig. 6G-N).

Features of the metaventrite and abdomen (Fig. 7A-G)

The range of size and shape of the spines on the metaventrite (Fig. 7A-B) and other metaventral details (Fig. 7C-E), together with the spinose form of some abdominal ventrites (Fig. 7F-G) are occasionally mentioned and are figured here.

\section{Measurements}

All measurements were taken from the mounted holotypes unless otherwise stated. The habitus and pronotum measurements were taken using the Leica camera, the length measurement being taken from the front of the head to the apex of the elytra. The length measurement of the pronotum is open to a certain amount of interpretation because of its tendency to be tilted forwards when carded. The antennomere

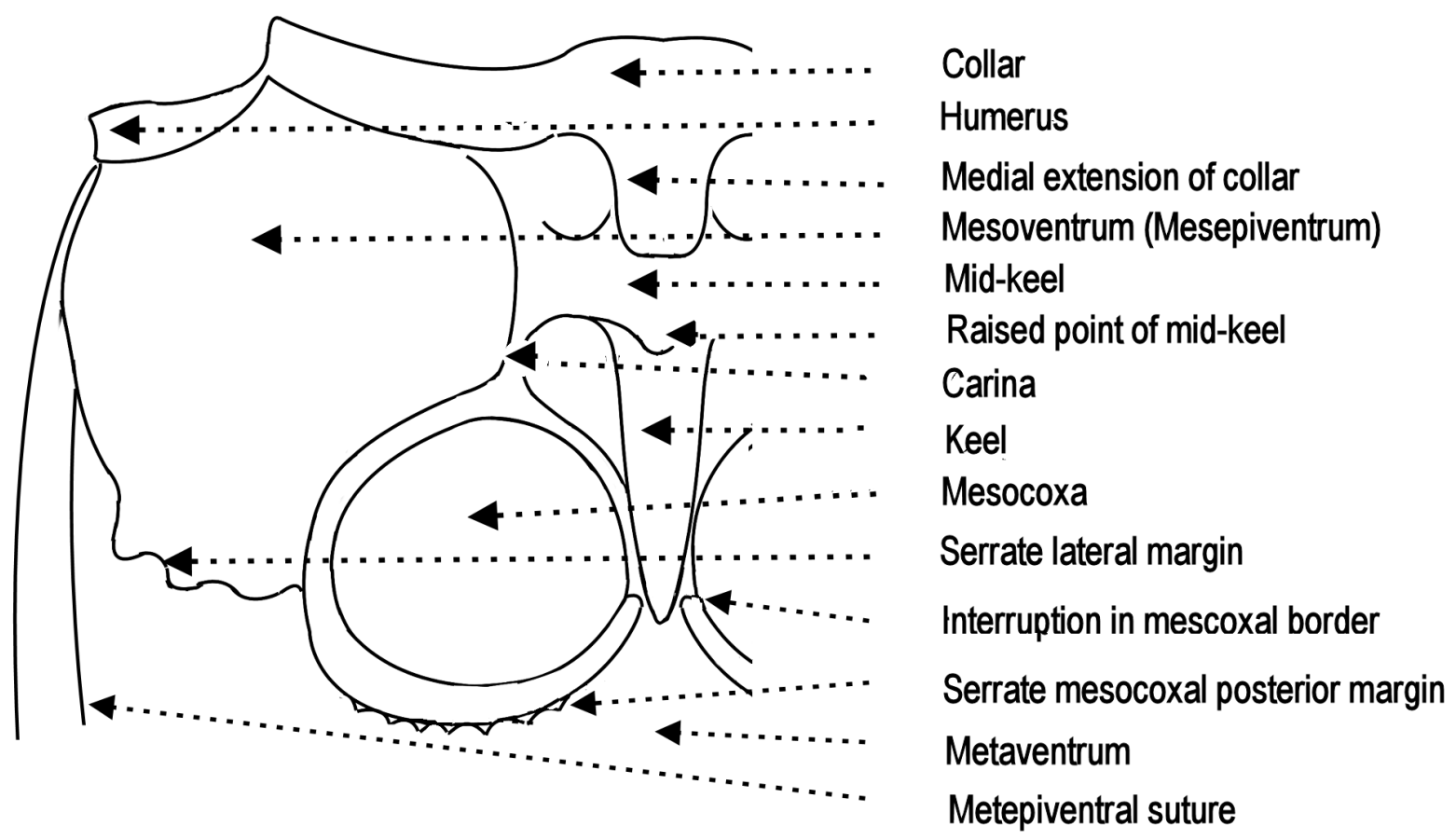

Fig. 1. Diagram of the ventral side of the pterothorax to explain terms used in the text. 


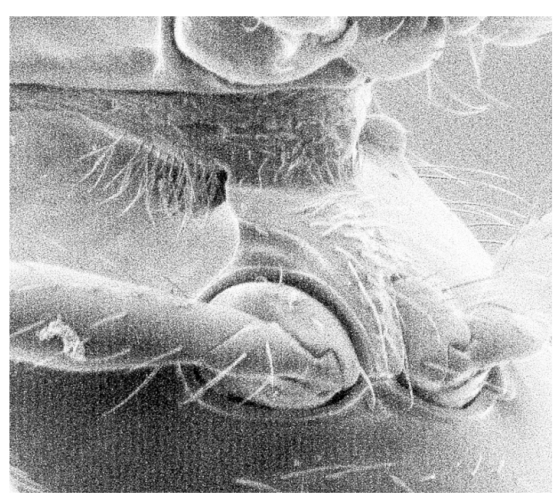

A

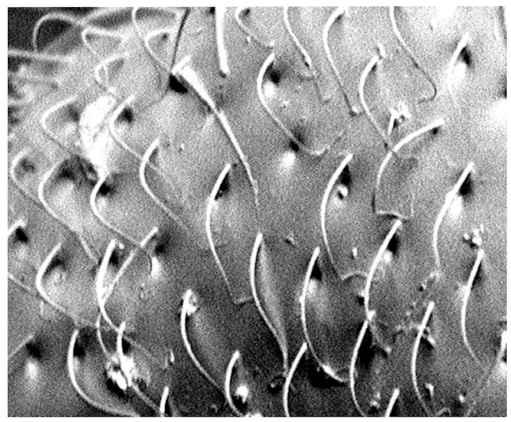

$\mathrm{C}$

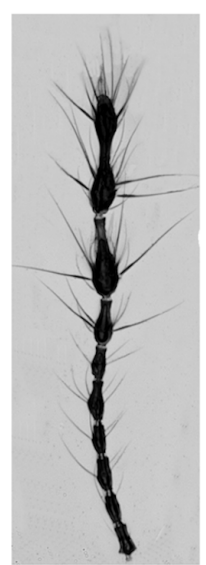

F

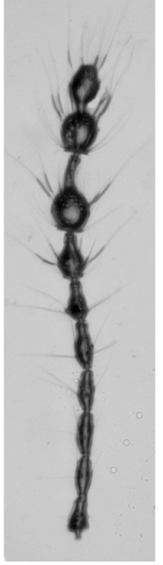

$\mathrm{G}$

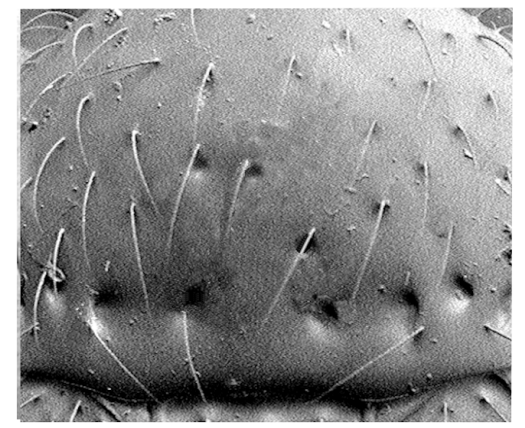

$\mathrm{D}$

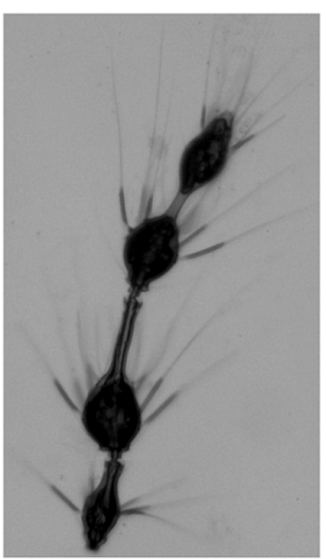

$\mathrm{Ha}$

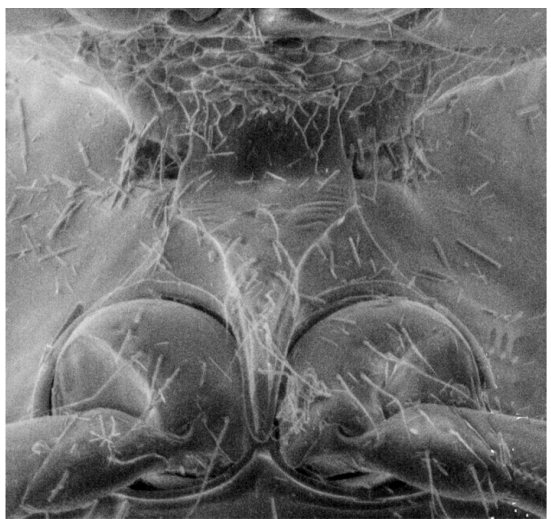

B

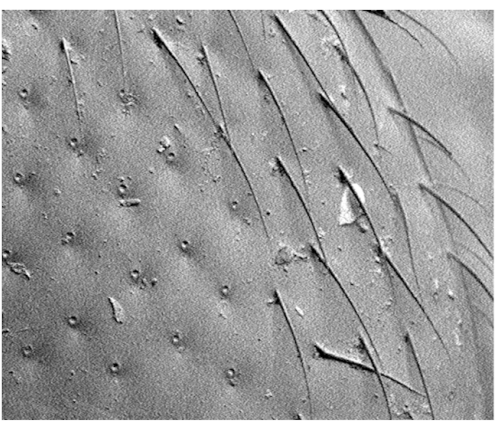

$\mathrm{E}$

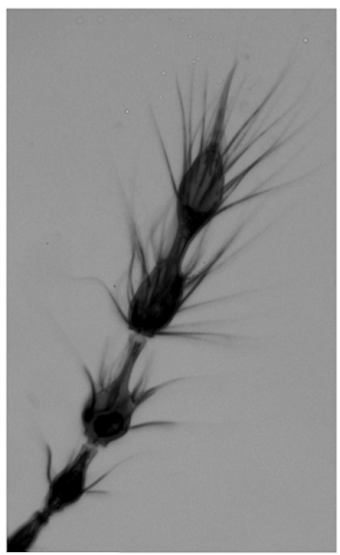

$\mathrm{Hb}$

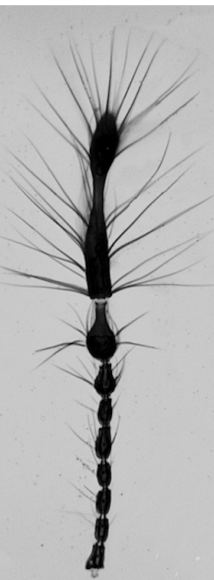

I

Fig. 2. A-B. Mesoventra of two species of Dacrysoma Grebennikov, 2009 to show form of mid-keel and perforation fringed by setae. C-E. Figures to explain use of the terms foveae, distinct foveolae and shallow foveolae in distinguishing the main species groups. C. Distinct foveolae, showing setae arising from the anterior margin of the depressions. D. Foveae and foveolae, showing setae randomly associated with foveae. E. Shallow foveolae, many setae rubbed off, but insertion points marked by punctures with slightly raised circular rims. F-I. Figures to show different forms of antennae. F. Elongate antenna of Cissidium lisae Darby, 2015. G. Globular antennomere of Cissidium globosum Darby, 2015. H. Female and male antennae of Cissidium petri Darby, 2015. I. Abnormal antennomere XI of Cissidium tigrum Darby, 2015. 

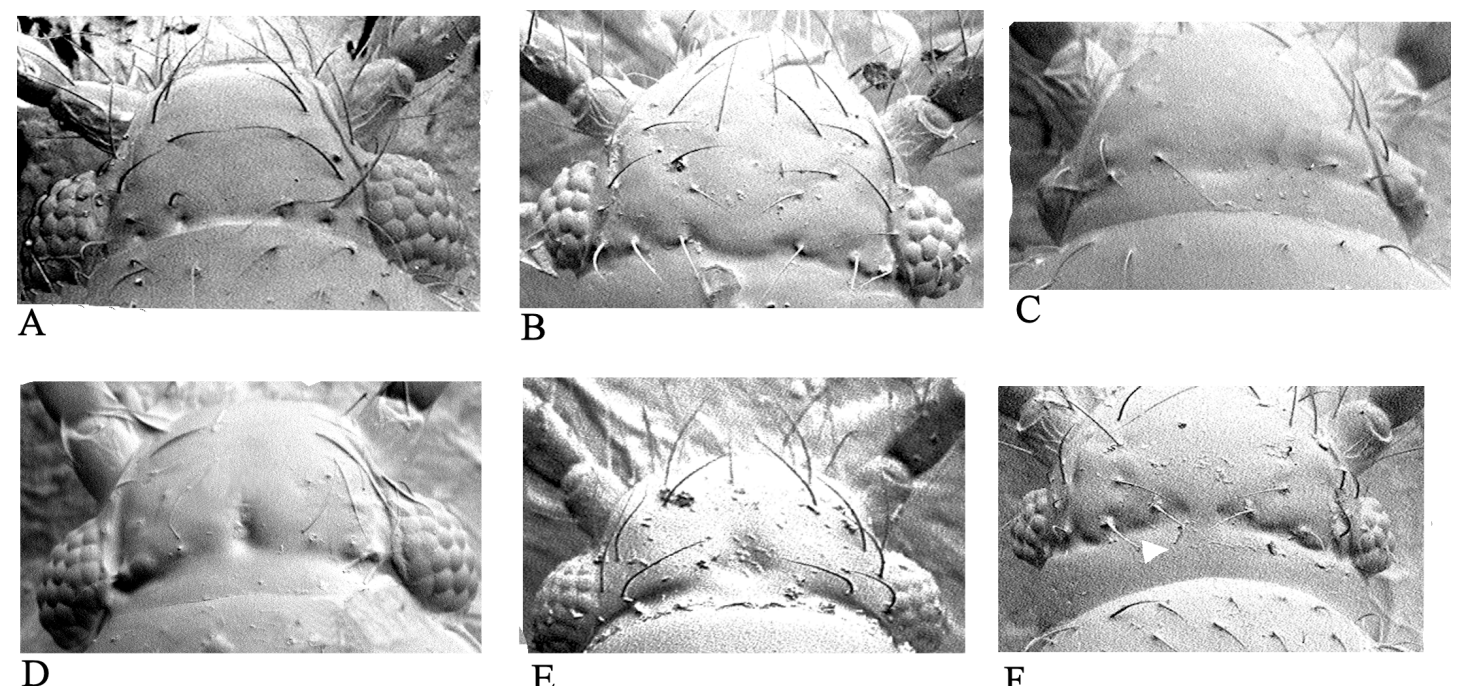

$\mathrm{E}$

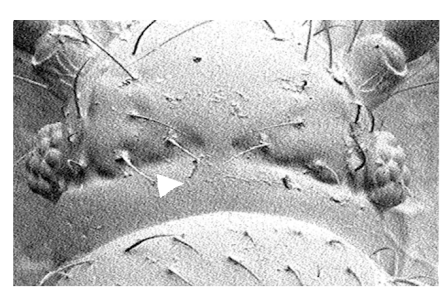

$\mathrm{F}$

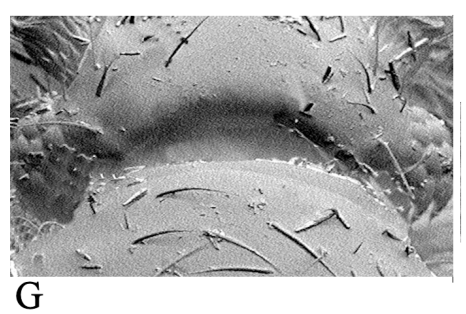

Fig. 3. Figures to show differences in morphological features of head between eyes. A. Cissidium upiense sp. nov., $\times$ 565. B. Cissidium sueae sp. nov., $\times$ 480. C. Cissidium delicatum sp. nov., $\times 1060$. D. Cissidium foveolatum Johnson, 1982, $\times 730$. E. Cissidium basale Motschulsky, $1855, \times 385$. F. Cissidium ibicarense sp. nov., $\times$ 505. G. Cissidium eciton sp. nov., $\times 650$.

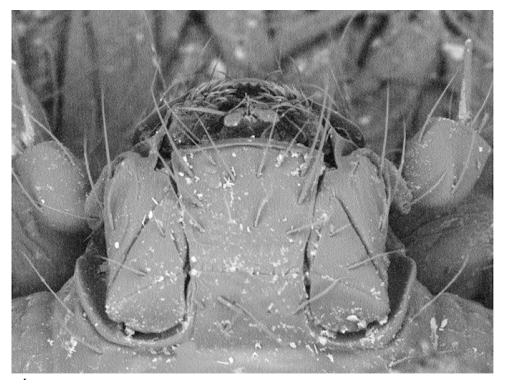

$\mathrm{A}$

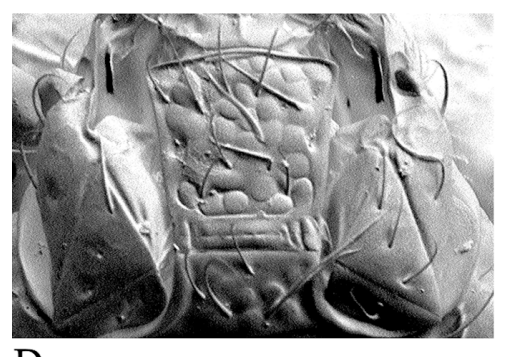

$\mathrm{D}$

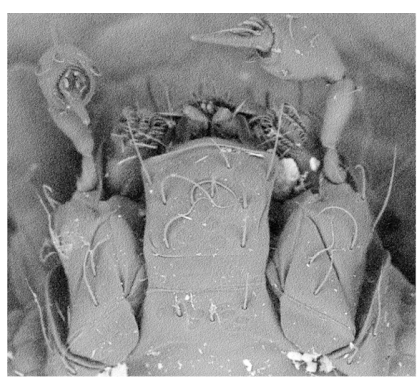

B

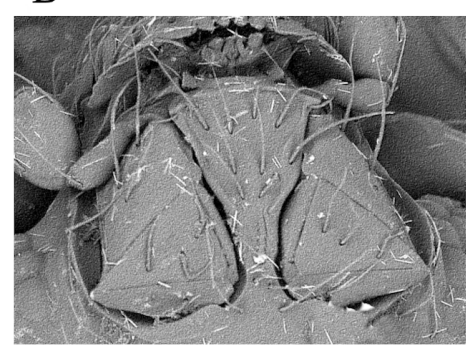

$\mathrm{E}$

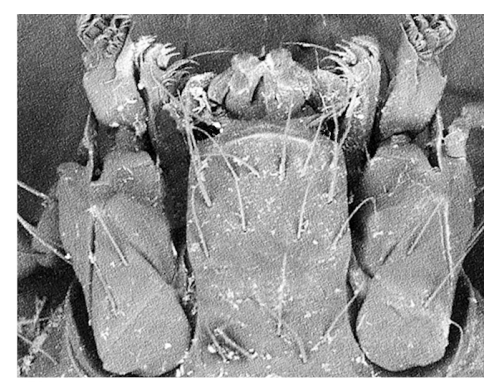

C

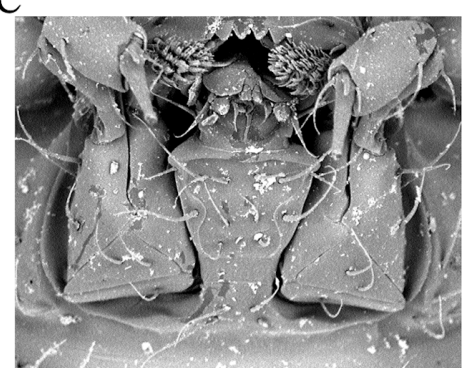

$\mathrm{F}$

Fig. 4. Menta and submenta. A. Cissidium petri Darby, 2015, $\times 1380$. B. Cissidium tigrum Darby, 2015, $\times 1220$. C. Cissidium amboroense Darby, 2015, $\times 1260$. D. Cissidium losbanos sp. nov., $\times 1100$. E. Cissidium triangulum Darby, 2019, $\times 650$. F. Cissidium pilosellum sp. nov., $\times 1420$. 
$\mathrm{H}$ is missing hereand metaventral measurements were taken using the SEM camera. Because of the density of setae on the terminal antennomere XI the exact length is often difficult to see in which case a judgement has been made by eye. The length of the metaventrite is taken from immediately below the fusion of the mesocoxal margins to the centre of the posterior margin between the metacoxae. The magnifications quoted in the figure captions are those of the original SEM pictures before being cropped.

\section{Colours}

References to colour refer to the mounted holotypes and are open to a degree of interpretation because the density of colour is very much affected by the underlying structures. In all cases when not mounted and placed in transmitted light or in alcohol most species appear much paler. This becomes particularly clear when elytra are raised. Dark elytra are often the result of underlying wings.

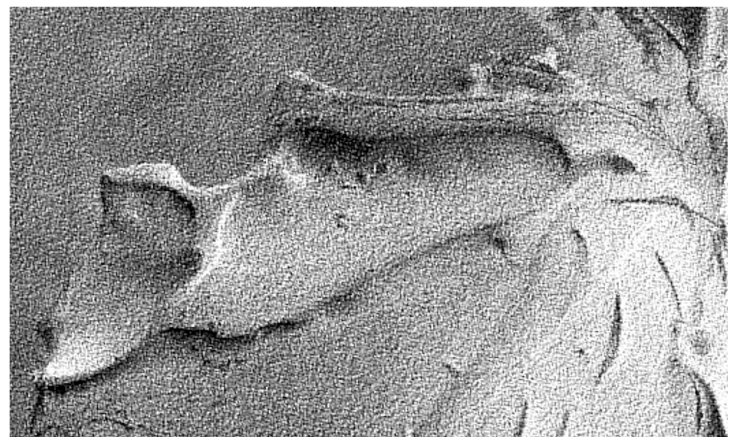

A
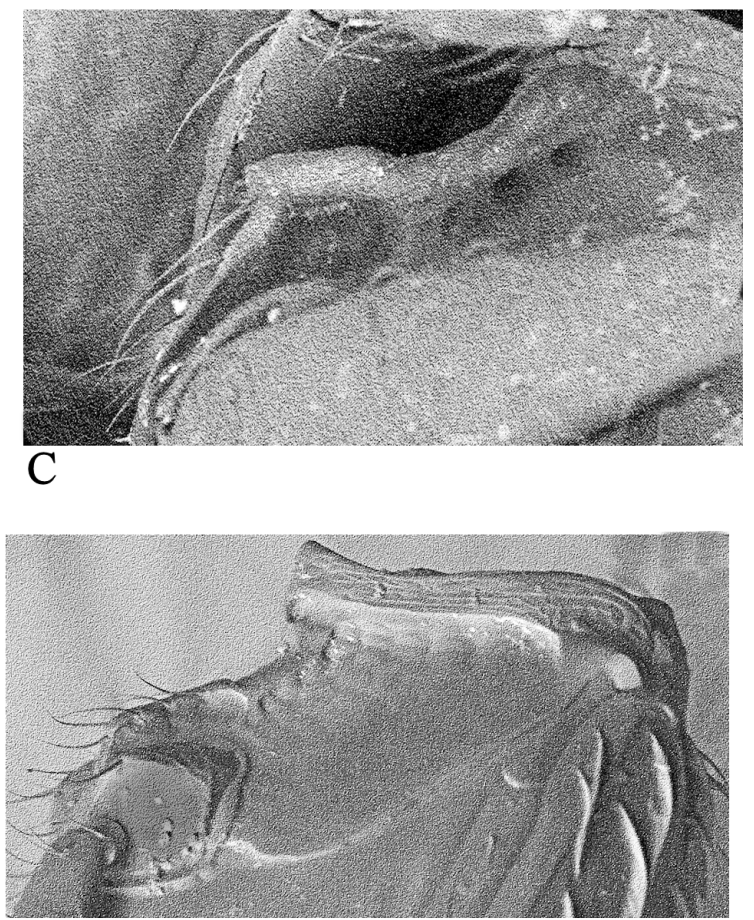

$\mathrm{E}$

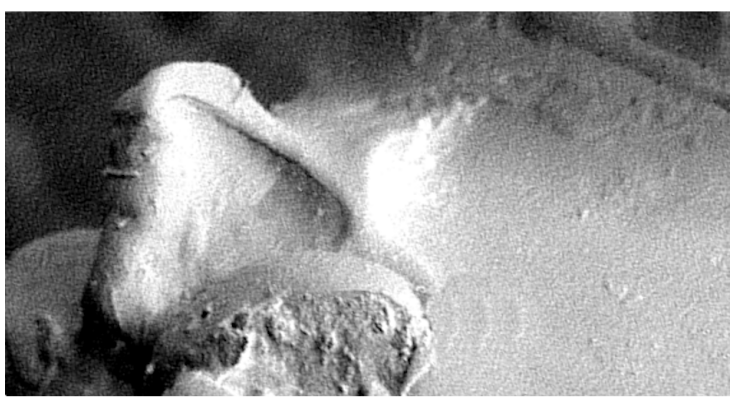

B

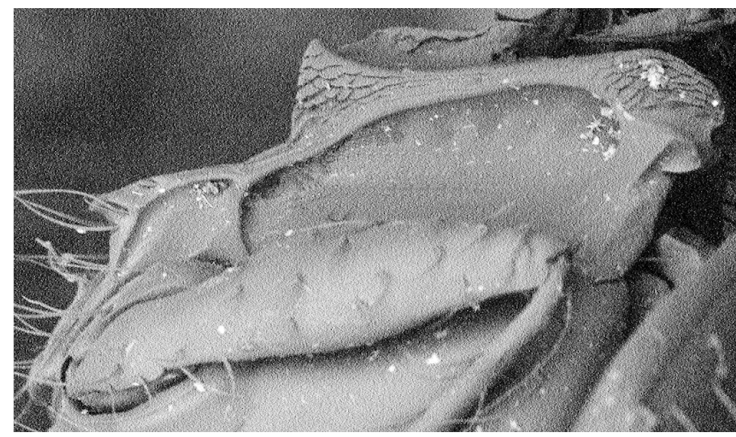

$\mathrm{D}$

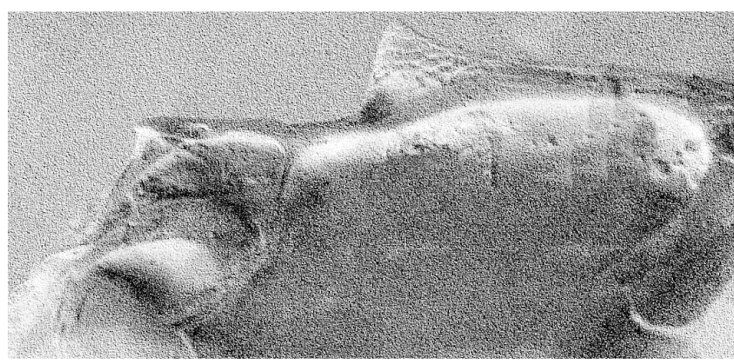

$\mathrm{F}$

Fig. 5. Figures to show keel shapes. A. Cissidium bifoveolatum sp. nov., $\times$ 515. B. Cissidium lucidulum sp. nov., $\times 780$. C. Cissidium scutellaris (Deane, 1931), $\times$ 1480. D. Cissidium tigrum Darby, 2015, $\times$ 840. E. Cissidium sawadai Darby, 2015, × 680. F. Cissidium lisae Darby, 2015, × 823 . 
Metepimeral sutures (metaventral lines of some authors)

The metepimeral sutures in Cissidium are situated close to the lateral borders and run parallel with them, and as such they are not evident in most views of the metaventrite.

\section{Dimorphism}

Sexual dimorphism between males and females is common in the genus, many males having smaller eyes, longer antennae, narrower elytra and a triangularly depressed metaventrite. In C. ikeuchii Sawada, 2008, the apices of the male elytra have two subconical raised areas not present in the female. The sex of the following descriptions is indicated in every case when known.

\section{Wings}

The genus also commonly exhibits macroptery, microptery and aptery. In the case of one species, C. delicatum sp. nov., aptery is accompanied by almost complete loss of eyes. Several of the Japanese

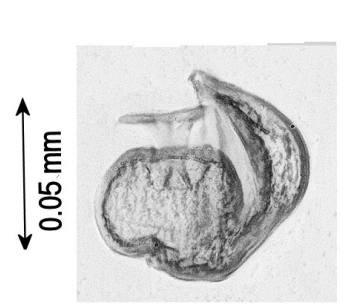

A

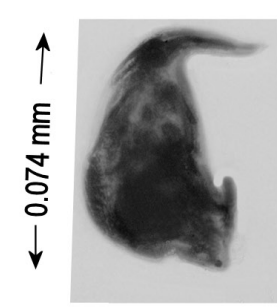

$\mathrm{Fa}$

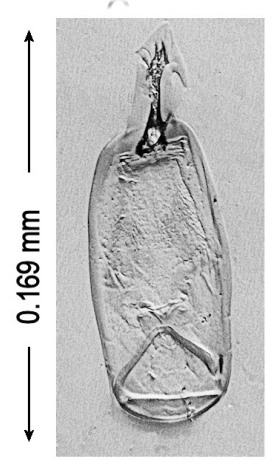

J

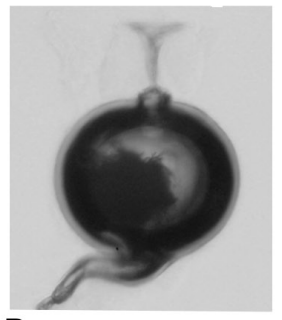

B

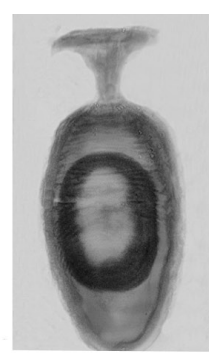

C

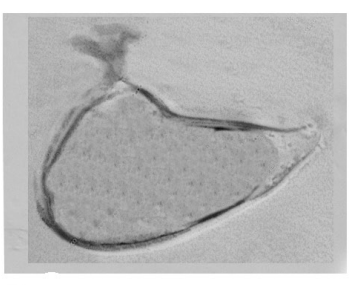

D

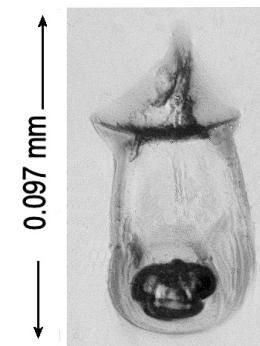

$\mathrm{H}$

la

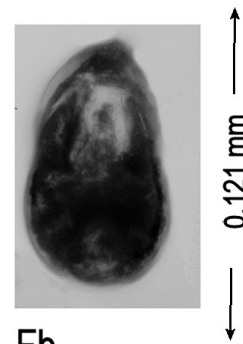

$\mathrm{Fb}$

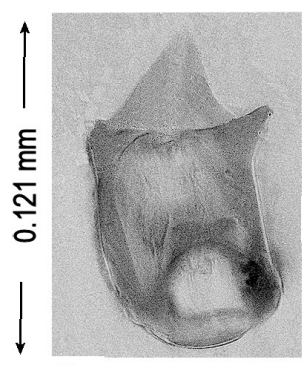

G

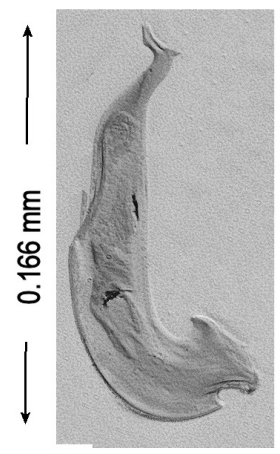

K

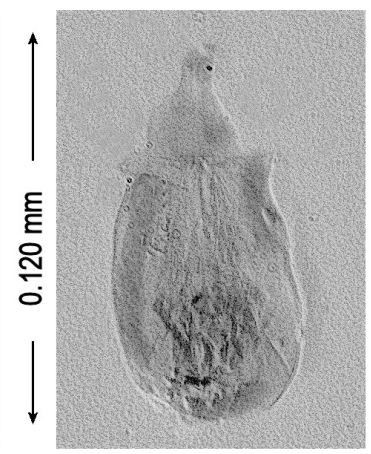

L

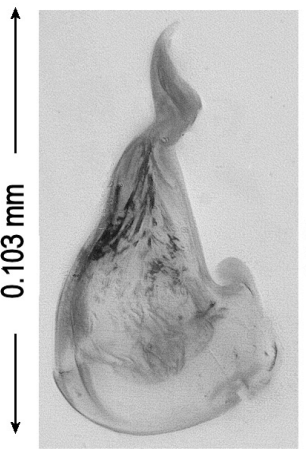

M

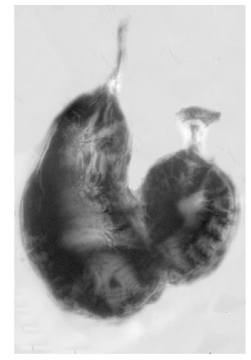

E
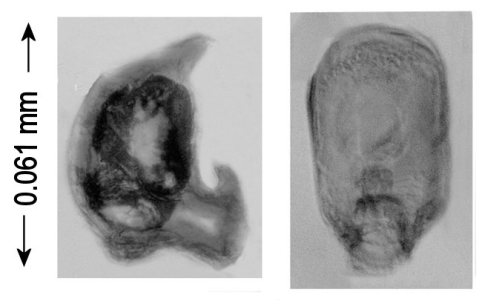

Ib

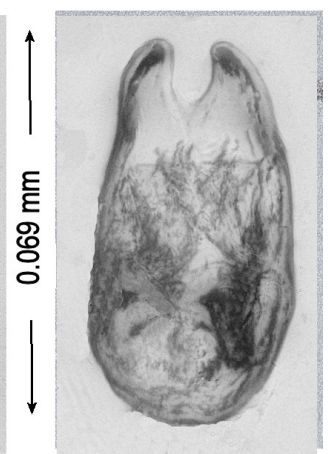

N

Fig. 6. Figures to show genitalia types. - Spermathecae. A. Cissidium bilineatum sp. nov. B. Cissidium amboroense Darby, 2015. C. Cissidium sawadai Darby, 2015. D. Cissidium arcuatum sp. nov. E. Cissidium murphyi sp. nov. - Aedeagi. F. Cissidium petri Darby, 2015. G. Cissidium clareae sp. nov. H. Cissidium fraternum sp. nov. I. Cissidium tigrum Darby, 2015. J. Cissidium apterum sp. nov. K. Cissidium brachypterum sp. nov. L. Cissidium greensladei sp. nov. M. Cissidium kolombangaricum sp. nov. N. Cissidium mindanao sp. nov. 
species also display this condition. This makes Cissidium the second genus outside of the Ptinellini in which aptery accompanied by blindness has been recorded the other being Bambara Vuillet, 1911 (Darby 2014). There appears to be a tendency for females with small eyes to have reduced wings.

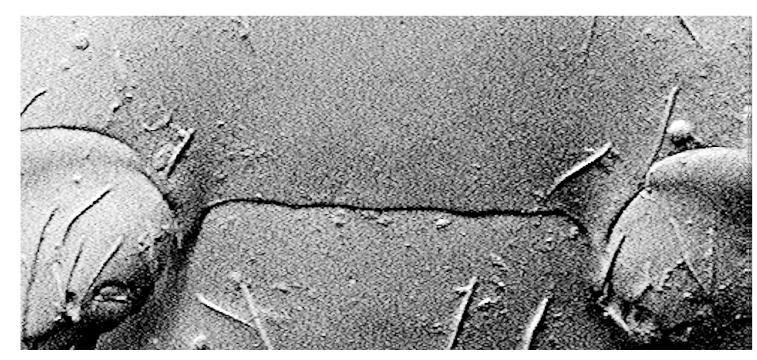

A

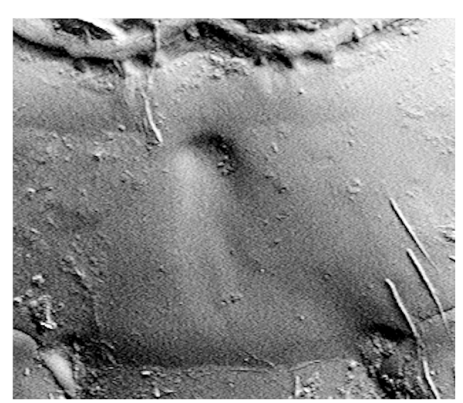

$\mathrm{C}$

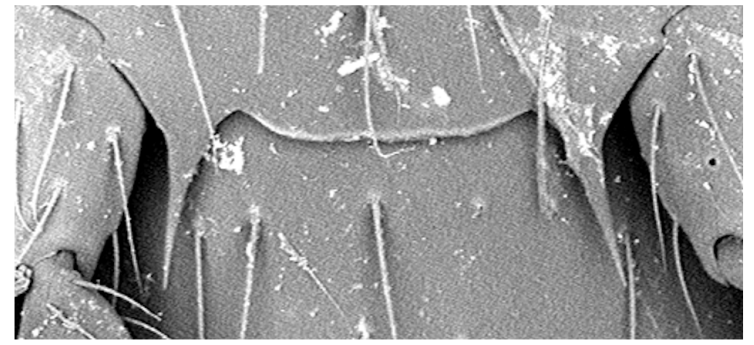

B

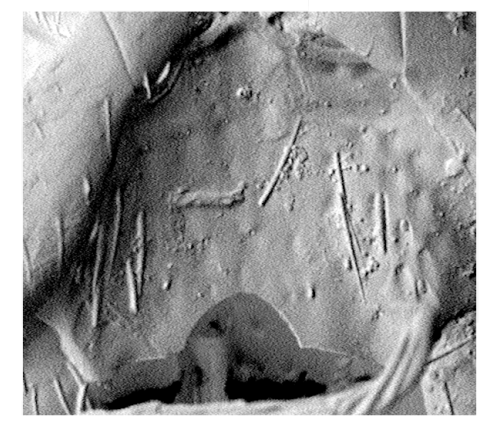

$\mathrm{D}$

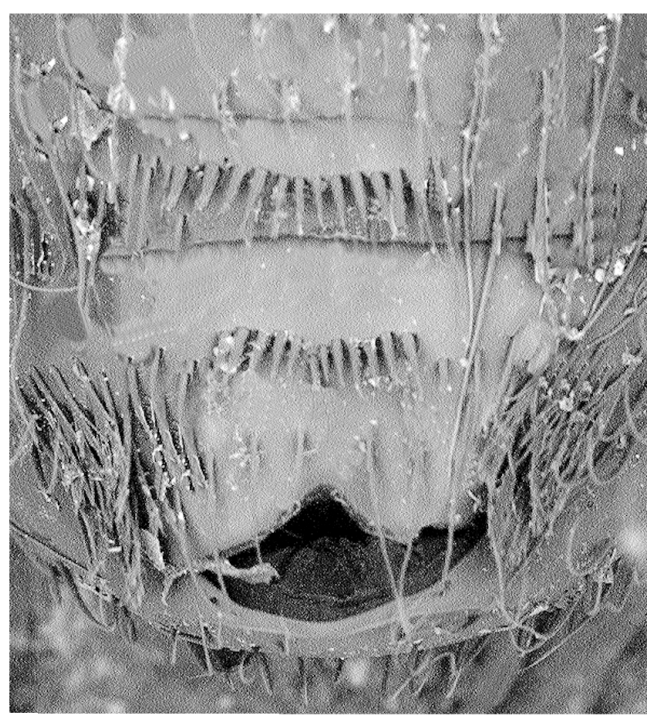

$\mathrm{F}$

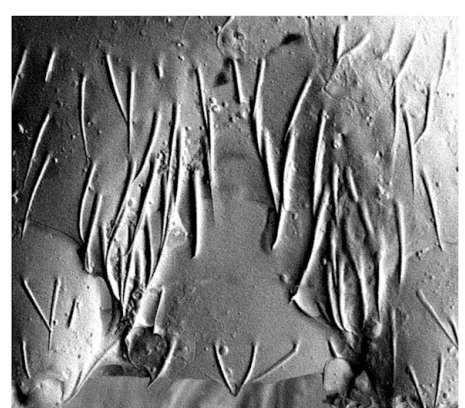

$\mathrm{E}$

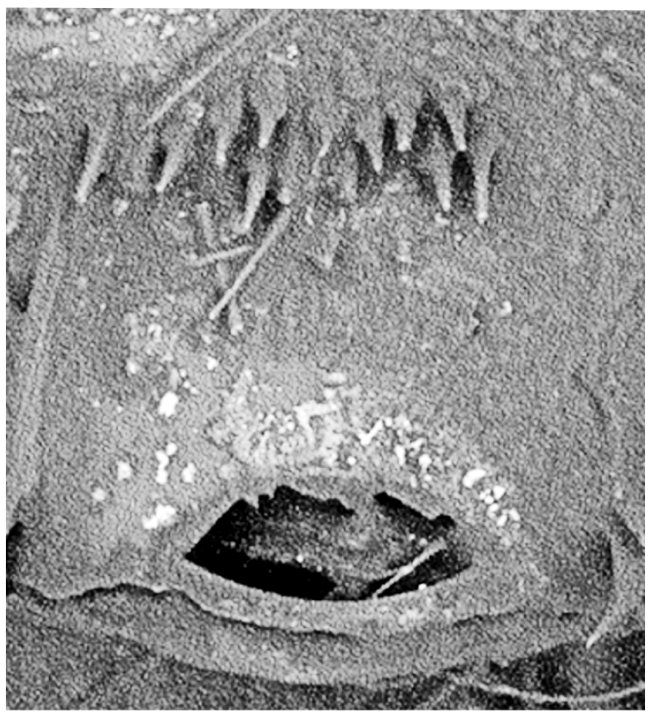

G

Fig. 7. Metaventral and male ventrite examples. A-B. Metaventrite posterior margin to show spines. A. Cissidium riparium sp. nov., $\times 610$. B. Cissidium plaumanni $\mathrm{sp}$. nov., $\times 970$. C-D. Metaventral discs. C. Cissidium greensladei $\mathrm{sp}$. nov., $\times$ 455. D. Cissidium insulare sp. nov., $\times$ 595. E. Cissidium obscenum sp. nov., $\times$ 840. F-G. Terminal male ventrites. F. Cissidium petri Darby, 2015, $\times 1580$. G. Cissidium amboroense Darby, 2015, $\times 1380$. 


\section{Collection location acronyms}

BMNH = London, Natural History Museum (formerly British Museum Natural History)

FMNH $=$ Chicago, Field Museum of Natural History, USA

MMBC $=$ Moravian Museum, Brno, Czech Republic

MMUE = Manchester, Manchester Museum, UK

MUSM $=$ Lima, University of San Marcos Museum of Natural History, Peru

NZAC $=$ Auckland, Land Care Research, New Zealand Arthropod Collection, New Zealand

SEMC = Kansas, Lawrence, University of Kansas, Snow Entomological Museum, USA

UASC = Santa Cruz de la Sierra, Museo de Historia Natural 'Noel Kempff Mercado', Bolivia

YS $=$ Dr Y. Sawada collection, Japan

ZMUM = Zoological Museum of Moscow, Lomonosov State University, Russia

\section{Results}

Order Coleoptera Linnaeus, 1758

Family Ptiliidae Erichson, 1845

Subfamily Ptiliinae Erichson, 1845

Tribe Discheramocephalini Grebennikov, 2009

Genus Cissidium Motschulsky, 1855

\section{Tribal placement}

Grebennikov's tribe Discheramocephalini was set up to contain six genera of Ptiliidae with perforated mesoventrites following phylogenetic analysis indicating monophly. At the same time he erected a new genus in the tribe - Dacrysoma - which like Cissidium is unique in possessing a dumb-bell-shaped antennomere XI. In separating the two genera, he pointed to the possession by Dacrysoma of a "clearly visible' perforation of the mesoventral collar (Fig. 2A-B) whereas the perforation in Cissidium was not well developed and sometimes obscured by a membrane.

With the possible exception of C. cryptophagoides sp. nov. and C. noumeae sp. nov., this study has not found any species of the genus to possess perforated mesoventrites whether obscured by a membrane or not, and as such agrees with the descriptions of Johnson and Sawada, published before Grebennikov's paper, which make no mention of this feature. In the unpublished manuscript of his Solomon Islands paper Johnson notices Grebennikov's work and expresses his preference for excluding Cissidium from the new tribe on the basis that it "also includes genera with typical ptinelline hind angles to mesosternum - effaced and far removed from metasternal sides" (Johnson ms 2010). The present author's inclination, however, after the study of many undescribed species of Ptinellini (unpublished), is to leave it where it is whilst at the same acknowledging that several of the features displayed by the genus are closely related to those in that tribe. It is also clear that Cissidium is very closely related to Dacrysoma in which mesoventral perforations are clearly present, and from the specimens in the MMUE boxes, that Johnson made no distinction between the two genera. On further aids to separating the two genera see below.

\section{Separation of Cissidim from Dacrysoma (Fig. 2A-B)}

The only species with which Cissidium are likely to be confused as mentioned above are those of the genus Dacrysoma which also possess a dumb-bell or hour glass like antennomere XI. Additionally, the two species also share a shallow emargination in the pronotum opposite the scutellum. The shape of the pronotum in many species of Dacrysoma is more cordate than those of Cissidium but a much clearer distinction between the two genera is provided by the form of the mesoventrite. Dacrysoma possess a wide mid-keel as a direct extension of the collar and distinct setae-fringed perforations either side of the mid-keel which are lacking in Cissidium. Additionally, the lateral margins of the mesoventrite are 
always effaced anteriorly in Dacrysoma, whereas the lateral margins of Cissidium are rarely effaced and then usually posteriorly.

\section{Revised generic description to include all species in the present paper}

Antennomere XI with a median restriction causing it to appear dumb-bell-shaped (though in some species the medial restriction is not clear). Dorsal surface glabrous and/or foveate and foveolate with long, fine, semi recumbent, usually overlapping, setae sometimes giving a 'hairy' appearance. Eyes large and prominent, smaller in the females than the males. Submentum with $4 / 5$ setae, when four the two central setae often much longer than the outer two. mentum with sides slightly or strongly tapering to base or parallel and slightly sinuous (Fig. 4A-F). Pronotum glabrous or pubescent, shallowly or markedly foveolate and/or with a series of two or more foveae anterior to the posterior margin. Lateral margins rounded or angled, clearly bordered the borders sometimes running along part or all of the posterior margin, posterior margin with or without a clearly defined emargination opposite the scutellum. Hind angles rectangular, obtuse or acute. Scutellum triangular with two deep foveae at the anterior angles. Elytra leaving 2/4 posterior abdominal segments exposed; elliptical/oblong elliptical, with/without foveolae and pubescence, sometimes truncate. Legs long and narrow. Most species fully winged with wings of usual ptiliid form but microptery, macroptery and aptery are not uncommon in the genus, one species recorded as both apterous and probably blind (C. delicatum sp. nov.). Mesoventral collar with/ without a short median extension onto the flattened median part of the mesoventral keel (mid-keel), posterior margin with shallow depressions occasionally forming deeper fossae particularly at the anterior angles; keel raised medially and extending posteriorly to between the mesocoxae; meso/metaventral suture curving anteriorly to meet collar at corners, sometimes obliterated externally in posterior half and only visible as an apodeme, with or without serrations, evenly rounded or angled. Arms of the metendosternite very long and thin reaching almost to the anterior corners of the mesoventrite. Hind coxae separated by approximately one quarter/one third of the metaventral width, coxal plates small. Metaventral margin between coxae with two pointed projections of varying length at the lateral corners. Spermathecae very small, commonly either globular or ovoid/tubular, sometimes with a small bulge on one side, occasionally in the shape of a horseshoe. Aedeagi very small, pointed or with a rounded or hooked tip, often bent giving a beak-like appearance in profile.

\section{Establishment of species groups}

Earlier work by the author on Cissidium (Darby 2013, 2015, 2019) emphasised the importance of the pronotum and in particular the mesoventrite in the separation and determination of species, and these were examined in an attempt to establish the validity of dividing the material into subgenera. Study of the mesoventral characters in particular was regarded as likely to provide a better indication of phylogenetic development than pronotal characters, and 17 character states were analysed using an Excel Pivot Table with data extracted from all the species. However, this produced many small groups of species varying too slightly to justify subgeneric classification, and it was decided to rely instead on the more easily recognisable features of the pronotum to establish species groups, rather than subgenera, and to use the mesoventral and other characters for the separation of individual species within each group. This approach appears to have followed that of Johnson (although he did not examine the undersides), who included some small sketches of pronota amongst some of the insects in the MMUE drawers. Five groups resulted, with one group split into two halves, as set out below.

Group $1=$ species with pronotum entirely glabrous

Group $2=$ species with pronotum foveate but lacking distinct foveolae

Group 3 = species with pronotum distinctly foveolate but lacking foveae

Group 4A $=$ species with pronotum lacking both foveolae and foveae, and with rounded sides

Group 4B = species with pronotum lacking both foveolae and foveae, and with angulate sides

Group $5=$ species with pronotum with both foveae and distinct foveolae 
The important distinction between 'distinct' foveolae and other foveolae, usually described as shallow foveolae, is made clear in Fig. 2C, E.

Apart from the species in the aforementioned groups are several specimens in the MMUE boxes either with insufficient data or in very poor condition preventing them being placed accurately. With one exception, Cissidium adustipenne (Motschulsky, 1869) described below, these have been omitted from this paper. The specimen of Cissidium rufulum Motschulsky, 1855 (Cissidium rufescens Motschulsky, 1868) from Panama, briefly noted by Motschulsky at the time of describing Cissidium basale Motschulsky, 1855 as "Une seconde espèce est plus courte et de couleur rouse" to which he added in 1868 "...et taille d'un tiers plus petite, d'un testacé roussâtre, un peu rembruni sur le milieu des élytres" has been located in ZMUM, but a loan has not been possible because retrieving the specimen from an earlier loan has failed.

\section{Cissidium adustipenne (Motschulsky, 1869)}

Fig. 8

Not included in the following because the fragmentary nature of the material prevented description. A single specimen bearing what appears to be a Matthews label inscribed in ink "Camptodium adustipenne", and with two printed labels "Nagasaki, 13.ii-21.iv.81" and "Japan, G. Lewis. 1910-320"

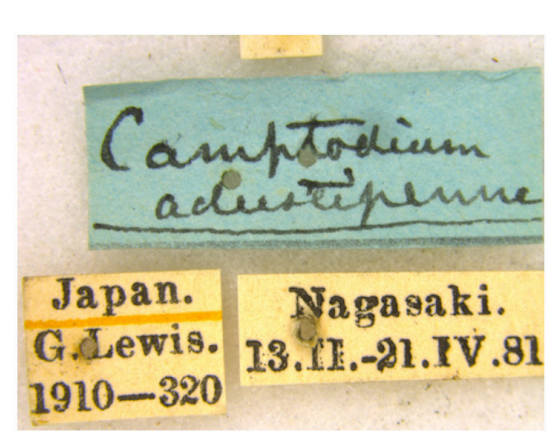

A

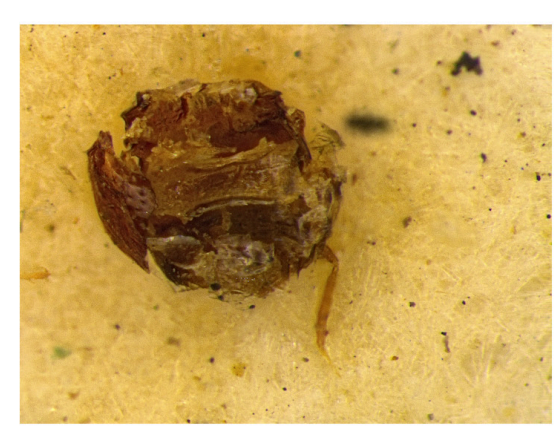

B

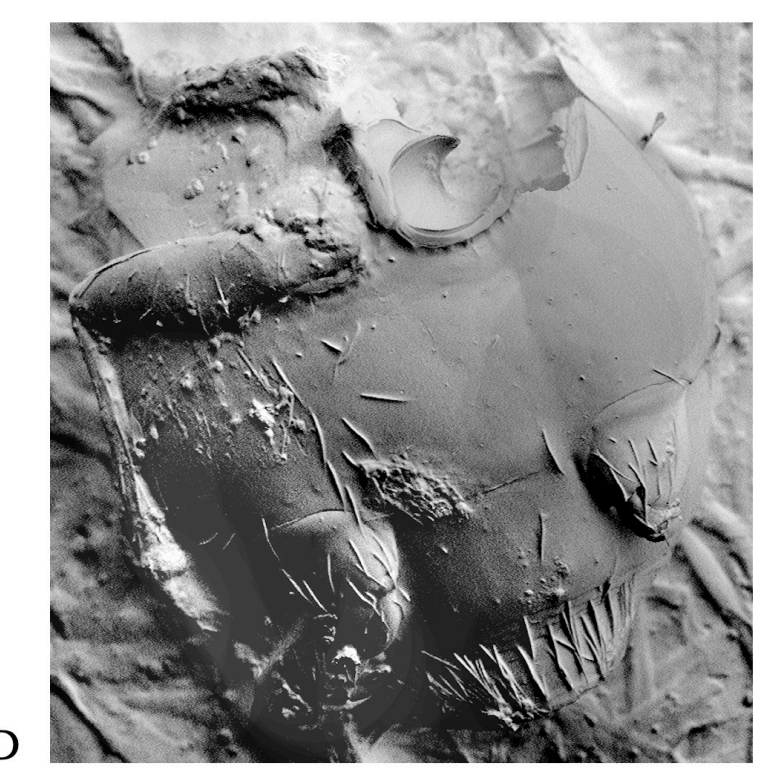

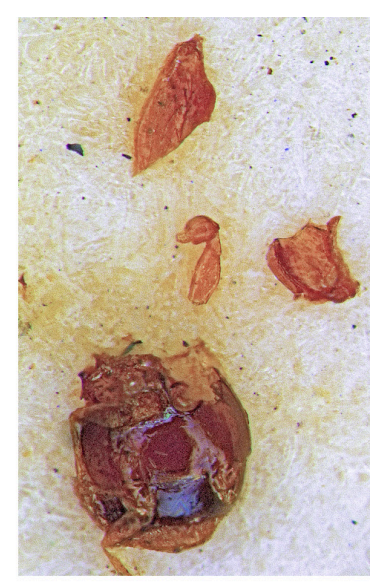

$\mathrm{C}$

Fig. 8. Cissidium adustipenne (Motschulsky, 1869). A. Labels. B. Specimen as found. C-D. Specimen after reassembly. 
exists in the BMNH acquired from the collector (Fig. 8A). The specimen was found in very poor condition missing head, elytra, pronotum and antennae (Fig. 8B) and has been reassembled and photographs taken (Fig. 8C-D). It is assumed that this specimen is the one described and figured by Matthews (1883), 1900) as "found in Japan by Mr Lewis nr the Suwa Temple, 14 April 1881 ....Mr Lewis has been fortunate enough to recover one of Col. Motschulsky's lost genera. The insect taken by Mr Lewis agrees entirely with the characters given in his short and very unsatisfactory description, and also with his figure". A second specimen in BMNH labelled "Camptodium Japan 1883, 3005, Matthews coll. 1904-120", being a slide of two legs and an antenna, may be related to this specimen. This slide was obtained by the Museum from the Mason collection and is mounted on one of Matthews' distinctive hexagonal cards. (For more information about the Mason collection see Darby (1986-on going).

A third specimen bearing a manuscript label "Gombak. Sel", referring to Gombak, Selangor, Kuala Lumpur, Malaysia, and a pencil label "adustipenne" by Johnson is in MMUE. This has been dissected and the ventral characters are very different from those in the Japanese specimen above. This specimen has been given the name Cissidium visendum sp. nov. and is described below.

\section{Species group 1: pronotum glabrous}

\section{Key to the group I species}

Note: the keys are based on the holotypes so that morphological features varying between male and female, e.g., length of antennae, size of eyes, elytral length and width, etc. have been excluded.

1. Pronotum with two large medial foveae and two smaller foveae near the hind angles

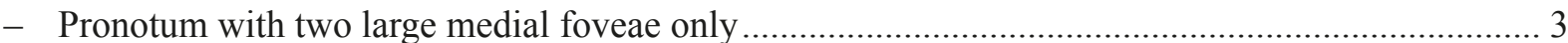

2. Base of pronotum wider than the medial angles, medial foveae smaller and elongate

C. lucidulum sp. nov.

- Base of pronotum narrower, large medial foveae transverse, composed of two smaller foveae joined

C. franzi sp. nov.

3. Pronotal sides rounded, foveae without setae

C. glabratum sp. nov.

- Pronotal sides angulate, foveae with setae C. semicalvum sp. nov.

Cissidium franzi i sp. nov.
urn:1sid:zoobank.org:act:D97EEE20-437A-4308-876A-8E26775C1907

Fig. 9

\section{Etymology}

Johnson ms name, after the collector H. Franz.

Material examined

Holotype

MADAGASCAR • đ̊; Perinet, forest of transition; 928 m a.s.1.; 15 Apr. 1969; H. Franz leg.; MMUE.

Paratype

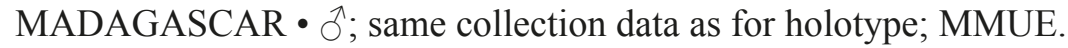

\section{Description}

Size. Habitus (Fig. 9A), length $0.66 \mathrm{~mm}$. 
CoLour. Dark brown, appearing polished, antennomeres and legs yellow.

HEAD. Without a clear transverse depression behind the eyes, width across eyes $0.21 \mathrm{~mm}$; antennomeres III-XI length $0.34 \mathrm{~mm}$, III-IX length $0.19 \mathrm{~mm}, \mathrm{X}-\mathrm{XI}$ length $0.15 \mathrm{~mm}$ globular; mentum as Fig. 4A.

Pronotum. Length $0.17 \mathrm{~mm}$, width $0.25 \mathrm{~mm}$, glabrous with six basal foveae the two inner pairs united to give the appearance of two large foveae, the outer foveae detached, small; lateral margins rounded almost parallel in basal third, narrowly bordered to rectangular hind angles, not continued along the posterior border which has a sinuous emargination before the scutellum (Fig. 9B).

ElYTRA. Length $0.45 \mathrm{~mm}$, width $0.35 \mathrm{~mm}$, glabrous.

Mesoventrite. Collar with broad medial extension lacking reticulation; mid-keel very short, posterior corners with flat carinae to mesocoxal anterior borders with a short, ridged top at junction with keel; keel short, broad with \pm five setae, terminating at interruption of mesocoxal border; mesoventral lateral margins smoothly rounded, serrate; humeri bluntly toothed (Fig. 9C).

Metaventrite. Length $0.16 \mathrm{~mm}$, glabrous, disc plain, width across spines $0.09 \mathrm{~mm}$, spines very short; posterior margins of mesocoxal cavities faintly serrate.
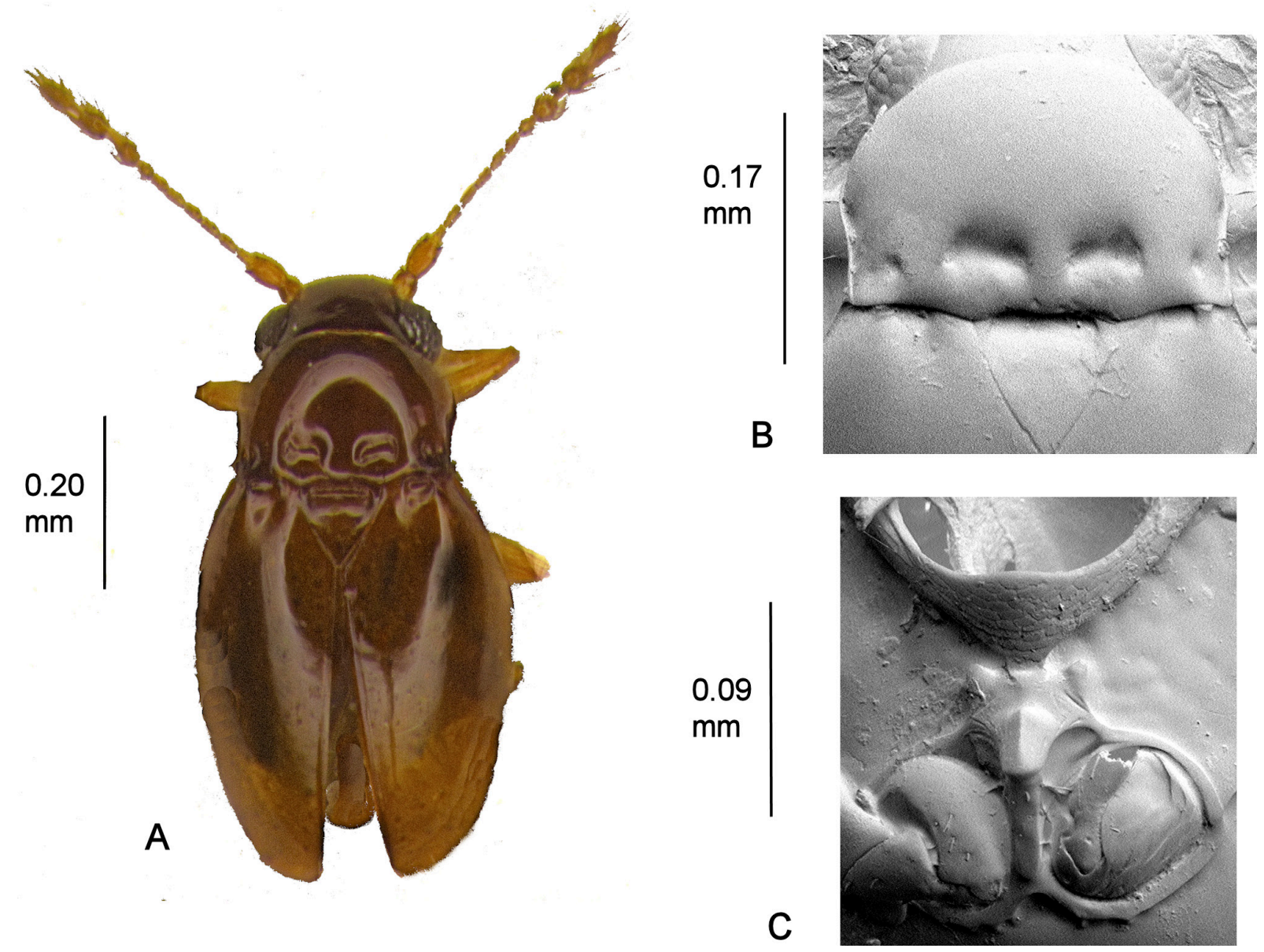

Fig. 9. Cissidium franzi sp. nov. A. Habitus. B. Pronotum, $\times$ 630. C. Mesoventrite showing median process of collar, mid-keel and keel, $\times 995$. 
Wings. Macropterous.

GenitaLia. Male aedeagus as Fig. 6Fa-b. Female spermatheca not known.

\section{Remarks}

The glabrous and strongly foveate pronotum is shared with $C$. glabratum sp. nov. and C. semicalvum sp. nov. both also from Madagascar, but $C$. franzi sp. nov. may be distinguished from them by the presence of the two small ancilliary foveae between the large foveae and the pronotal lateral margins.

\section{Cissidium glabratum sp. nov.}

urn:Isid:zoobank.org:act:09C451E7-C2F0-4F98-AF07-2A6492B08B72

Fig. 10

\section{Etymology}

Johnson ms name after the glabrous dorsal surface.
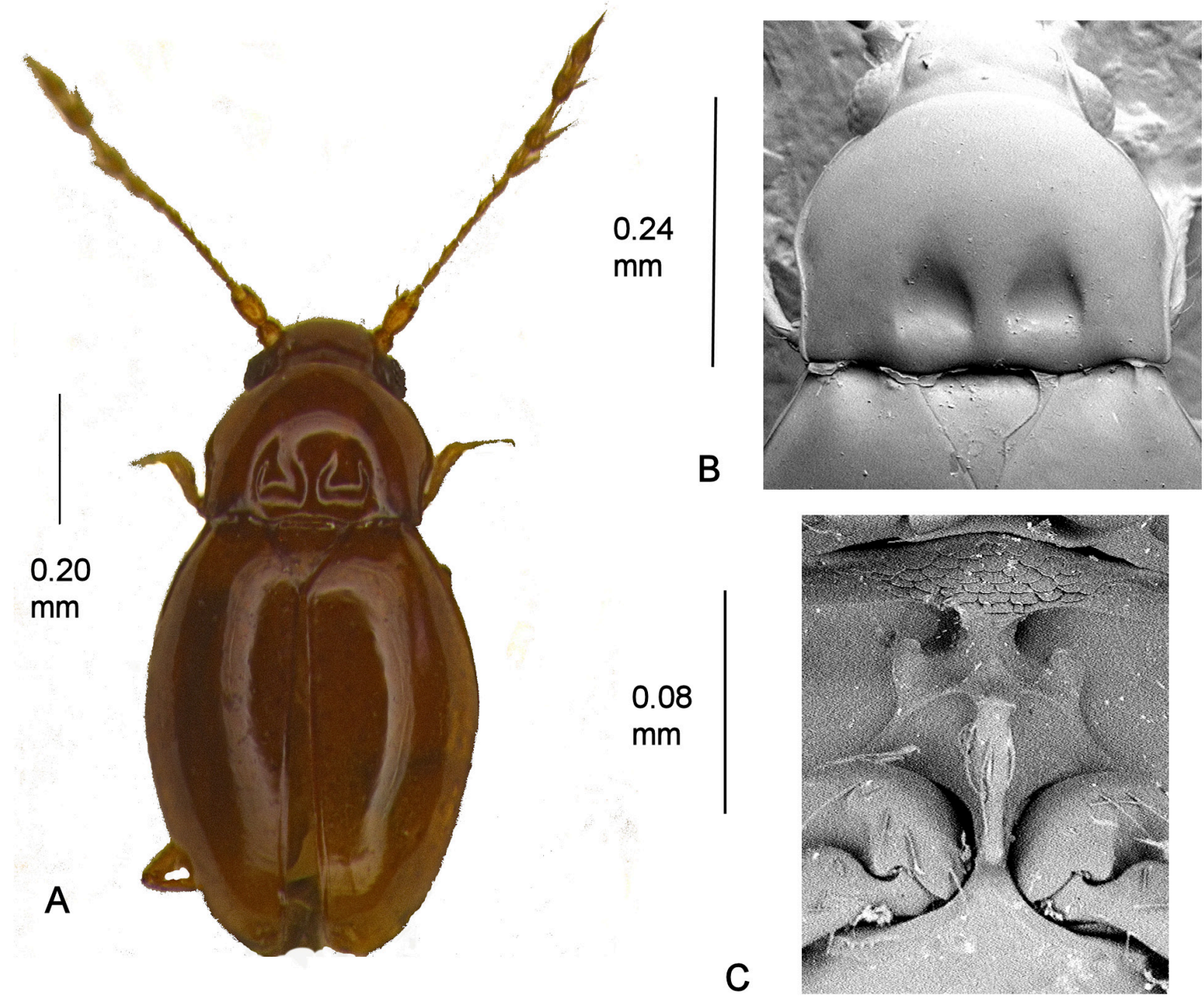

Fig. 10. Cissidium glabratum sp. nov. A. Habitus. B. Pronotum, $\times$ 380. C. Mesoventrite showing median process of collar, mid-keel and keel, $\times 685$. 


\section{Material examined}

\section{Holotype}

MADAGASCAR • ^’; Perinet, forest of transition; 928 m a.s.1.; 15 Apr. 1969; H. Franz leg. (Mg10); MMUE.

\section{Paratypes}

MADAGASCAR -4 우, same collection data as for holotype; one mounted verso, two on one pin; MMUE, BMNH.

\section{Description}

Size. Habitus (Fig. 10A), length $0.90 \mathrm{~mm}$.

CoLour. Dark brown, appearing polished, antennomeres and legs dusky yellow.

HEAD. With a transverse depression interrupted medially behind the eyes, width across eyes $0.23 \mathrm{~mm}$; antennomeres III-XI length $0.45 \mathrm{~mm}$, III-IX length $0.21 \mathrm{~mm}$, very thin and elongate, X-XI length $0.24 \mathrm{~mm}$; mentum as Fig. 4A.

Pronotum. Length $0.23 \mathrm{~mm}$, width $0.32 \mathrm{~mm}$, glabrous with two large basal foveae; lateral margins rounded almost parallel in basal third, narrowly bordered to rectangular hind angles, not continued along the posterior border which has a sinuous emargination before the scutellum (Fig. 10B).

ELYTRA. Length $0.58 \mathrm{~mm}$, width $0.44 \mathrm{~mm}$, glabrous.

Mesoventrite. Collar with a broad medial extension lacking reticulation; mid-keel very short, anterior corners rounded, posterior corners joining mesocoxae with well-defined carinae, sharply raised prior to junction with keel; keel narrow, with \pm four setae, slightly widening before termination at interruption of mesocoxal borders; mesoventral lateral margins serrate; humeri toothed (Fig. 10C).

MetaVentrite. Length $0.18 \mathrm{~mm}$, sparsely pubescent towards lateral margins, disc plain, width across the thin, sharply pointed spines $0.15 \mathrm{~mm}$; posterior margins of mesocoxal cavities partially serrate.

WiNGS. Macropterous in both sexes.

Genitalia. Male aedeagus as Fig. 6Fa-b. Female spermatheca globular.

\section{Remarks}

Lacks the two ancilliary foveae of $C$. franzi sp. nov. and distinguished from both that species and C. glabratum sp. nov. by the angulate pronotal side margins.

Cissidium lucidulum sp. nov.

urn:lsid:zoobank.org:act:A60A855C-4027-450F-A2B0-576BC746B873

Figs 5B, 11

\section{Etymology}

Johnson ms name. Named after the Latin adjective 'lucidus', meaning 'bright, clear' and referring to the dorsal surface. 


\section{Material examined}

\section{Holotype}

SOLOMON ISLANDS • Guadalcanal, Mt. Austen, 4 Jul. 1966; no. 23371; P. Greenslade leg.; BMNH.

\section{Description}

Size. Habitus (Fig. 11A), length $0.52 \mathrm{~mm}$.

Colour. Yellow brown, glabrous, shining.

HEAD. Without pubescence and with a shallow linear depression across the mid-point of the eyes, width across eyes $0.17 \mathrm{~mm}$; antennomeres III-XI length $0.32 \mathrm{~mm}$, III-IX length $0.17 \mathrm{~mm}, \mathrm{X}-\mathrm{XI}$ length $0.15 \mathrm{~mm}$; mentum and prementum obscured.

Pronotum. Length $0.14 \mathrm{~mm}$, width $0.24 \mathrm{~mm}$, basal half with pair of well-defined oval, longitudinal foveae, one on each side of disc, separated by about a third of pronotal width, with similar but much smaller ones near pronotal hind angles, a further pair of more rounded foveae by the lateral margin angles, surface smooth and shining without foveolae; sides sharply angled, slightly widening posteriorly to almost rectangular hind angles, front angles rounded, conspicuously bordered, the border not continued along the basal margin, hind margin slightly wider than elytral base with a sinuous emargination before the scutellum (Fig. 11B).

ELYTRA. Length $0.35 \mathrm{~mm}$, width $0.31 \mathrm{~mm}$, surface smooth and shining, without foveolae.
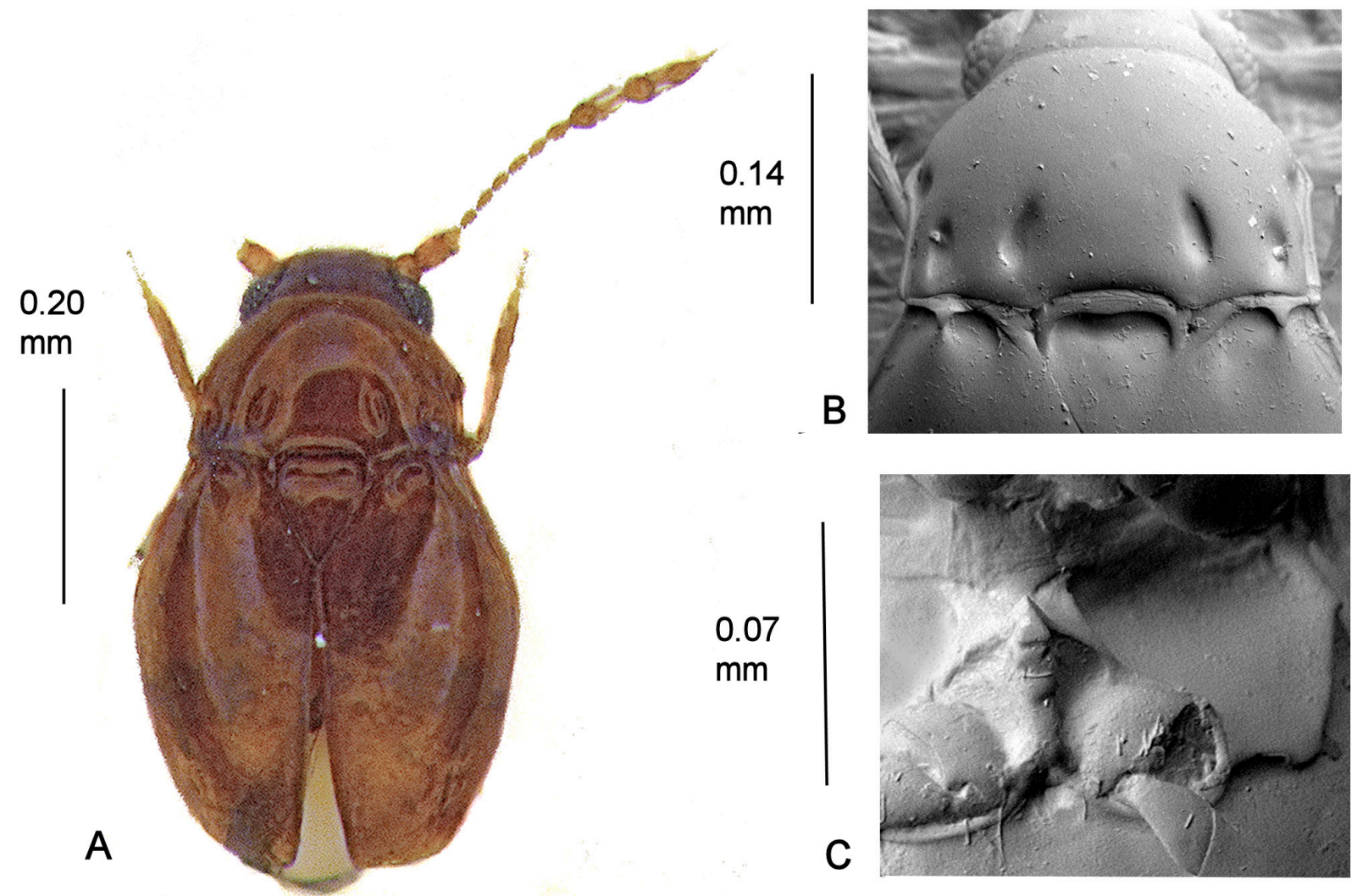

Fig. 11. Cissidium lucidulum sp. nov. A. Habitus. B. Pronotum, $\times 670$. C. Mesoventrite showing median process of collar, mid-keel, keel and angular lateral margin without serrations, $\times 690$. 
Mesoventrite. Collar with a median process onto the mid-keel; mid keel widenend anteriorly and posteriorly with carinae joining mesocoxae, sharply raised medially with a ridged top before junction with keel; keel parallel-sided, relatively broad between the mesocoxae (Fig. 5B); lateral margins angulate without serrations (Fig. 11C).

MetaVentrite. Disc simple; posterior borders of mesocoxal cavities without serrations.

WINGS. Macropterous in both sexes.

\section{Remarks}

The sex of this unique specimen is unknown as the abdomen was unfortunately lost during preparation, but eye size suggests a female. The smallest species of the Solomon Islands and the only one to have a glabrous pronotum.

Cissidium semicalvum sp. nov.

urn:lsid:zoobank.org:act:9769DC7C-6A25-4324-933E-6C310F16C20C

Fig. 12

\section{Etymology}

Johnson ms name, after the Latin adjective 'calvus', meaning 'bald'.
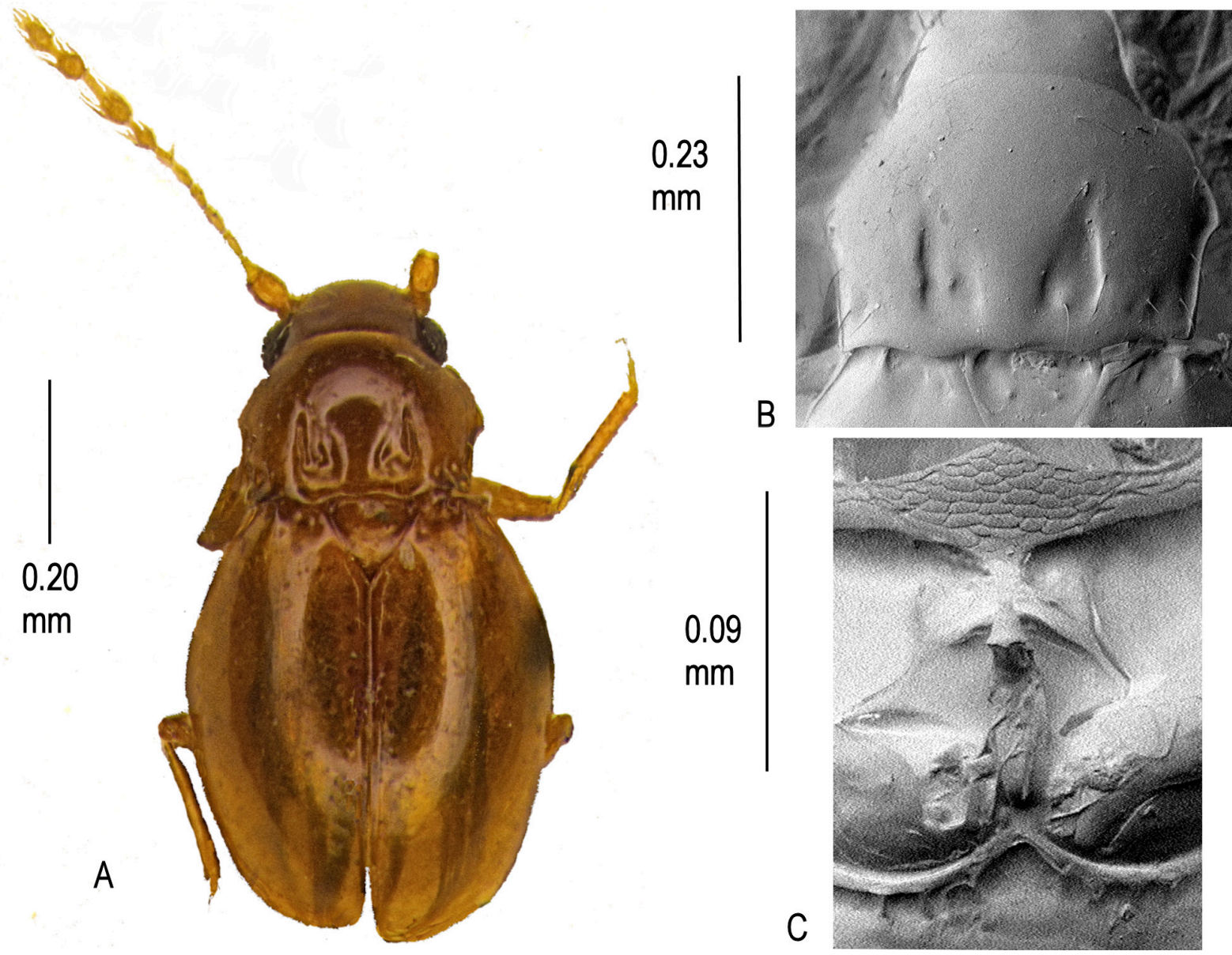

Fig. 12. Cissidium semicalvum sp. nov. A. Habitus. B. Pronotum, $\times 520$. C. Mesoventrite showing median process of collar, mid-keel and keel, $\times 700$. 


\section{Material examined}

Holotype

MADAGASCAR • +; Montagne d'Ambre, Diego Suarez, Mont du Petit Lac forest; 1100-1800 m a.s.l.; 21 May 1969; H. Franz leg.; MM holotype; MMUE.

\section{Description}

Size. Habitus (Fig. 12A), length $0.80 \mathrm{~mm}$.

CoLour. Yellow brown, shining, head darker, pubescence, legs and antennae dusky yellow.

HEAD. Glabrous; width across eyes $0.23 \mathrm{~mm}$; mentum obscured; antennomeres III-XI, length $0.41 \mathrm{~mm}$, III-IX length $0.24 \mathrm{~mm}, \mathrm{X}-\mathrm{XI}$ length $0.17 \mathrm{~mm}$.

Pronotum. $0.23 \mathrm{~mm}$ long, $0.31 \mathrm{~mm}$ wide, glabrous, with two large basal foveae slightly elongate in part, two additional smaller foveae at hind angles; lateral margins sharply angled then almost parallel to rectangular hind angles, anterior angles obtuse, bordered, the border running for a short distance along the posterior margin, posterior margin strongly sinuate with an emargination before the scutellum (Fig. 12B).

ElYTRA. Length $0.51 \mathrm{~mm}$, width $0.45 \mathrm{~mm}$, glabrous.

MesoventRIte. Medial extension of collar very short; mid-keel short, front angles effaced, hind angles wide, carinate continuing to outer edge of mesocoxae; keel with \pm six setae, short, tapering to rounded termination at interruption of mesocoxal borders; mesoventral lateral margins evenly rounded, serrate in posterior half; humeri toothed (Fig 12C).

Metaventrite. Glabrous, length $0.17 \mathrm{~mm}$, disc simple, width across spines $0.13 \mathrm{~mm}$; posterior margin of mesocoxae serrate.

WINGs. Macropterous

Genitalia. Female spermatheca globular. Males not known.

\section{Species group 2: pronotum with foveae but without distinct foveolae}

\section{Key to species in species group 2}

1. Species in which the mesocoxal borders are clearly separated ..................................................... 2

- Species with united mesocoxal borders (join sometimes obscured by longer keels) ......................... 8

2. Keel spatulate (Fig. 37C) ................................................................................ noumeae sp. nov.

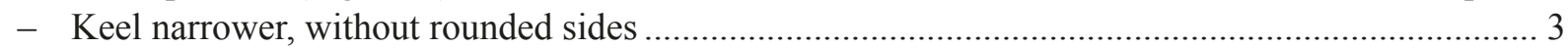

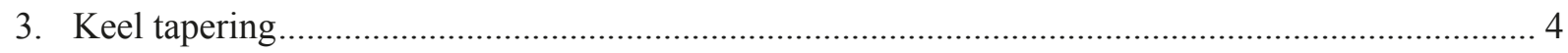

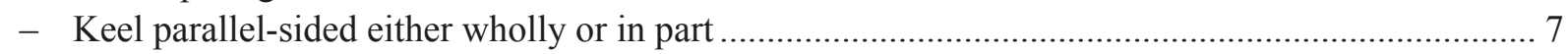

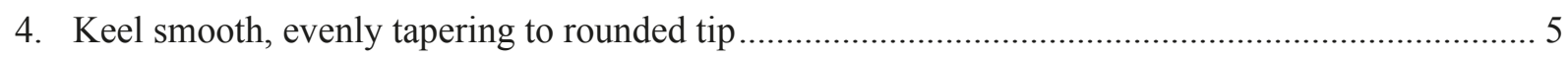

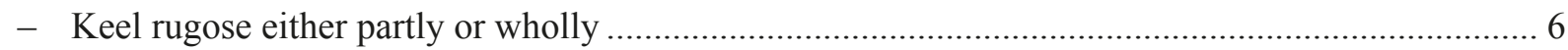

5. Anterior angles of mid-keel rounded not reaching collar....................................... pinense sp. nov.

- Anterior angles of mid-keel broad reaching collar .............................................. . amieuense sp. nov. 
6. Keel setose throughout

C. mussardi sp. nov.

- Keel setose and parallel-sided at base then smooth to tip

C. riparium sp. nov.

7. Keel broad with rectangular tip

C. subfoveolatum Darby, 2019

- Keel narrower with slightly rounded tip

8. Lateral margins of mesoventrite serrate.

- Lateral margins of mesoventrite without serrations

9. Elytra without foveolae

C. advena sp. nov.

- Elytra with foveolae

10. Keel broadening and rounded posteriorly.....

C. logunovi sp. nov.

- Keel pointed or parallel-sided or tapering posteriorly

11. Pronotal lateral margins with sharp angles medially

- Pronotal lateral margins without sharp medial angles

12. One pair of pronotal foveae elongate.

C. banari Darby, 2013

- All the pronotal foveae more or less round

C. clareae sp. nov.

13. Pronotal sides distinctly concave before hind angles, sides more sharply rounded (Fig. 28C)

C. inexspectatum sp. nov.

- Pronotal sides shallowly concave, almost straight, before hind angles

14. Micropterous species

C. crowsoni Johnson, 1982

- Fully winged or apterous species.

15. Apterous species

- Fully winged species.

16. Median process of collar long, keel narrow and pointed.

C. montanum sp. nov.

- Median process of collar very short, keel wider

C. okuense Grebennikov, 2009

17. Head with a distinct fovea between the eyes

C. foveolatum Johnson 1982

- Head without a fovea

18. Elytra appearing almost parallel-sided

C. ishigakiense Sawada, 2008

- Elytral sides more rounded

19. Pronotal foveae small, rounded

- Pronotal foveae larger two medial ones elongate

C. aristophanousi sp. nov.

20. Species with only one or two pronotal foveae

C. delicatum sp. nov.

- Species with at least four pronotal foveae

21. Species with a short border along part of the posterior edge of the pronotum

- Species without a pronotal posterior border.

22. Pronotum with two large basal foveae.

C. bifoveolatum sp. nov.

- Pronotum with four smaller basal foveae C. yoruba sp. nov. 


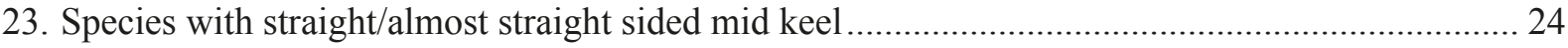

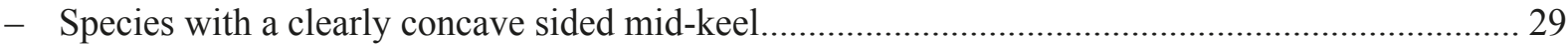

24. Posterior angles of mid-keel with carinae to mesocoxal borders .....................C ceylonicum sp. nov.

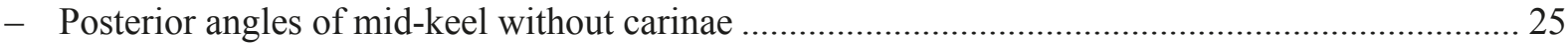

25. Sides of pronotum straight, parallel-sided before hind angles ............................. houailou sp. nov.

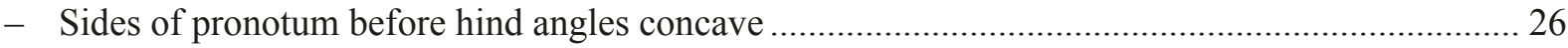

26. Medial process of collar onto mid keel almost reaching to basal tip.................. C. misellum sp. nov.

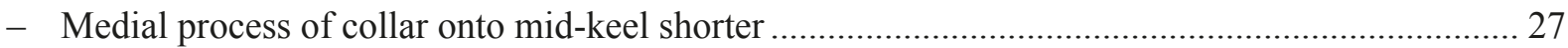

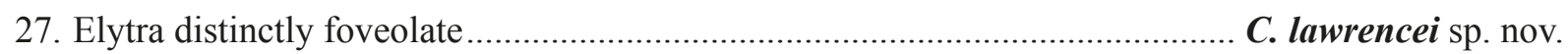

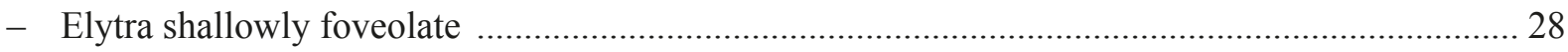

28. Pronotum with eight foveae across the basal margin ............................................ . rogeri sp. nov.

- Pronotum with four foveae across the basal margin .................................................. deanei sp. nov.

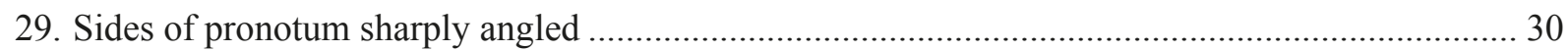

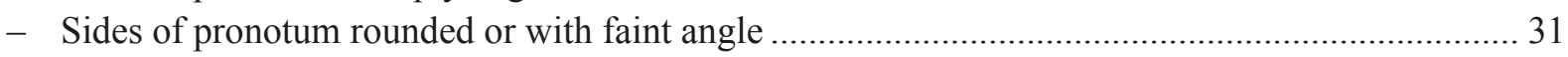

30. Mid-keel broad, medial extension of collar reaching to raised posterior margin of mid-keel

C. robustum sp. nov.

- Medial extension of collar very short/effaced not reaching posterior margin of mid-keel

C. greensladei sp. nov.

31. Keel long, parallel-sided, without pubescence C. scutellaris (Deane, 1931)

- Keel pubescent

32. Front angles of mid-keel not reaching collar, keel sharply pointed

C. davaoense sp. nov.

- Keel narrow, parallel-sided, foveolate

C. lamington sp. nov.

Cissidium advena sp. nov.

urn:Isid:zoobank.org:act:3DB446BE-D563-4B2E-82DE-26F856A8AFD2

Fig. 13

\section{Etymology}

Johnson ms name. Presumed to be from the Latin 'advena', meaning 'a stranger'. Noun in apposition.

\section{Material examined}

\section{Holotype}

PHILIPPINES • \} \text { ; Mindanao, Todaya, E slope of Mt Apo, Davida Prov.; } 1 6 \text { Jun. 1946; } 2 8 0 0 \mathrm { ft } \text { a.s.l.; in } decaying leaf fragments under young bamboo petioles; F. Werner leg.; FM(HD) \# 46.43; mounted as a disarticulated slide; FMNH.

\section{Description}

SizE. Habitus (Fig. 13A), length $0.76 \mathrm{~mm}$.

CoLour. Yellow brown, pubescence, legs and antennae yellow. 
HEAD. With a clearly marked linear depression and short median longitudinal depression between the eyes, width across eyes $0.23 \mathrm{~mm}$; antennomeres III-XI length $0.34 \mathrm{~mm}$, III-IX length $0.19 \mathrm{~mm}, \mathrm{X}-\mathrm{XI}$ length $0.15 \mathrm{~mm}$; mentum as Fig. 4A.

Pronotum. Length $0.21 \mathrm{~mm}$, width $0.28 \mathrm{~mm}$, sparsely pubescent mostly confined to anterior corners, with row of eight basal foveae, the median four tending to form two large ones; side margins rounded, slightly concave before rectangular hind angles, border not extending onto posterior margin, emargination before scutellum sinuate (Fig. 13B).

ELYTRA. Length $0.42 \mathrm{~mm}$, width $0.42 \mathrm{~mm}$, sparsely pubescent without foveolae.

Mesoventrite. Medial extension of collar short, broad; mid-keel tapering from anterior corners to posterior margin with carinae at the corners reaching to the mesocoxal anterior borders, medially with a sharply defined longitudinal ridge rising to a blunt point before the keel; keel parallel-sided to rounded termination past mid-point of the mesocoxae; mesoventral lateral margins serrate posteriorly (Fig.13C).

Metaventrite. Length $0.12 \mathrm{~mm}$, width across spines $0.08 \mathrm{~mm}$, with scattered setae near margins, disc depressed; mesoventral posterior margins serrate.

WINGS. Macropterous.

Genitalia. Male aedeagus as Fig. $6 \mathrm{Fa}-\mathrm{b}$. Female not known.
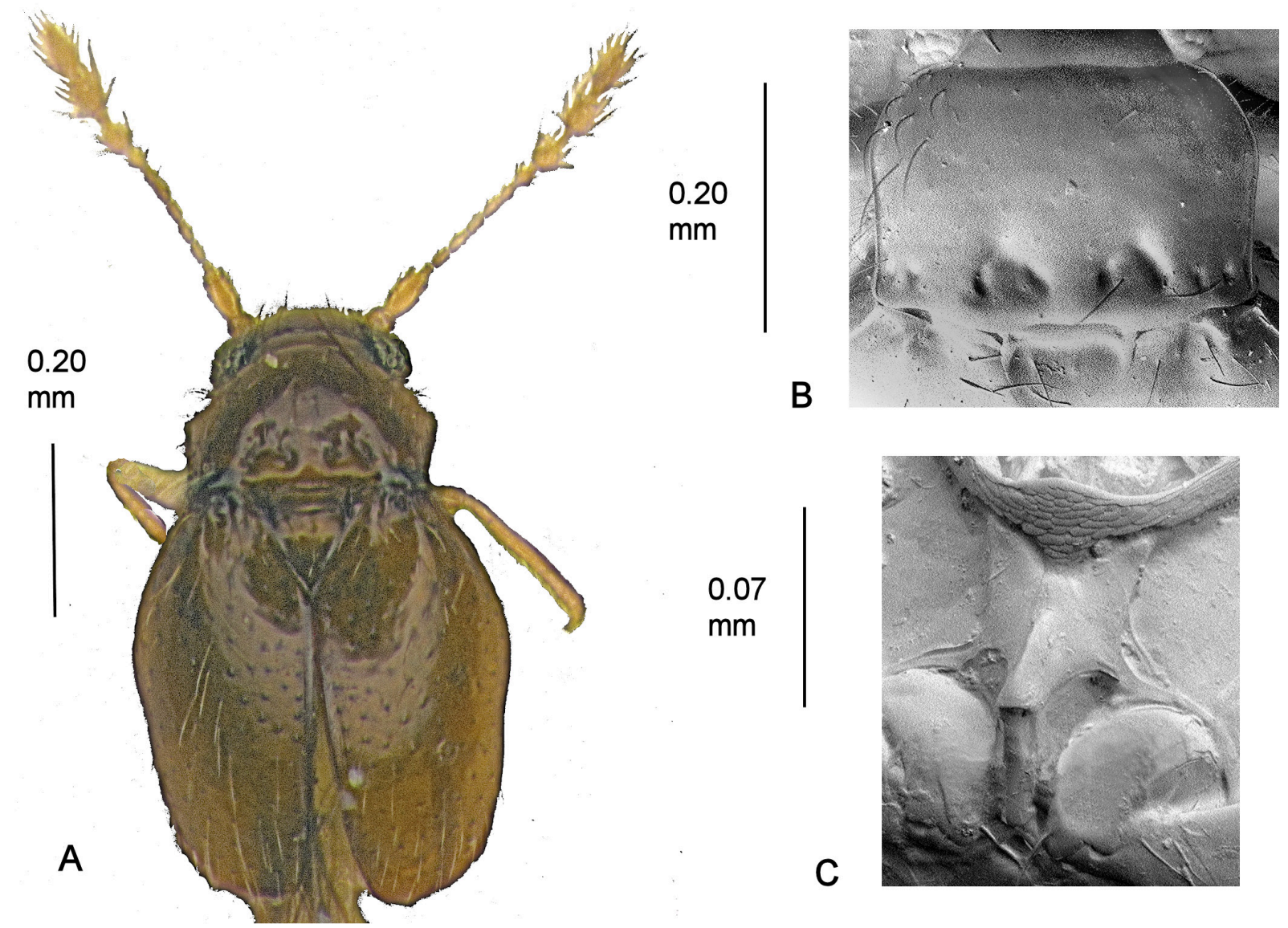

Fig. 13. Cissidium advena sp. nov. A. Habitus. B. Pronotum, $\times 550$. C. Mesoventrite showing median process of collar, mid-keel and keel, $\times 1180$. 


\section{Remarks}

One of the only two species of Cissidium in this group from the Philippines. Distinguished by the larger pronotal foveae than those on $C$. davaoense sp. nov.

\section{Cissidium amieuense sp. nov.}

urn:1sid:zoobank.org:act:556E5FC9-A322-4C73-B37B-AF9BF5D923AF

Fig. 14

\section{Etymology}

Johnson ms name. Named after the Col d'Amieu, New Caledonia, where the insects were captured.

\section{Material examined}

\section{Holotype}

NEW CALEDONIA • $\widehat{O}$; Table de Union, Col d'Amieu [no further data recorded]; MM; MMUE.

\section{Paratype}

NEW CALEDONIA • + ; same collection data as for holotype; MMUE.

\section{Description}

Size. Habitus (Fig. 14A), length $0.67 \mathrm{~mm}$.
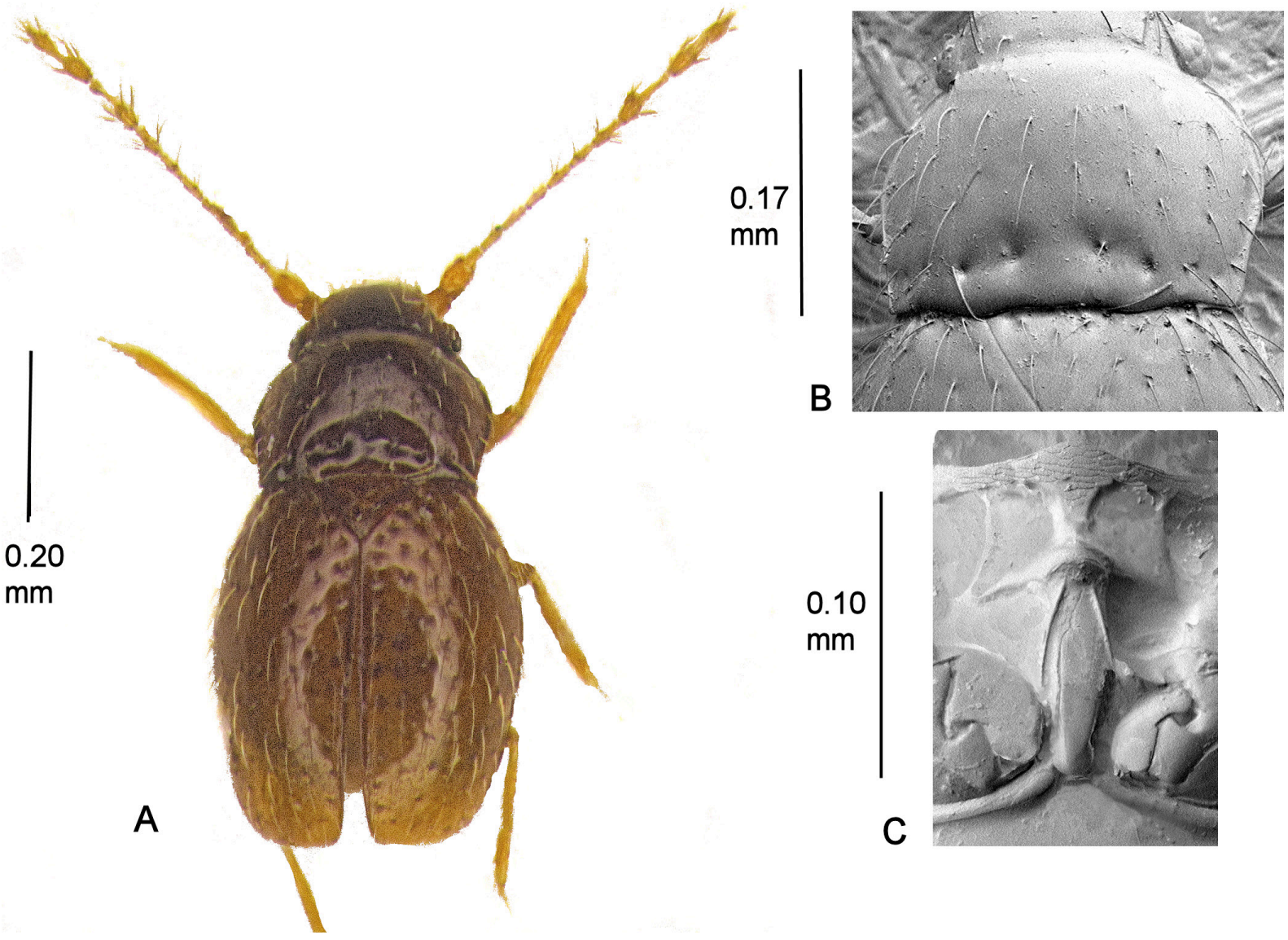

Fig. 14. Cissidium amieuense sp. nov. A. Habitus. B. Pronotum, $\times$ 525. C. Mesoventrite showing median process of collar, mid-keel and keel, $\times 715$. 
CoLour. Dark brown, elytra dusky yellow where translucent, head almost black, pubescence, legs and antennae yellow.

HEAD. Without a clearly marked linear depression behind the eyes, width across eyes $0.21 \mathrm{~mm}$; mentum and submentum as Fig. 4A; antennomeres III-XI length $0.44 \mathrm{~mm}$, III-IX length $0.26 \mathrm{~mm}, \mathrm{X}-\mathrm{XI}$ length $0.18 \mathrm{~mm}$.

Pronotum. Length $0.17 \mathrm{~mm}$, width $0.29 \mathrm{~mm}$, sparsely pubescent, with a row of six basal foveae, the median two placed slightly anterior to the lateral four, side margins rounded almost straight in basal half, border not extending onto posterior margin, hind angles rectangular, posterior border with a sinuous emargination before the scutellum (Fig. 14B).

ELYTRA. Length $0.42 \mathrm{~mm}$, width $0.37 \mathrm{~mm}$, sparsely pubescent and shallowly foveolate, length of setae as pronotum.

Mesoventrite. Medial extension of collar onto mid-keel tapering, posterior margin of mid-keel not reaching mesocoxae; keel sharply raised anteriorly with two long setae then flat and tapering posteriorly to a rounded termination between the mesocoxae; mesoventral lateral margins serrate posteriorly (Fig. 14C).

MetaventRite. Length $0.13 \mathrm{~mm}$, width across spines $0.12 \mathrm{~mm}$, with scattered setae, disc plain.

Wings. Apterous.

Genitalia. Male aedeagus as Fig. 6Fa-b. Female spermatheca globular.

\section{Remarks}

Seven species of Cissidium, all that have been recorded from New Caledonia, belong in this group and are difficult to separate on pronotal characters, the mesoventral characters providing a better guide. The concave sides of the mid-keel together with the flat tapering keel and pair of anterior setae distinguish this species.

Cissidium aristophanousi $\mathrm{sp}$. nov. urn:1sid:zoobank.org:act:32172E7B-8DEA-411B-93F6-CCC304DD98FC

Fig. 15

\section{Etymology}

Named after the collector, Dr Marios Aristophanous.

\section{Material examined}

\section{Holotype}

IVORY COAST • + ; Mt. Tonkoui Peak; 07²7'15.2" N, 07³8'12.5" W; 1171m a.s.1.; 1-8 Nov. 2015; Winkler soil; M. Aristophanous, P. Moretto and E. Ruzzier leg.; BMNH(E) 2015-177; BMNH.

\section{Paratype}

IVORY COAST • ; same collection data as for holotype; missing elytra; BMNH.

\section{Description}

Size. Habitus (Fig. 15A), length $0.83 \mathrm{~mm}$.

CoLour. Yellow brown shining, pubescence, legs and antennae slightly paler. 
HEAD. Without a linear depression behind the eyes, width across eyes $0.21 \mathrm{~mm}$; antennomeres III-XI length $0.41 \mathrm{~mm}$, III-IX length $0.23 \mathrm{~mm}, \mathrm{X}-\mathrm{XI}$ length $0.18 \mathrm{~mm}$, mentum and submentum as Fig 4A.

Pronotum. Length $0.20 \mathrm{~mm}$, width $0.28 \mathrm{~mm}$, with two groups of four foveae in basal third; side margins angular then straight to rectangular hind angles, bordered, the borders not continued along the sinuate posterior margin which has an emargination before the scutellum (Fig. 15B).

ELYTRA. Length $0.49 \mathrm{~mm}$, width $0.39 \mathrm{~mm}$, foveolate in basal third, length of setae as pronotum.

MesoventRIte. Medial extension of collar onto mid-keel short, tapering; posterior margin of midkeel slightly narrower than anterior, posterior corners barely reaching anterior margin of mesocoxal cavities; keel with a series of \pm six setae, hooked (as Fig. 5D) parallel-sided to a rounded tip between the mesocoxae; mesoventral lateral margins serrate; humeri toothed (Fig. 15C).

MetaVentRite. Length $0.17 \mathrm{~mm}$, scattered setae on disc and posterior margin, spines long, tapering to a fine point, width across spines $0.15 \mathrm{~mm}$; posterior margins of mesocoxal cavities serrate.

WINGS. Macropterous.
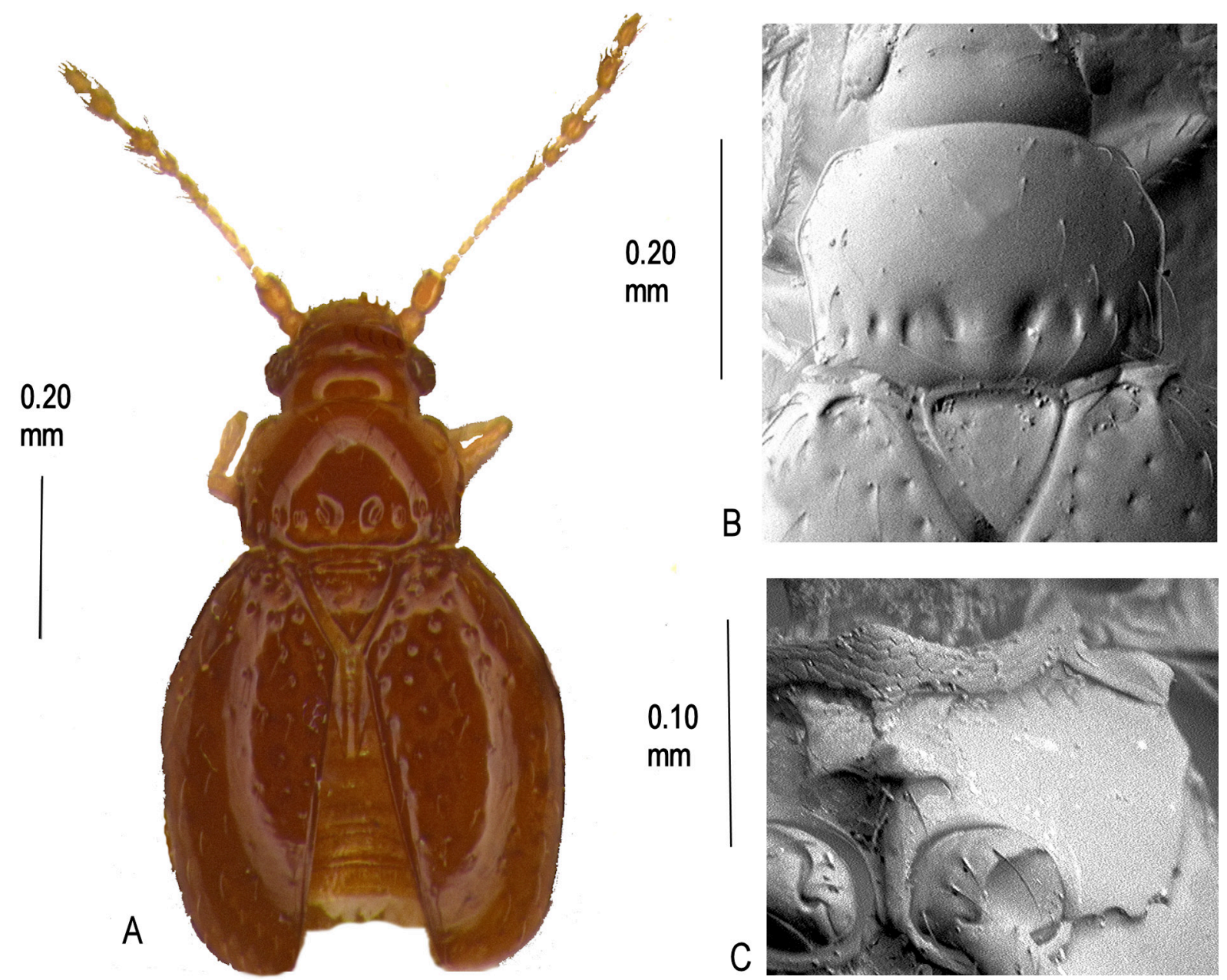

Fig. 15. Cissidium aristophanousi sp. nov. A. Habitus. B. Pronotum, $\times 370$. C. Mesoventrite showing median process of collar, mid-keel, keel and serrate lateral margin, $\times 640$. 
GenitaLia. Female spermatheca globular. Males not known.

\section{Remarks}

Distinguished from $C$. arcuatum sp. nov. by the groups of foveae on the pronotum and by the more pronounced foveolae on the elytra.

Cissidium banari Darby, 2013

Fig. 16

\section{Material examined}

\section{Holotype}

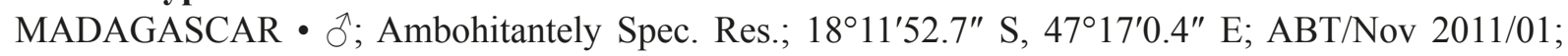
1603 m a.s.l.; forest litter under big Pandanus; sifting; Winkler app. extr.; 16 Nov. 2011; L.S. Rahanitriniaina and P. Baňar̆ leg.; BMNH.

\section{Supplementary description}

The following description amplifies the type description of Darby (2013), in particular by adding more details of the meso- and metaventral characters in order to conform with the requirements of the present paper.

Size. Habitus (Fig. 16A), length $0.79 \mathrm{~mm}$.

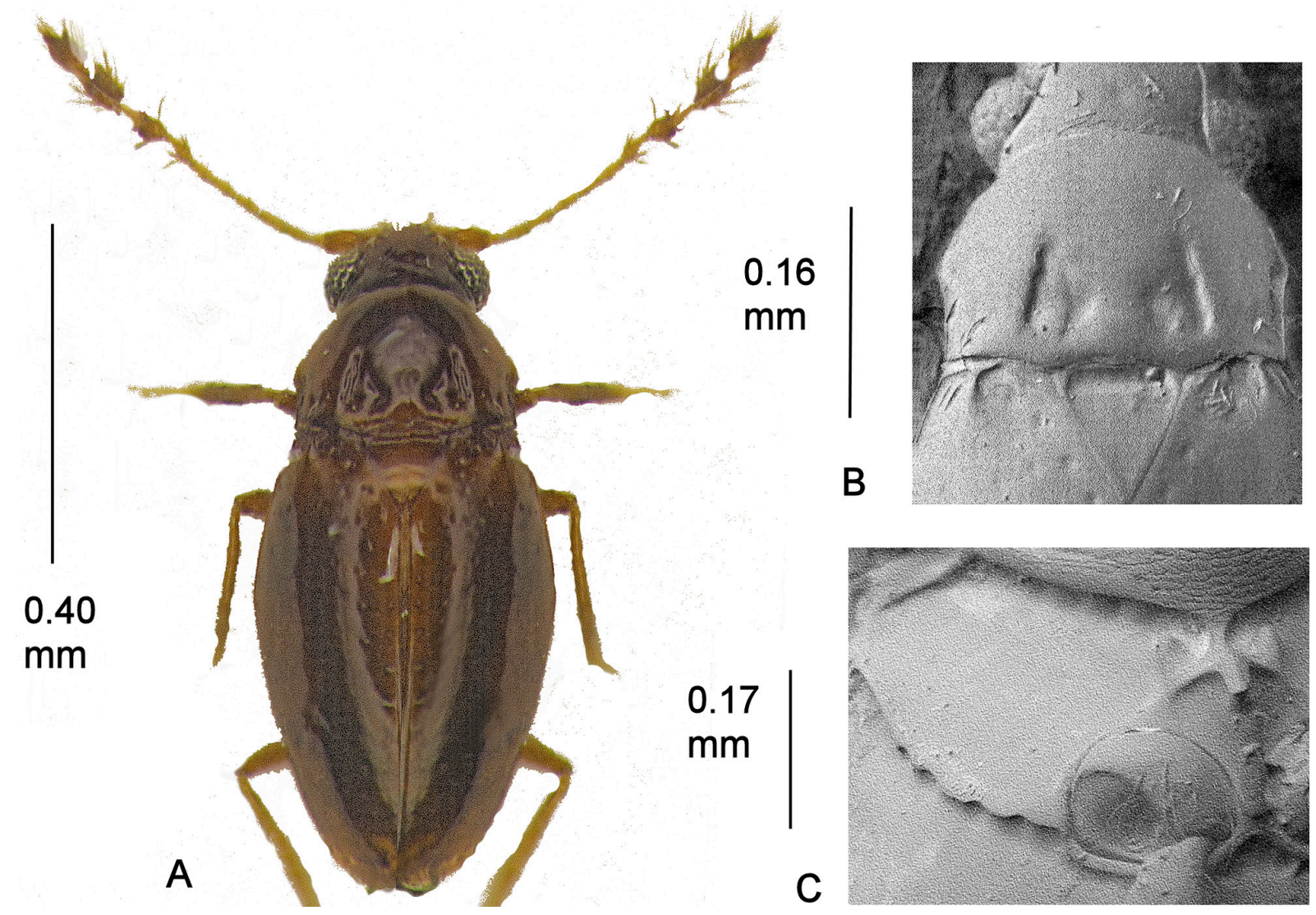

Fig. 16. Cissidium banari Darby, 2013. A. Habitus. B. Pronotum, $\times 540$. C. Mesoventrite showing median process of collar, mid-keel and keel, $\times 680$. 
CoLour. Yellow brown, very shining, antennae and legs dusky yellow.

HEAD. With a shallow median fovea between the eyes, antennomeres III-XI length $0.39 \mathrm{~mm}$, III-IX $0.20 \mathrm{~mm}, \mathrm{X}-\mathrm{XI} 0.19 \mathrm{~mm}$.

Pronotum. Length $0.18 \mathrm{~mm}$, width $0.26 \mathrm{~mm}$, with two foveae on each side tending to form a single fovea of distorted shape; lateral margins sharply angled, parallel before hind angles which are slightly acute, narrowly bordered, the border not continuing along the posterior margin, the emargination in front of the scutellum sinuous (Fig. 16B).

ElYTRA. $0.52-54 \mathrm{~mm}$ long, $0.37-0.40 \mathrm{~mm}$ wide, sparsely and shallowly foveolate particularly along sides of the scutellum and suture, tapering strongly to apex.

Mesoventrite. Mid-keel very short, anteriorly with two rounded corners either side of the median process of the collar, posteriorly with two pointed corners not reaching the mesocoxae, strongly raised to point before meeting keel, keel parallel-sided terminating in a rounded end between the mesocoxae; humeri with small teeth and hind margin sloping posteriad (Fig. 16C).

Metaventrite. Glabrous, disc simple, posterior margins of mesocoxae with slight serrations near interruption in borders.

Wings. Male macropterous, female micropterous/apterous.

Genitalia. Male aedeagus as Fig. 6Fa-b. Female spermatheca globular.

\section{Remarks}

Distinguished from C. bifoveolatum sp. nov. the only other Madagascan species with a pubescent pronotum by its larger size, much sparser and shorter pronotal pubescence and pronotum with angular lateral margins.

Cissidium bifoveolatum sp. nov. urn:1sid:zoobank.org:act:793E71EC-48C7-4E7E-A407-98F783A8835D

Figs $5 \mathrm{~A}, 17$

\section{Etymology}

Johnson ms name, presumably after the two large foveae on the pronotum.

\section{Material examined}

Holotype

MADAGASCAR - O'; East, Baie d'Antongil, Ambohitsitondroina; $500 \mathrm{~m}$ a.s.1.; roots of Asplenium; Dec. 1959; J. Vadon leg.; identified as Camptodium by CJ; MMUE.

\section{Paratypes}

MADAGASCAR • 8 ex.; same collection data as for holotype; MMUE, BMNH.

\section{Description}

Size. Habitus (Fig. 17A), length $0.69 \mathrm{~mm}$.

CoLour. Yellow brown appearing polished, head darker, pubescence, legs and antennae paler. 
HEAD. With a shallow depression interrupted medially behind the eyes, width across eyes $0.21 \mathrm{~mm}$; antennomeres III-XI length $0.35 \mathrm{~mm}$, III-IX length $0.21 \mathrm{~mm}, \mathrm{X}-\mathrm{XI}$ length $0.14 \mathrm{~mm}$, mentum and submentum as Fig. 4A, but with faint circular depressions.

Pronotum. Length $0.20 \mathrm{~mm}$, width $0.27 \mathrm{~mm}$, pubescence sparse, with four foveae in the posterior third the two medial ones much larger than the two close to the corners; side margins rounded then sinuate to rectangular hind angles, narrowly bordered, the border extending for a short distance along the posterior margin which has a sinuous emargination before the scutellum (Fig. 17B).

ELYTRA. Length $0.45 \mathrm{~mm}$, width $0.38 \mathrm{~mm}$, pubescence mainly confined to lateral margins.

MesoventRite. Medial extension of collar narrow, short; mid-keel posterior and anterior corners of approximately same width, the posterior margin reaching anterior margin of the mesocoxal cavities, sharply raised medially to keel; keel narrow, parallel-sided, bearing $2 / 3$ setae, terminating between the mesocoxae (Fig. 5A); mesoventral lateral margins loosely serrate in posterior half; humeri strongly toothed (Fig. 17C).

Metaventrite. Length $0.14 \mathrm{~mm}$, width across spines $0.09 \mathrm{~mm}$, glabrous, disc plain. Posterior margins of mesocoxal cavities serrate.
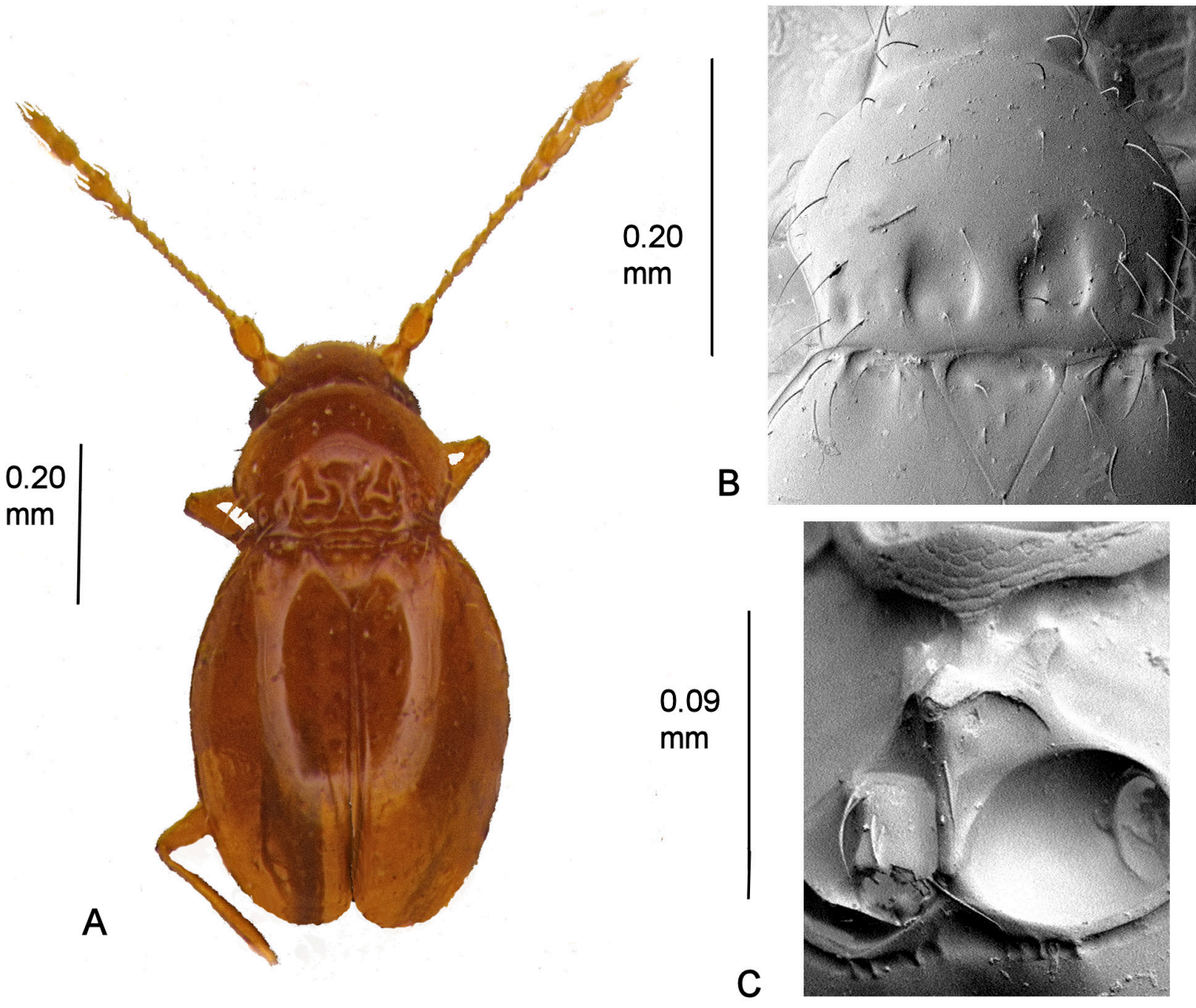

Fig. 17. Cissidium bifoveolatum sp. nov. A. Habitus. B. Pronotum, $\times 620$. C. Mesoventrite showing median process of collar, mid-keel and keel, $\times 945$. 
WINGS. Macropterous.

Genitalia. Female spermatheca globular. Male aedeagus as Fig. 6L but tip blunter.

\section{Remarks}

One of the five species of Cissidium recorded from Madagascar in this group, only likely to be confused with $C$. banari, but distinguished by its smaller size and longer pronotal pubescence.

\section{Cissidium ceylonicum sp. nov.}

urn:lsid:zoobank.org:act:92DE2EED-460C-4482-9AD2-6EEAE0CBA59A

Fig. 18

\section{Etymology}

Johnson ms name after the country where the insect was collected.

\section{Material examined}

\section{Holotype}

SRI LANKA • + ; Sabaragamuwa, 2 miles east of Kalawana; 20 Jan. 1970; Mussard, Besuchet and Löbl leg.; MMUE.

\section{Paratypes}

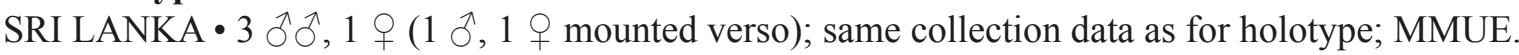
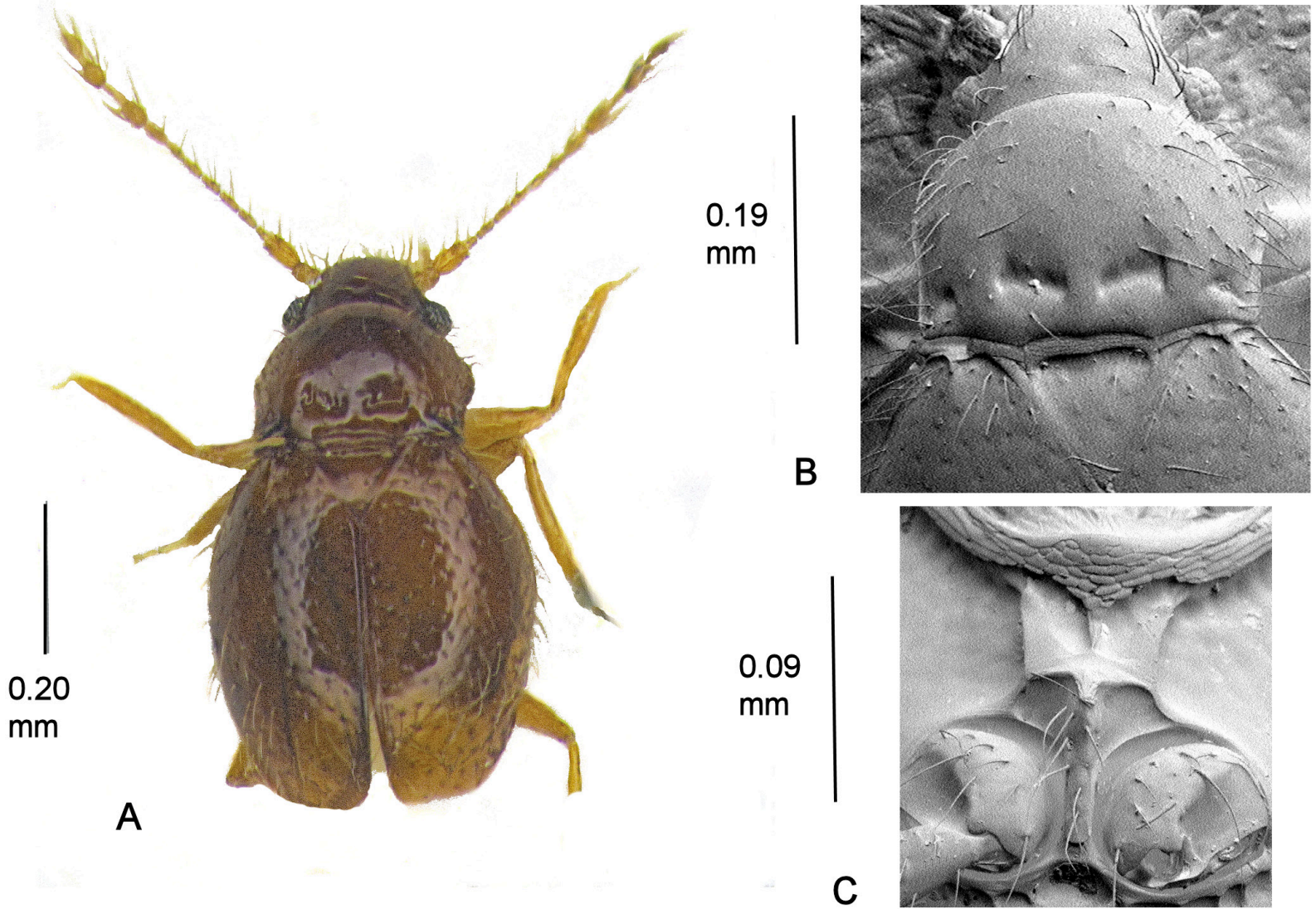

Fig. 18. Cissidium ceylonicum sp. nov. A. Habitus. B. Pronotum, $\times$ 590. C. Mesoventrite showing median process of collar, mid-keel and keel, $\times 630$. 


\section{Description}

Size. Habitus (Fig. 18A), length $0.69 \mathrm{~mm}$.

CoLour. Dark yellow brown, head slightly darker, pubescence, legs and antennae yellow.

HEAD. Without a clear linear depression behind the eyes, width across eyes $0.21 \mathrm{~mm}$, antennomeres III-XI length $0.38 \mathrm{~mm}$, III-IX length $0.22 \mathrm{~mm}, \mathrm{X}-\mathrm{XI}$ length $0.16 \mathrm{~mm}$, mentum and prementum as Fig $4 \mathrm{~A}$ but sides a little more concave.

Pronotum. Length $0.19 \mathrm{~mm}$, width $0.28 \mathrm{~mm}$, sparsely pubescent with a series of \pm eight foveae along the posterior margin, the six medial ones united into two large transverse ones; lateral margins rounded to rectangular hind angles, bordered, the border not extending along the posterior margin which has a sinuous emargination before the scutellum (Fig. 18B).

ELYTRA. Length $0.43 \mathrm{~mm}$, width $0.41 \mathrm{~mm}$, pubescent, the setae arising from shallow foveolae.

Mesoventrite. Medial extension of collar pointed; mid-keel wider anteriorly, posterior corners with carinae to anterior margins of mesocoxal borders, sharply raised medially before keel; keel with a series of \pm eight setae, parallel-sided to a blunt termination beyond the interruption of the mesocoxal margins; mesoventral lateral margins serrate in posterior half; humeri toothed (Fig. 18C).

MetaVentrite. Length $0.13 \mathrm{~mm}$, pubescent, width across narrow finely pointed spines $0.11 \mathrm{~mm}$, disc simple; posterior margins of mesocoxal cavities serrate.

WINGS. Macropterous.

Genitalia. Female spermatheca globular. Male aedeagus as Fig. 6Fa-b.

\section{Remarks}

The only species of Cissidium from Sri Lanka in this group.

Cissidium clareae sp. nov. urn:1sid:zoobank.org:act:60592E41-BF69-4746-87C0-58D9D06F6370

Figs 6G, 19

\section{Etymology}

Johnson ms name, named after his wife Clare.

\section{Material examined}

\section{Holotype}

SOLOMON ISLANDS • đ'; Guadalcanal, Mt. Austen; 14 Jul. 1964; no. 16411; P.J.M. Greenslade leg.; $\mathrm{BMNH}$.

\section{Paratypes}

SOLOMON ISLANDS • 1 q; Guadalcanal, Mt. Austen; 14 May 1963; no. 6018; P. Greenslade leg.;

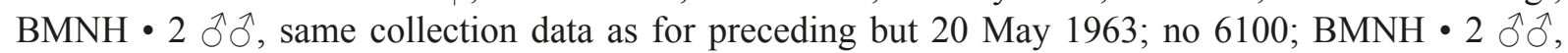
same collection data as for preceding but 19 Jun. 1963; no. 6487; BMNH $\bullet 1$ §; same collection data as for preceding but $1 \mathrm{Jul}$. 1963; no. 1269; MMUE 1 \% ; same collection data as for preceding but 29 Jun. 1963; no. 11031; BMNH • 1 §; same collection data as for preceding but 22 Jul. 1963; no. 11278; MMUE • 1 क; same collection data as for preceding but 13 Oct. 1963; no. 11326; MMUE • 1 đ; Mt. 
Jonapau; 3500-3750 ft a.s.1.; 6 May 1965; P. Greenslade leg.; BMNH • 1 §̊; Nuhu; $1000 \mathrm{ft}$ a.s.1.; 28-31 Oct. 1965; forest litter; P.N. Lawrence leg.; MMUE • 1 क; Popomanasiu; 5000 ft a.s.1.; Oct. 1965; litter sample 6; no. 20489; P. Greenslade leg.; BMNH • 1 q; New Georgia, Kolombangara; nr Kuzi; $50 \mathrm{ft}$ a.s.1.; 8 Sep. 1965; 781-800 m a.s.l.; valley litter; P.N. Lawrence leg.; BMNH 1 , , same collection data as for preceding; 3-9 Sep. 1965; forest litter; BMNH.

\section{Additional material}

SOLOMON ISLANDS • 1 क; New Georgia, Wagina Is.; 3 Jul. 1965; no. 23223; P. Greenslade leg.; BMNH.

\section{Description}

Size. Habitus (Fig. 19A), length $0.66 \mathrm{~mm}$.

\section{CoLour. Yellow.}

HEAD. Without a clear linear depression behind the eyes, width across eyes $0.21 \mathrm{~mm}$; antennomeres III-XI length $0.44 \mathrm{~mm}$; mentum as Fig 4A.

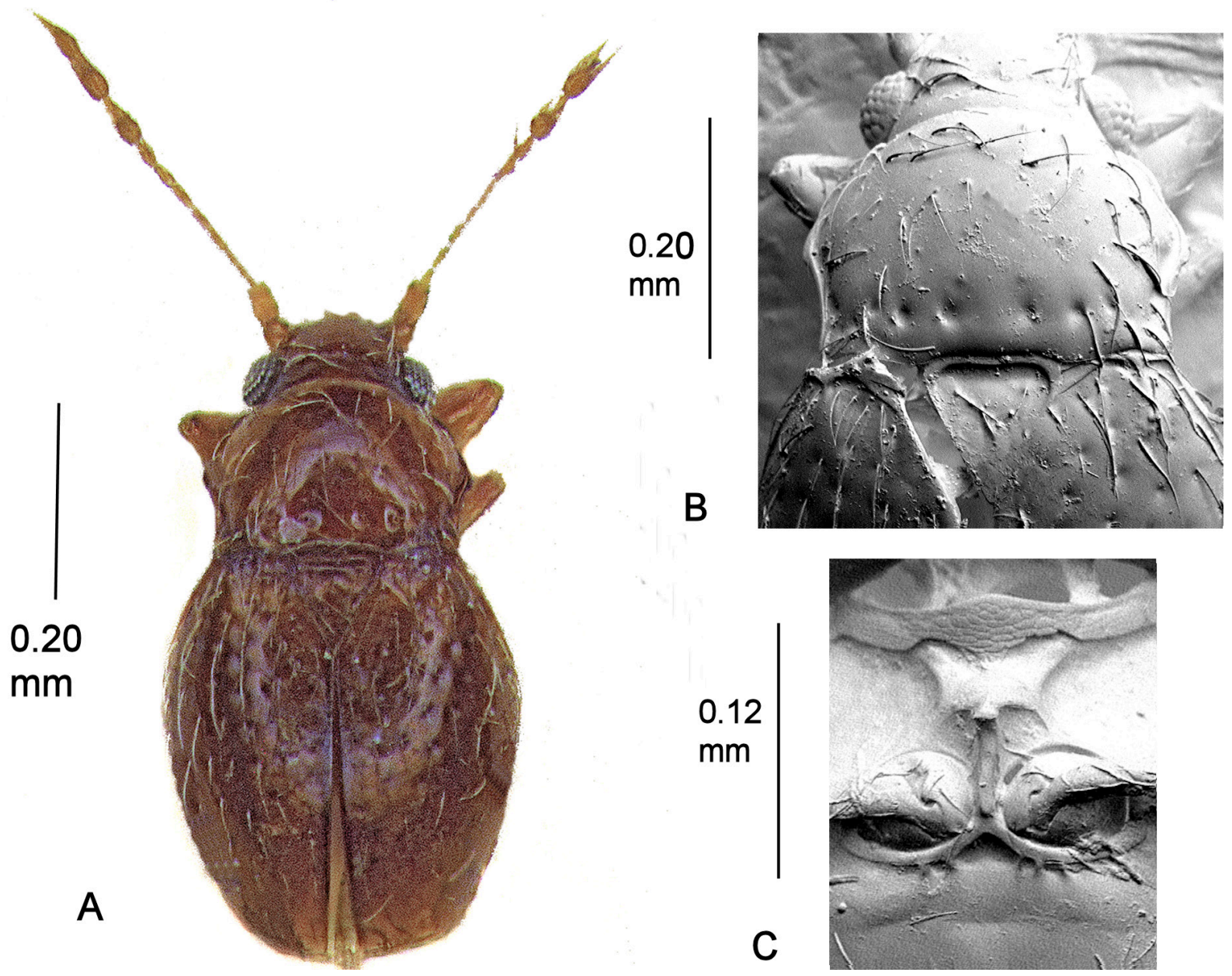

Fig. 19. Cissidium clareae sp. nov. A. Habitus. B. Pronotum, $\times 530$. C. Mesoventrite showing median process of collar, mid-keel and keel, $\times 425$. 
Pronotum. Length $0.20 \mathrm{~mm}$, width $0.28 \mathrm{~mm}$, sparsely pubescent with a series of six foveae along the posterior margin in two pairs of three separated by a wider median gap; lateral margins sharply angled, concave posteriorly to rectangular hind angles, strongly bordered, the border not extending along the posterior margin which has a sinuous emargination before the scutellum (Fig. 19B).

ELYTRA. Length $0.44 \mathrm{~mm}$, width $0.39 \mathrm{~mm}$, pubescent, foveate in basal third.

Mesoventrite. Medial extension of collar onto mid-keel pointed; mid-keel wider anteriorly, posterior corners clearly reaching mesocoxae, sharply raised medially before keel; keel with \pm two setae, parallelsided to a blunt termination beyond interruption of mesocoxal margins; mesoventral lateral margins serrate in posterior half; humeri bluntly toothed (Fig. 19C).

Metaventrite. Length $0.16 \mathrm{~mm}$, with scattered pubescence and a shallow linear depression posterior to mesocoxae, disc in male strongly depressed, female with a small median fovea posterior to mesocoxae, width across the short triangular spines $0.12 \mathrm{~mm}$; posterior margins of mesocoxal cavities serrate.

Wings. Macropterous.

Genitalia. Male aedeagus Fig. 6G. Female spermatheca globular.

\section{Remarks}

Distinguished from the other Cissidium in this group from the Solomon Islands by the absence of a medial extension of the mesoventral collar.

Cissidium crowsoni Johnson, 1982

Fig. 20

\section{Material examined}

NEW ZEALAND • 1 ex.; Northland, Waipoua forest station; 120 m a.s.1.; 10-11 Dec. 1983; Kauri forest litter; P.M. Hammond leg.; BMNH • 1 ex.; Auckland, Waitakere Range, Cascades Kauri Park; 8 Jan. 1984; wet litter by stream; P.M. Hammond leg.; BMNH 11 ex.; Waikato: Hakarimata; ca 100 300 m a.s.1.; 20 Nov. 1983; native forest litter; P.M. Hammond leg.; BMNH • 3 ex.; Hapuakohe Range, Maungakawa; 500 m a.s.1.; 3 Jan. 1984; Nikau leaf bases on ground; P.M. Hammond leg.; BMNH.

\section{Supplementary description}

The description below concentrates in particular on amplifying Johnson's description with more details of the meso- and metaventral characters in order to conform with the present paper.

Size. Habitus (Fig. 20A), length $0.78 \mathrm{~mm}$.

CoLour. Dusky yellow.

HEAD. With a shallow linear depression and short medial longitudinal depression between the eyes, width across eyes $0.21 \mathrm{~mm}$; antennomeres III-XI length $0.39 \mathrm{~mm}$, III-IX $0.23 \mathrm{~mm}, \mathrm{X}-\mathrm{XI}$ length $0.16 \mathrm{~mm}$ globular; mentum and prementum as Fig.4A.

Pronotum. Length $0.20 \mathrm{~mm}$, width $0.30 \mathrm{~mm}$, widest along the posterior margin, pubescent, with a row of eight foveae along the base, the outer two on each side smaller than the inner four; lateral margins evenly rounded anteriorly and slightly concave posteriorly before the acute hind angles, bordered, the border 
continuing for a short distance along the posterior margin which has a sinuous emargination before the scutellum (Fig. 20B).

ElYTRA. Length $0.53 \mathrm{~mm}$, width $0.43 \mathrm{~mm}$, pubescent, foveolate.

Mesoventrite. Medial extension of collar widening posteriorly; mid-keel short with concave sides, posterior corners with narrow carinae to mesocoxal anterior margins, raised sharply to keel base; keel with \pm two setae, narrow, tapering to termination between the mesocoxae; mesoventral lateral margins serrate in posterior half; humeri strongly toothed (Fig. 20C).

Metaventrite. Length $0.19 \mathrm{~mm}$, width across spines $0.14 \mathrm{~mm}$; posterior margins of mesocoxal cavities not serrate.

WINGs. Micropterous.

GenitaLia. Male aedeagus as Fig. 6Fa-b. Female spermatheca globular.

\section{Remarks}

Described by Johnson on the basis of a single female from New Zealand, North Island, Northland, Parahaki, Whangerei, mixed leaf litter, 8.xi.1956, leg. R.A. Crowson (NZAC). Distinguished from C. foveolatum Johnson, 1982, the only other Cissidium reported from New Zealand, by the smaller foveae on the basal margin of the pronotum.
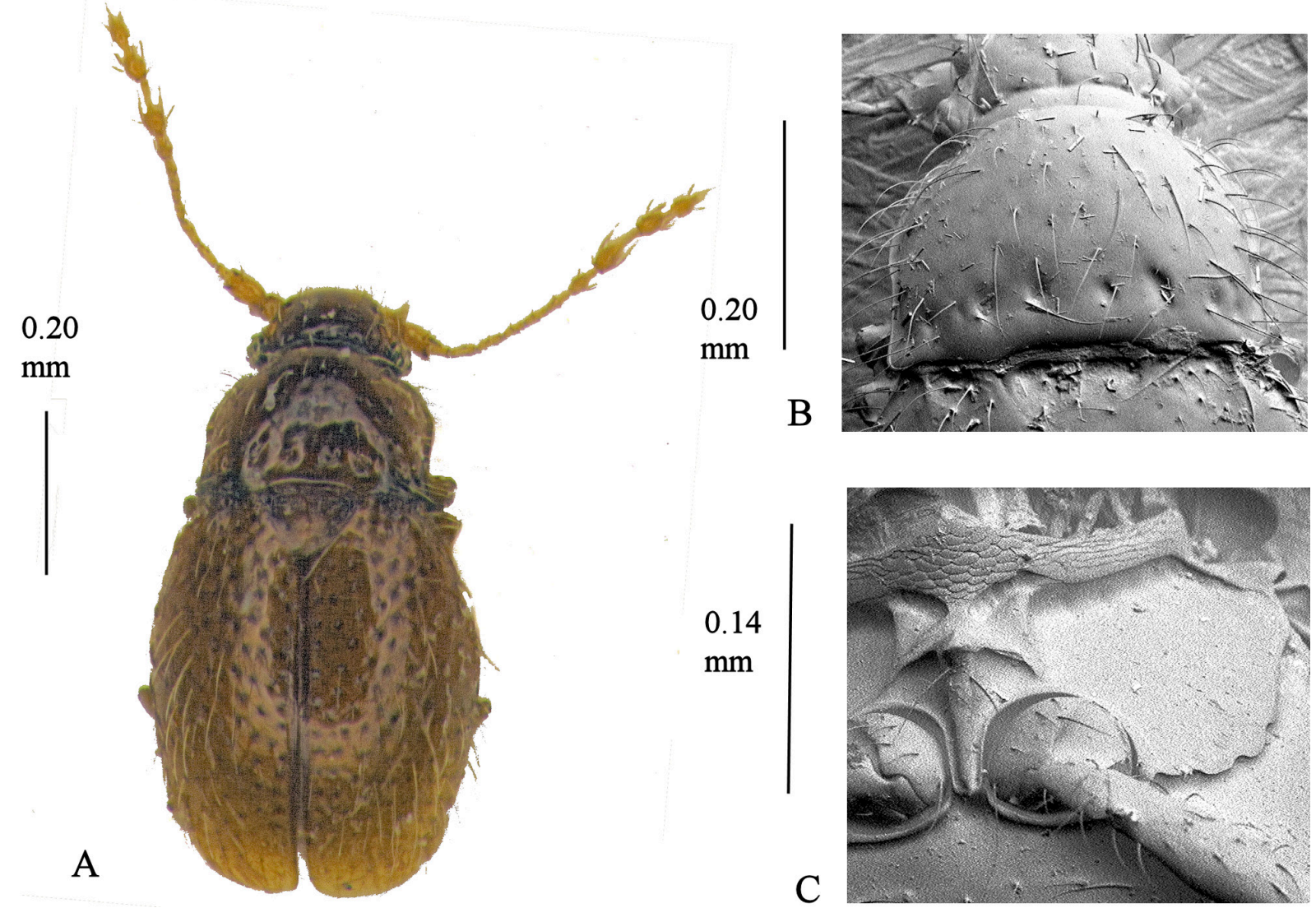

Fig. 20. Cissidium crowsoni Johnson, 1982. A. Habitus. B. Pronotum, $\times 550$. C. Mesoventrite showing median process of collar, mid-keel and keel, $\times 595$. 


\section{Cissidium davaoense sp. nov.}

urn:Isid:zoobank.org:act:A184CD9F-CE94-4F39-A310-9DF4DBE068B9

Fig. 21

\section{Etymology}

Named after the region in the Philippines where the specimen was found.

\section{Material examined}

\section{Holotype}

PHILIPPINES - đ; Davao, Mindanao, E. slope of Mt McKinley; $3500 \mathrm{ft}$ a.s.1.; 15 Aug. 1946; flight dusk; F.G.Werner leg.; FM(HD) 46.10; FMNH.

\section{Description}

Size. Habitus (Fig. 21A), length $0.54 \mathrm{~mm}$.

Colour. Dusky yellow.

HEAD. With a shallow median depression between the eyes, width across eyes $0.18 \mathrm{~mm}$; antennomeres III-XI length $0.25 \mathrm{~mm}$, III-IX $0.14 \mathrm{~mm}, \mathrm{X}-\mathrm{XI}$ length $0.11 \mathrm{~mm}$; mentum as Fig. 4A.
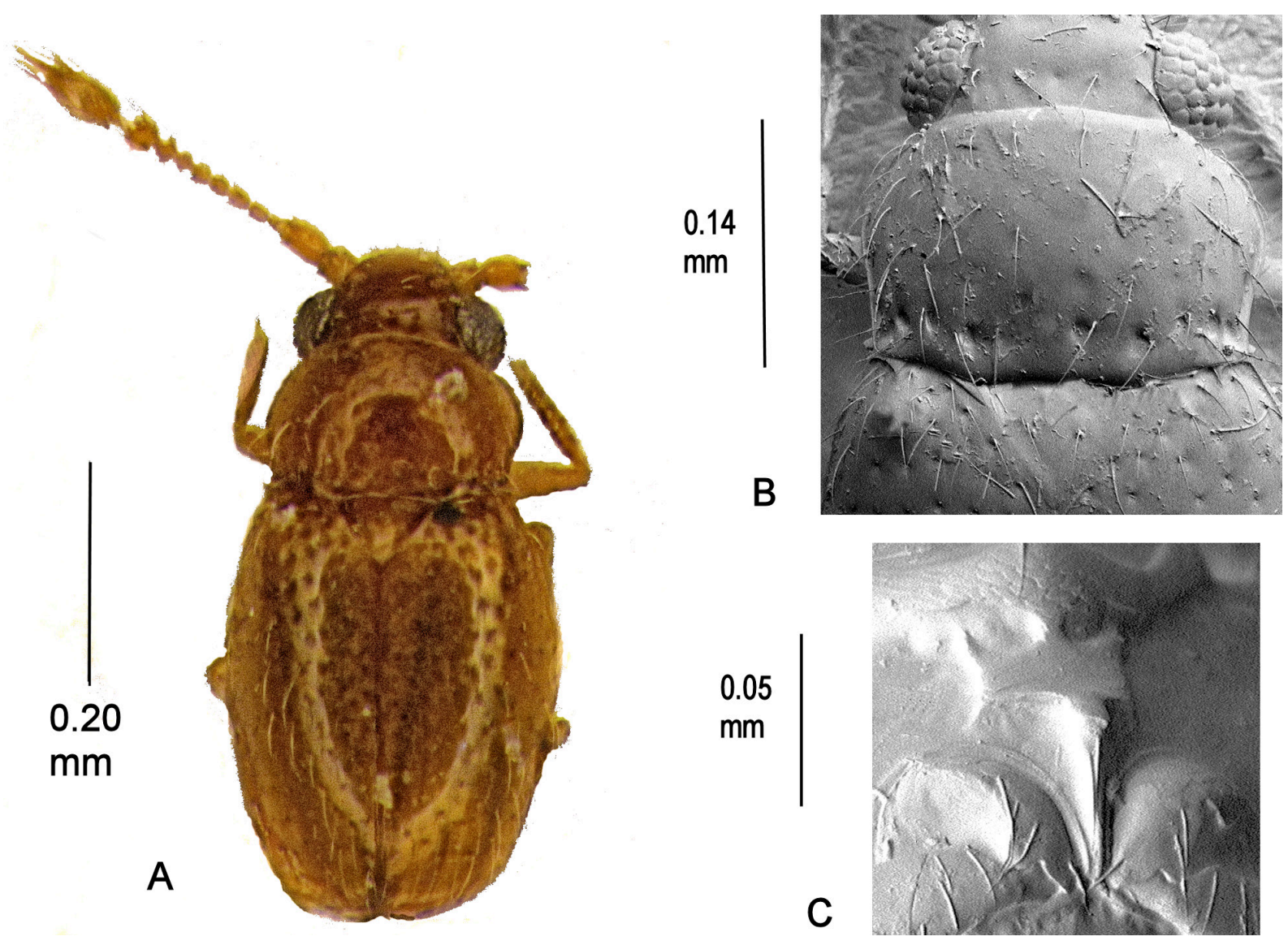

Fig. 21. Cissidium davaoense sp. nov. A. Habitus. B. Pronotum, $\times 870$. C. Mesoventrite showing median process of collar, mid-keel and keel, $\times 1000$. 
Pronotum. Length $0.14 \mathrm{~mm}$, width $0.21 \mathrm{~mm}$, sparsely pubescent, with a row of \pm nine foveae along the posterior margin, and \pm three shallow foveae anterior to these; lateral margins bordered, rounded then almost straight to slightly obtuse hind angles, border not extending onto the posterior margin which has a sinuous emargination before the scutellum (Fig. 21B).

ELYTRA. Length $0.36 \mathrm{~mm}$, width $0.27 \mathrm{~mm}$, pubescent, foveolate in basal third.

MesoventRITE. Medial extension of collar onto mid-keel narrow, anterior margin with two semi-circular emarginations, posterior corners joining mesocoxae; mid-keel sharply raised medially before keel; keel with two setae, sharply pointed to termination almost reaching posterior margin of the mesocoxae; mesoventral lateral margins coarsely serrate in posterior half; humeri with small tooth (Fig. 21C).

Metaventrite. Length $0.12 \mathrm{~mm}$, width across short triangular spines $0.06 \mathrm{~mm}$; posterior margins of mesocoxal cavities serrate.

WINGS. Macropterous.

Genitalia. Male aedeagus as Fig. 6Fa-b. Females not known.

\section{Remarks}

One of the only two species of Cissidium in this group from the Philippines. Distinguished by the smaller pronotal foveae than those on C. advena sp. nov.

Cissidium deanei sp. nov. urn:1sid:zoobank.org:act:0CC5DA87-ED16-4002-87ED-EE22765CB812

Fig. 22

\section{Etymology}

Johnson ms name, named after Cedric Deane, who was the author of three important papers on the Australian ptiliid fauna

\section{Material examined}

\section{Holotype}

AUSTRALIA • ○’; S.W., Warren National Park, Pemberton; 1970; H. Franz leg.; MMUE.

\section{Description}

SizE. Habitus (Fig. 22A), length $0.65 \mathrm{~mm}$.

Colour. Dusky yellow, pubescence, legs and antennae slightly paler.

HEAD. Without an obvious depression behind the eyes, width across eyes $0.19 \mathrm{~mm}$; antennomeres III-XI length $0.33 \mathrm{~mm}$, III-IX length $0.20 \mathrm{~mm}, \mathrm{X}-\mathrm{XI}$ length $0.13 \mathrm{~mm}$; mentum obscured.

Pronotum. Length $0.17 \mathrm{~mm}$, width $0.25 \mathrm{~mm}$, sparsely pubescent, with two pairs of foveae at the base and \pm three less deeply impressed foveae anterior to these; lateral margins bordered, rounded then almost straight to acute hind angles, border not extending onto the posterior margin which has a sinuous emargination before the scutellum (Fig. 22B).

ELYTRA. Length $0.43 \mathrm{~mm}$, width $0.36 \mathrm{~mm}$, pubescent, setae same length as pronotum, foveolate in basal third. 
Mesoventrite. Medial extension of collar broad; mid-keel anterior margins effaced, posterior corners with wide carinae to mesocoxal anterior borders, mid-keel sharply raised medially before keel; keel with \pm six setae, parallel-sided to termination almost reaching posterior margin of mesocoxae; mesoventral lateral margins not serrate in posterior half; humeri with small tooth (Fig. 22C).

Metaventrite. Length $0.14 \mathrm{~mm}$, disc simple, width across spines $0.08 \mathrm{~mm}$; posterior margins of mesocoxal cavities not serrate.

WINGS. Macropterous.

Genitalia. Male aedeagus as Fig. 6G. Females not known.

\section{Remarks}

The five species of Cissidium from Australia all belong in this group and with the exception of $C$. delicatum sp. nov. are difficult to separate on dorsal characteristics. The short median extension of the mesoventral collar coupled with the parallel sided mid-keel distinguishes this species from the remainder.
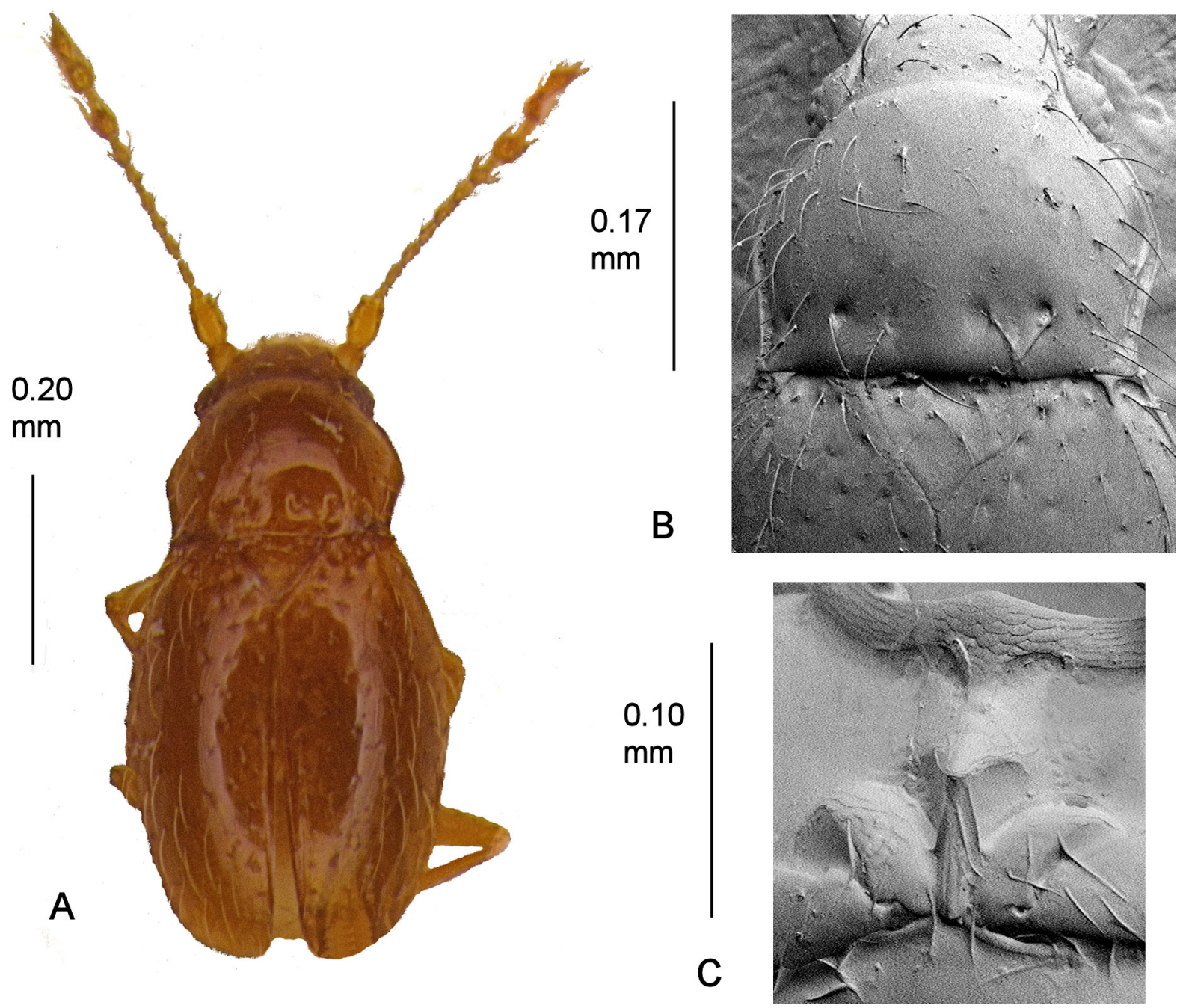

Fig. 22. Cissidium deanei sp. nov. A. Habitus. B. Pronotum, $\times 570$. C. Mesoventrite showing median process of collar, mid-keel and keel, $\times 700$. 
Cissidium delicatum sp. nov.

urn:1sid:zoobank.org:act:AC999121-61B9-4EF3-B3B3-1F692F285D33

Figs 3C, 23

\section{Etymology}

Johnson ms name, presumably after the delicate nature of this species.

\section{Material examined}

\section{Holotype}

AUSTRALIA • O; Queensland, Maiala Nat. Park, Mt Glorious, Brisbane; 4 Aug. 1966; mixed leaf litter; R.A. Crowson leg.; MMUE.

\section{Description}

Size. Habitus (Fig. 23A), length $0.60 \mathrm{~mm}$.

CoLour. Yellow.

HEAD. With a shallow linear depression behind the eyes (Fig. 3C); eyes very much reduced, only \pm four ommatidia present, presumed blind, width across these $0.15 \mathrm{~mm}$; antennomeres III-XI length $0.27 \mathrm{~mm}$, III-IX length $0.16 \mathrm{~mm}, \mathrm{X}-\mathrm{XI}$ length $0.11 \mathrm{~mm}$ globular; mentum as Fig. 4A.

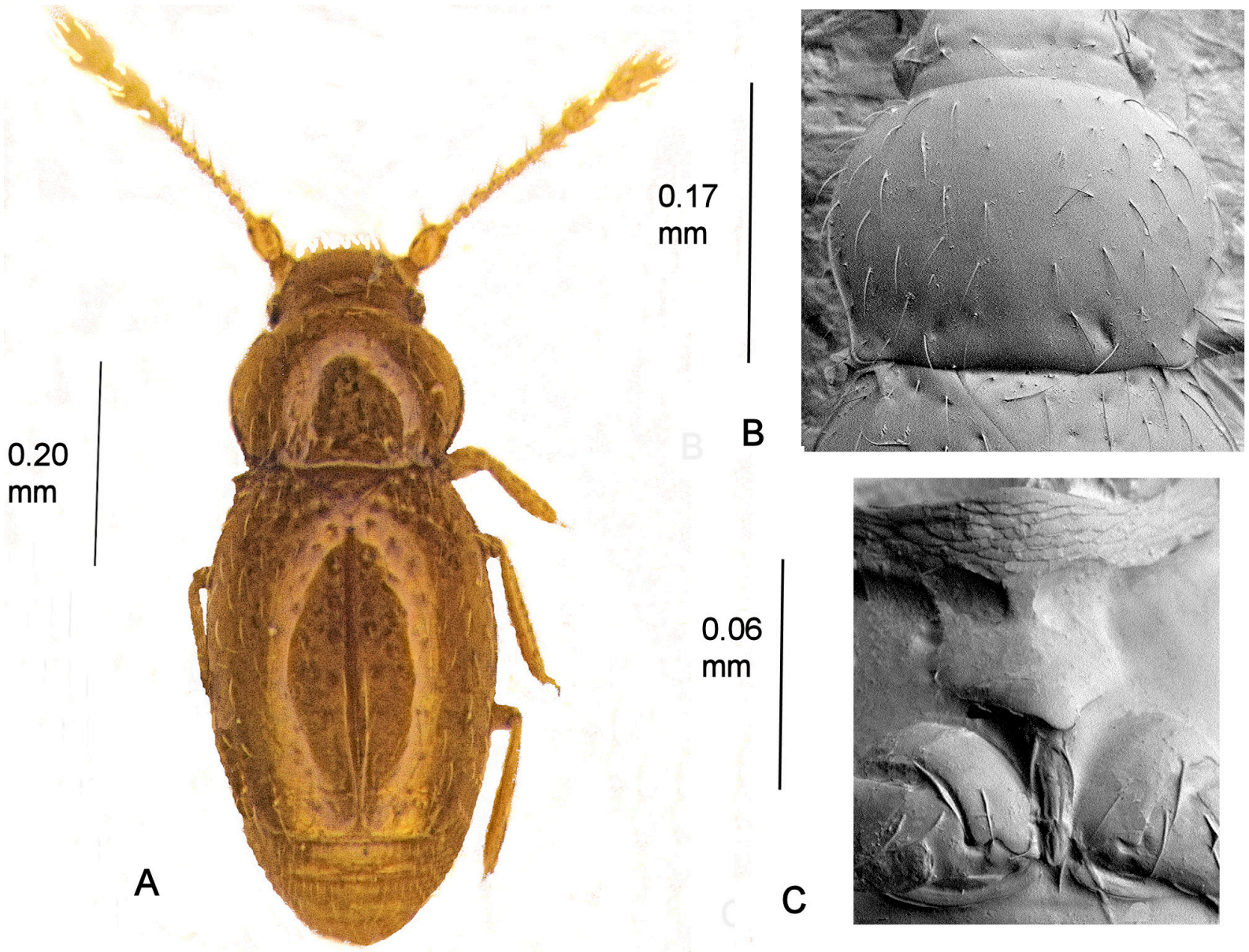

Fig. 23. Cissidium delicatum sp. nov. A. Habitus. B. Pronotum, $\times$ 695. C. Mesoventrite showing median process of collar, mid-keel and keel, $\times 1600$. 
Pronotum. Length $0.17 \mathrm{~mm}$, width $0.23 \mathrm{~mm}$, sparsely pubescent, with a pair of foveae at the base; lateral margins evenly rounded almost to rectangular hind angles, narrowly bordered, border extending a short way onto the posterior margin; posterior border without an emargination in front of the scutellum (Fig. 23B).

ElytRA. Length $0.38 \mathrm{~mm}$, width $0.29 \mathrm{~mm}$, pubescent, setae same length as pronotum, foveae slightly larger in basal third.

Mesoventrite. Medial extension of collar short; mid-keel lateral margins sinuate, posterior corners not joining mesocoxae, sharply raised medially before keel; keel with \pm four setae, tapering to point at base of the mesocoxae; mesoventral lateral margins obscured; humeri with small tooth (Fig. 23C).

MetaVentrite. Length $0.11 \mathrm{~mm}$, sparsely pubescent, disc simple, width across spines $0.09 \mathrm{~mm}$; posterior margins of mesocoxal cavities not serrate.

Wings. Apterous.

\section{Remarks}

The rounded pronotal sides almost to the hind angles distinguishes this species from the other Australian Cissidium.

\section{Cissidium foveolatum Johnson, 1982}

Figs 3D, 24

\section{Material examined}

\section{Paratypes}

NEW ZEALAND • 1 ex.; Ratoma Reserve; 2 Dec. 1980; fungi and rotten wood; E.W. Aubrook; MMUE • 1 ex.; Lynfield Ak., Tropicana Drive; 18 Jan.-29 Mar. 1975; G. Kuschel leg.; BMNH • 1 ex.; Waikato, Bay of Plenty, Te Aroba; $1400 \mathrm{ft}$ a.s.1.; 22 Oct. 1956; R.A. Crowson leg.; BMNH - 2 ex.; Northland, Western Hills, Whangarei; 2 Nov. 1956; leaf litter; R.A. Crowson leg.; MMUE.

\section{Additional material}

NEW ZEALAND • 1 ex.; Hapuakohe Range, Maungakawa; 500 m a.s.l.; 3 Jan. 1984; Nikau leaf bases on ground; P.M. Hammond leg.; BMNH • 1 ex.; Waitakere Range, Cascades Kauri Park; 6 Nov. 1983; P.M. Hammond leg.; BMNH.

\section{Supplementary description}

The description below concentrates in particular on amplifying Johnson's description with more details of the meso- and metaventral characters in order to conform with the entries in the present paper.

SizE. Habitus (Fig.24A), length $0.76 \mathrm{~mm}$.

CoLour. Dark red brown, legs and antennae dusky yellow.

HEAD. With a median fovea between the eyes (Fig. 3D), width across eyes $0.21 \mathrm{~mm}$; antennomeres IIIXI $0.44 \mathrm{~mm}$ long, II-IX $0.24 \mathrm{~mm}$ long, X-XI $0.20 \mathrm{~mm}$ long.

Pronotum. Length $0.21 \mathrm{~mm}$, width $0.28 \mathrm{~mm}$ with four basal foveae on each side the two outer ones being much smaller and shallower than the inner ones which are slightly elongate and tending to join together to become one large fovea, sides rounded then shallowly concave to rectangular hind angles, 
evenly rounded anteriorly, bordered, the borders not continuing along the posterior margin, medial emargination opposite the scutellum sinuate (Fig. 24B).

ELYTRA. Length $0.51 \mathrm{~mm}$, breadth $0.43 \mathrm{~mm}$, strongly foveolate, particularly in basal half. MESOVENTRITE. Median extension of collar very short, pointed; mid-keel parallel-sided, the hind angles almost meeting the mesocoxal border, raised portion before keel ridged.; keel narrow, with \pm four setae, tapering to a point at the base of the mesocoxae; mesoventral lateral margins serrate in posterior half; humeri toothed (Fig. 24C).

MetaVentrite. Glabrous, disc simple. Hind margins of mesocoxal borders without serrations.

WINGS. Macropterous.

Genitalia. Male aedeagus as Fig. 6Fa-b. Female spermatheca globular.

\section{Remarks}

Described by Johnson on the basis of specimens collected in New Zealand, North Island. Distinguished from C. crowsoni, the only other Cissidium reported from New Zealand, by the four large foveae on the pronotum.
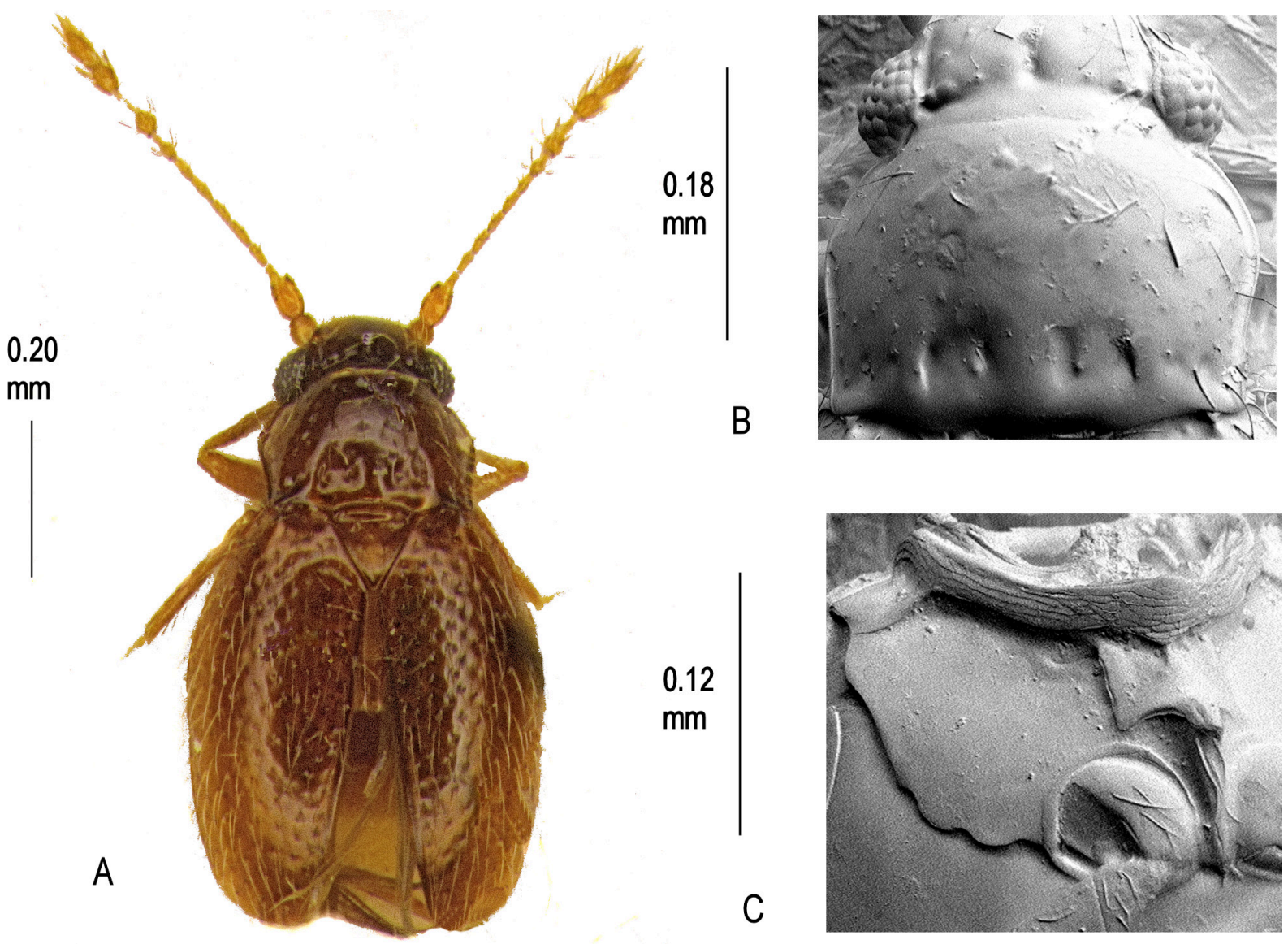

Fig. 24. Cissidium foveolatum Johnson, 1982. A. Habitus. B. Pronotum, $\times$ 715. C. Mesoventrite showing median process of collar, mid-keel and keel, $\times 555$. 
Cissidium greensladei sp. nov.

urn:1sid:zoobank.org:act:4F505BEE-816C-4B98-A537-37DA9480F89A

Figs $6 \mathrm{~L}, 7 \mathrm{C}, 25$

\section{Etymology}

Johnson ms name, in recognition of the late P. Greenslade, collector of this and other Solomon Island specimens.

\section{Material examined}

\section{Holotype}

SOLOMON ISLANDS • \} \text { ; Guadalcanal, Mt. Austen; } 2 2 \text { Jul. 1963; no. 11278; P. Greenslade leg.; } $\mathrm{BMNH}$

\section{Paratypes}

SOLOMON ISLANDS • 1 đ; Guadalcanal, Kukum; Jun.-Jul. 1966; no. 21759; P. Greenslade leg.; BMNH • 1 万人; Mt. Austen; 14 May 1963; no. 6048; P. Greenslade leg.; MMUE • 1 q; same collection data as for preceding but 29 Nov. 1963; no. 11031; MMUE • 1 ; ; same collection data as for preceding but 21 Sep. 1965; no. 19247; MMUE • 1 \%; same collection data as for preceding but Feb. 1966; no. 21243; BMNH • 1 ; ; same collection data as for preceding but Mar. 1966; no. 21336; BMNH.
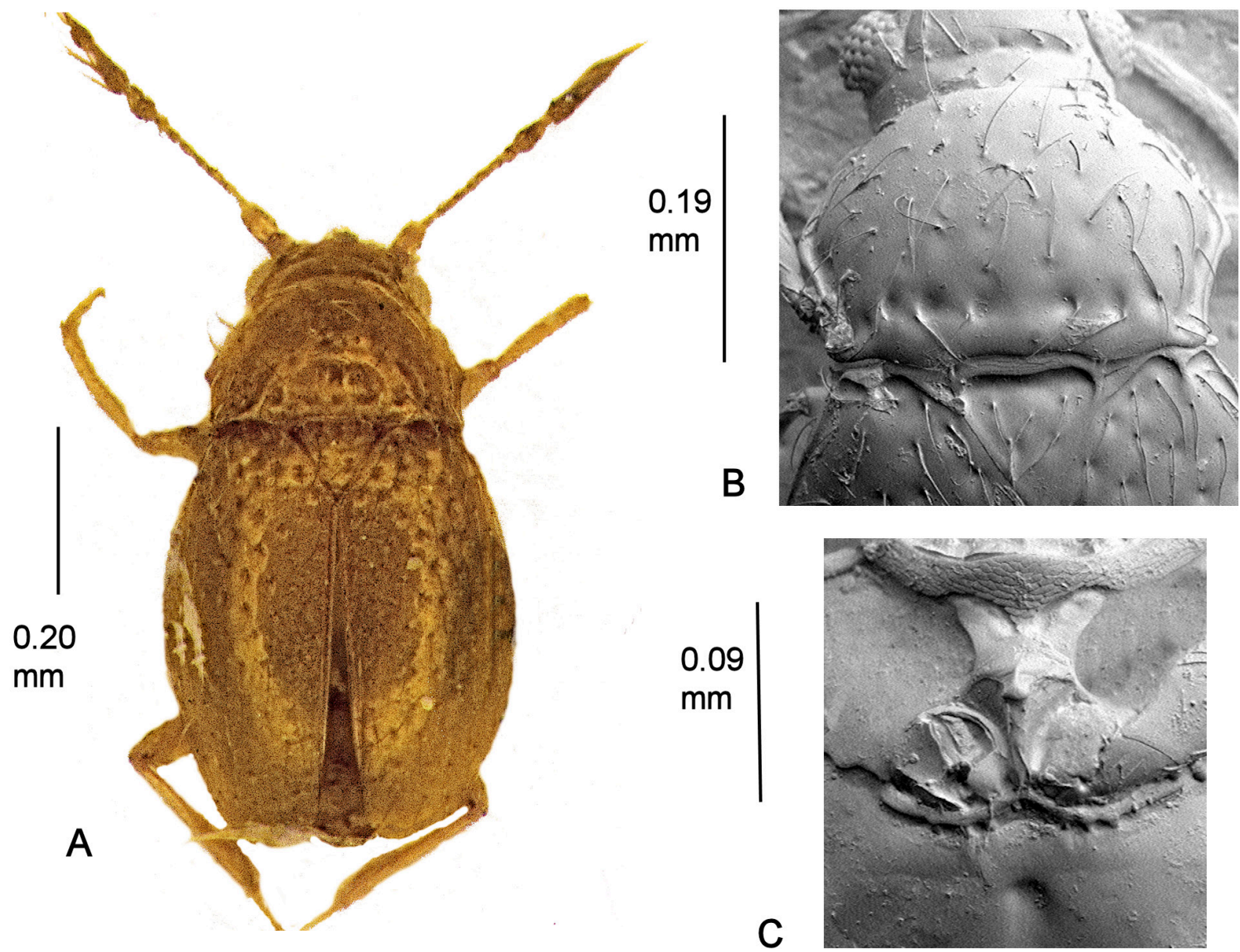

Fig. 25. Cissidium greensladei sp. nov. A. Habitus. B. Pronotum, $\times 565$. C. Mesoventrite showing median process of collar, mid-keel and keel, $\times 455$. 


\section{Description}

SizE. Habitus (Fig. 25A), length $0.67 \mathrm{~mm}$.

Colour. Dusky yellow.

HEAD. Shallowly foveolate between eyes, width across eyes $0.21 \mathrm{~mm}$; antennomeres III-XI $0.32 \mathrm{~mm}$ long, III-IX $0.16 \mathrm{~mm}$ long, X-XI $0.16 \mathrm{~mm}$; mentum as Fig.4A.

Pronotum. Length $0.19 \mathrm{~mm}$, width $0.29 \mathrm{~mm}$, sparsely pubescent, base with a series of five or six foveae of approximately equal size and spacing but with a wider gap opposite the scutellum; sides sharply angled, slightly convexly curved to rectangular hind angles, front angles obtuse, not evenly rounded, conspicuously bordered, the border not continuing along the posterior margin which has a sinuous emargination before the scutellum (Fig. 25B).

ElYTRA. Length $0.43 \mathrm{~mm}$, breadth $0.37 \mathrm{~mm}$; foveolate, the foveolae more conspicuous and denser in the basal half.

Mesoventrite. Medial extension of collar short, pointed; mid keel wider anteriorly, hind angles with carinae to mesocoxae, medially raised with a ridge; keel narrow with \pm three setae tapering to a point past the mid-point of the mesocoxae; mesoventral lateral borders serrate in posterior half; humeri toothed (Fig. 25C).

Metaventrite. Length $0.13 \mathrm{~mm}$, no spines detected but two clear foveae may mark their insertion points if abraded, width across these $0.11 \mathrm{~mm}$, with a large medial fovea on disc in front the mesocoxae (Fig. 7C), disc slightly depressed behind this; mesocoxal posterior margins serrate.

WINGS. Macropterous.

Genitalia. Male aedeagus (Fig. 6L). Female spermatheca globular.

\section{Remarks}

Distinguished from other species from the Solomon Islands in this group by the narrower mesoventral mid-keel and the form of the male aedeagus.

Cissidium houailou sp. nov. urn:1sid:zoobank.org:act:7BE8B0E1-CE58-49E8-AA40-98EA88881FEB

Fig. 26

\section{Etymology}

Johnson ms name, after Houailou, a commune in the North Province of New Caledonia where the insect was found. Noun in apposition.

\section{Material examined}

Holotype

NEW CALEDONIA • +; Col de Hou b. Houailou; 1970; H. Franz leg.; MM holotype; MMUE.

\section{Paratype}

NEW CALEDONIA $\bullet$, same collection data as for holotype; MMUE. 


\section{Description}

Size. Habitus (Fig. 26A) length $0.66 \mathrm{~mm}$.

CoLour. Dark brown, shining, pubescence, antennae and legs paler.

HEAD. With a shallow linear depression interrupted medially by a small foveola behind the eyes, width across eyes $0.22 \mathrm{~mm}$; antennomeres III-XI length $0.37 \mathrm{~mm}$, III-IX length $0.22 \mathrm{~mm}$, X-XI length $0.15 \mathrm{~mm}$; mentum and prementum obscured.

Pronotum. Length $0.18 \mathrm{~mm}$, width $0.28 \mathrm{~mm}$, pubescence mainly confined to lateral margins one or two scattered setae on disc, with a row of six shallow foveae along the posterior margin; sides rounded then almost parallel to slightly acute hind angles, border on lateral margins not continued along the posterior margin which has a sinuous emargination opposite the scutellum (Fig. 26B).

ELYTRA. Length $0.44 \mathrm{~mm}$, width $0.37 \mathrm{~mm}$, pubescent, foveolate throughout contrasting with the pronotum.

Mesoventrite. Collar with a long, pointed medial extension almost reaching to posterior margin of the mid-keel; mid-keel parallel-sided, anterior corners rounded before reaching collar, posterior corners almost reaching mesocoxae, sharply raised at junction with keel; keel with \pm three setae, parallel-sided to rounded termination close to base of mesocoxae; mesoventral lateral margins with one or two serrations in posterior half; humeri bluntly toothed (Fig. 26C).

Metaventrite. Length $0.14 \mathrm{~mm}$, almost glabrous, one or two scattered setae only, disc plain, width across spines $0.12 \mathrm{~mm}$, spines short; posterior margins of mesocoxae without serrations.

WINGs. Macropterous.
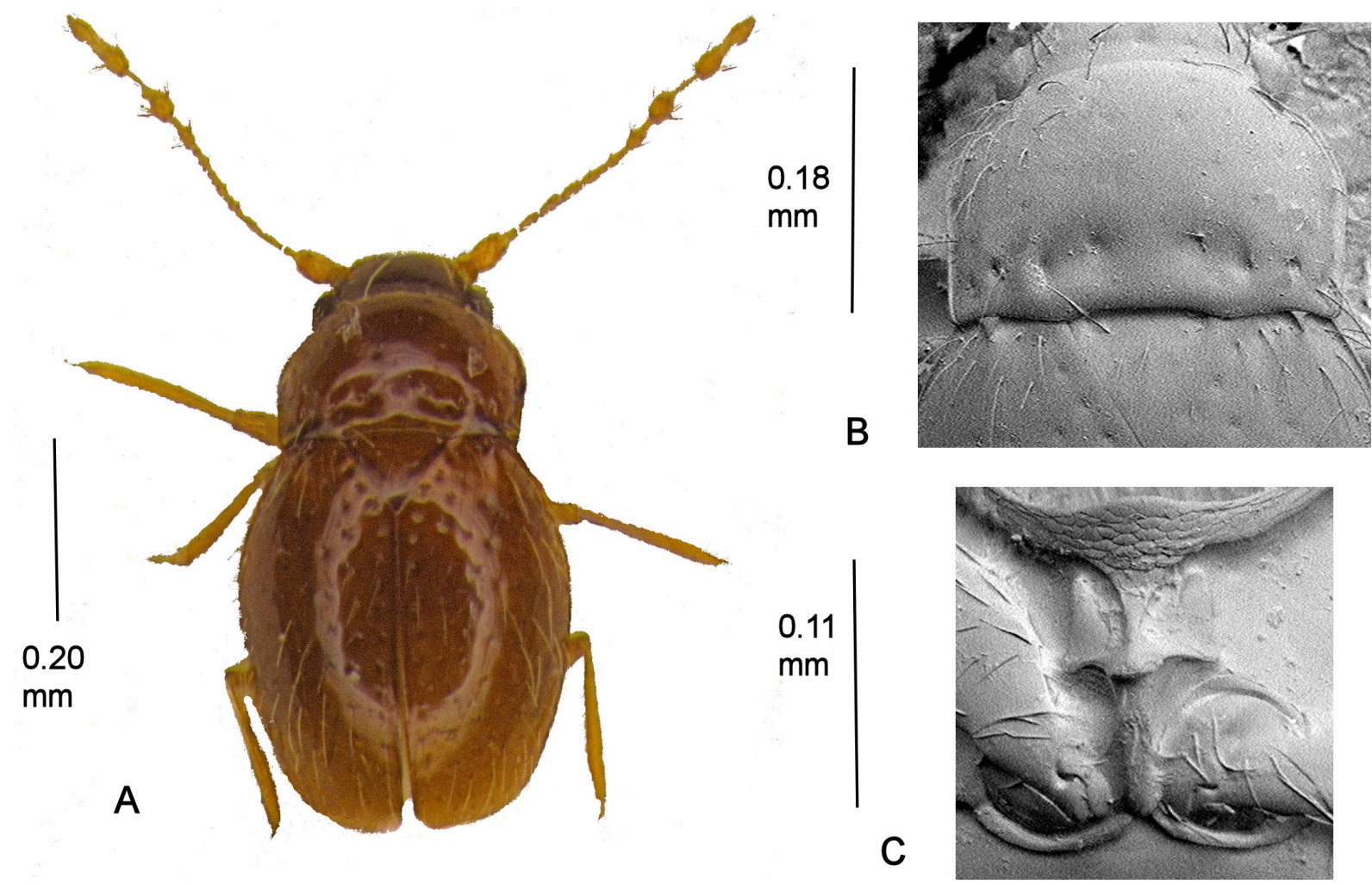

Fig. 26. Cissidium houailou sp. nov. A. Habitus. B. Pronotum, $\times$ 585. C. Mesoventrite showing median process of collar, mid-keel and keel, $\times 580$. 
GenitaLia. Female spermatheca globular. Males not known.

\section{Remarks}

See remarks for $C$. amieuense sp. nov. Cissidium houailou sp. nov. differs from that species in having a parallel sided mid-keel.

\section{Cissidium impressum sp. nov.}

urn:1sid:zoobank.org:act:C0B9A307-ED66-45D0-A2A8-AA1D58461442

Fig. 27

\section{Etymology}

Johnson ms name, presumably referring to the appearance of the dorsum.

\section{Material examined}

\section{Holotype}

AUSTRALIA • 9 ; Queensland, Samford, Brisbane; 7 Aug. 1966; under heap of cut grass in garden; R.A. Crowson leg.; MMUE.
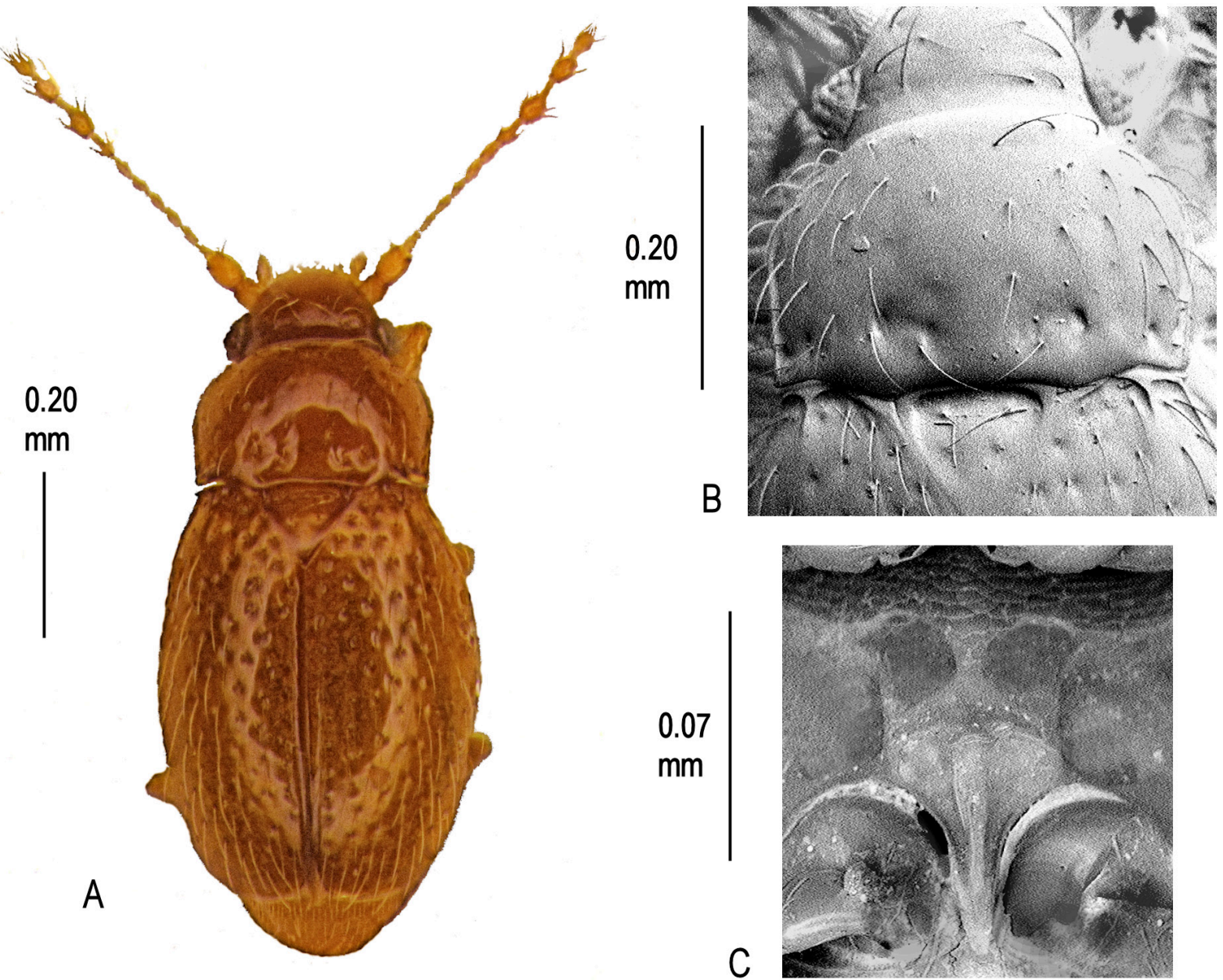

Fig. 27. Cissidium impressum sp. nov. A. Habitus. B. Pronotum, $\times$ 505. C. Mesoventrite showing median process of collar, mid-keel and keel, $\times 860$. 


\section{Paratypes}

AUSTRALIA 1 \%; same collection data as for holotype; mounted verso; MMUE $\bullet 1$ ex.; Queensland, Tamborine Mt.; 1970; H. Franz leg.; MMUE.

\section{Description}

Size. Habitus (Fig. 27A), length $0.73 \mathrm{~mm}$.

CoLour. Yellow brown, shining, pubescence and antennae slightly paler.

HEAD. With a shallow linear depression behind the eyes, width across eyes $0.21 \mathrm{~mm}$; antennomeres IIIXI length $0.25 \mathrm{~mm}$, III-IX length $0.13 \mathrm{~mm}, \mathrm{X}-\mathrm{XI}$ length $0.12 \mathrm{~mm}$; mentum as Fig. 4C.

Pronotum. Length $0.20 \mathrm{~mm}$, width $0.29 \mathrm{~mm}$, sparsely pubescent, with a row of six foveae in two groups of \pm three separated medially; lateral margins rounded then almost parallel to rectangular hind angles, lateral border not running onto the posterior margin which has a sinuous emargination in front of the scutellum (Fig. 27B).

ELYTRA. Length $0.49 \mathrm{~mm}$, width $0.38 \mathrm{~mm}$, pubescent, setae same length as pronotum, foveolate, the foveolae more strongly marked in basal half.

Mesoventrite. Collar medial extension onto mid-keel widening posteriorly; mid-keel almost parallelsided, posterior corners with short carinae reaching mesocoxal anterior borders, sharply raised at junction with keel; keel narrow, long, with pointed termination slightly below interruptions of mesocoxae; mesoventral lateral margins without serrations; humeri toothed (Fig. 27C).

Metaventrite. Length $0.13 \mathrm{~mm}$, setose, disc plain, width across spines $0.10 \mathrm{~mm}$, posterior margins of mesocoxae serrate.

WINGs. Macropterous.

\section{Remarks}

See remarks under $C$. deanei sp. nov. The large size, broad, partly parallel-sided mesoventral mid-keel and very narrow keel distinguish this species.

Cissidium inexspectatum sp. nov. urn:1sid:zoobank.org:act:213F3821-506C-42ED-8272-63DFB5D0C9C1

Fig. 28

\section{Etymology}

Johnson ms name, derivation unclear.

\section{Material examined}

Holotype

NEW CALEDONIA • `ં Col des Rousiettes; 1970; H. Franz leg.; MM holotype; MMUE.

Paratype

NEW CALEDONIA • 1 \%; Table d'Union, Col d'Amieu; label lettering style suggests also collected by H. Franz; MMUE. 


\section{Description}

Size. Habitus (Fig. 28A), length $0.63 \mathrm{~mm}$.

CoLour. Dark brown, shining, elytra dusky yellow where translucent, pubescence and antennae yellow.

HEAD. Without a clear linear depression behind the eyes, width across eyes $0.21 \mathrm{~mm}$; antennomeres IIIXI length $0.42 \mathrm{~mm}$, III-IX length $0.25 \mathrm{~mm}, \mathrm{X}-\mathrm{XI}$ length $0.17 \mathrm{~mm}$; mentum as Fig 4A.

Pronotum. Length $0.15 \mathrm{~mm}$, width $0.25 \mathrm{~mm}$, sparsely pubescent, with a row of six foveae in two groups of three separated medially; lateral margins rounded almost parallel posteriad to rectangular hind angles, lateral border not running onto the posterior margin which has a sinuous emargination in front of the scutellum (Fig. 28B).

ELYTRA. Length $0.45 \mathrm{~mm}$, width $0.35 \mathrm{~mm}$, pubescent, setae same length as pronotum, faintly foveolate the foveolae more strongly marked in basal half.

MesoventRIte. Collar medial extension pointed; mid-keel parallel-sided, posterior corners with short carinae reaching mesocoxae, sharply raised medially at junction with keel; keel with \pm two setae, narrow,
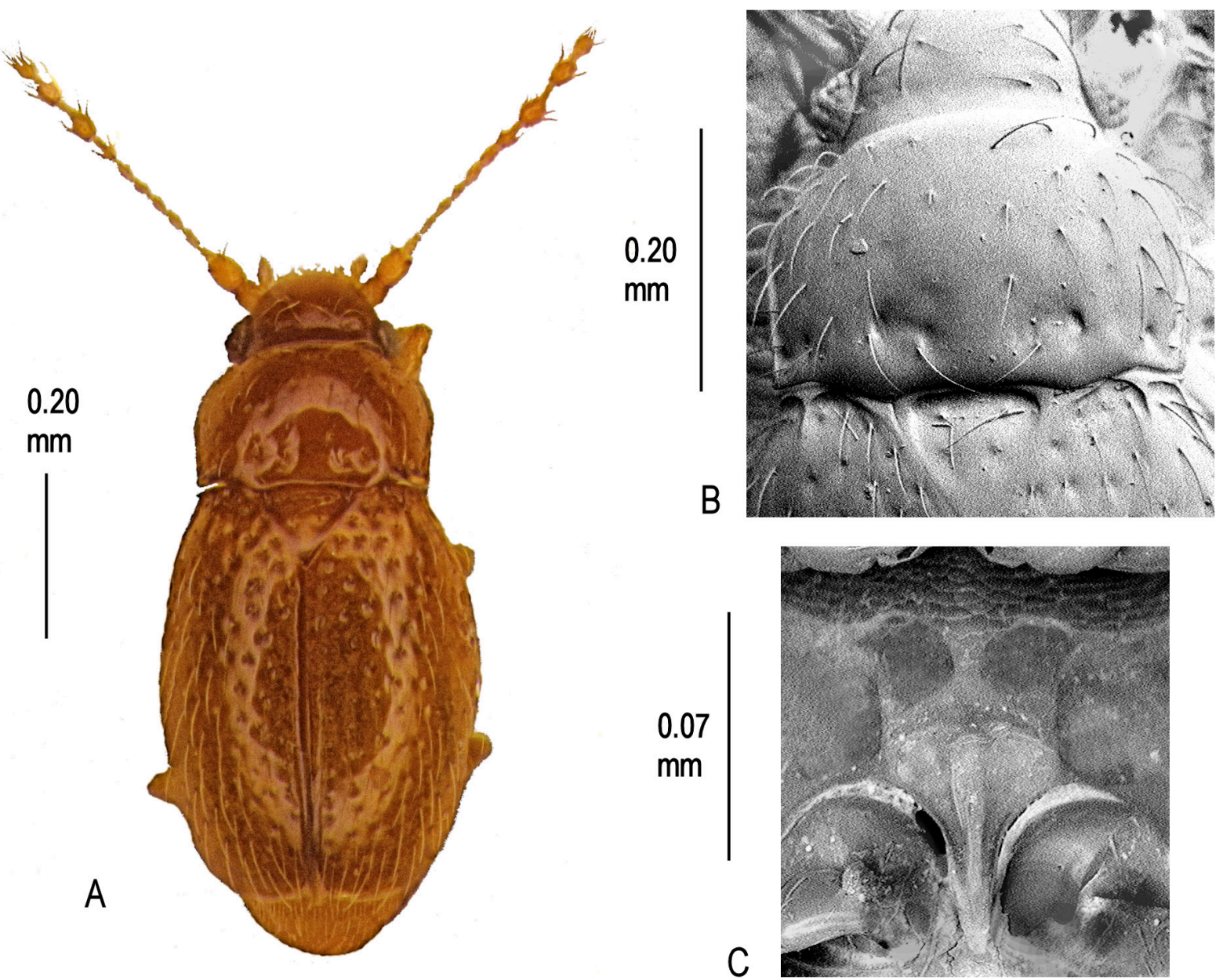

Fig. 28. Cissidium inexspectatum sp. nov. A. Habitus. B. Pronotum, $\times 660$. C. Mesoventrite showing median process of collar, mid-keel and keel, $\times 1120$. 
long, with pointed termination slightly below interruption of mesocoxal margins; mesoventral lateral margins with \pm two wide serrations; humeri toothed (Fig. 28C).

MetaVentrite. Length $0.12 \mathrm{~mm}$, with scattered setae, disc plain, width across spines $0.11 \mathrm{~mm}$, posterior margins of mesocoxae not serrate.

Wings. Macropterous.

Genitalia. Male aedeagus as Fig. 6Fa-b. Female spermatheca pear-shaped.

\section{Remarks}

The very long mesoventral mid-keel distinguishes this species from other New Caledonian Cissidium.

\section{Cissidium ishigakiense Sawada, 2008}

Fig. 29

\section{Material examined}

\section{Paratype}

JAPAN • 1 ठ̊; Komi, Ishigaki Island, Okinawa Pref.; 9 May 1999; pile of straw; Y. Sawada leg.; mounted as a disarticulated slide; YS.

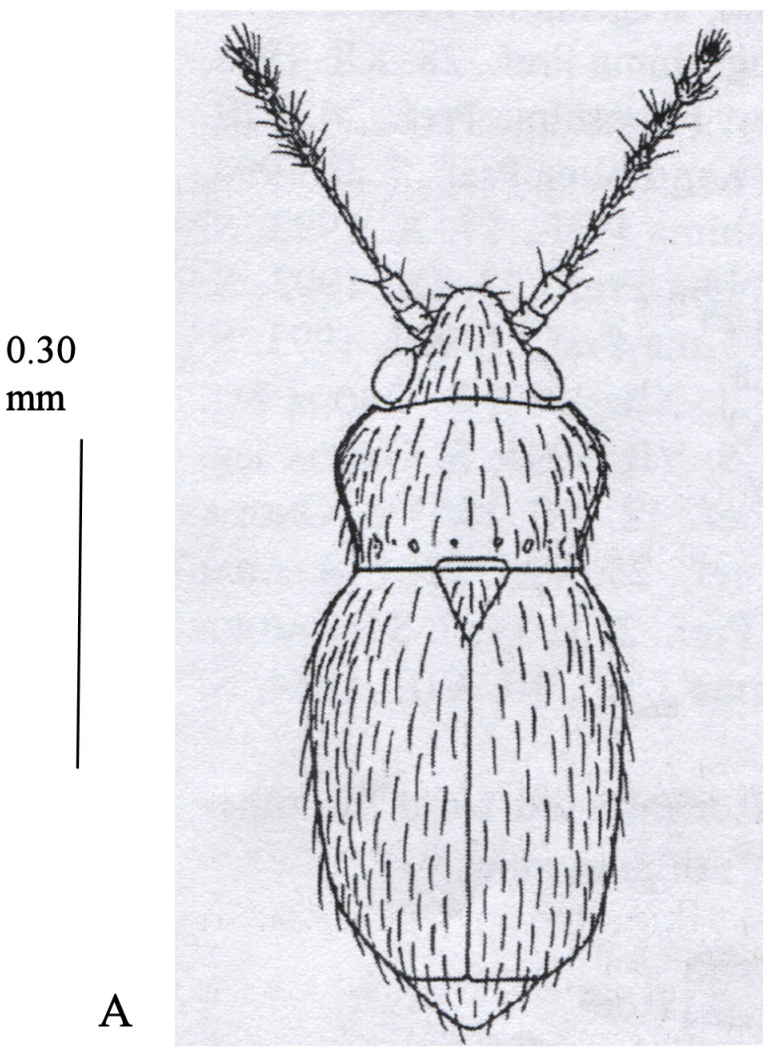

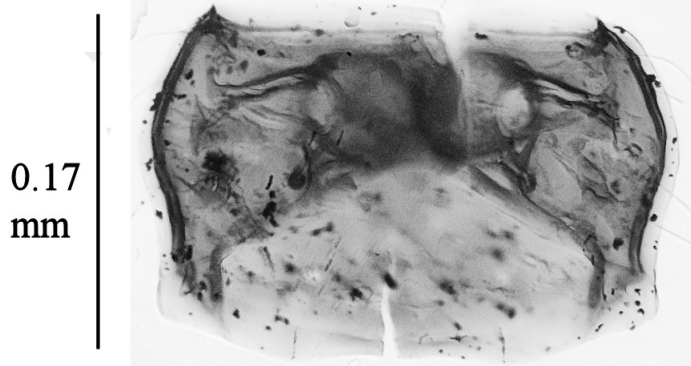

B

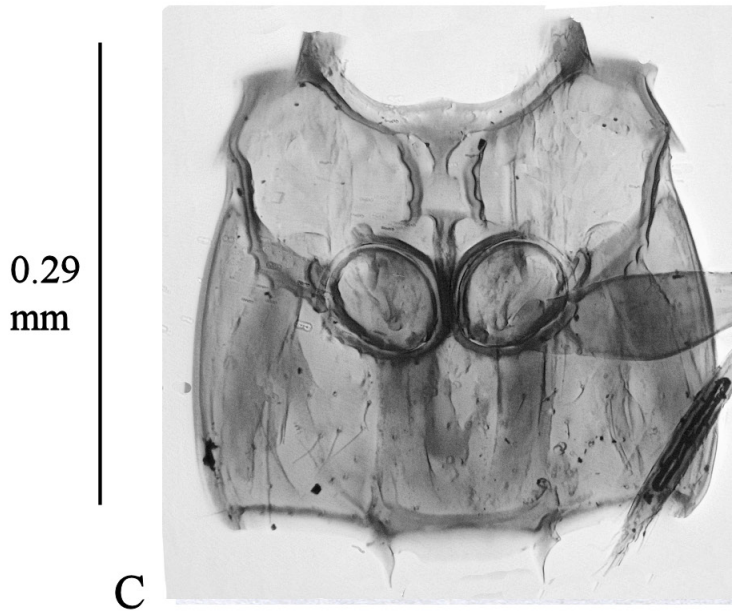

Fig. 29. Cissidium ishigakiense Sawada, 2008. A. Habitus. B. Pronotum from slide preparation. C. Mesoand metaventrite from slide preparation. 


\section{Supplementary description}

The description below concentrates on amplifying Sawada (2008) with more details of the meso- and metaventral characters in order to conform with the entries in the present paper.

Size. Habitus (Fig. 29A copied from Sawada 2008), length $0.7 \mathrm{~mm}$.

CoLour. Dark brown, antennae dusky yellow.

HEAD. Width across eyes $0.32 \mathrm{~mm}$; mentum obscured; antennomeres III-XI, length $0.33 \mathrm{~mm}$, III-IX length $0.17 \mathrm{~mm}$, X-XI length $0.16 \mathrm{~mm}$.

Pronotum. $0.17 \mathrm{~mm}$ long, $0.27 \mathrm{~mm}$ wide, lateral margins rounded then almost parallel sided to rectangular hind angles, bordered, the borders not continuing along the posterior margin, medial emargination opposite the scutellum shallowly sinuate (Fig. 29B).

ELYTRA. $0.42 \mathrm{~mm}$ long, $0.40 \mathrm{~mm}$ wide.

Mesoventrite. Medial extension of collar tapering from broad base to mid-point of mid-keel; mid-keel sides concave, hind angles not reaching mesocoxal anterior borders, raised medially before keel; keel long, narrow, terminating in a point between the mesocoxae; mesoventral lateral margins serrate in posterior half; humeri toothed (Fig. 29C).

Metaventrite. Sparsely pubescent, length $0.12 \mathrm{~mm}$, disc simple, width across spines $0.08 \mathrm{~mm}$; posterior margin of mesocoxae serrate.

Genitalia. Male aedeagus as Fig. 6Fa-b but slightly more elongate. Females not known.

\section{Remarks}

This is the only Japanese species into this group apart from C. matthewsi Johnson, 2007. It may be distinguished from that species and all other Japanese species by the narrow almost parallel sided elytra.

Cissidium lamington sp. nov. urn:lsid:zoobank.org:act:C49061B6-8A0D-4C18-9DD4-CA06BC9D4F13

Fig. 30

\section{Etymology}

Named after the Lamington National Park, part of the Gondwana Forest World Heritage Area on the Gold Coast of Queensland, Australia where the insect was collected. Noun in apposition.

\section{Material examined}

\section{Holotype}

AUSTRALIA • O’; S. Queensland, Picnic Rock Trail, O’Reilly's, Lamington Nat. Park; 3 Sep. 1966; R.A. Crowson leg.; MMUE.

\section{Description}

Size. Habitus (Fig. 30A), length $0.72 \mathrm{~mm}$.

CoLour. Yellow brown.

HEAD. With a shallow fovea between the eyes, width across eyes $0.22 \mathrm{~mm}$; antennomeres III-XI length $0.38 \mathrm{~mm}$, III-IX length $0.25 \mathrm{~mm}, \mathrm{X}-\mathrm{XI}$ length $0.13 \mathrm{~mm}$; mentum sides rounded. 
Pronotum. Length $0.18 \mathrm{~mm}$, width $0.30 \mathrm{~mm}$, pubescent the setae sparse on the disc, more numerous near the sides, with a row in basal third of two pairs of four foveae separated by the width of the scutellum, lateral margins rounded then almost parallel-sided to rectangular hind angles, bordered, the border not continuing along the posterior margin which has a sinuous emargination opposite the scutellum (Fig. 30B).

ELYTRA. Length $0.49 \mathrm{~mm}$, width $0.35 \mathrm{~mm}$, foveolate in basal third, pubescence as pronotum.

Mesoventrite. Medial extension bluntly pointed; mid-keel widened anteriorly, posterior corners not reaching mesocoxae, sharply raised medially before junction with keel; keel with \pm six setae, parallelsided, terminating below midpoint of the mesocoxae; mesoventral lateral margins with serrations in basal third; humeri toothed, the posterior border long (Fig. 30C).

MetaVentrite. Length $0.18 \mathrm{~mm}$, distance across the narrow, sharply pointed spines $0.10 \mathrm{~mm}$, disc simple; posterior margins of mesocoxae not serrate.

WINGS. Macropterous.

Genitalia. Male aedeagus as Fig. 6Fa-b. Females not known.

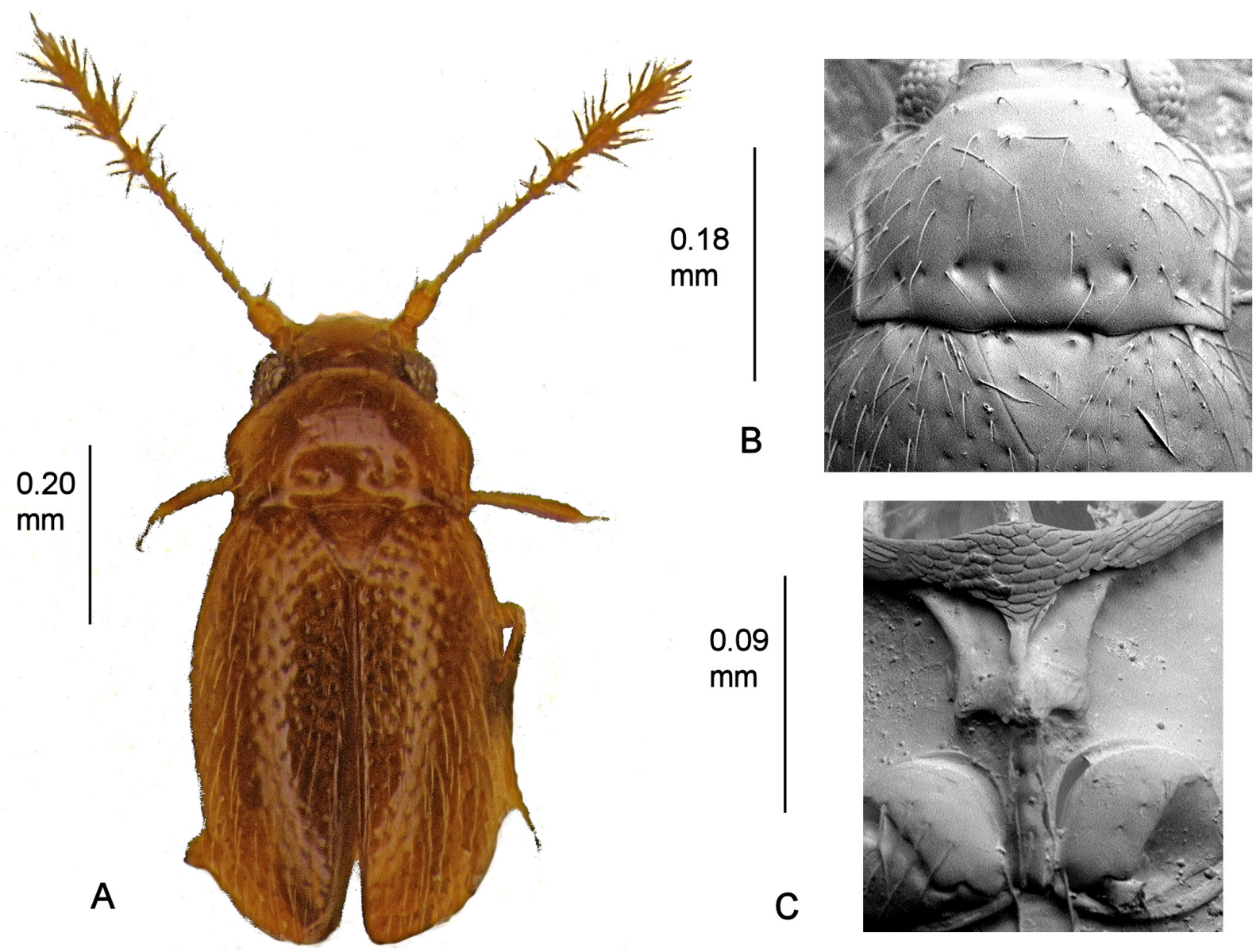

Fig. 30. Cissidium lamington sp. nov. A. Habitus. B. Pronotum, $\times$ 585. C. Mesoventrite showing median process of collar, mid-keel and keel, $\times 1140$. 


\section{Remarks}

See remarks under $C$. deanei sp. nov. The narrow, pointed median extension of the mesoventral collar coupled with the setose keel distinguish this species .

Cissidium lawrencei sp. nov.

urn:1sid:zoobank.org:act:58D7A1B0-57CC-4386-8C00-D528528BB002

Fig. 31

\section{Etymology}

Johnson ms name, in recognition of the collector, Dr Peter N. Lawrence, specialist in Collembola, and outstanding collector of many new ptiliids in the Solomon Islands.

\section{Material examined}

Holotype

SOLOMON ISLANDS • ${ }^{\text {; }}$; Guadalcanal, Mt. Gallego; $2500 \mathrm{ft}$ a.s.1.; 12 Jul. 1965; ridge forest litter; no. 101-130; P. N. Lawrence leg.; BMNH.
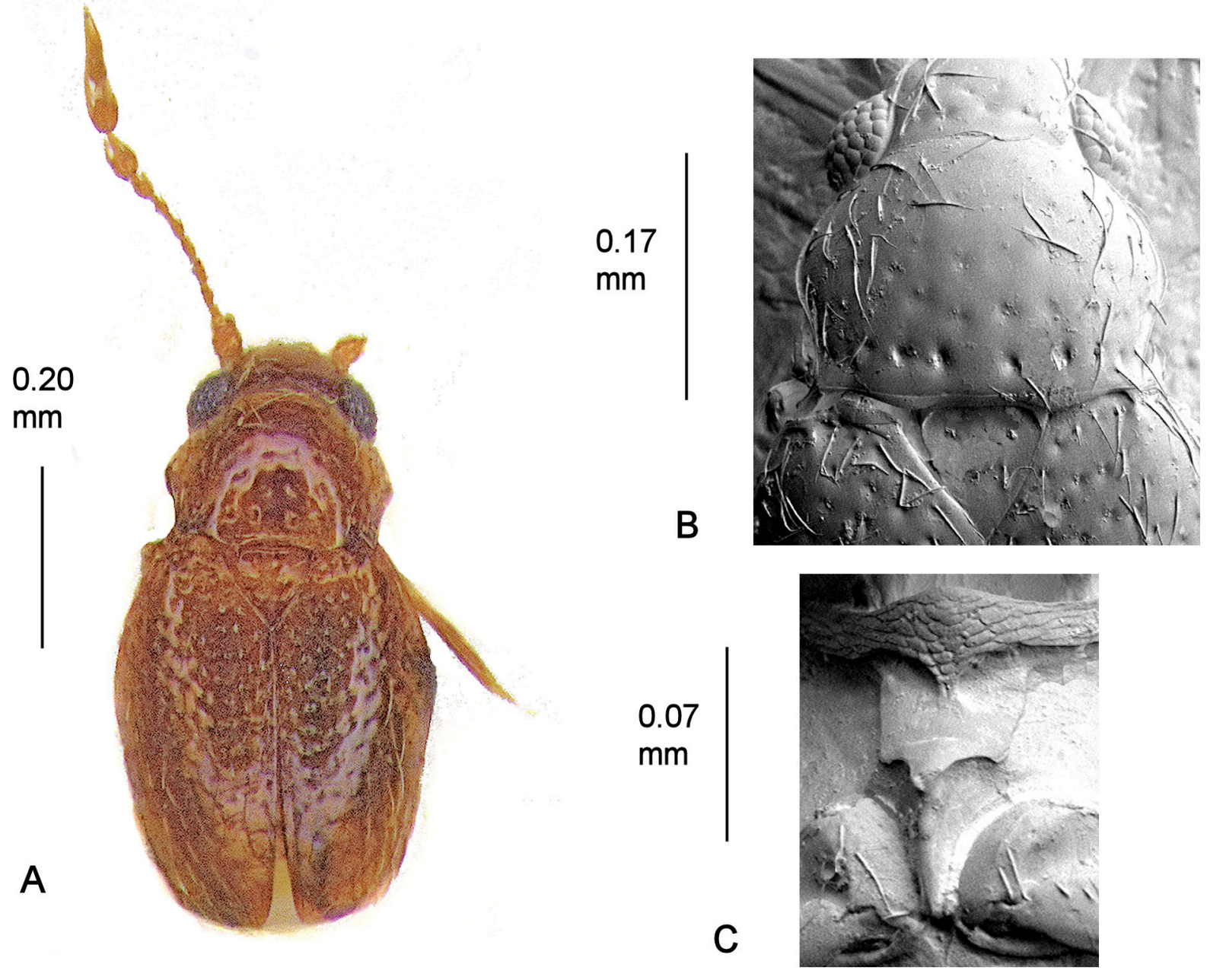

Fig. 31. Cissidium lawrencei sp. nov. A. Habitus. B. Pronotum, $\times$ 475. C. Mesoventrite showing median process of collar, mid-keel and keel, $\times 665$. 


\section{Paratypes}

SOLOMON ISLANDS • 1 \%; same collection data as for holotype; MMUE $\bullet 1$ + ; Mt. Jonapau; 35003750 ft a.s.1.; 6 May 1965; no. 18302; P. Greenslade leg.; BMNH • 1 ơ; Guadalcanal, Popomanasiu; $4500 \mathrm{ft}$ a.s.l.; x.1965, no. 20508, P. Greenslade leg.; MMUE • 1 \%; San Cristoval, 4 miles up Warahito from R. Pagato; 4 Aug. 1965; forest litter; Isiah and Leone leg.; BMNH • 1 \&; Guadalcanal, Tambalase; 4 Sep. 1965; $1500 \mathrm{ft}$ a.s.l.; dry ridge litter; P.N. Lawrence leg.; BMNH・1 §̇; Guadalcanal, Mt Austen; 21 Sep. 1965; litter; P. Greenslade leg.; MMUE.

\section{Description}

Size. Habitus (Fig. 31A), length $0.59 \mathrm{~mm}$.

CoLour. Yellow brown, pubescence and antennomeres slightly paler.

HEAD. With several shallow foveae not forming a distinct linear depression behind the eyes, width across eyes $0.20 \mathrm{~mm}$; antennomeres III-XI length $0.36 \mathrm{~mm}$; mentum sides narrowed to base.

Pronotum. Length $0.17 \mathrm{~mm}$, width $0.25 \mathrm{~mm}$, base with a series of four foveae on each side, separated medially, smaller foveae anterior to these on the disc; sides rounded, slightly concave posteriad before rectangular hind angles, sides bordered, the border continuing along the entire length of the posterior margin including the emargination opposite the scutellum, as a thin incised line (Fig. 31B).

ELYTRA. Length $0.38 \mathrm{~mm}$, breadth $0.33 \mathrm{~mm}$, basal third strongly foveolate.

MesoventRITE. Median process of collar pointed; mid-keel widest anteriorly, sides straight to posterior rounded angles which do not reach mesocoxae, mid-keel raised before junction with keel; keel with \pm three setae, narrow, parallel, terminating between the mesocoxae; mesoventral lateral margins obtusely angled before one or two shallow serrations before mesocoxae (Fig. 31C).

MetaVentrite. Length $0.13 \mathrm{~mm}$, pubescence very sparse almost entirely confined to lateral borders, width across spines $0.08 \mathrm{~mm}$, disc simple in male, with a distinct medial fovea posteriad to mesocoxae in female as Fig. 7C.

Genitalia. Male aedeagus as Fig. 6L. Female spermatheca globular.

\section{Remarks}

Distinguished from all other species of this group in the Solomon Islands by the rounded lateral margins of the pronotum.

Cissidium logunovi sp. nov. urn:1sid:zoobank.org:act:122C9AE2-B006-44CB-950A-058A2A927799

Fig. 32

\section{Etymology}

I am pleased to be able to name this species after Dr Dmitri Logunov, Keeper of Entomology at the Manchester Museum, who has always been most helpful to me.

\section{Material examined}

Holotype

NEPAL • Barahbise geg, Ting-Sang-La; H. Franz leg.; MMUE. 
A fragment of a second specimen bearing this label, without head and pronotum, was also found in the collection.

\section{Description}

Size. Habitus (Fig. 32A), length $0.54 \mathrm{~mm}$.

CoLour. Yellow brown, pubescence, legs and antennae pale yellow.

HEAD. With shallow median depression between eyes, width across eyes $0.20 \mathrm{~mm}$; mentum obscured; antennomeres III-XI, length $0.28 \mathrm{~mm}$, III-IX length $0.16 \mathrm{~mm}, \mathrm{X}-\mathrm{XI}$ length $0.12 \mathrm{~mm}$.

Pronotum. $0.19 \mathrm{~mm}$ long, $0.28 \mathrm{~mm}$ wide, with \pm ten loosely formed fovea in basal half, some tending to join together; sides rounded, almost parallel sided to slightly acute hind angles, bordered, the borders not continuing along the posterior margin, medial emargination opposite the scutellum sinuate (Fig. 32B).

ELYTRA. $0.52 \mathrm{~mm}$ long, $0.40 \mathrm{~mm}$ wide, sparsely pubescent, foveolate, contrasting with the pronotum.

Mesoventrite. Medial extension of collar pointed; mid-keel posterior angles with carinae to mesocoxae, raised slightly medially before keel; keel parallel-sided then broadening to rounded spatulate termination between mesocoxae; mesoventral lateral margins serrate in posterior half; humeri rounded barely toothed (Fig. 32C).
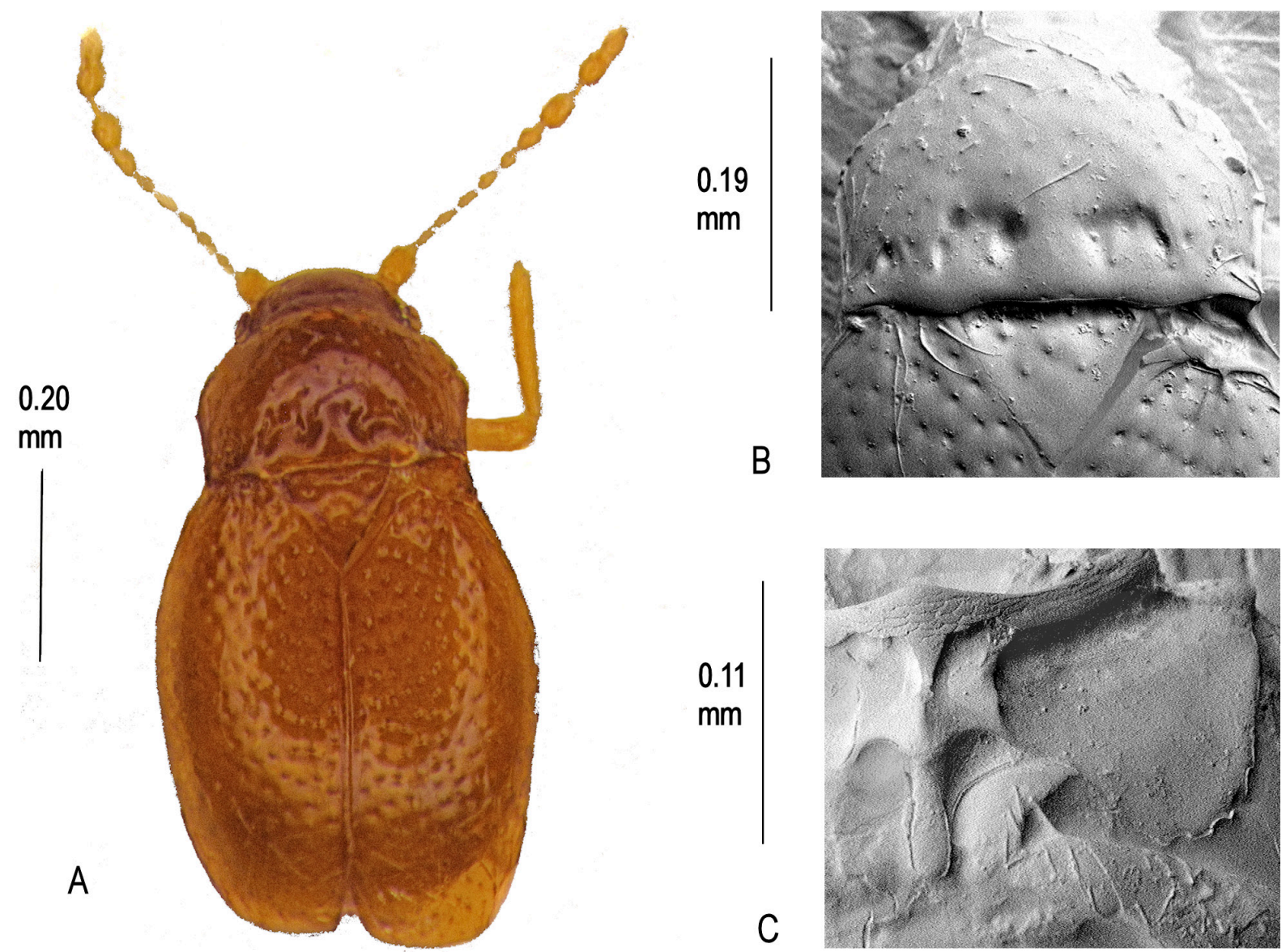

Fig. 32. Cissidium logunovi sp. nov. A. Habitus. B. Pronotum, $\times 620$. C. Mesoventrite showing median process of collar, mid-keel, keel and lateral margin, $\times 595$. 
MetaVEnTRItE. Sparsely pubescent, length $0.15 \mathrm{~mm}$, disc simple, width across spines $0.14 \mathrm{~mm}$; posterior margin of mesocoxae serrate.

Wings. Apterous.

Genitalia. Gender not known, specimen considered too fragile to risk dissection.

\section{Remarks}

This is the only species of Cissidium in this group recorded from Nepal.

Cissidium matthewsi Johnson, 2007

Fig. 33

Johnson (2004) erroneously gave Cissidium matthewsi as a replacement name for Camptodium adustipenne Matthews, 1884, but corrected that in 2007 (Johnson 2007) pointing out that the latter was a misidentification of Camptodium adustipenne (Johnson 2007).

Cissidium matthewsi Johnson sp. nov. was characterized in Matthews (1884: 83) and the holotype recorded as being in MMUE. The following is based on an examination of the holotype and on the description given by Sawada (2008) who also examined it.

\section{Etymology}

Named after the reverend A. Matthews.

\section{Material examined}

\section{Holotype}

JAPAN • O’; Manazuru, Kanagawa Pref.; 3 Nov. 1967; M. Kubota leg.; MM holotype; MMUE.

\section{Paratypes}

JAPAN $\bullet 1$ q, 1 क; same collection data as for holotype; MMUE, BMNH $\bullet 2$ 우; Odawara, Kanagawa Pref.; 7 Apr. 1946; M. Kubota leg.; one mounted verso also bears a label stating Camptodium sp. E. Sundt; v.66; MMUE, BMNH • 4 ex.; same collection data as for preceding but 28 Mar. 1971; one mounted verso; MMUE.

\section{Additional material}

Sawada lists numerous records from Japan where the species appears to be the commonest Cissidium.

\section{Supplementary description}

Size. Habitus (Fig. 33A), length $0.66 \mathrm{~mm}$.

Colour. Dark brown, shining, pubescence, legs and antennae yellow.

HEAD. With a narrow foveolate linear depression behind the eyes, width across eyes $0.21 \mathrm{~mm}$; antennomeres III-XI length $0.30 \mathrm{~mm}$, III-IX length $0.19 \mathrm{~mm}, \mathrm{X}-\mathrm{XI}$ length $0.11 \mathrm{~mm}$. globular; mentum and prementum obscured.

Pronotum. Length $0.17 \mathrm{~mm}$, pubescent, without foveolae, two pairs of three foveae along posterior margin the outside pair much smaller than the other four; lateral margins rounded then slightly concave to rectangular hind angles, front angles rounded, sides bordered, the border not extending along the posterior margin, medial emargination in front of scutellum with shallow angulate corners (Fig. 33B). 
ELYTRA. Length $0.56 \mathrm{~mm}$, width $0.45 \mathrm{~mm}$, densely pubescent and foveolate contrasting with the pronotum, the foveolae more marked in basal half, setae of the same length as those on the pronotum.

Mesoventrite. Medial extension of collar parallel-sided; mid-keel anterior and posterior margins of same length, anterior angles not reaching mesocoxae, raised medially to a sharp point before keel; keel wide, parallel-sided with \pm four setae and rounded termination just below interruption of mesocoxal margins; mesoventral lateral margins serrate in posterior half; humeri bluntly toothed (Fig. 33C).

Metaventrite. Length $0.18 \mathrm{~mm}$, disc simple, distance across spines $0.15 \mathrm{~mm}$; posterior margins of mesocoxae serrate.

Genitalia. Male aedeagus as Fig. 6Fa-b. Female spermatheca globular.

\section{Remarks}

This is the only Japanese species in this group apart from $C$. ishigakiense from which it may be distinguished by the more rounded elytra and broader based pronotum.
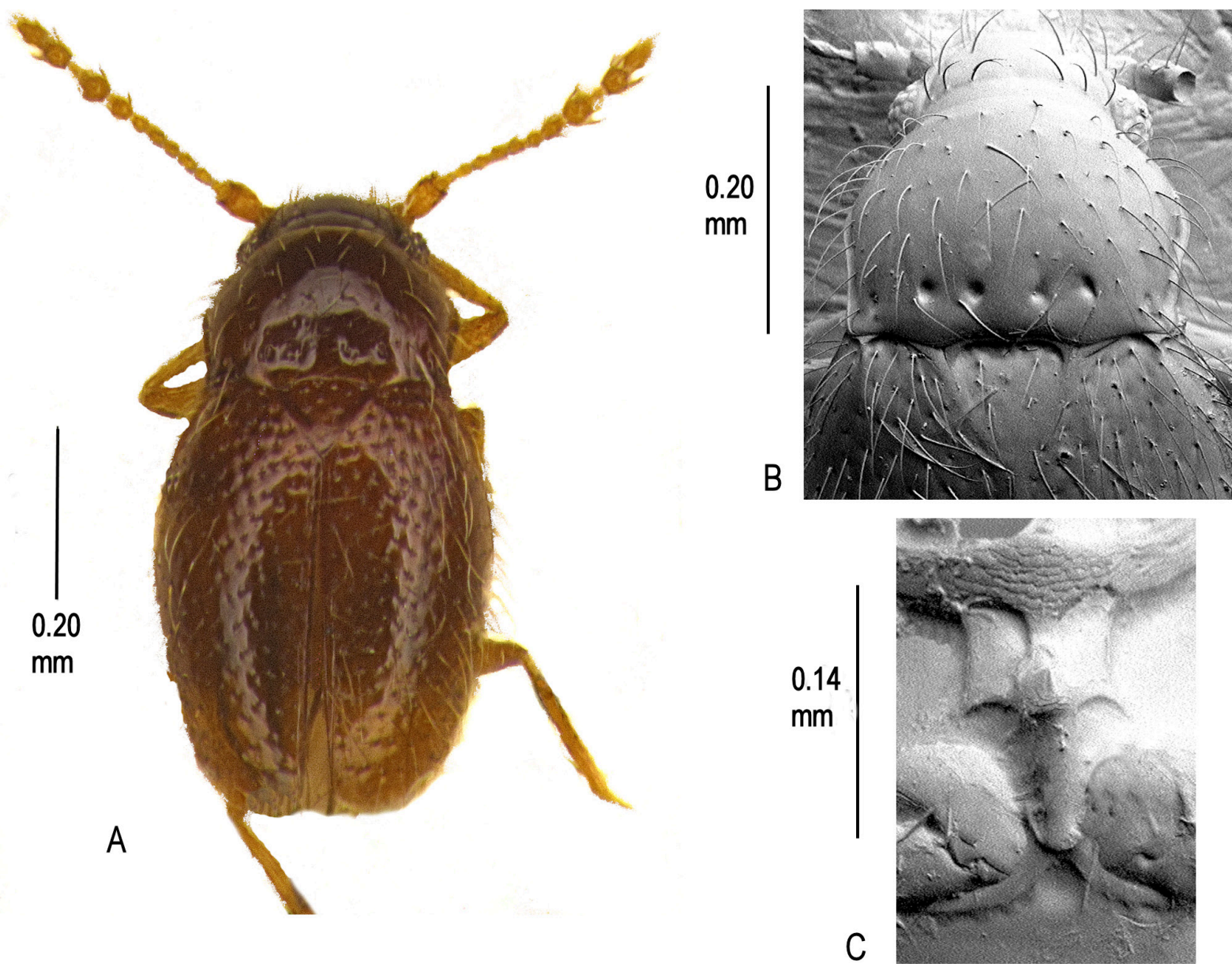

Fig. 33. Cissidium matthewsi Johnson, 2007. A. Habitus. B. Pronotum, $\times 430$. C. Mesoventrite showing median process of collar, mid-keel and keel, $\times 1295$. 
Cissidium misellum sp. nov.

urn:Isid:zoobank.org:act:BE7C5078-DF8C-4C85-B5EB-8F0D3B2ED665

Fig. 34

\section{Etymology}

Johnson ms name after the Latin adjective misellus meaning poor, little.

\section{Material examined}

\section{Holotype}

NEW CALEDONIA • ${ }^{\wedge}$; Table d'Union, b Col d'Amieu; MM holotype; MMUE.

\section{Paratypes}

NEW CALEDONIA $\cdot 2 \widehat{\partial}$; same collection data as for holotype; one mounted verso; MMUE, BMNH.

\section{Description}

Size. Habitus (Fig. 34A), length $0.60 \mathrm{~mm}$.
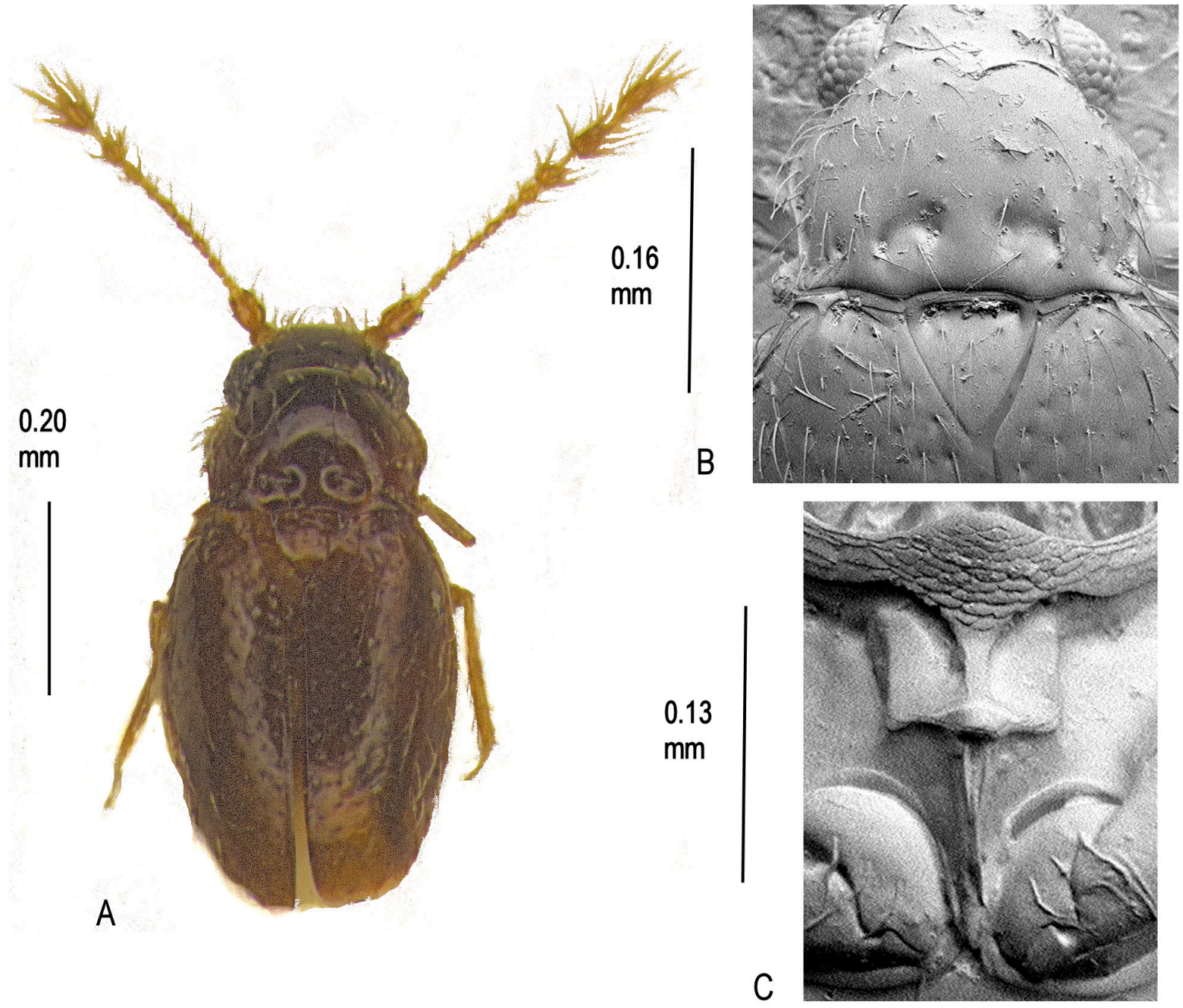

Fig. 34. Cissidium misellum sp. nov. A. Habitus. B. Pronotum, $\times$ 550. C. Mesoventrite showing median process of collar, mid-keel and keel, $\times 745$. 
CoLour. Dark brown, pubescence, legs and antennae dusky yellow.

HEAD. Head without a linear depression between or behind the eyes, width across eyes $0.20 \mathrm{~mm}$ : antennomeres III-XI length $0.37 \mathrm{~mm}$, III-IX length $0.19 \mathrm{~mm}, \mathrm{X}-\mathrm{XI}$ length $0.11 \mathrm{~mm}$. globular; mentum and prementum obscured.

Pronotum. Length $0.16 \mathrm{~mm}$, width $0.24 \mathrm{~mm}$, sparsely pubescent without foveolae but with six foveae along the posterior margin in two pairs of three the outer pair very small, the median two pairs larger, merging to form two large foveae; sides rounded slightly concave to acute hind angles, bordered, the border not continuing along the posterior margin which has a sinuous emargination in front of the scutellum (Fig. 34B).

ElytRA. Length $0.40 \mathrm{~mm}$, width $0.32 \mathrm{~mm}$; pubescent and foveolate markedly contrasting with the pronotum.

MesoventRite. Median process of mesoventral collar almost reaching posterior margin of mid-keel; mid-keel parallel-sided, the posterior angles rounded not reaching mesocoxae, raised sharply before joining keel; keel with \pm four setae, narrow, terminating in a point at the interruption of the mesocoxal borders; mesoventral lateral margins angled and serrate posteriorly; humeri toothed (Fig. 34C).

Metaventrite. Length $0.15 \mathrm{~mm}$, setose, disc simple, width across spines $0.09 \mathrm{~mm}$, spines narrow, sharply pointed.

Wings. Macropterous.

Genitalia. Aedeagus as Fig. 6Fa-b. Female not known.

\section{Remarks}

The short parallel sided mid-keel is only likely to be confused among the New Caledonian species with C. houailou sp. nov. from which it differs by its smaller size.

Cissidium montanum sp. nov. urn:1sid:zoobank.org:act:928ED73C-E9AC-47B6-8805-397115195829

Fig. 35

\section{Etymology}

The name is a reference to Kilimanjaro, the mountain in Tanzania where the specimens were collected.

\section{Material examined}

\section{Holotype}

TANZANIA • P; Kilimanjaro, Gebirgswald ob Marangu; H. Franz leg.; MMUE.

\section{Paratypes}

TANZANIA • 3 + $q, 1$ ते; same collection data as for holotype; 1 mounted verso; MMUE, BMNH.

\section{Description}

Size. Habitus (Fig. 35A), length $0.64 \mathrm{~mm}$.

CoLour. Dusky yellow, shining, pubescence, antennae and legs yellow. 
HEAD. With a setose foveate medial depression between the eyes, width across eyes $0.18 \mathrm{~mm}$; antennomeres III-XI length $0.29 \mathrm{~mm}$, III-IX length $0.17 \mathrm{~mm}$, X-XI length $0.12 \mathrm{~mm}$, globular; mentum and prementum obscured.

Pronotum. Length $0.19 \mathrm{~mm}$, width $0.24 \mathrm{~mm}$, sparsely pubescent, with a row of ten foveae of different sizes in two groups of five separated medially along the posterior margin, lateral margins evenly rounded, almost parallel-sided to rectangular hind angles, narrowly bordered, the borders not extending along the posterior margin which is almost straight, the emargination before the scutellum sinuous (Fig. 35B).

ELYTRA. Length $0.43 \mathrm{~mm}$, width $0.32 \mathrm{~mm}$, very sparsely pubescent and shallowly foveolate most noticeable towards the base.

Mesoventrite. Medial extension of collar with a central ridge, becoming bifurcate posteriorly and reaching to hind angles of the mid-keel; mid-keel widest anteriorly, hind angles not reaching mesocoxae; keel tapering to narrow point close to base of mesocoxae, without setae; mesoventral lateral margins serrate in posterior half; humeri toothed (Fig. 35C).

MetaVentRite. Length $0.15 \mathrm{~mm}$, sparsely pubescent, disc simple, width across spines $0.10 \mathrm{~mm}$; posterior margins of mesocoxal borders serrate.
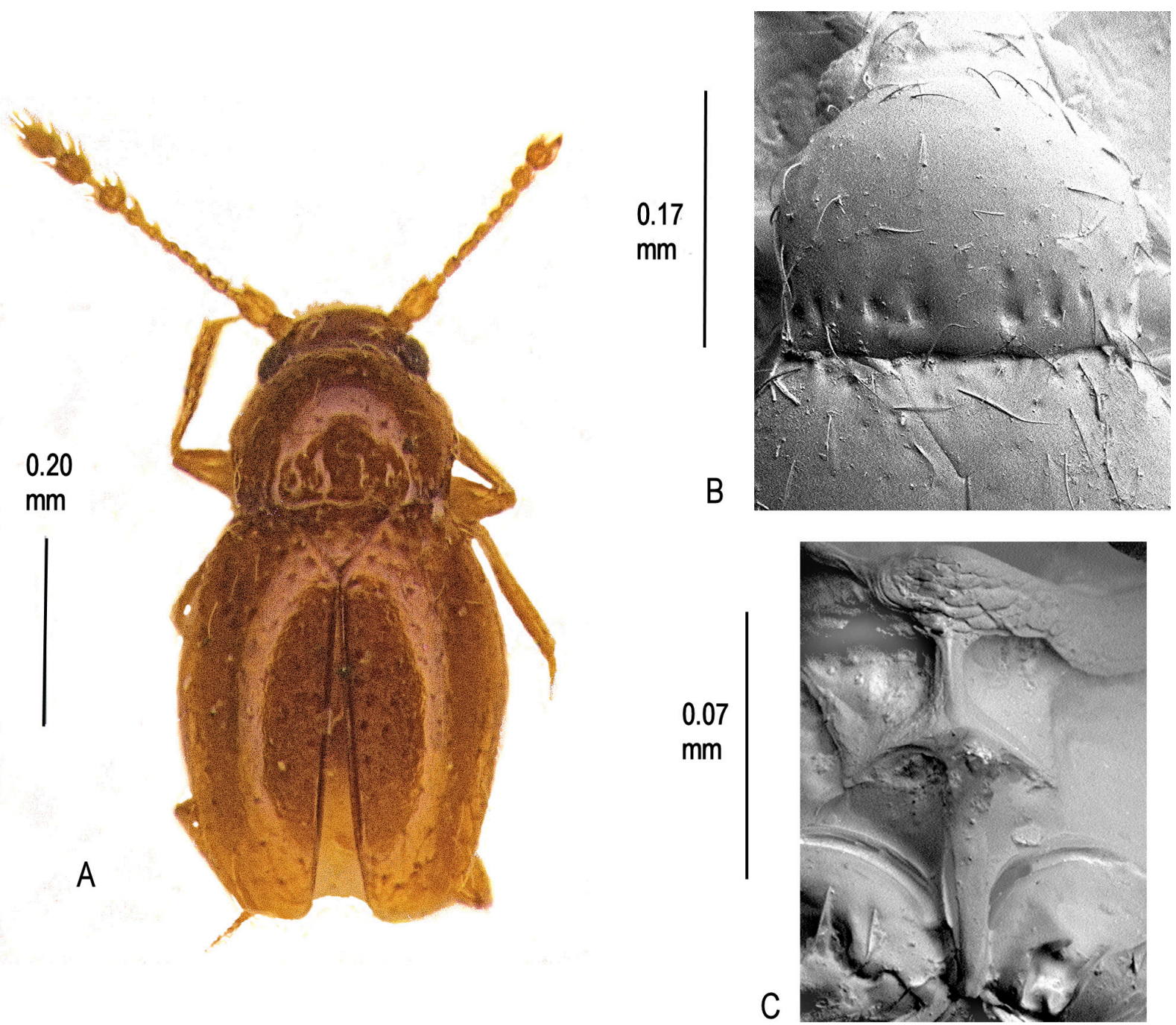

Fig. 35. Cissidium montanum sp. nov. A. Habitus. B. Pronotum, $\times$ 615. C. Mesoventrite showing median process of collar, mid-keel and keel, $\times 635$. 
Wings. Apterous in both sexes.

Genitalia. Female spermatheca globular. Male aedeagus not detected in the dissection.

\section{Remarks}

The only species of Cissidium to have been described from Tanzania.

Cissidium mussardi sp. nov.

urn:1sid:zoobank.org:act:3761B099-6D14-45B6-A257-E8AA5BFB35BF

Fig. 36

\section{Etymology}

Johnson ms name after the collector.

\section{Material examined}

\section{Holotype}

SRI LANKA• • ; Hatton; 1400 m a.s.1.; 9 Feb. 1970; Mussard, Besuchet and Löbl leg.; MMUE.
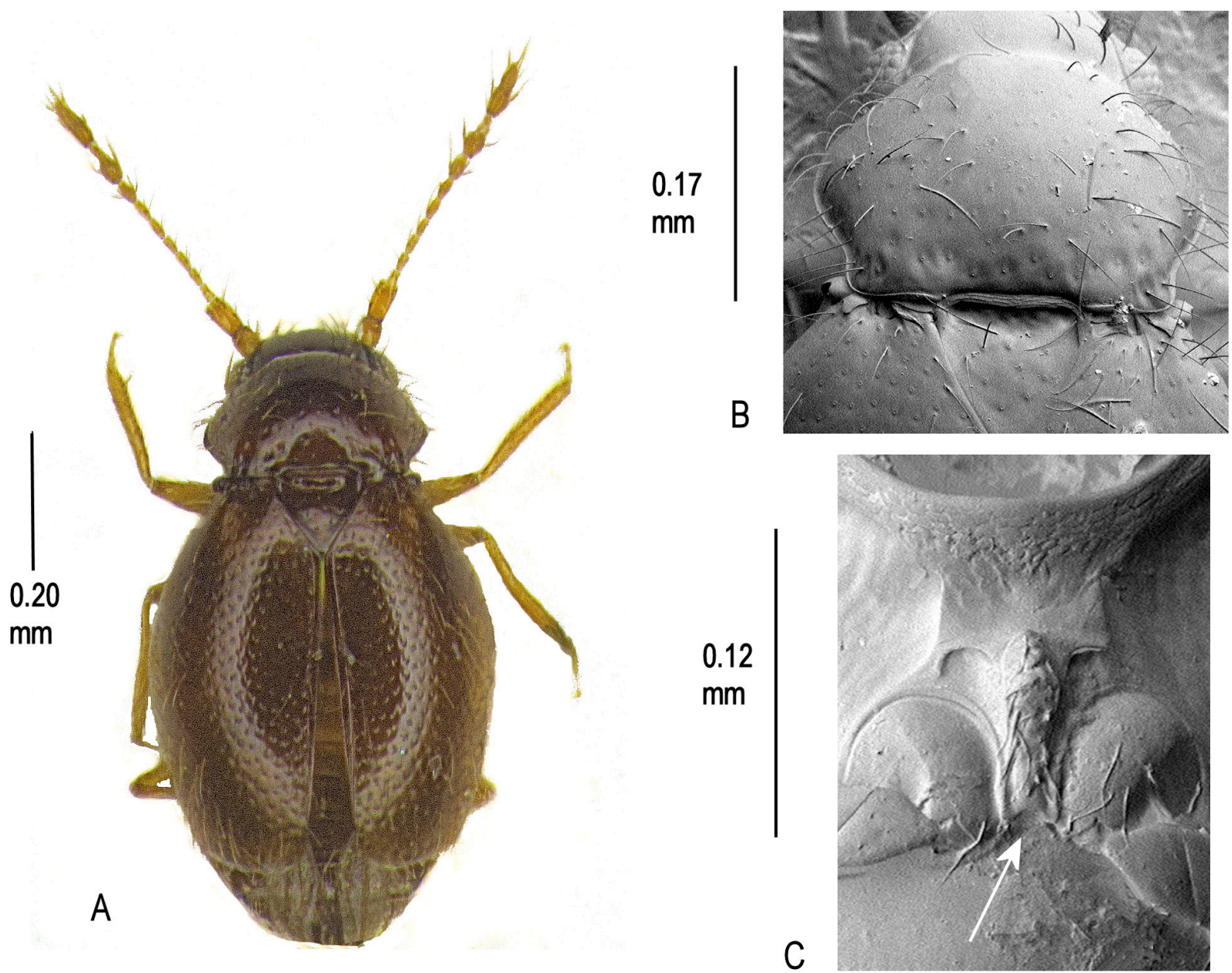

Fig. 36. Cissidium mussardi sp. nov. A. Habitus. B. Pronotum, $\times$ 550. C. Mesoventrite showing median process of collar, mid-keel and keel, $\times 745$. 


\section{Paratypes}

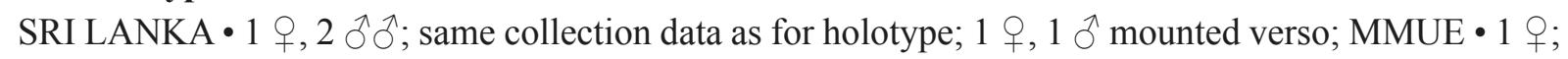
Sabaragamuwa, 2 miles east of Kalawana; 20 Jan. 1970; Mussard, Besuchet and Löbl leg.; BMNH.

\section{Description}

SizE. Habitus (Fig. 36A), length $0.82 \mathrm{~mm}$.

CoLour. Dark brown, antennae, legs and pubescence dusky yellow, shining.

HEAD. With a narrow linear depression between the eyes, width across eyes $0.24 \mathrm{~mm}$; antennomeres III-XI length $0.33 \mathrm{~mm}$, III-IX length $0.21 \mathrm{~mm}, \mathrm{X}-\mathrm{XI}$ length $0.12 \mathrm{~mm}$; mentum as Fig. 4B.

Pronotum. Length $0.19 \mathrm{~mm}$, width $0.30 \mathrm{~mm}$, sparsely pubescent, with a row of \pm fifteen shallow, setae bearing foveae along the posterior margin; sides sharply rounded then parallel-sided for a short distance before the rounded rectangular hind angles, lateral borders continuing along basal margin to the wellmarked median emargination opposite the scutellum (Fig. 36B).

ELYTRA. Length $0.51 \mathrm{~mm}$, width $0.46 \mathrm{~mm}$, more densely pubescent than the pronotum, the setae arising from clearly marked circular raised pits.

MESOVENTRITE. With a shallowly raised reticulation, collar without a clearly marked median extension onto the mid-keel; mid-keel wide, slightly narrower anteriorly, the posterior angles with short raised carinae to the mesocoxal anterior margins; keel strongly sculptured, with \pm ten setae, widest anteriorly then broadly tapering to termination with a small concave emargination between the mesocoxae, mesocoxae not contiguous; mesoventral lateral margins angulate, effaced posteriorly; humeri very short, bluntly toothed (Fig. 36C).

Metaventrite. Length $0.17 \mathrm{~mm}$, sparsely pubescent, disc simple, width across spines $0.1 \mathrm{~mm}$, spines small, short, posterior margins of mesocoxal cavities not serrate.

Wings. Macropterous.

Genitalia. Female spermatheca globular.

\section{Remarks}

The only species of Cissidium from Sri Lanka in this group.

Cissidium noumeae sp. nov.

urn:1sid:zoobank.org:act:6312A594-0589-4201-9780-98B097414FC7

Fig. 37

\section{Etymology}

Named after Noumea, the capital city of New Caledonia, close to which the insects were collected.

\section{Material examined}

Holotype

NEW CALEDONIA • $q$; Mont Koghis near Noumea; Sep. 1970; H. Franz leg.; MM holotype; MMUE. 
Paratypes

NEW CALEDONIA $・ 1$,$+ 3 \hat{\partial}$; same collection data as for holotype; the $q$ mounted verso; MMUE, BMNH.

\section{Description}

Size. Habitus (Fig. 37A), length $0.76 \mathrm{~mm}$.

Colour. Yellow brown, shining, antennae, legs and pubescence dusky yellow.

HEAD. With a shallow median depression between the eyes, width across eyes $0.24 \mathrm{~mm}$; antennomeres III-XI length $0.37 \mathrm{~mm}$, III-IX length $0.24 \mathrm{~mm}, \mathrm{X}-\mathrm{XI}$ length $0.13 \mathrm{~mm}$; mentum as Fig. 4A but anterior border sinuous.

Pronotum. Length $0.23 \mathrm{~mm}$, width $0.34 \mathrm{~mm}$, sparsely pubescent, without foveolae but with a row of eight foveae along the posterior margin in two groups of four, the outer two in each group much small than the inner two; sides evenly and broadly rounded becoming parallel-sided in posterior half
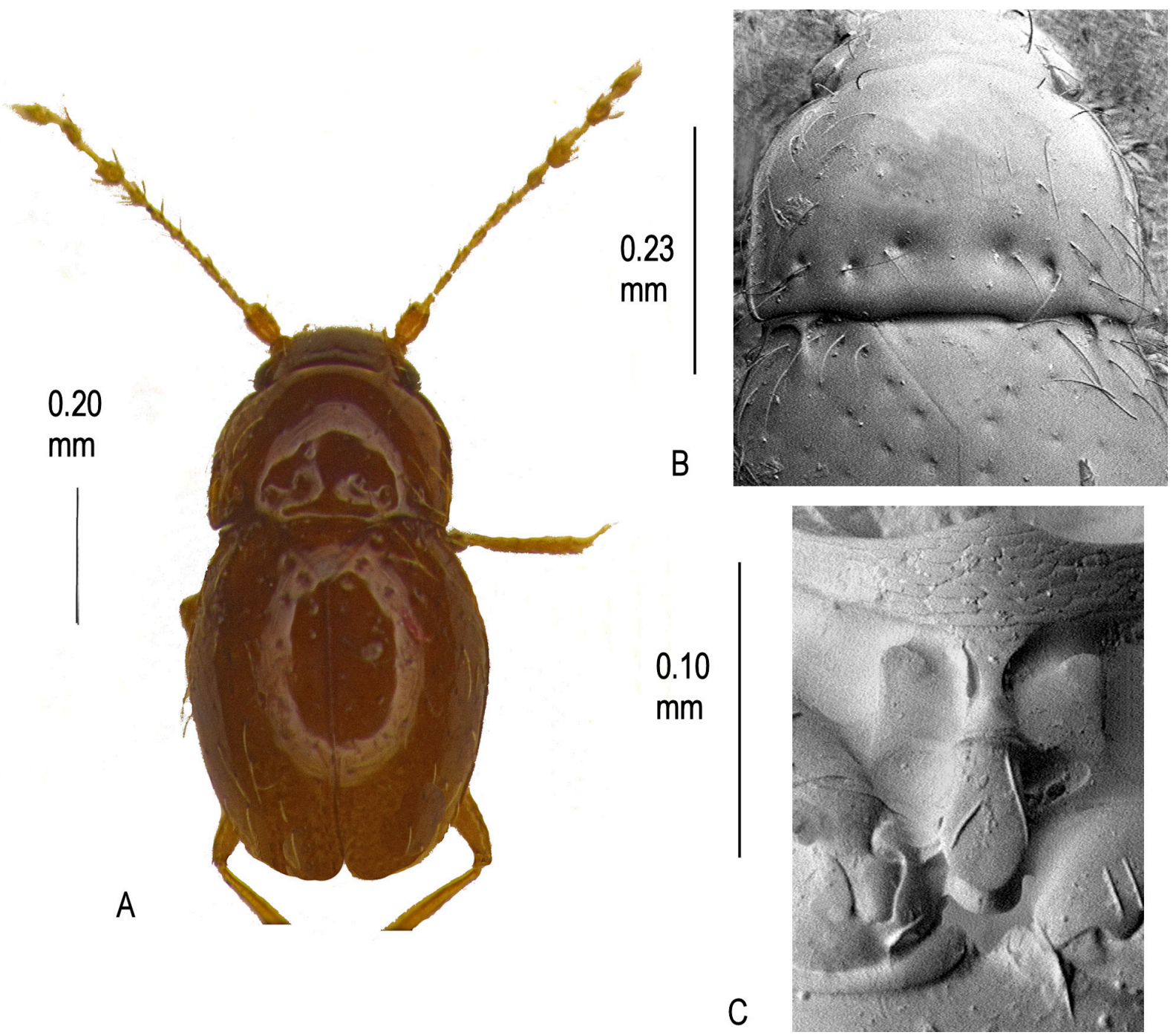

Fig. 37. Cissidium noumeae sp. nov. A. Habitus. B. Pronotum, $\times$ 547. C. Mesoventrite showing median process of collar, mid-keel and keel, $\times 760$. 
before slightly obtuse hind angles, lateral borders wide, not continued along the basal margin, medial emargination in front of scutellum sinuous. (Fig. 37B).

ELYTRA. Length $0.49 \mathrm{~mm}$, width $0.42 \mathrm{~mm}$, sparsely pubescent and shallowly foveolate.

Mesoventrite. Collar with a tapering median extension widening posteriorly; mid-keel wide, parallelsided, the anterior angles rounded before reaching the collar, the posterior angles with broad, shallowly raised, partly effaced carinae to the mesocoxae; keel with two setae, broadly spatulate and reaching to the mid-point of the mesocoxae, the mesocoxae are not contiguous and separated in the holotype by a wide ' $u$ '-shaped perforation; mesoventral lateral margins rounded, serrate posteriorly; humeri strongly sloping, barely toothed (Fig. 37C).

Metaventrite. Glabrous, length $0.13 \mathrm{~mm}$, width across spines $013 \mathrm{~mm}$, spines small, short; margins of mesocoxal cavities not serrate.

Wings. Macropterous.

GenitaLia. Female spermatheca globular.

\section{Remarks}

Differs from all other species described in this paper by the spatulate form of the mesoventral keel.

Cissidium okuense Grebennikov, 2009

Fig. 38

\section{Material examined}

SEMs of a paratype and photographs of a slide of the holotype
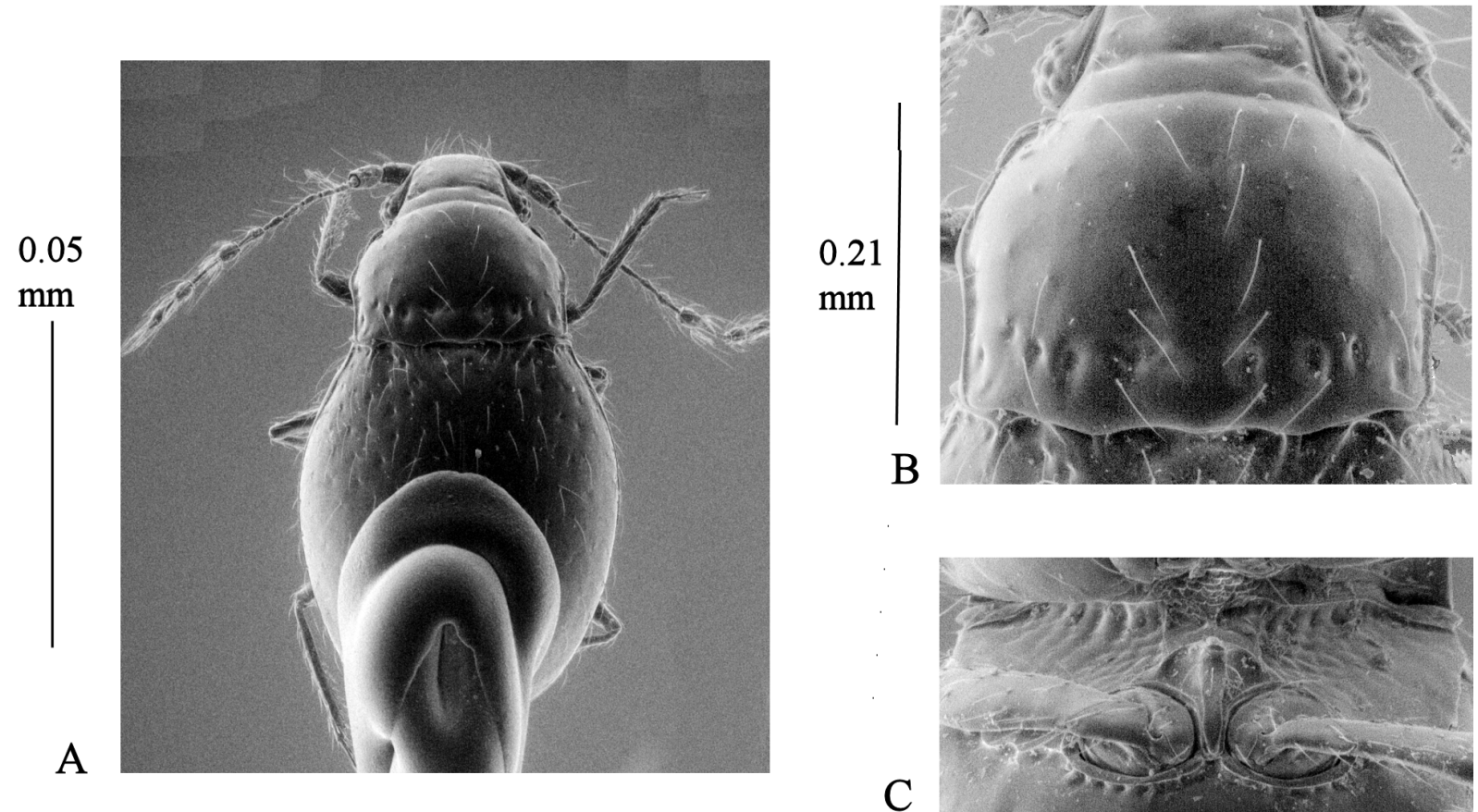

Fig. 38. Cissidium okuense Grebennikov, 2009. A. Habitus. B. Pronotum, C. Mesoventrite (fore shortened by camera position, SEM images provided to me by V. Grebennikov) 
CAMEROON • North West province, Mt and Lake Oku; $6^{\circ} 12.218^{\prime} \mathrm{N}, 010^{\circ} 27.596^{\prime} \mathrm{E} ; 2200 \mathrm{~m}$ a.s.1.; 6 May 2006; V. Grebennikov coll.

\section{Supplementary description}

The following amplifies the description of Grebennikov (2009) to conform with the other entries in this paper. It is based on the paratype illustrated in 20 SEM images and a single photograph of a slide given to the author by Grebennikov. This specimen was subsequently destroyed in the SEM, but was also used as the basis for Grebennikov's short textual description.

Size. Habitus (Fig. 38A), length $1.03 \mathrm{~mm}$.

CoLour. Yellow brown.

HEAD. With a shallow median depression between the eyes; width across eyes $0.21 \mathrm{~mm}$; antennomeres III-XI length $0.39 \mathrm{~mm}$, III-IX length $0.20 \mathrm{~mm}, \mathrm{X}-\mathrm{XI}$ length $0.19 \mathrm{~mm}$; mentum as Fig. 4A.

Pronotum. Length $0.21 \mathrm{~mm}$, width $0.30 \mathrm{~mm}$, sparsely pubescent, without foveolae but with a row of \pm ten foveae along the posterior margin in two groups of five, the outermost two in each group smaller than the others; sides with rounded medial angles, straight to obtuse anterior angles, almost parallelsided to hind angles, bordered, the border not continuing along the posterior margin which has a sinuous emargination opposite the scutellum (Fig. 38B).

ELYTRA. Length $0.58 \mathrm{~mm}$, width $0.42 \mathrm{~mm}$, sparsely pubescent and foveolate contrasting with the pronotum.

MESOVENTRITE. Collar with a short, strongly tapering median extension widening posteriorly; mid-keel wide, parallel-sided, the posterior angles with narrow carinae to the mesocoxal anterior borders; keel with a single medial seta, slightly sinuate before termination at interruption point of the mesocoxal borders; mesoventral lateral margins serrate posteriorly; humeri toothed (Fig. 38C fore-shortened by camera position)

MetaVentrite. Glabrous, length $0.21 \mathrm{~mm}$, disc simple, width across spines $0.12 \mathrm{~mm}$; mesocoxal posterior borders serrate.

Wings. Apterous.

Genitalia. Female spermatheca globular.

Cissidium pinense sp. nov. urn:1sid:zoobank.org:act:7AAC3F0E-C71E-4988-8916-B9C5A59C0B36

Fig. 39

\section{Etymology}

Johnson ms name, after the place of collection.

\section{Material examined}

Holotype

NEW CALEDONIA • + ; Pic du Pin; H. Franz leg.; MMUE. 


\section{Description}

Size. Habitus (Fig. 39A), length $0.73 \mathrm{~mm}$.

CoLour. Dark red brown, antennae, legs and pubescence dusky yellow.

HEAD. With a very shallow linear depression between the eyes, width across eyes $0.23 \mathrm{~mm}$; antennomeres III-XI length $0.45 \mathrm{~mm}$, III-IX length $0.26 \mathrm{~mm}, \mathrm{X}-\mathrm{XI}$ length $0.19 \mathrm{~mm}$; mentum tapering towards base but not as pronounced as Fig. 4F.

Pronotum. Fig. 39B, length $0.21 \mathrm{~mm}$, width $0.31 \mathrm{~mm}$, sparsely pubescent, six foveae across base the central four equally spaced, larger than the outside pair; lateral margins rounded anteriorly almost parallel-sided in basal half, hind angles slightly acute, bordered, the border not continued along the hind margin; median emargination opposite scutellum present only as a slight insinuation.

ELYTRA. Length $0.48 \mathrm{~mm}$, width $0.42 \mathrm{~mm}$ sparsely pubescent and shallowly foveolate contrasting with the pronotum.

Mesoventrite. Collar with a long tapering median extension; mid-keel parallel-sided the front angles rounded before reaching the collar creating two converging depressions, hind angles with short carinae
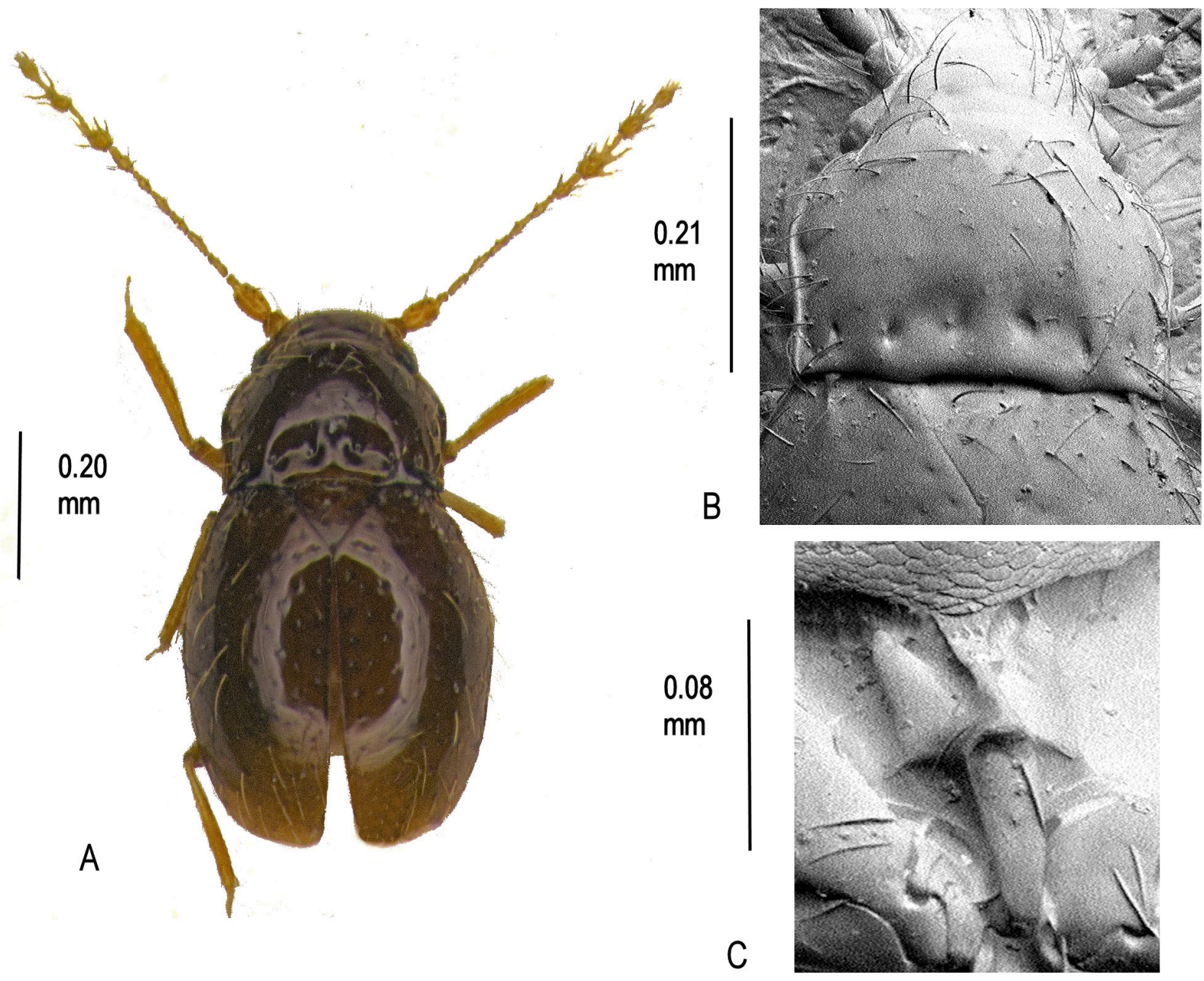

Fig. 39. Cissidium pinense sp. nov. A. Habitus. B. Pronotum, $\times$ 445. C. Mesoventrite showing median process of collar, mid-keel and keel, $\times 600$. 
not reaching the mesocoxal anterior borders, strongly raised before keel to form a blunt projection; keel with \pm three setae, broad, flat, tapering to a rounded termination between the mesocoxae; mesoventral lateral margins serrate in posterior half; humeri sloping posteriorly, barely toothed (Fig. 39C).

Metaventrite. Sparsely pubescent, disc simple, length $0.15 \mathrm{~mm}$ width between spines $0.14 \mathrm{~mm}$, spines narrow, sharply pointed; margins of mesocoxal cavities not serrate.

Wings. Apterous.

GenitALIA. Female spermatheca globular. Males not known.

\section{Remarks}

See remarks for C. amieuense sp. nov. On mesoventral characters, this species is only likely to be confused with $C$. houailou sp. nov., but the keel differs in being wider and more tapering.

Cissidium riparium sp. nov. urn:1sid:zoobank.org:act:3A299211-20B2-4DD6-9B38-09F2085ADED1

Figs $7 \mathrm{~A}, 40$

\section{Etymology}

Johnson ms name, after the riparian habitat of the specimen.

\section{Material examined}

Holotype

NEW CALEDONIA • $q$; S, Riviere Bleu; H. Franz leg.; MM holotype; MMUE.

\section{Description}

Size. Habitus (Fig. 40A), length $0.58 \mathrm{~mm}$.

Colour. Yellow brown, antennae, legs and pubescence yellow.

HEAD. With a shallow linear depression between the eyes; width across eyes $0.19 \mathrm{~mm}$; antennomeres III-XI length $0.31 \mathrm{~mm}$, III-IX length $0.19 \mathrm{~mm}, \mathrm{X}-\mathrm{XI}$ length $0.12 \mathrm{~mm}$; mentum as Fig 4A.

Pronotum. Length $0.15 \mathrm{~mm}$, width $0.25 \mathrm{~mm}$, almost glabrous but some scattered pubescence anteriorly and at sides, posterior margin with four large foveae separated medially into two pairs, and two pairs of smaller foveae outside these; lateral margins rounded straightening to almost parallel-sided before the rectangular hind angles, bordered, the border not continuing along the posterior margin, medial emargination in front of scutellum sinuate (Fig. 40B).

ELYTRA. Length $0.42 \mathrm{~mm}$, width $0.33 \mathrm{~mm}$ with a few scattered setae, appearing glabrous.

MESOVENTRITE. Medial extension of collar very widely based, sharply tapering to a point before raised portion of mid-keel; mid-keel wide, sides concave, the hind angles with carinae reaching to the mesocoxa; anterior borders; keel with \pm five setae in basal half tapering to parallel-sided and rounded termination at base of mesocoxae; mesoventral lateral margins serrate in basal half; humeri toothed (Fig. 40C).

Metaventrite. Sparsely pubescent, disc simple, length $0.14 \mathrm{~mm}$, width between spines $0.11 \mathrm{~mm}$ (Fig. 7A); posterior margins of mesocoxal cavities serrate. 
Wings. Macropterous.

GenitaLia. Female spermatheca globular. Males not known.

\section{Remarks}

Distinguished from other New Caledonian species by the wide anterior margin of the medial collar extension.
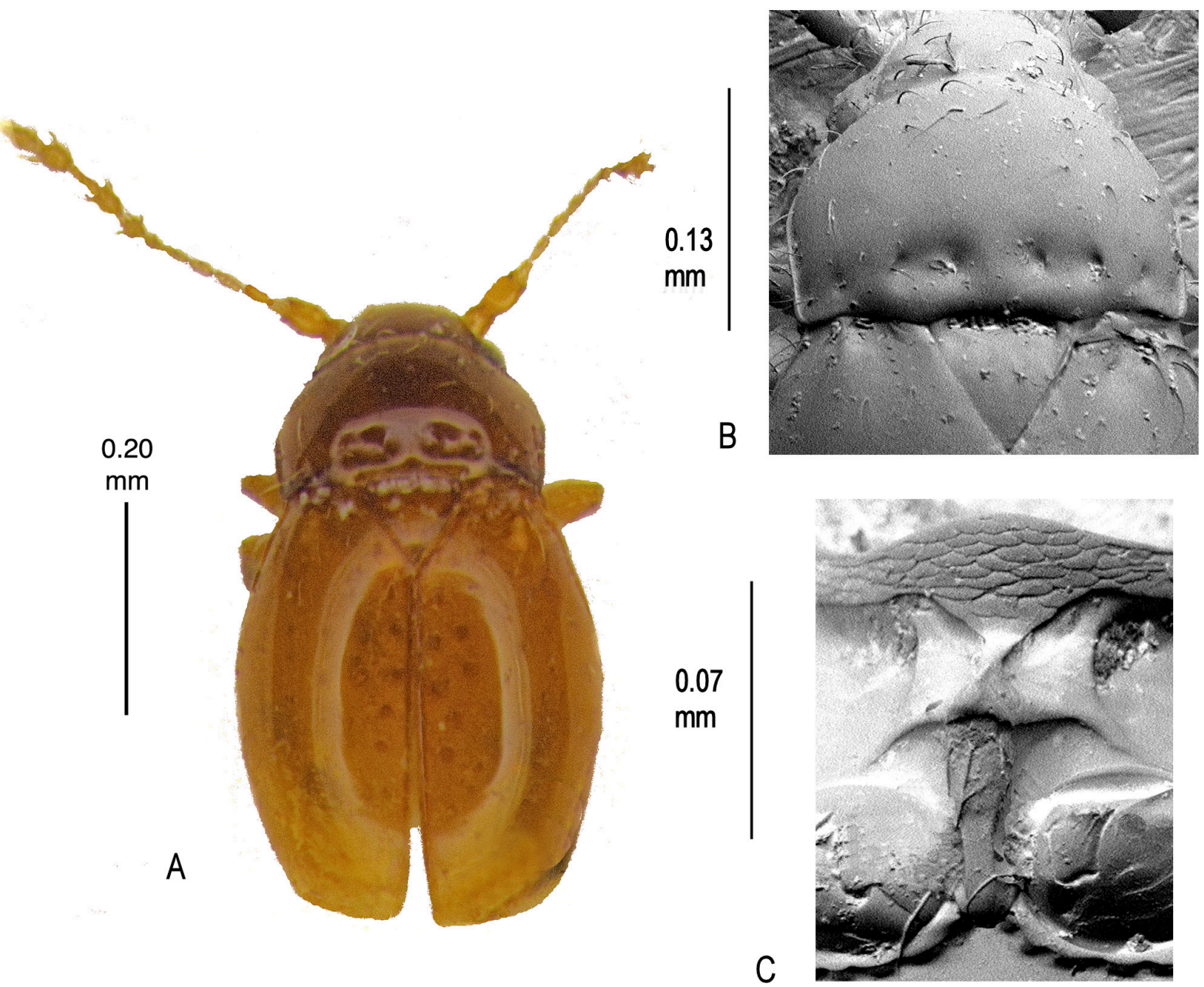

Fig. 40. Cissidium riparium sp. nov. A. Habitus. B. Pronotum, $\times 615$. C. Mesoventrite showing median process of collar, mid-keel and keel, $\times 1240$. 
Cissidium robustum $\mathrm{sp}$. nov.

urn:lsid:zoobank.org:act:8AB09488-EE5E-4F80-AAAE-71E8885D9187

Fig. 41

\section{Etymology}

Johnson ms name, from the Latin adjective 'robustus', meaning 'strong, robust' and probably referring to appearance of the species.

\section{Material examined}

\section{Holotype}

SOLOMON ISLANDS • ○’; Guadalcanal, Mt. Austen; 19 Jun. 1963; no. 6487; P. Greenslade leg.; BMNH.

\section{Description}

Size. Habitus (Fig. 41A), length $0.63 \mathrm{~mm}$.

CoLOuR. Dark yellow brown, pubescence, legs and antennae dusky yellow.

HEAD. With a shallow median depression between the eyes and a narrow linear ridge posterior to this, width across eyes $0.22 \mathrm{~mm}$; antennomeres III-XI, $0.38 \mathrm{~mm}$; mentum obscured.
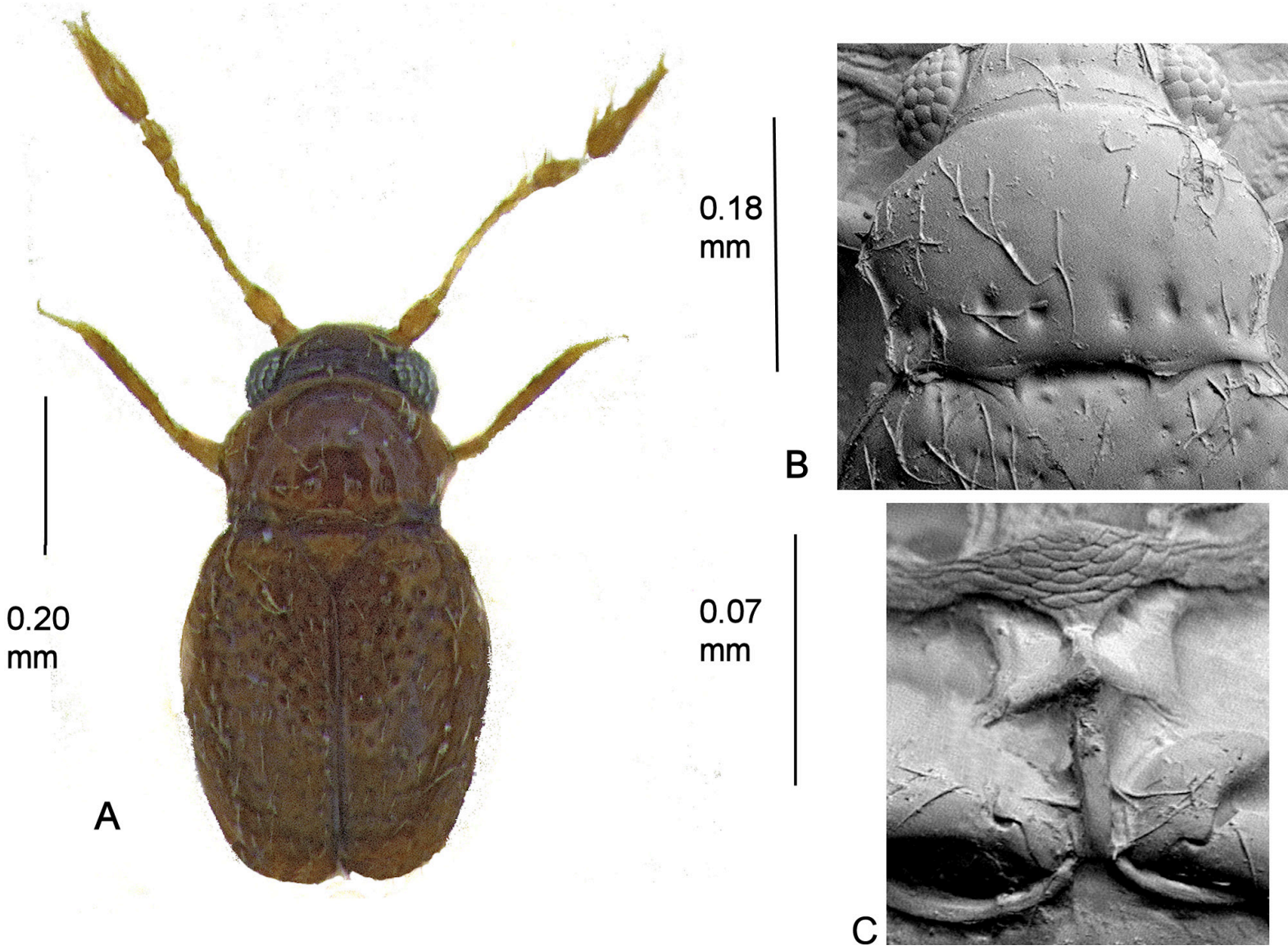

Fig. 41. Cissidium robustum sp. nov. A. Habitus. B. Pronotum, $\times$ 470. C. Mesoventrite showing median process of collar, mid-keel and keel, $\times 620$. 
Pronotum. Length $0.18 \mathrm{~mm}$, width $0.28 \mathrm{~mm}$, base with a series of four foveae on each side with slightly wider separation opposite the scutellum, the two inner pairs larger than the outer pair, surface sparsely pubescent without foveolae; sides angulate, convexly narrowed to effaced front angles, concavely narrowed to slightly acute hind angles, sides bordered, the borders not continuing along the posterior margin though there are two short, shallow impressed lines on each side of the median emargination opposite the scutellum (Fig. 41B).

ELYTRA. $0.36 \mathrm{~mm}$ wide, $0.40 \mathrm{~mm}$ long, basal half somewhat closely covered with rather large foveolae contrasting with the pronotum.

Mesoventrite. Medial extension of collar very widely based, sharply tapering to raised portion of mid-keel; mid-keel wide, sides concave, the hind angles effaced before mesocoxae; keel with \pm five setae in basal half tapering to almost parallel-sided, with a rounded termination at base of mesocoxae; mesoventral lateral margins serrate in posterior half (Fig. 41C).

MetaVentrite. Length $0.15 \mathrm{~mm}$, sparsely pubescent, disc simple, distance across spines $0.11 \mathrm{~mm}$.

WINGs. Macropterous.

Genitalia. Male aedeagus as Fig. 6Fa-b, but slightly longer. Females unknown.

\section{Remarks}

Distinguished from other Solomon Islands species in this group by the wider mid-keel.

Cissidium rogeri $\mathrm{sp}$. nov. urn:1sid:zoobank.org:act:F2BA9299-E1DB-4804-957D-DE575C7A7AB3

Fig. 42

\section{Etymology}

I am pleased to name this species after my brother-in-law Roger Allen.

\section{Material examined}

\section{Holotype}

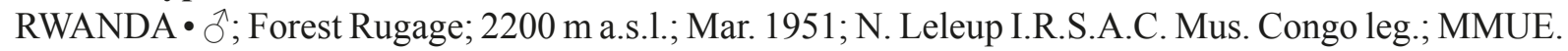

\section{Paratypes}

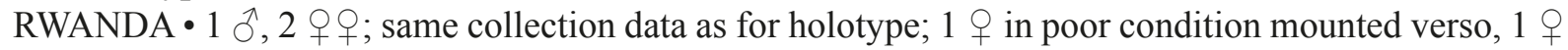
missing antennae; MMUE, BMNH.

\section{Description}

Size. Habitus (Fig. 42A), length $0.90 \mathrm{~mm}$.

CoLour. Yellow brown, head darker, pubescence, legs and antennae dusky yellow.

HeAD. Width across eyes $0.24 \mathrm{~mm}$; antennomeres III-XI, length $0.44 \mathrm{~mm}$, III-IX length $0.25 \mathrm{~mm}, \mathrm{X}-\mathrm{XI}$ length $0.19 \mathrm{~mm}$.

Pronotum. Length $0.25 \mathrm{~mm}$, width $0.32 \mathrm{~mm}$, base with series of four foveae on each side, two series slightly separated opposite scutellum, all the foveae of approximately equal size, surface sparsely pubescent without foveolae; sides rounded, concavely narrowed to slightly acute hind angles; sides 
bordered, the borders continuing along the entire basal margin, without a median emargination opposite the scutellum (Fig. 42B).

ELYTRA. $0.56 \mathrm{~mm}$ long, $0.50 \mathrm{~mm}$ wide, without foveolae.

MESOVENTRITE. With prominent reticulation; medial extension of collar widely based, sharply tapering to mid-point of mid-keel; mid-keel widest anteriorly then sides almost straight to angular hind angles, raised medially to sharp point before the keel; keel with \pm three setae, tapering to narrow parallel-sided termination close to base of mesocoxae; mesoventral lateral margins serrate in posterior half (Fig. 42C).

MetaVentrite. Length $0.15 \mathrm{~mm}$, sparsely pubescent, almost glabrous, disc simple, distance across spines $0.13 \mathrm{~mm}$; posterior margins of mesoventral coxal borders serrate.

WINGS. Macropterous.

Genitalia. Aedeagus as Fig. 6Fa-b.

\section{Remarks}

The only species of Cissidium to have been described from Rwanda.
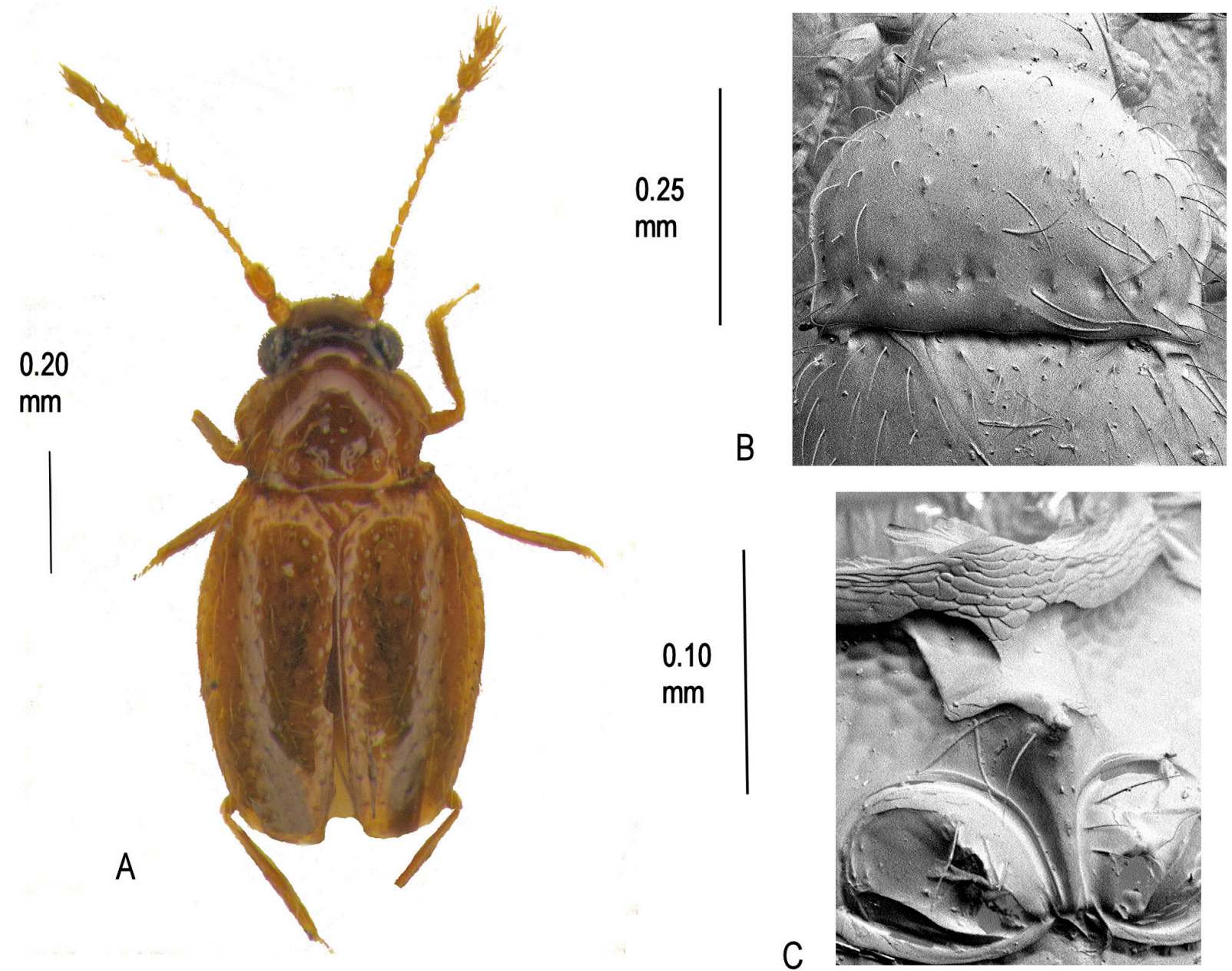

Fig. 42. Cissidium rogeri sp. nov. A. Habitus. B. Pronotum, $\times$ 610. C. Mesoventrite showing median process of collar, mid-keel and keel, $\times 1000$. 
Cissidium scutellaris (Deane, 1931)

Figs 5C, 43

\section{Etymology}

Derivation unclear.

\section{Material examined}

\section{Holotype}

AUSTRALIA • đ̇; Queensland, Caves Track, Sinna Burra, Lamington Nat. Park; 4 May 1966; leaf litter; R.A. Crowson leg.; MMUE.

\section{Paratypes}

AUSTRALIA • 2 우; same collection data as for holotype; MMUE $\bullet 2$ ex.; Queensland, Picnic Rock Trail, O'Reilly's, Lamington Nat. Park; 3 Sep. 1966; fungus bark sample; R.A. Crowson leg.; MMUE - 2 우; Queensland, Maiala Nat. Park, Mt. Glorious, Brisbane; 4 Aug. 1966; mixed leaf litter; R.A. Crowson leg.; BMNH.
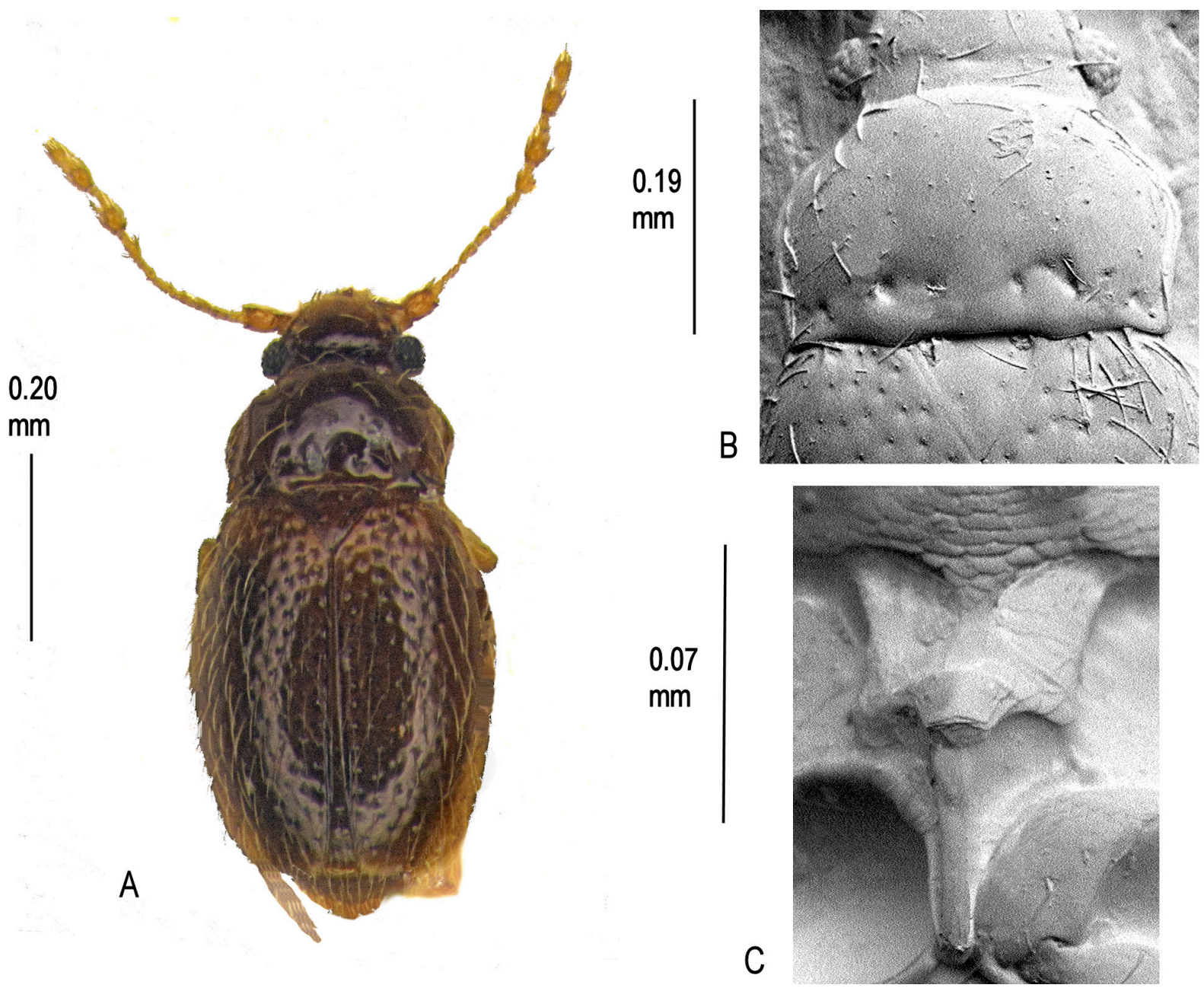

Fig. 43. Cissidium scutellare (Deane, 1931). A. Habitus. B. Pronotum, $\times 655$. C. Mesoventrite showing median process of collar, mid-keel and keel, $\times 1480$. 


\section{Description}

Size. Habitus (Fig. 43A), length $0.67 \mathrm{~mm}$.

Colour. Yellow brown, head darker, pubescence, legs and antennae dusky yellow.

HEAD. With a shallow medial depression between eyes, width across eyes $0.22 \mathrm{~mm}$; mentum with rounded anterior angles; antennomeres III-XI, length $0.37 \mathrm{~mm}$, III-IX length $0.21 \mathrm{~mm}, \mathrm{X}-\mathrm{XI}$ length $0.16 \mathrm{~mm}$.

Pronotum. Length $0.19 \mathrm{~mm}$ long, width $0.30 \mathrm{~mm}$, base with series of four foveae on each side the innermost pair being smaller, the pair opposite the scutellary angles being larger than the others, surface sparsely pubescent without foveolae; sides rounded, becoming almost parallel to rectangular hind angles, bordered, the border not continuing along the posterior margin, median emargination opposite scutellum sinuate (Fig. 43B).

ELYTRA. $0.49 \mathrm{~mm}$ long, $0.40 \mathrm{~mm}$ wide, pubescent and foveolate contrasting with the pronotum.

Mesoventrite. Medial extension of collar widely based tapering to mid-point of mid-keel; mid-keel widest anteriorly then sides concave to narrower hind angles, sharply raised medially with a domed top before the keel; keel without setae, narrow parallel-sided to blunt termination close to base of mesocoxae (Fig. 5C); mesoventral lateral margins evenly rounded, without serrations; humeri toothed (Fig. 43C).

MetaVentRIte. Length $0.16 \mathrm{~mm}$, sparsely pubescent, almost glabrous, disc simple, distance across spines $0.12 \mathrm{~mm}$.

WINGs. Macropterous.

Genitalia. Male aedeagus as Fig. 6Ia-b. Female spermatheca globular.

\section{Remarks}

See remarks under $C$. deanei sp. nov. The broad median extension of the mesoventral collar coupled with the parallel-sided keel lacking setae distinguish this species.

Cissidium subfoveolatum Darby, 2019

Fig. 44

\section{Material examined}

\section{Holotype}

MALAYSIA - 3 ; Sarawak, $4^{\text {th }}$ division, on Mulu NP; May-Aug. 1978; comp 5 alluvial forest litter; P.M. Hammond and J.E. Marshall leg.; BM 1978-49; mounted ventral side uppermost; BMNH.

\section{Supplementary description}

The following description amplifies the description of Darby (2019) in particular by adding more details of the meso- and metaventral characters, in order to conform with the present paper.

SizE. Habitus (Fig. 44A), length $0.59 \mathrm{~mm}$.

CoLour. Dark brown, antennae, legs and pubescence yellow. 
HEAD. Distance across eyes $0.23 \mathrm{~mm}$; antennomeres III-XI, length $0.39 \mathrm{~mm}$; mentum and submentum as Fig. 4C.

Pronotum. Length $0.22 \mathrm{~mm}$, width $0.32 \mathrm{~mm}$, sparsely pubescent, with a row of eight foveae along the posterior margin, the four medial ones tending to form two large ones, the outer two smaller; lateral margins rounded, concave before the acute hind angles, rounded anteriorly, bordered, the border not continuing along the posterior margin, medial emargination in front of scutellum sinuous (Fig. 44B).

ELYTRA. Length $0.49 \mathrm{~mm}$, width $0.55 \mathrm{~mm}$, pubescent, shallowly foveolate, contrasting with the pronotum.

MeSOVENTRITE. Medial process of collar broad, tapering, almost meeting raised portion of mid-keel; mid keel broad, sides parallel, hind angles with carinae to anterior margins of mesocoxal borders; keel broad, parallel-sided, with \pm four setae, terminated at interruption of mesocoxal margins; mesoventral lateral margins serrate in posterior half; humeri sharply toothed (Fig. 44C).

Metaventrite. Length $0.19 \mathrm{~mm}$, sparsely pubescent, disc simple, width across spines $0.15 \mathrm{~mm}$, spines short.

Genitalia. Not dissected.

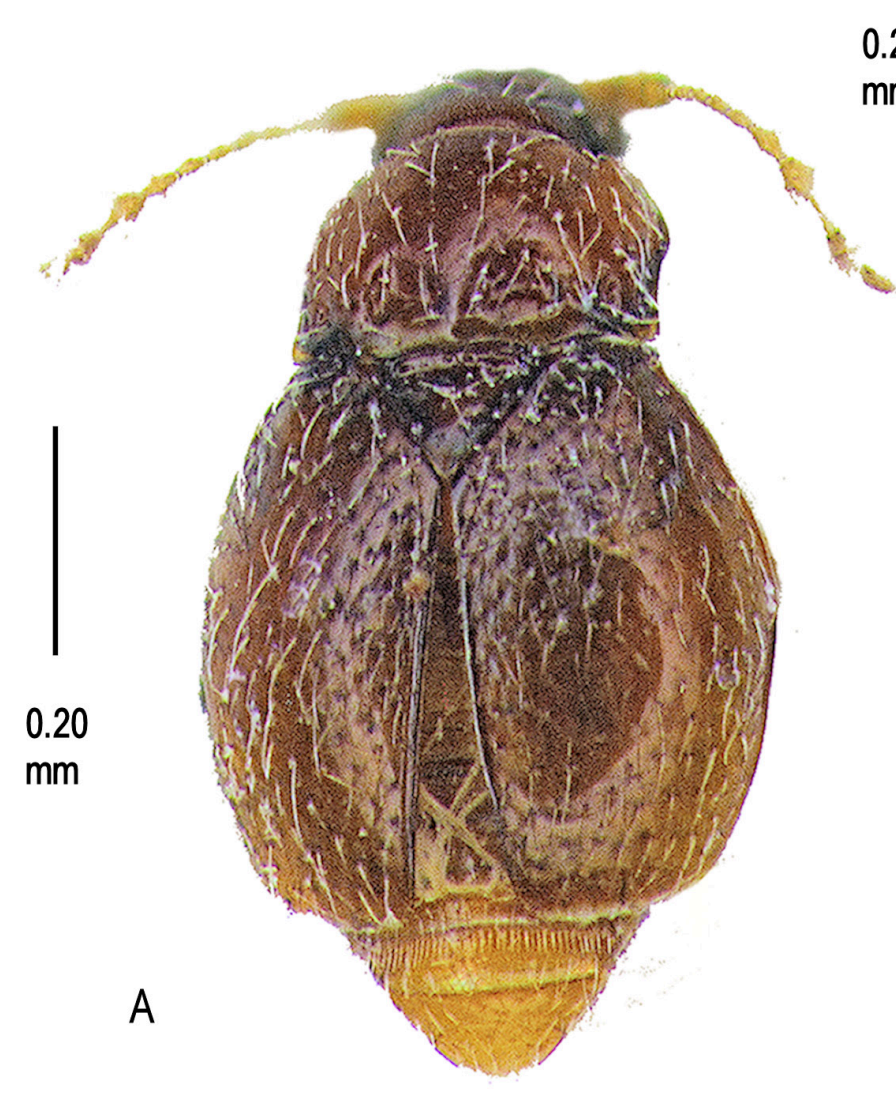

.22

$\mathrm{mm}$

B
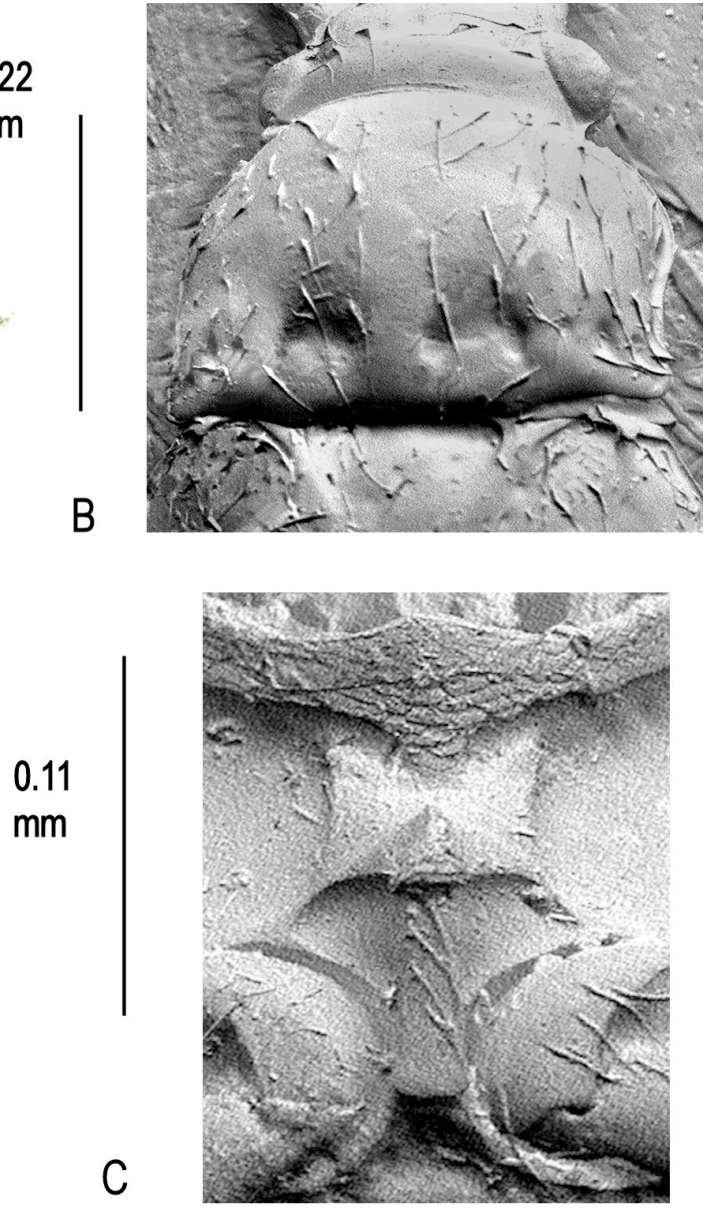

Fig. 44. Cissidium subfoveolatum Darby, 2019. A. Habitus. B. Pronotum, $\times$ 485. C. Mesoventrite showing median process of collar, mid-keel and keel, $\times 455$. 


\section{Remarks}

This is the only species of Cissidium from Sarawak in this group.

Cissidium yoruba sp. nov.

urn:1sid:zoobank.org:act:473BE444-6BC1-42BC-B5A8-CE1EDC4C77E4

Fig. 45

\section{Etymology}

Named after Yoruba, the West African language. Ile-Ife, known as Ife, in Osun State, Nigeria is believed to be the oldest Yoruba speaking city. Noun in apposition.

\section{Material examined}

\section{Holotype}

NIGERIA • ○’; Ile-Ife; 29 Dec. 1970; black light trap; J.T. Medlar leg.; MMUE.

\section{Paratypes}

NIGERIA $\bullet 2$ + $\odot$; same collection data as for holotype; one mounted verso; MMUE, BMNH.
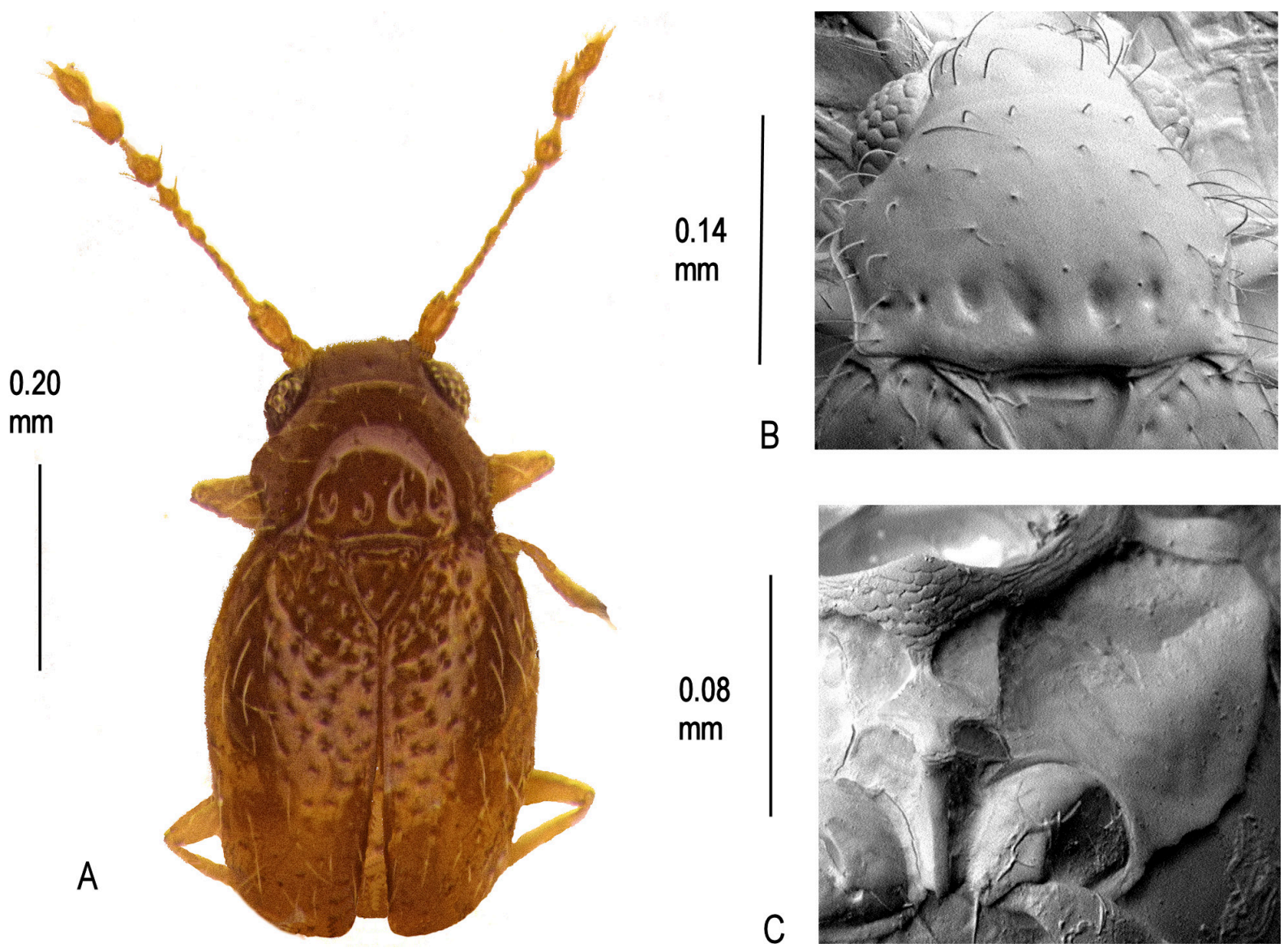

Fig. 45. Cissidium yoruba sp. nov. A. Habitus. B. Pronotum, $\times$ 640. C. Mesoventrite showing median process of collar, mid-keel, keel and lateral margin, $\times 1040$. 


\section{Description}

Size. Habitus (Fig. 45A), length $0.59 \mathrm{~mm}$.

CoLour. Dark brown, shining, antennae, legs and pubescence dusky yellow.

HEAD. With a shallow median depression between the eyes, width across eyes $0.21 \mathrm{~mm}$;. antennomeres III-XI length $0.30 \mathrm{~mm}$, III-IX length $0.16 \mathrm{~mm}, \mathrm{X}-\mathrm{XI}$ length $0.14 \mathrm{~mm}$; mentum obscure.

Pronotum. Length $0.15 \mathrm{~mm}$, width $0.24 \mathrm{~mm}$, sparsely pubescent, without foveolae but with a row of \pm four foveae along the posterior margin; sides sharply rounded not quite angled, then slightly concave to the rectangular hind angles, lateral borders wide, continued more thinly for a short distance along basal margin to the emargination in front of the scutellum (Fig 45B, tilted forwards)

ELYTRA. Length $0.42 \mathrm{~mm}$, width $0.33 \mathrm{~mm}$, foveolate, densest in basal half, pubescence sparse.

MesoventRITE. Collar with a tapering median extension widening posteriorly; mid-keel parallel-sided, the posterior angles with short raised carinae to the mesocoxal anterior borders; keel without setae, narrow, slightly tapering to a point near base of mesocoxae; mesoventral lateral margins rounded, serrate posteriorly; humeri large, bluntly toothed (Fig. 45C).

MetaVentrite. Length $0.15 \mathrm{~mm}$, sparsely pubescent, disc simple, width across spines $0.11 \mathrm{~mm}$; margins of mesocoxal cavities serrate.

WINGs. Macropterous.

Genitalia. Male aedeagus not found in the dissection. Female spermatheca globular.

\section{Remarks}

The only species of Cissidium to have been described from Nigeria.

\section{Species group 3: pronotum with distinct foveolae but without foveae}

\section{Key to species in species group 3}

1. Pronotum with two linear depressions composed of united foveolae (note: C. longum Darby, 2019 shows traces on one side of the pronotum of a short depression but is not treated in this section of the key, see below)...

- Pronotum without linear depressions.

2. Posterior corners of mid-keel rounded (Fig. 48C)....

C. dewhurst sp. nov.

- Posterior corners of mid-keel with projecting angles

3. Lateral margins of pronotum rounded

- Lateral margins of pronotum angulate.

4. Larger more rounded species

C. globulum Darby, 2019

- Smaller, narrower species C. murphyi sp. nov.

5. Mesoventral mid-keel elongate (Fig. 56C) C. mindanao sp. nov.

- Mesoventral mid-keel square (Fig. 55C) ..... C. marshallae Darby, 2019

6. Pronotal disc with only a trace of foveolae C. amazonicum sp. nov.

- Pronotal foveolae covering the disc 


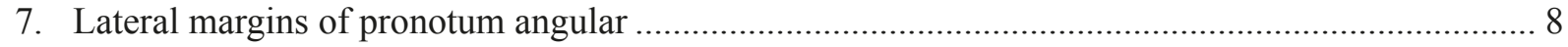

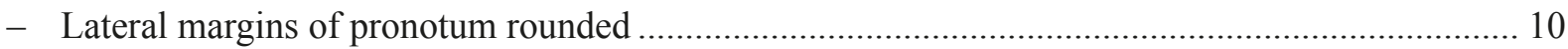

8. Mesoventral lateral margins rectangular, hind angles acute......................... C. longum Darby, 2019

- Mesoventral lateral margins not rectangular

9. Mid-keel very narrow at junction with collar.

- Mid-keel wide at junction with collar. C. puncticolle sp. nov.

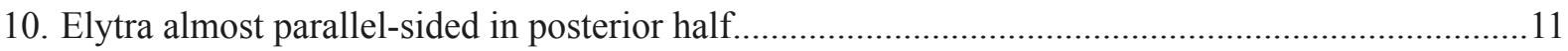

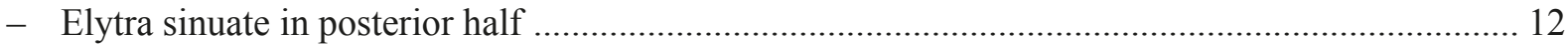

11. Pronotum densely and finely foveolate (Fig. 54B) .............................................. mahleri sp. nov.

- Pronotum sparsely and more coarsely foveolate ................................................... werneri sp. nov.

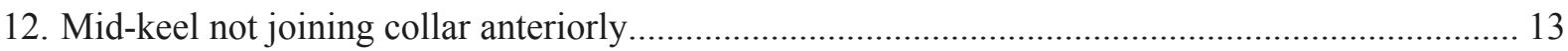

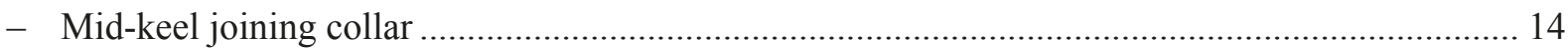

13. Smaller species length $0.6-0.7 \mathrm{~mm}$, elytra shorter in proportion to pronotum .. C. itoi Sawada, 2008

- Larger species length $0.8 \mathrm{~mm}$, elytra longer in proportion to pronotum .........C. latum Sawada, 2008

14. Mid-keel almost parallel-sided, hind angles rounded......................................... pilosellum sp. nov.

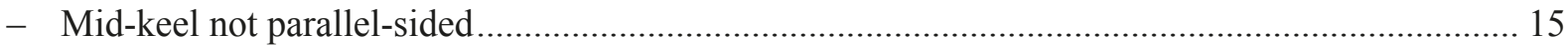

15. Mid keel tapering from wide base by collar to keel.................................. C. nomurai Sawada, 2008

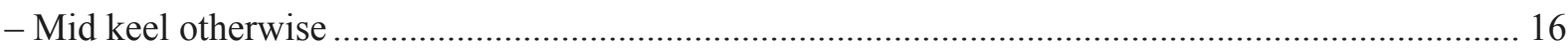

16. Mid keel with projecting hind angles ........................................................ pauxillum Darby, 2019

- Mid keel reduced to small fragments either side of medial extension of the collar.....

C. ikeuchii Sawada, 2008

Cissidium amazonicum sp. nov. urn:1sid:zoobank.org:act:D685D95C-622F-4042-875B-F74E26A8DB42

Fig. 46

\section{Etymology}

Named after the region in which the specimens were found.

\section{Material examined}

\section{Holotype}

BRAZIL • P; surroundings of Manaus, Amazonas; L. Beck leg.; MMUE.

\section{Additional material}

A second teneral specimen with the same collection details in MMUE may be this species.

\section{Description}

Size. Habitus (Fig. 46A), length $0.73 \mathrm{~mm}$.

CoLour. Dark red brown, antennae and legs dusky yellow. 
HEAD. With a linear depression behind the eyes effaced medially, distance across eyes $0.27 \mathrm{~mm}$; antennomeres III-X1, length $0.39 \mathrm{~mm}$, IV-IX $0.21 \mathrm{~mm}, \mathrm{X}-\mathrm{XI} 0.16 \mathrm{~mm}$; mentum and submentum obscured.

Pronotum. Length $0.22 \mathrm{~mm}$, width $0.39 \mathrm{~mm}$, distinctly foveolate but foveolae absent medially; lateral margins bordered and sharply angled, posterior margin bordered including emargination opposite scutellum, hind angles rectangular (Fig. 46B).

ELYTRA. Length $0.57 \mathrm{~mm}$, width $0.51 \mathrm{~mm}$. pubescent and more shallowly foveolate than pronotum.

MESOVEnTRITE. Medial extension of collar parallel-sided extending almost to middle of the mid-keel; midkeel widest anteriorly tapering strongly to junction with keel; keel setose, tapering to a blunt termination between mesocoxae; mesoventral lateral margins without serrations, sharply angulate; humeri bluntly toothed (Fig. 46C).

Metaventrite. With scattered pubescence medially, disc simple, length $0.17 \mathrm{~mm}$, distance between spines $0.14 \mathrm{~mm}$.

WiNGS. Macropterous.

Genitalia. The female spermatheca was not detected in the dissection.
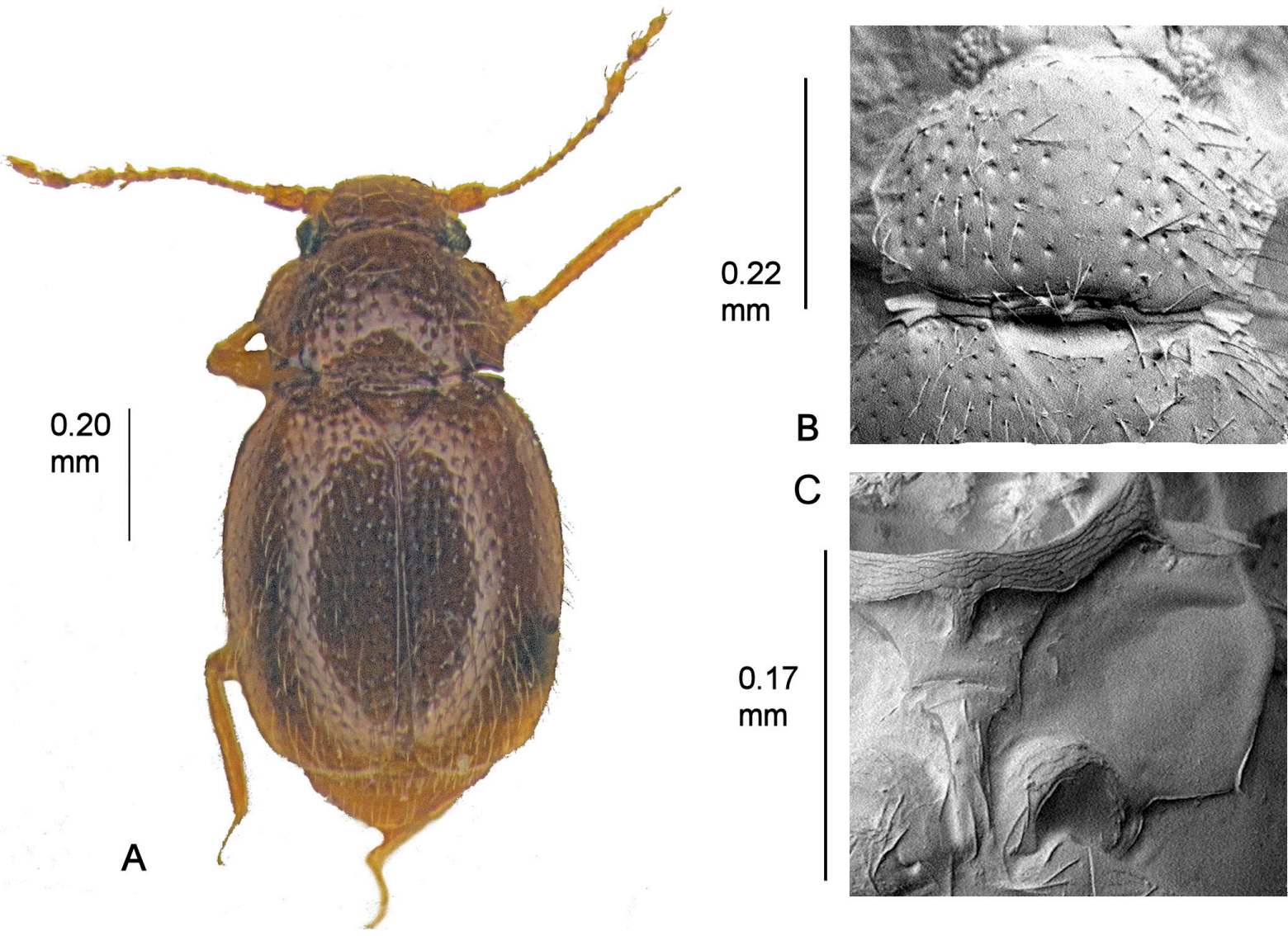

Fig. 46. Cissidium amazonicum sp. nov. A. Habitus. B. Pronotum, $\times 365$. C. Mesoventrite showing median process of collar, mid-keel, keel and lateral margin, $\times 480$. 


\section{Remarks}

The only species from Brazil in this group.

\section{Cissidium amboroense Darby 2015}

Figs $4 \mathrm{C}, 6 \mathrm{~B}, 7 \mathrm{G}, 47$

\section{Material examined}

\section{Holotype}

BOLIVIA - ; Santa Cruz dep., W. Amboro NP, Siberia Pass env.; 2450 m a.s.l.; 28 Nov. 2013; $17^{\circ} 50^{\prime} 12^{\prime \prime}$ S, 64ㄴ2'08" E; sifting litter; Winkler app. extr.; P. Baňař leg.; UASC.

\section{Paratypes}

BOLIVIA $・ 2$ 우, 1 ; same collection data as for holotype; MMBC/BMNH 11 ex.; "GPS 31, BOL/ Nov 2013/08; BOLIVIA 2013 Santa Cruz dep.", W. Amboro NP, Siberia Pass env.; 1750'25" S, 644ㄴ'58" E; 2481 m a.s.1.; sifting litter; Winkler app. extr.; P. Baňar̆ leg.; BMNH.

\section{Supplementary description}

The following description amplifies the type description of Darby (2015), in particular by adding more details of the meso- and metaventral characters, in order to conform with the present paper.
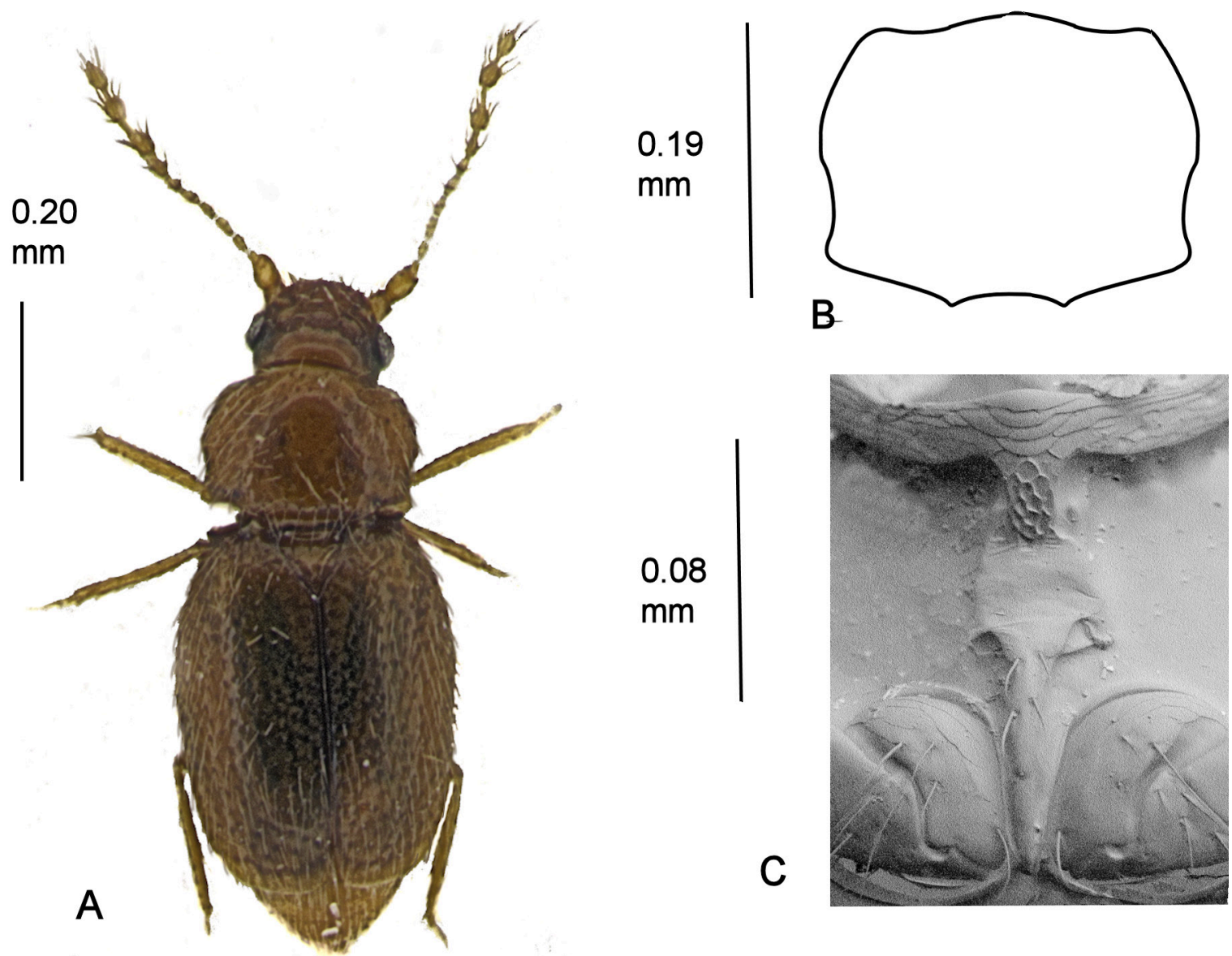

Fig. 47. Cissidium amboroense Darby, 2015. A. Habitus. B. Pronotum. C. Mesoventrite showing median process of collar, mid-keel and keel, $\times 1220$. 
Size. Habitus (Fig. 47A), length $0.78 \mathrm{~mm}$.

CoLour. Dusky yellow, legs and antennae a little paler.

HEAD. Antennomeres III-XI length $0.38 \mathrm{~mm}$, III-IX length $0.19 \mathrm{~mm}, \mathrm{X}-\mathrm{XI}$ length $0.19 \mathrm{~mm}$; width across eyes $0.21 \mathrm{~mm}$; mentum and submentum (Fig. 4C).

Pronotum. Length $0.31 \mathrm{~mm}$, width, $0.20 \mathrm{~mm}$, shining, pubescent; lateral margins slightly angled medially, concave to rectangular hind angles, bordered, the border continuing along the posterior margin, medial emargination before scutellum sinuous. (Fig. 47B).

ELYTRA. $0.47 \mathrm{~mm}$ long, $0.38 \mathrm{~mm}$ wide.

Mesoventrite. Medial extension of collar, broad, parallel-sided; mid-keel widest posteriorly, hind angles not reaching mesocoxal borders; keel long, with 4 setae, tapering narrowly to point at the base of the mesocoxae; mesoventral lateral margins evenly rounded without serrations; humeri toothed, posterior margin sloping strongly posteriad (Fig. 47C).

Metaventrite. Pubescent, length $1.10 \mathrm{~mm}$, width across spines $0.85 \mathrm{~mm}$, disc simple.

GenitaLia. Female spermatheca globular (Fig. 6B). Male aedeagus pointed, not so beak-shaped as many species and with 15 short, thick, blunt setae on ventrite VIII (Fig. 7G).

\title{
Remarks
}

The form of antennomere XI with a short median interruption and the sinuate posterior margin of the pronotum before the hind angles distinguish this species from the other Bolivian Cissidium.

\author{
Cissidium dewhurst sp. nov. \\ urn:lsid:zoobank.org:act:A543DF10-FBBF-4AAE-878A-C53CAEA25316 \\ Fig. 48
}

\section{Etymology}

Named after the place of capture, noun in apposition.

\section{Material examined}

\section{Holotype}

MALAYSIA - O; Sabah, Kinabatangan district, SE end of Dewhurst Bay; 2 Jun.1950; air sweep in primary forest; R.F. Inger and D.D.Davis leg.; FM(HD) \#50.33; FMNH. Specimen found damaged, part of the remaining antenna was lost in the SEM.

\section{Description}

Size. Habitus (Fig. 48A), length $0.71 \mathrm{~mm}$.

CoLour. Dark brown, pubescence, antennae and legs paler.

HEAD. Frons obscured; eyes very prominent, width across $0.23 \mathrm{~mm}$; antennomeres III-XI length $0.34 \mathrm{~mm}$, III-IX length $0.18 \mathrm{~mm}, \mathrm{X}-\mathrm{XI}$ length $0.16 \mathrm{~mm}$; mentum obscured.

Pronotum. Length $0.21 \mathrm{~mm}$, width $0.30 \mathrm{~mm}$, pubescent, setae confined mainly to lateral margins, with a pair of linear foveae at base; lateral margins rounded, slightly angled, hind angles rectangular, widely 
bordered, border extending narrowly onto the posterior margin which has a sinuous emargination in in front of the scutellum (Fig. 48B).

ElYTRA. Length $0.43 \mathrm{~mm}$, width $0.42 \mathrm{~mm}$, pubescent, setae same length as pronotum, without foveolae.

Mesoventrite. Medial extension of collar broad; mid-keel lateral margins almost parallel, posterior corners not joining mesocoxal borders, barely raised at junction with keel; keel foveolate throughout (perhaps indicating presence of setae which have been abraded) tapering to blunt termination between the mesocoxae; mesoventral lateral margins shallowly serrate in posterior third; humeri toothed (Fig. 48C).

Metaventrite. Sparsely pubescent, with shallow medial depression, posterior margins of mesocoxal cavities not serrate.

Wings. Macropterous.

Genitalia. Male aedeagus as Fig. 6L. Female not known.

\section{Remarks}

The only species of Cissidium to have been described from Sabah.
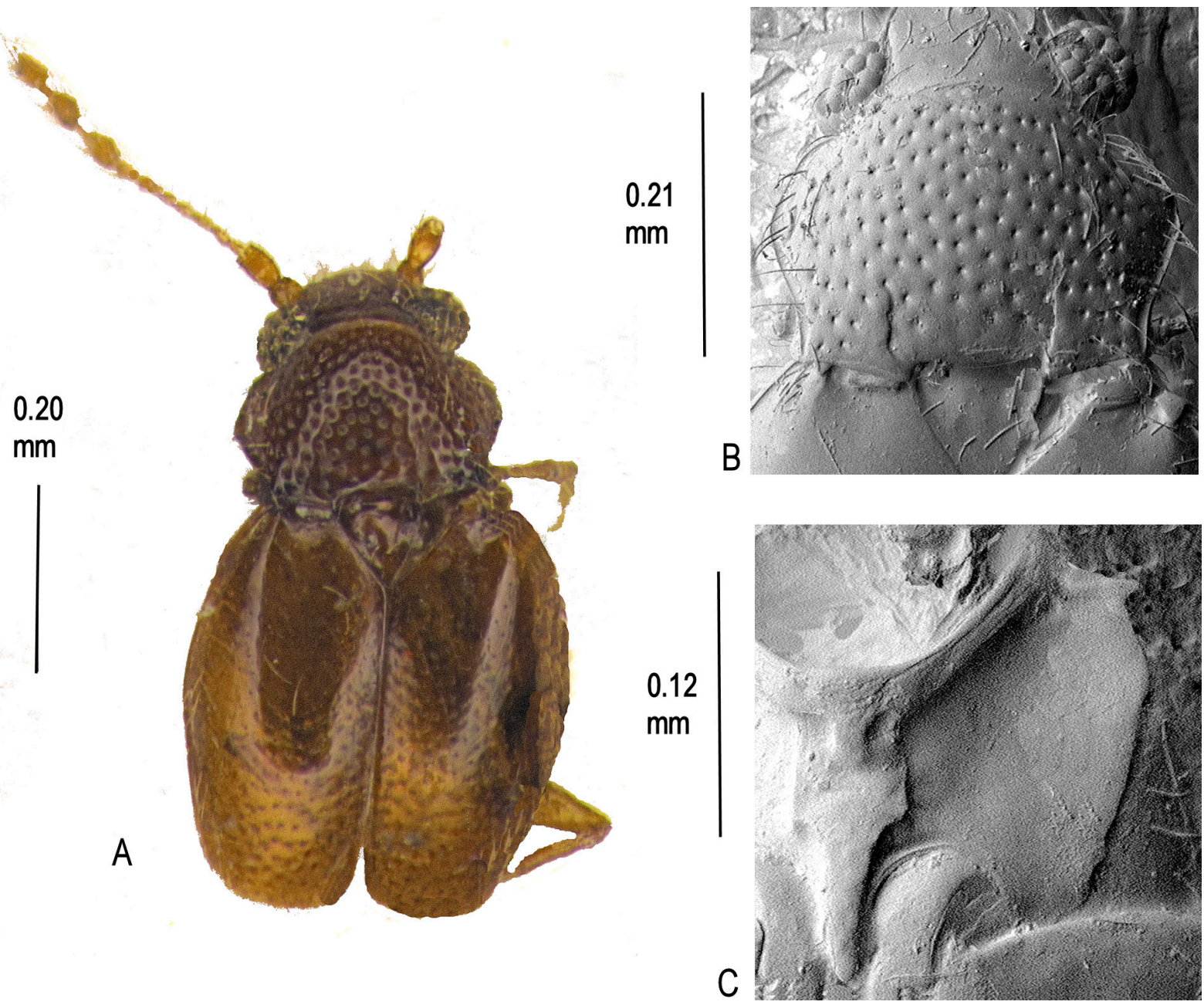

Fig. 48. Cissidium dewhurst sp. nov. A. Habitus. B. Pronotum, $\times 530$. C. Mesoventrite showing median process of collar, mid-keel, keel and lateral margin, $\times 565$. 
Cissidium globulum Darby, 2019

Fig. 49

\section{Material examined}

\section{Holotype}

MALAYSIA -9 ; Sarawak, $4^{\text {th }}$ division, on Mulu NP; May-Aug. 1978; alluvial forest litter near lab; P.M. Hammond and J.E. Marshall leg.; BM 1978-49; BMNH.

\section{Paratypes}

MALAYSIA -1 ex., same collection data as for holotype; BMNH 11 ex.; Sarawak, on Mulu NP, limestone forest; $200 \mathrm{~m}$ a.s.1.; 1978; pitfalls; N.M. Collins leg.; BMNH -3 ex., Sarawak, $4^{\text {th }}$ division, on Mulu NP; May-Aug. 1978; limestone forest litter; P.M. Hammond and J.E. Marshall leg.; BM197849; BMNH; two of the three missing one elytron - 2 ex.; Sarawak, Mulu, limestone forest; $200 \mathrm{~m}$ a.s.1.; 1978; pitfalls; N.M.Collins leg.; BMNH • 1 ex.; Sarawak, $4^{\text {th }}$ division, on Mulu NP; May-Aug. 1978; base litter on hill[?]; P.M. Hammond and J.E. Marshall leg.; BM1978-49; BMNH 1 ex.; Sarawak, $4^{\text {th }}$ division, on Mulu NP; May-Aug. 1978; comp. 5 alluvial forest litter; P.M. Hammond and J.E. Marshall leg.; BM1978-49; BMNH.

\section{Supplementary description}

The following description amplifies the type description of Darby (2019), in particular by adding more details of the meso- and metaventral characters, in order to conform with the entries in the present paper.
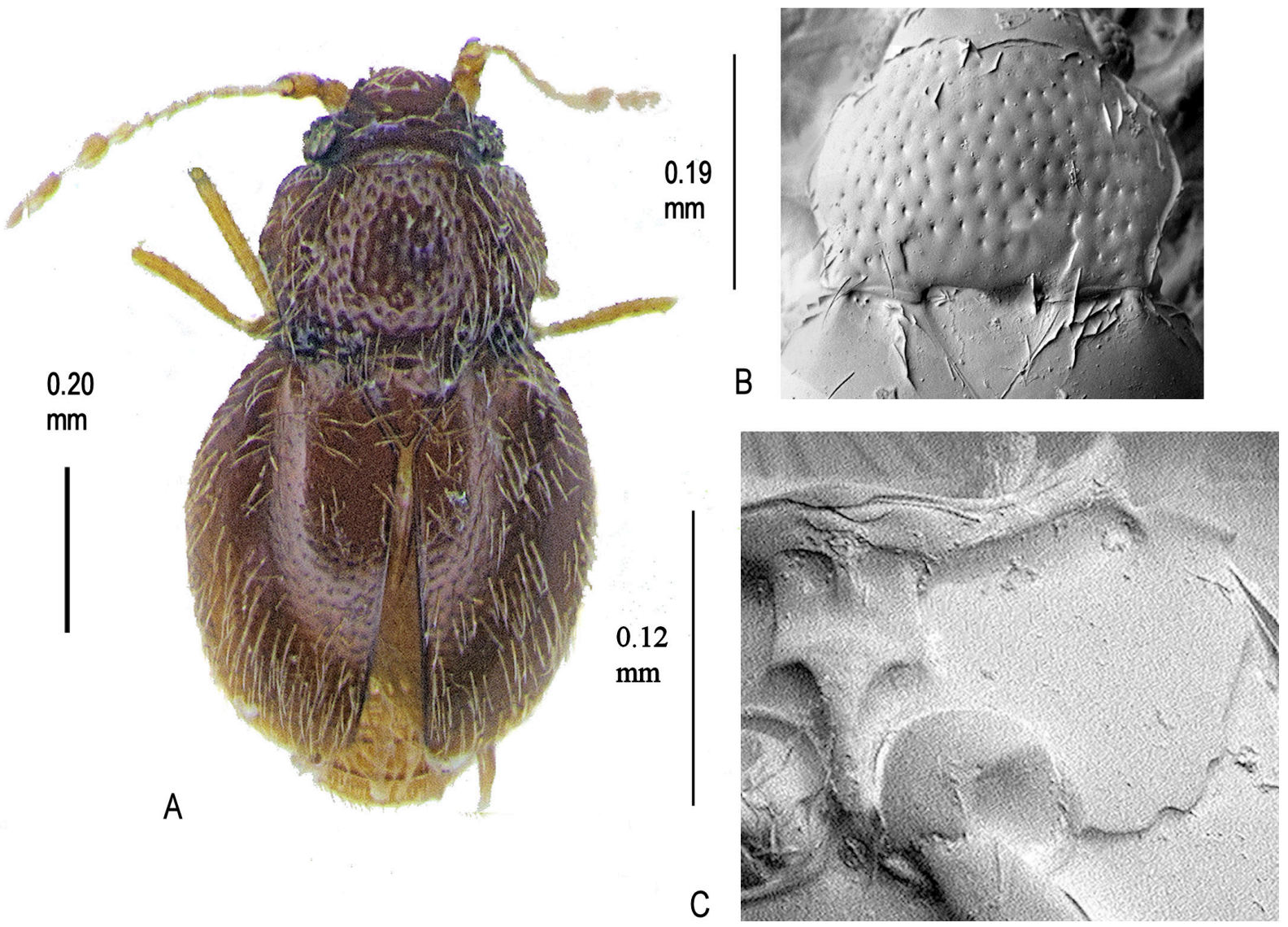

Fig. 49. Cissidium globulum Darby, 2019. A. Habitus. B. Pronotum, $\times 450$. C. Mesoventrite showing median process of collar, mid-keel, keel and lateral margin, $\times 470$. 
Size. Habitus (Fig. 49A), length $0.61 \mathrm{~mm}$.

Colour. Pronotum and head almost black, elytra dark brown, shining, pubescence, antennae and legs yellow.

HEAD. With a row of indistinctly formed foveolae on a level with the top of the eyes; antennomeres III-XI, length $0.25 \mathrm{~mm}$; mentum and submentum with \pm circular foveolae (not always clearly defined) as Fig. 4A.

Pronotum. Length $0.19 \mathrm{~mm}$, width $0.29 \mathrm{~mm}$, foveolate throughout, two short carinae at the base very faint, apparently the result of the fusion of several foveolae; side margins angled medially, posterior margin with sinuous emargination in front of the scutellum (Fig. 49B).

ELYTRA. Length $0.43 \mathrm{~mm}$, width $0.40 \mathrm{~mm}$, smooth, evenly rounded, broadest at middle, pubescence as pronotum.

Mesoventrite. Collar with large medial patches without reticulation, medial extension narrow, sides slightly concave broadening posteriorly; mid-keel sides slightly concave, hind corners not reaching mesocoxal borders; keel tapering to parallel-sided between mesocoxae; mesoventral lateral margins serrate in posterior half; humeri sharply toothed (Fig. 49C).

Metaventrite. With scattered pubescence, length $0.18 \mathrm{~mm}$, disc simple, width across spines $0.12 \mathrm{~mm}$; mesocoxal posterior borders serrate.

\section{Remarks}

Only likely to be confused with $C$. marshallae in the other four Malaysian species in this group but lacking the pair of linear depressions at the pronotal base in that species

Cissidium ikeuchii Sawada, 2008

Fig. 50A-C

\section{Material examined}

Paratypes

JAPAN • 4 q ; ; Honsyu, Mt. Wasamatayama, Nara Pref.; 10 Aug. 1989; R. Ikeuchi and Y. Sawada leg.; YS.

\section{Supplementary description}

The following description amplifies the type description of Sawada (2008) to conform with the format of the entries in the present paper.

Size. Habitus (Fig. 50A), length $0.65 \mathrm{~mm}$.

Colour. Reddish brown to dark brown, antennae dusky yellow.

HEAD. With a row of indistinctly formed foveolae on a level with the back of the eyes; antennomeres III-XI, length $0.27 \mathrm{~mm}$.

Pronotum. Length $0.19 \mathrm{~mm}$, width $0.32 \mathrm{~mm}$, densely foveolate and pubescent throughout; side margins rounded, slightly concave before obtuse hind angles, with a shallowly crenulate border, hind margin without an emargination in front of the scutellum (Fig. 50B). 
ELYTRA. Length $0.42 \mathrm{~mm}$, width $0.37 \mathrm{~mm}$, pubescent but without foveolae; apex of male elytra strongly sinuate before suture and with two subconical raised areas.

Mesoventrite. Median extension of collar broadest anteriorly tapering only very slightly to mid-keel; mid-keel and keel united without extensions to the anterior mesocoxal borders, strongly setose and sculpted, terminating in a point between the mesocoxae; humeri toothed; mesoventral lateral borders smoothly rounded without serrations (Fig. 50C).

MetAVEnTRite. Sparsely pubescent, length $0.13 \mathrm{~mm}$, width across spines $0.11 \mathrm{~mm}$, disc simple; mesocoxal posterior borders without serrations

Genitalia. Female spermatheca globular. Male aedeagus as Fig. 6Fa-b.

\section{Remarks}

This is the smallest of the Japanese species and it is unique amongst the species described here in having strongly sinuate and subconical apices to the male elytra.
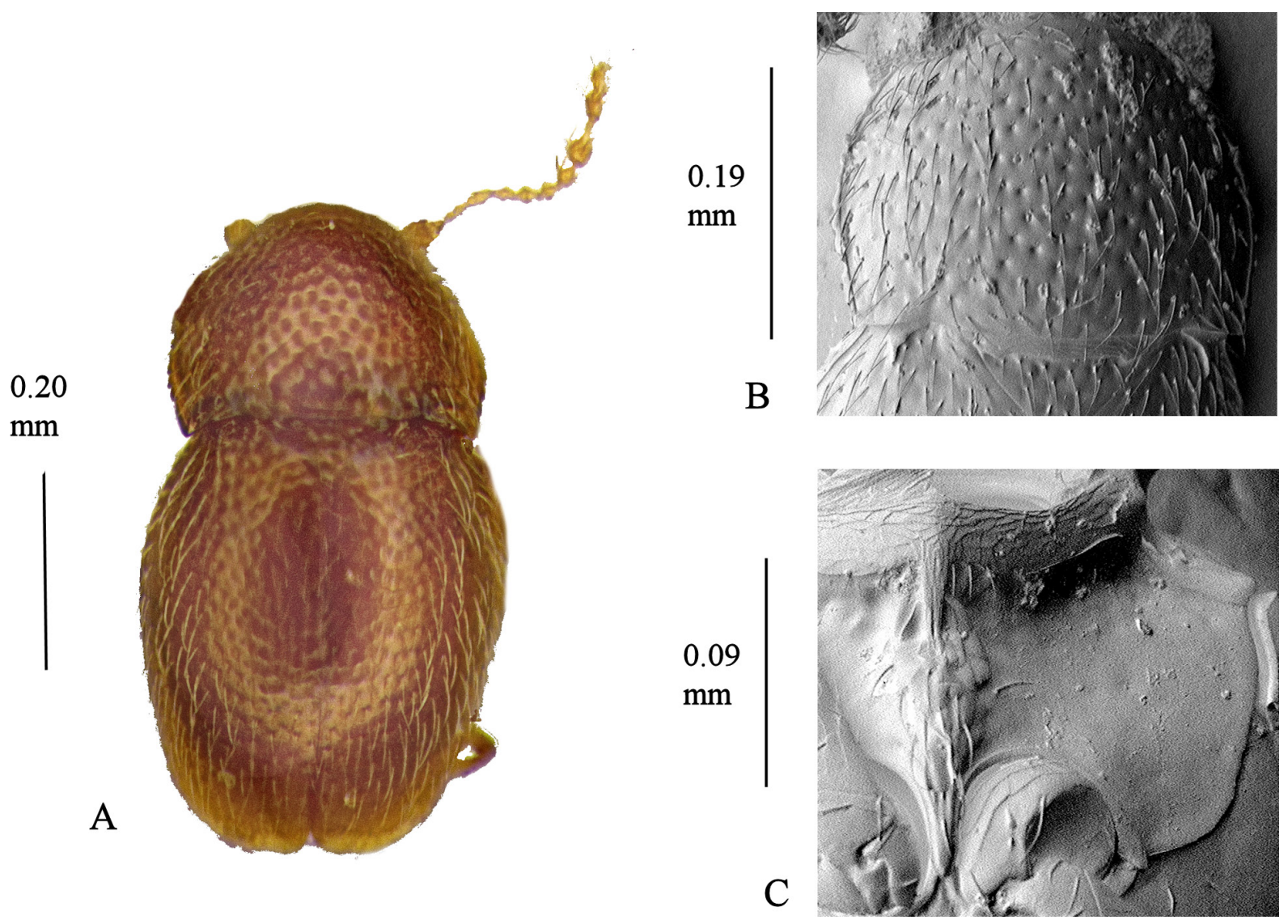

Fig. 50. Cissidium ikeuchii Sawada, 2008. A. Habitus. B. Pronotum, $\times 485$. C. Mesoventrite showing median process of collar, mid keel, keel and lateral margin, $\times 760$. 
Cissidium itoi Sawada, 2008

Fig. 51

\section{Material examined}

Paratypes

JAPAN • 17 ex.; Shikoku, Ashizuri, Cape Kohchi Pref.; 1-3 May 1997; T. Ito leg.; YS, BMNH.

\section{Supplementary description}

The following description amplifies the type description of Sawada (2008) to conform with the entries in the present paper.

Size. Habitus (Fig. 51A), length $0.66 \mathrm{~mm}$.

CoLour. Dark brown, antennae, legs and pubescence paler.

HEAD. With a row of indistinctly formed foveolae between the eyes; width across eyes $0.20 \mathrm{~mm}$; antennomeres III-XI, length $0.27 \mathrm{~mm}$, terminal antennomeres globular.

Pronotum. Length $0.21 \mathrm{~mm}$, width $0.29 \mathrm{~mm}$, densely foveolate and pubescent throughout; side margins rounded to slightly concave before acute hind angles, border shallowly crenulate, not continued along the hind margin which has a shallow sinuous emargination in front of the scutellum (Fig. 51B).
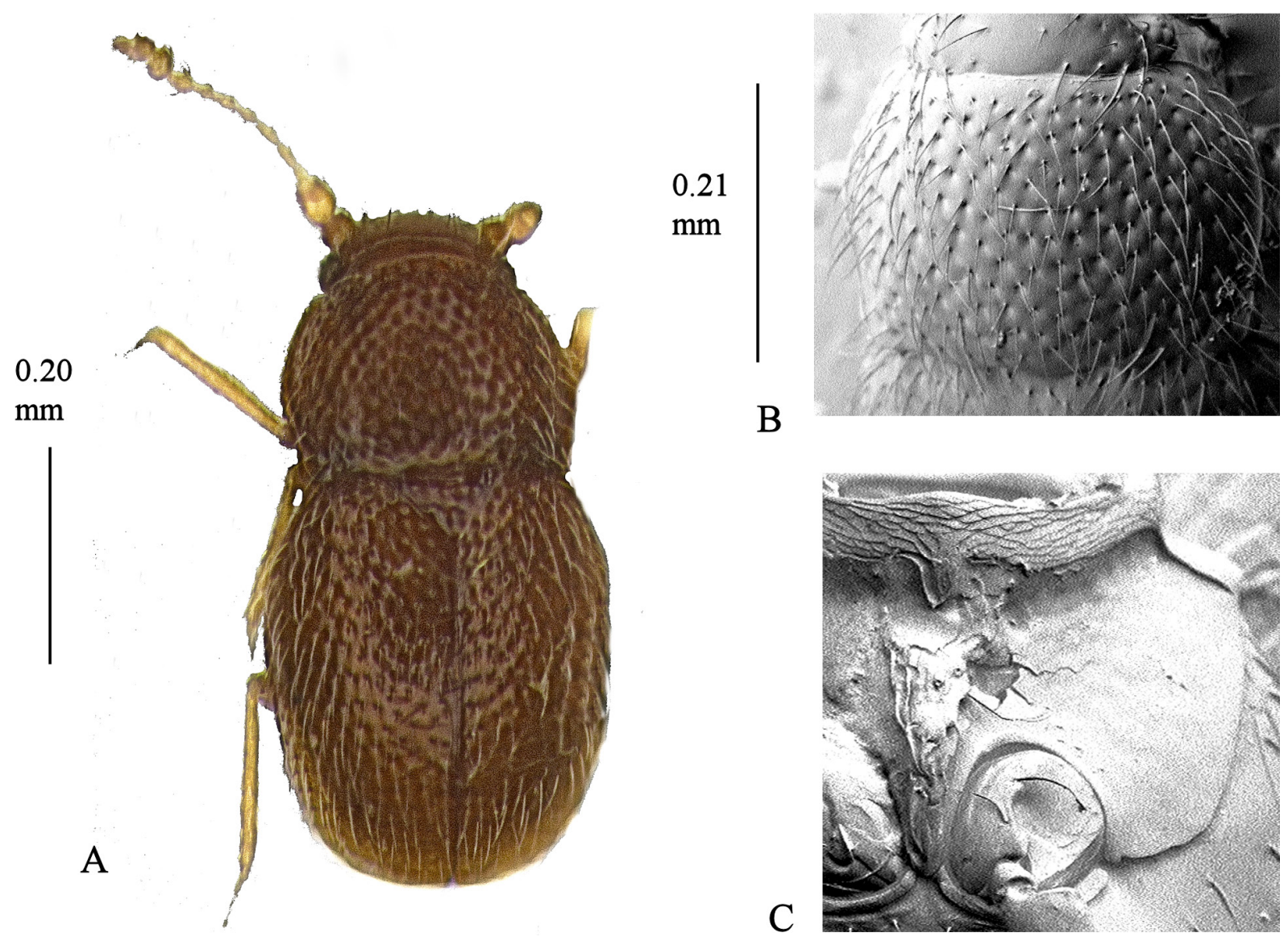

Fig. 51. Cissidium itoi Sawada, 2008. A. Habitus. B. Pronotum, $\times$ 375. C. Mesoventrite showing median process of collar, mid keel, keel and lateral margin, $\times 590$. 
ELYTRA. Length $0.41 \mathrm{~mm}$, width $0.32 \mathrm{~mm}$, pubescent but without foveolae.

Mesoventrite. Median extension of collar short; mid-keel and keel united without extensions to the anterior mesocoxal borders, strongly setose and sculpted, terminating in a rounded point between the mesocoxae; humeri shallowly toothed; mesoventral lateral borders smoothly rounded without serrations (Fig. 51C).

Metaventrite. Sparsely pubescent, length $0.11 \mathrm{~mm}$, width across spines $0.10 \mathrm{~mm}$, disc foveolate medially; mesocoxal posterior borders without serrations

Genitalia. Male aedeagus pointed, not beak-shaped in profile; female spermatheca elongate as Fig. 6D.

\section{Remarks}

This is one of three species in this group from Japan and differs from C. latum Sawada, 2008 in being narrower and from C. nomurai Sawada, 2008 in the form of the female spermatheca.

Cissidium latum Sawada, 2008

Fig. 52

\section{Material examined}

Paratypes

JAPAN • 1 O ; Okinawa, Ryukyu, Gaji rindo, NE of Mt Terukubi; 290 m a.s.1.; 21 Oct. 1987; Y. Nishikawa leg.; BMNH • 1 ô; Hiji, Kunigami-son, Okinawa Pref.; 12 Apr. 1997; Y. Sawada leg.; YS.

\section{Supplementary description}

The following description amplifies the type description of Sawada (2008) to conform with the entries in the present paper.

SizE. Habitus (Fig. 52A), length $0.76 \mathrm{~mm}$.

CoLour. Reddish brown to dark brown, antennae, legs and pubescence paler.

HEAD. With a transverse row of indistinctly formed foveolae between the eyes.

Pronotum. Length $0.21 \mathrm{~mm}$, width $0.37 \mathrm{~mm}$, densely pubescent and very shallowly foveolate throughout; side margins rounded to concave before rectangular hind angles, narrowly bordered, the border continuing along the entire posterior margin, which is without an emargination opposite the scutellum (Fig. 52B).

ELYTRA. Length $0.47 \mathrm{~mm}$, width $0.42 \mathrm{~mm}$, pubescent more widely distributed than pronotum.

MesoventRITE. Collar with 3 projecting setae along the posterior margin opposite the mid-keel, median extension widest anteriorly then slightly tapering posteriorly, with very short setae; mid-keel strongly sculpted and pubescent, widest medially; keel long, pointed, terminating past the mid-point of the mesocoxae; lateral margins very shallowly rounded, without serrations; humeri toothed (Fig. 52C).

Metaventrite. $0.15 \mathrm{~mm}$ long, reticulate towards lateral margins, sparsely pubescent, disc simple, distance between spines $0.10 \mathrm{~mm}$; mesocoxal posterior borders serrate. 
Genitalia. Male aedeagus as Fig. $6 \mathrm{Fa}-\mathrm{b}$ but beak not so strongly bent.

\section{Remarks}

This is one of three species in this group from Japan and differs from them and from all other Japanese Cissidium in having wider and more rounded elytra.
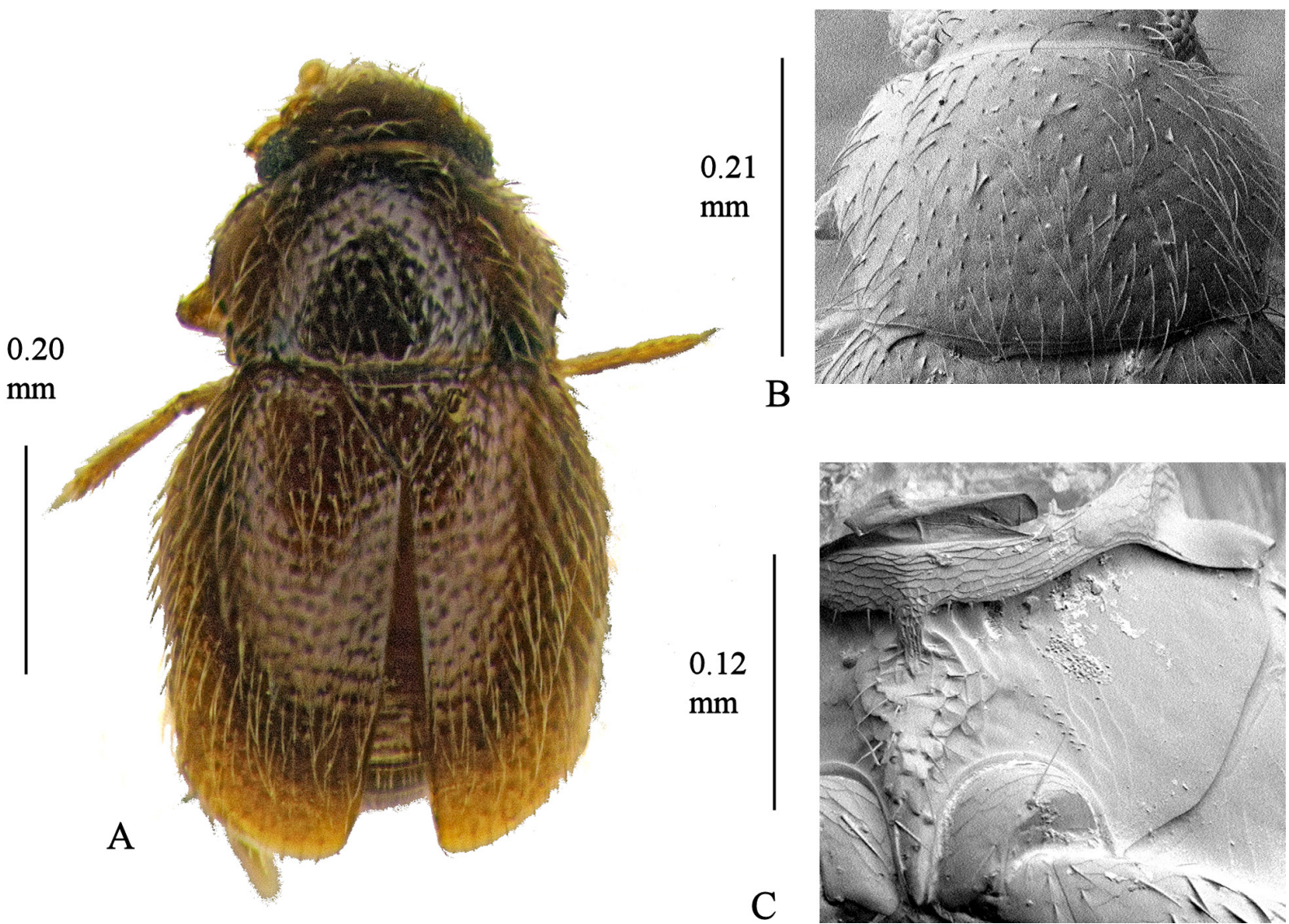

$\mathrm{B}$

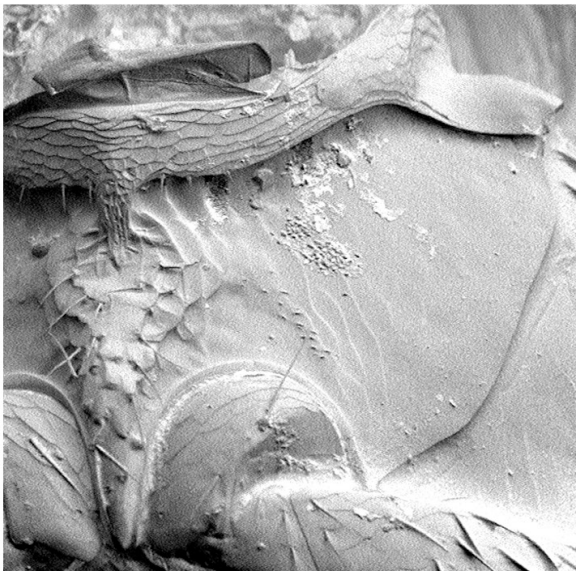

Fig. 52. Cissidium latum Sawada, 2008. A. Habitus. B Pronotum, $\times 620$. C. Mesoventrite showing median process of collar, mid-keel, keel and lateral margin, $\times 800$.

\section{Cissidium longum Darby, 2019}

Fig. 53

\section{Material examined}

\section{Holotype}

MALAYSIA • + ; Sarawak, $4^{\text {th }}$ division, Gunung Mulu National Park; May-Aug. 1978; P.M. Hammond and J.E. Marshall leg.; BM 1978-49; base camp, alluvial forest litter near laboratory; BMNH.

\section{Supplementary description}

The following description amplifies the type description of Darby (2019), in particular by adding more details of the meso- and metaventral characters, in order to conform with the entries in the present paper.

Size. Habitus (Fig. 53A), length $0.67 \mathrm{~mm}$. 
CoLour. Yellow, shining, antennae, legs and pubescence yellow.

HeAD. Distance across eyes $0.20 \mathrm{~mm}$; antennomeres III-XI, length $0.37 \mathrm{~mm}$, III-IX length $0.22 \mathrm{~mm}$, $\mathrm{X}-\mathrm{XI}$ length $0.15 \mathrm{~mm}$; mentum as Fig. 4A.

Pronotum. Length $0.19 \mathrm{~mm}$, width $0.29 \mathrm{~mm}$, with three or four foveae joining to form short longitudinal depressions on each side of the base, foveolate on disc and at sides; side margins strongly sinuate posteriorly, hind angles acute, wider than elytra, anterior angles rounded, bordered, the border not continued along the posterior margin, medial emargination opposite the scutellum sinuous (Fig. 53B).

ELYTRA. Length $0.43 \mathrm{~mm}$, width $0.37 \mathrm{~mm}$, basal third strongly foveolate.

Mesoventrite. Without pubescence, almost imperceptibly reticulate, medial projection of collar very small expanding to meet keel, mid-keel much reduced without anterior or posterior angles, tapering posteriorly to join keel, the junction marked by a series of \pm six small raised bumps (possibly once setae bearing?); keel terminating past interruptions of mesocoxal margins; humeri toothed; mesoventral lateral margins long and straight then rectangular with rounded angles, without serrations (Fig. 53C).
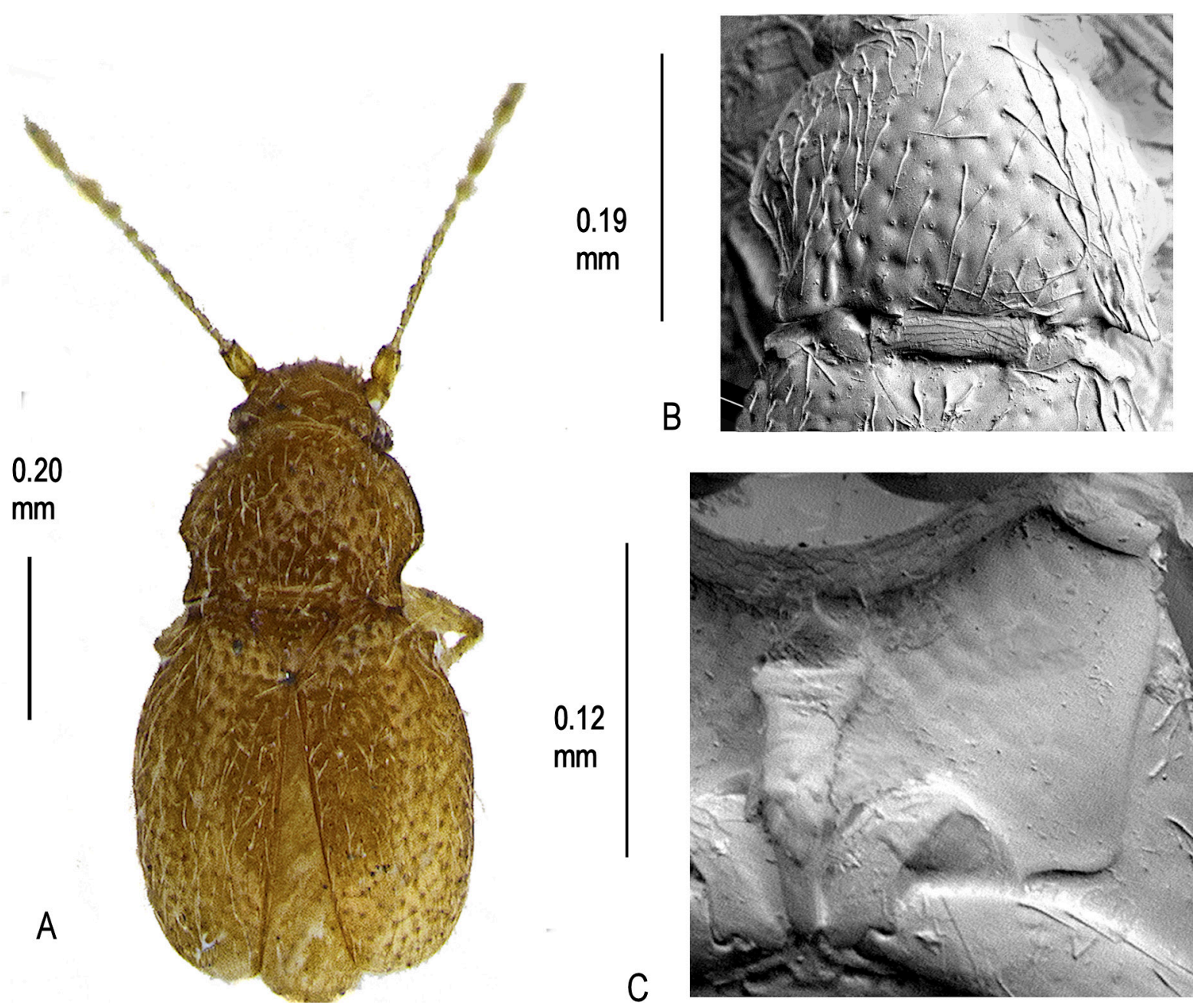

Fig. 53. Cissidium longum Darby, 2019. A. Habitus. B. Pronotum, $\times$ 485. C. Mesoventrite showing median process of collar, mid-keel and keel, $\times 895$. 
MetaVentrite. Length $0.13 \mathrm{~mm}$, pubescent, width across spines $0.10 \mathrm{~mm}$, posterior margin of mesocoxae serrate.

\section{Remarks}

This is the only species from Malaysia in this group which has angulate lateral margins to the mesoventrite.

Cissidium mahleri sp. nov.

urn:1sid:zoobank.org:act:FCBA1166-5BB1-496E-B971-2DAB12C75938

Fig. 54

\section{Etymology}

Named after the collector V. Mahler.

\section{Material examined}

\section{Holotype}

SRI LANKA・ • ; Pidurutalagala; 2480 m a.s.1.; 18 Dec. 1979; V. Mahler leg.; MMUE.

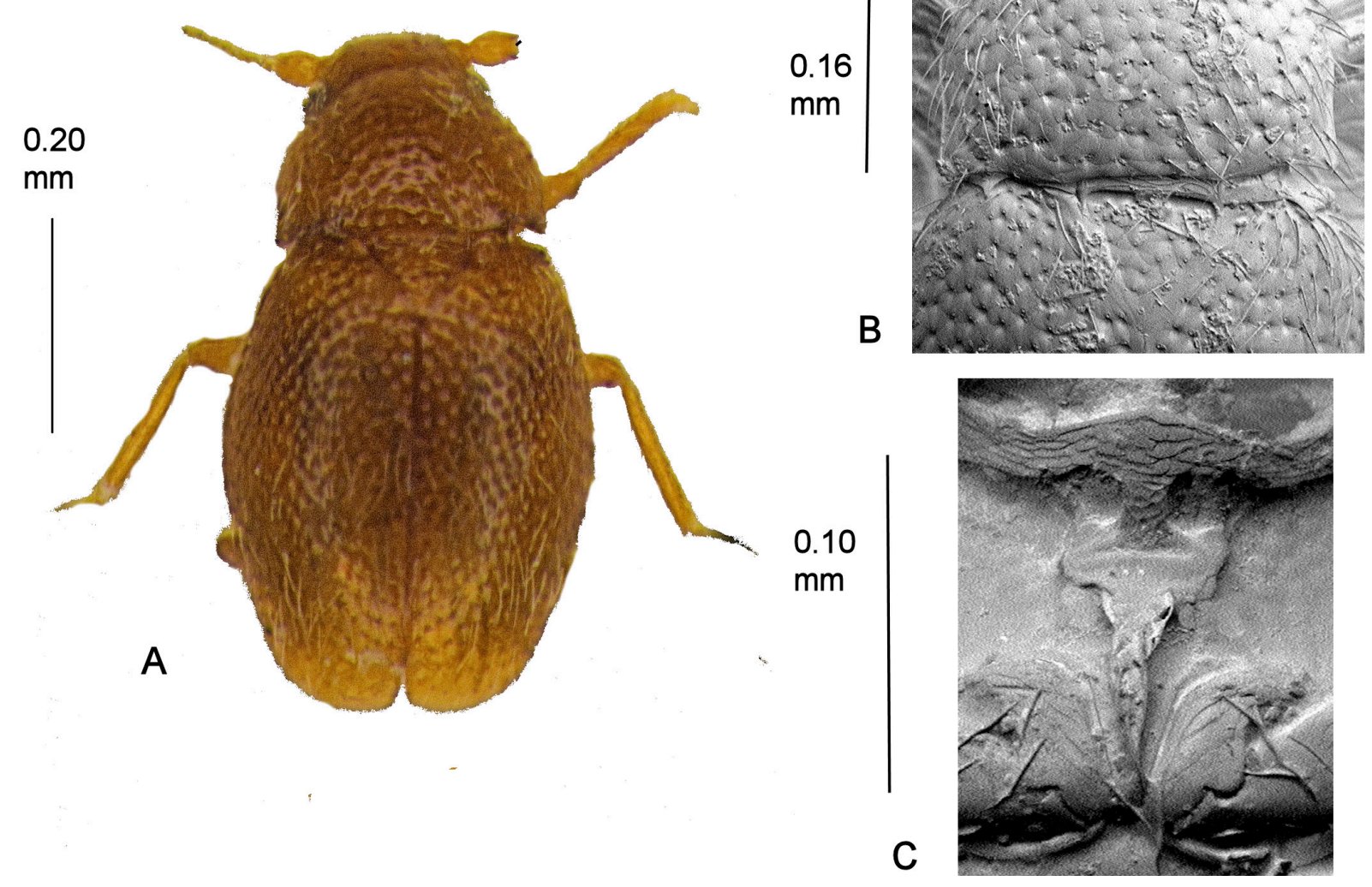

Fig. 54. Cissidium mahleri sp. nov. A. Habitus. B. Pronotum,$\times 630$. C. Mesoventrite showing median process of collar, mid-keel and keel, $\times 545$. 


\section{Description}

Size. Habitus (Fig. 54A), length $0.61 \mathrm{~mm}$.

Colour. Yellow.

HEAD. With a shallow median fovea between the eyes, width across eyes $0.18 \mathrm{~mm}$; antennomeres missing; mentum and prementum obscured.

Pronotum. Length $0.14 \mathrm{~mm}$, width $0.25 \mathrm{~mm}$, densely pubescent and foveolate; sides rounded continuing almost parallel-sided to slightly acute hind angles, bordered, the border not continued along the basal margin, medial emargination opposite scutellum sinuous (Fig. 54B).

ELYTRA. Length $0.42 \mathrm{~mm}$, width $0.34 \mathrm{~mm}$; densely pubescent and foveolate as pronotum.

MesoventRITE. Median process of mesoventral collar broad, widening posteriorly; mid-keel short, widenend and effaced anteriorly creating two semi-circular depressions, hind angles rounded not reaching mesocoxal anterior borders, raised slightly before joining keel; keel with \pm eight setae from concave foveolae, tapering to bluntly pointed termination posteriad to the interruption point of the mesocoxal margins; mesoventral lateral margins serrate posteriorly; humeri sloping posteriorly, barely toothed (Fig. 54C).

Metaventrite. Length $0.15 \mathrm{~mm}$, setose, disc simple, width across spines $0.09 \mathrm{~mm}$.

WINGs. Macropterous.

Genitalia. Female spermatheca slightly pear-shaped.

\section{Remarks}

One of the only two species of Cissidium from Sri Lanka in this group. Distinguished from C. pilosellum sp. nov. by the shorter and broader median extension of the mesoventral collar.

Cissidium marshallae Darby, 2019

Fig. 55

\section{Material examined}

Holotype

MALAYSIA - + ; Sarawak, $4^{\text {th }}$ division, on Mulu NP, Camp 5; May-Aug. 1978; alluvial forest litter; P.M. Hammond and J.E. Marshall leg.; BM 1978-49; BMNH.

\section{Paratype}

MALAYSIA • 1 ex.; same collection data as for holotype; mounted as a disarticulated slide; BMNH.

\section{Supplementary description}

The following description amplifies the type description of Darby (2019), in particular by adding more details of the meso- and metaventral characters to conform with the entries in the present paper.

Size. Habitus (Fig. 55A), length $0.58 \mathrm{~mm}$.

CoLour. Dark brown, antennae, legs and pubescence yellow. 
HeAd. Distance across eyes $0.19 \mathrm{~mm}$; antennomeres III-XI, length $0.29 \mathrm{~mm}$; mentum as Fig. 4A.

Pronotum. Length $0.16 \mathrm{~mm}$, width $0.26 \mathrm{~mm}$, pubescent and foveolate throughout, foveolae forming short, obscure, longitudinal depressions at base; side margins sharply angled, thence concave to rectangular hind angles, bordered, the border continuing along the posterior margin to the medial emargination opposite the scutellum (Fig. 55B).

ELYTRA. Length $0.40 \mathrm{~mm}$, width $0.35 \mathrm{~mm}$, pubescent throughout.

Mesoventrite. Medial extension of collar narrow, parallel-sided, slightly widened posteriorly; midkeel parallel-sided, hind angles not reaching mesocoxal anterior borders; keel foveolate with \pm seven setae, broad basally, tapering to parallel-sided with rounded termination past interruption of mesocoxal borders; mesoventral lateral margins with $2 / 3$ serrations; humeri toothed (Fig. 55C).

Metaventrite. With scattered pubescence, disc simple.

\section{Remarks}

Distinguished from the other four Peruvian species in this group by the pair of linear depressions at the pronotal base.
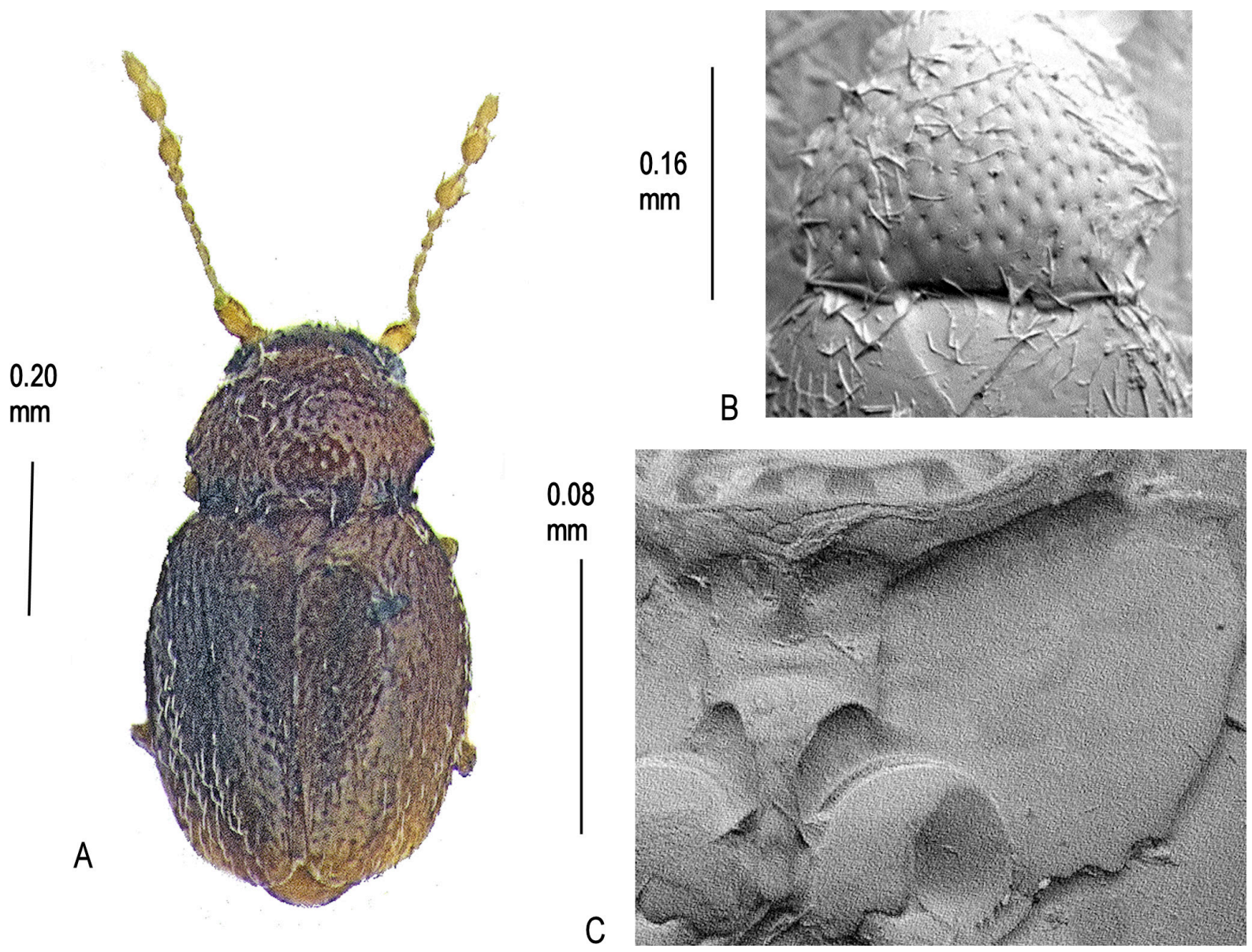

Fig. 55. Cissidium marshallae Darby, 2019. A. Habitus. B. Pronotum, $\times$ 640. C. Mesoventrite showing median process of collar, mid-keel, keel and lateral margin, $\times 750$. 


\section{Cissidium mindanao sp. nov.}

urn:1sid:zoobank.org:act:05800208-5A5F-48D0-AC96-2616B8A34B4B

Figs 6N, 56

\section{Etymology}

Named after Mindanao, the second largest island in the Philippines where the specimen was collected.

Noun in apposition.

\section{Material examined}

\section{Holotype}

PHILIPPINES • ^̊; Mindanao, E slope of Mt McKinley, Davao Prov.; 3300 ft a.s.l.; 28 Aug. 1946; flight dusk; Werner leg.; FMNH.

\section{Description}

Size. Habitus (Fig. 56A), length $0.67 \mathrm{~mm}$.

CoLour. Dark brown, pubescence, legs and antennae dusky yellow.
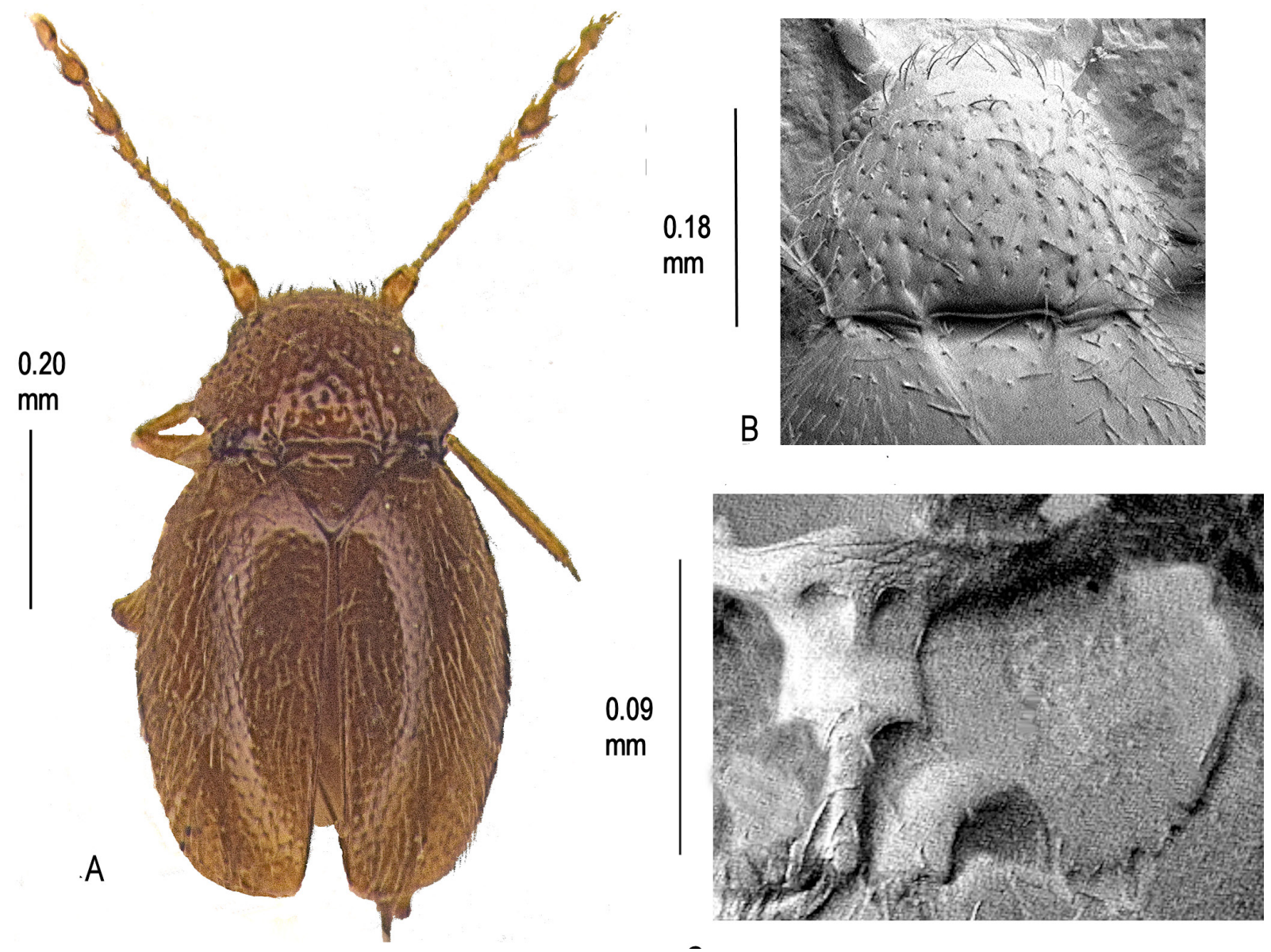

Fig. 56. Cissidium mindanao sp. nov. A. Habitus. B. Pronotum, $\times$ 430. C. Mesoventrite showing median process of collar, mid-keel, keel and lateral margin, $\times 660$. 
HeAD. Densely setose; antennomeres III-XI length $0.37 \mathrm{~mm}$, III-IX length $0.20 \mathrm{~mm}, \mathrm{X}-\mathrm{XI}$ length $0.17 \mathrm{~mm}$; width across eyes $0.22 \mathrm{~mm}$; mentum parallel-sided, otherwise obscured.

Pronotum. Length $0.21 \mathrm{~mm}$, width $0.30 \mathrm{~mm}$, densely pubescent and foveolate, without foveae along basal margin; sides sharply angled, concave to rectangular hind angles slightly concave to obtuse front angles, bordered, the border continuing along the entire posterior margin including the sinuous emargination in front of the scutellum (Fig. 56B).

ELYTRA. Length $0.49 \mathrm{~mm}$, width $0.40 \mathrm{~mm}$, pubescent without distinct foveolae markedly contrasting with the pronotum.

MESOVENTRITE. Median process of mesoventral collar narrow, parallel-sided; mid-keel anterior angles joining collar, posterior angles not reaching mesocoxal anterior borders, raised medially at junction with keel; keel with \pm eight setae, parallel-sided, with rounded termination at the interruption of the mesocoxal borders; mesoventral lateral margins angled below humeri, serrate posteriorly; humeri toothed (Fig. 56C).

Metaventrite. Length $0.18 \mathrm{~mm}$, setose, disc simple, width across spines $0.11 \mathrm{~mm}$.

WINGS. Macropterous.

Genitalia. Male aedeagus (Fig. 6N). Female not known.

\section{Remarks}

One of the only two species of Cissidium in this group from the Philippines. Distinguished from C. werneri sp. nov. by the more densely foveolate pronotum.

Cissidium murphyi sp. nov. urn:lsid:zoobank.org:act:486E11B8-F72A-4E20-A432-4AAFE32E6FB4

Figs 6E, 57

\section{Etymology}

Johnson ms name, after the collector D.H. Murphy.

\section{Material examined}

\section{Holotype}

MALAYSIA • +; Selangor, Ulu Gombak; 7 Nov. 1967; chloropierin extract of forest litter at stream side; D.H. Murphy leg.; no. 377; FMNH.

\section{Paratypes}

MALAYSIA • 1 क; same collection data as for holotype; BMNH $\bullet 1$ § ; Selangor, Gombak, vicinity of University of Malaya Field Station, $9^{\text {th }}$ mile; 9 Feb. 1967; litter and debris over sand low forest flood plain; D.H. Murphy leg.; no. 327; BMNH • 2 ex.; same collection data as for preceding; litter on high level flood plain over sand in secondary forest; one missing antennae; MMUE.

\section{Description}

Size. Habitus (Fig. 57A), length $0.69 \mathrm{~mm}$.

CoLour. Yellow brown, antennae, legs and pubescence yellow, shining. 
HEAD. Without a linear depression behind the eyes, width across eyes $0.22 \mathrm{~mm}$, ventral side of neck with a band of shallow, slightly elongate foveolae; antennomeres III-XI length $0.34 \mathrm{~mm}$, III-IX length $0.19 \mathrm{~mm}, \mathrm{X}-\mathrm{XI}$ length $0.15 \mathrm{~mm}$ globular; mentum as Fig. 4A.

Pronotum. Length $0.19 \mathrm{~mm}$, width $0.29 \mathrm{~mm}$, densely pubescent and foveolate, with a pair of short, poorly formed linear depressions extending forwards from the base; lateral margins sharply angled medially then concave to acute hind angles, bordered, the border on the posterior margin enlarged convexly either side of the medial emargination opposite the scutellum which is well marked (Fig. 57B).

ELYTRA. Length $0.46 \mathrm{~mm}$, width $0.41 \mathrm{~mm}$, shallowly foveolate contrasting with the pronotum.

Mesoventrite. Collar with reticulation confined to a small median triangular area and on the parallelsided medial extension; mid-keel parallel-sided widening sharply before meeting collar, posterior angles effaced before joining mesocoxal anterior borders; keel foveolate with \pm ten setae, parallel-sided to rounded termination between the mesocoxae; mesoventral lateral margins serrate in posterior half; humeri bluntly toothed (Fig. 57C).

Metaventrite. Length $0.16 \mathrm{~mm}$, sparsely pubescent, disc simple, width across spines $0.12 \mathrm{~mm}$, spines small, short; posterior margins of mesocoxal cavities serrate.
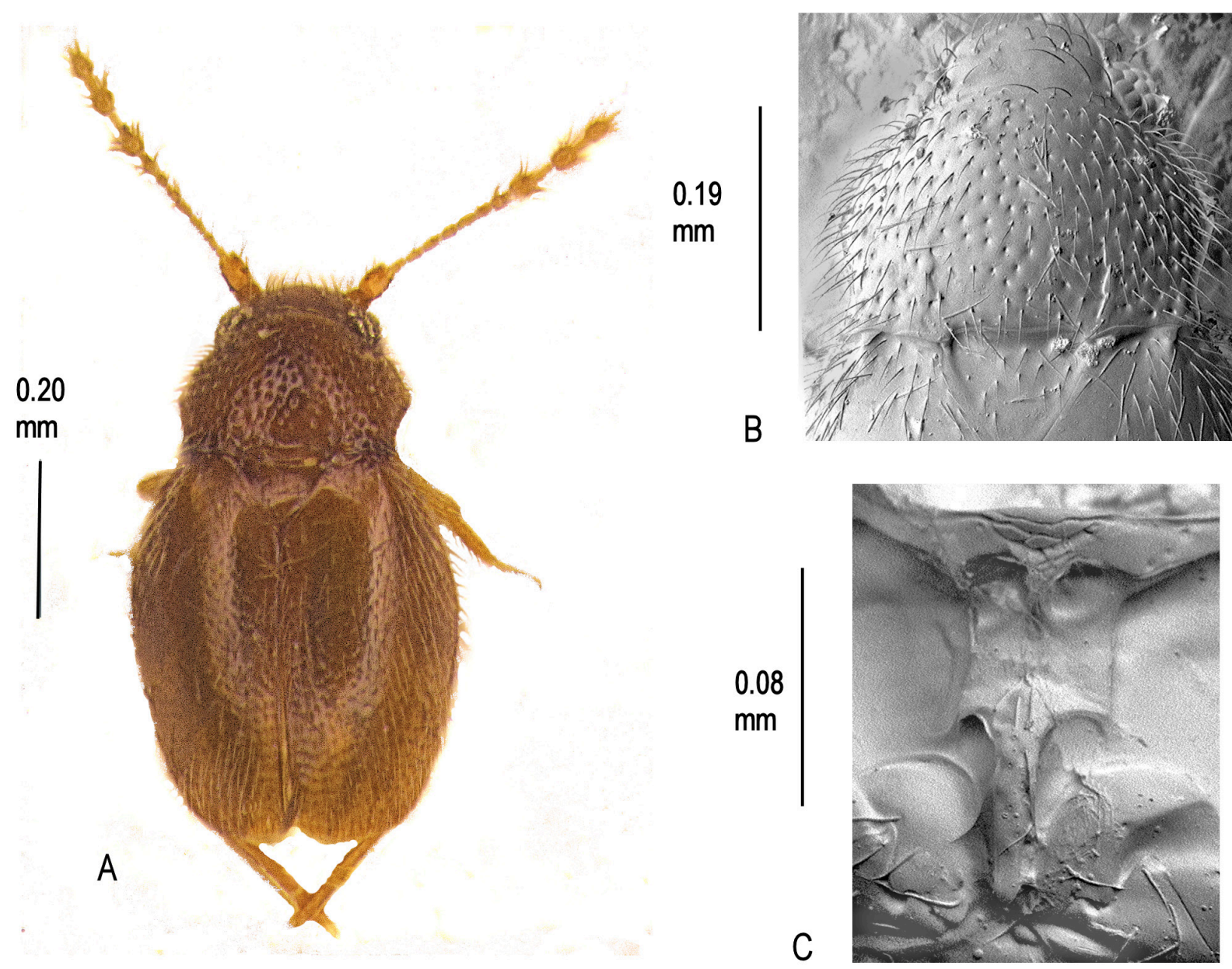

Fig. 57. Cissidium murphyi sp. nov. A. Habitus. B. Pronotum, $\times$ 555. C. Mesoventrite showing median process of collar, mid-keel and keel, $\times 995$. 
WINGS. Macropterous.

Genitalia. Female spermatheca (Fig. 6E). Male aedeagus as Fig 6Fa-b but a little longer.

\section{Remarks}

This is the only species of Cissidium recorded from Malaya in this group.

Cissidium nomurai Sawada, 2008

Fig. 58

\section{Material examined}

\section{Paratypes}

JAPAN • 2 ex.; Kyusyu, Mt Tsubakiyama, Hatayama Town, Saga; 16 Jun. 1990; S. Nomura leg.; YS • 1 ex.; Kyusyu, Shiratani, Yakushima Is., Kagoshima Pref.; 15 May 1987; S. Nomura leg.; BMNH • 1 ex.; Kyusyu, Miike, Miyazaki Pref.; 8 May 1985; S. Nomura leg.; YS • 3 ex.; Kyusyu, Mt. Ichihusa, Kumamoto Pref.; 13 May 1985; S. Nomura leg.; BMNH • 1 ex.; Kyusyu, Okinawa, Ryukyu, Gaji rindô,
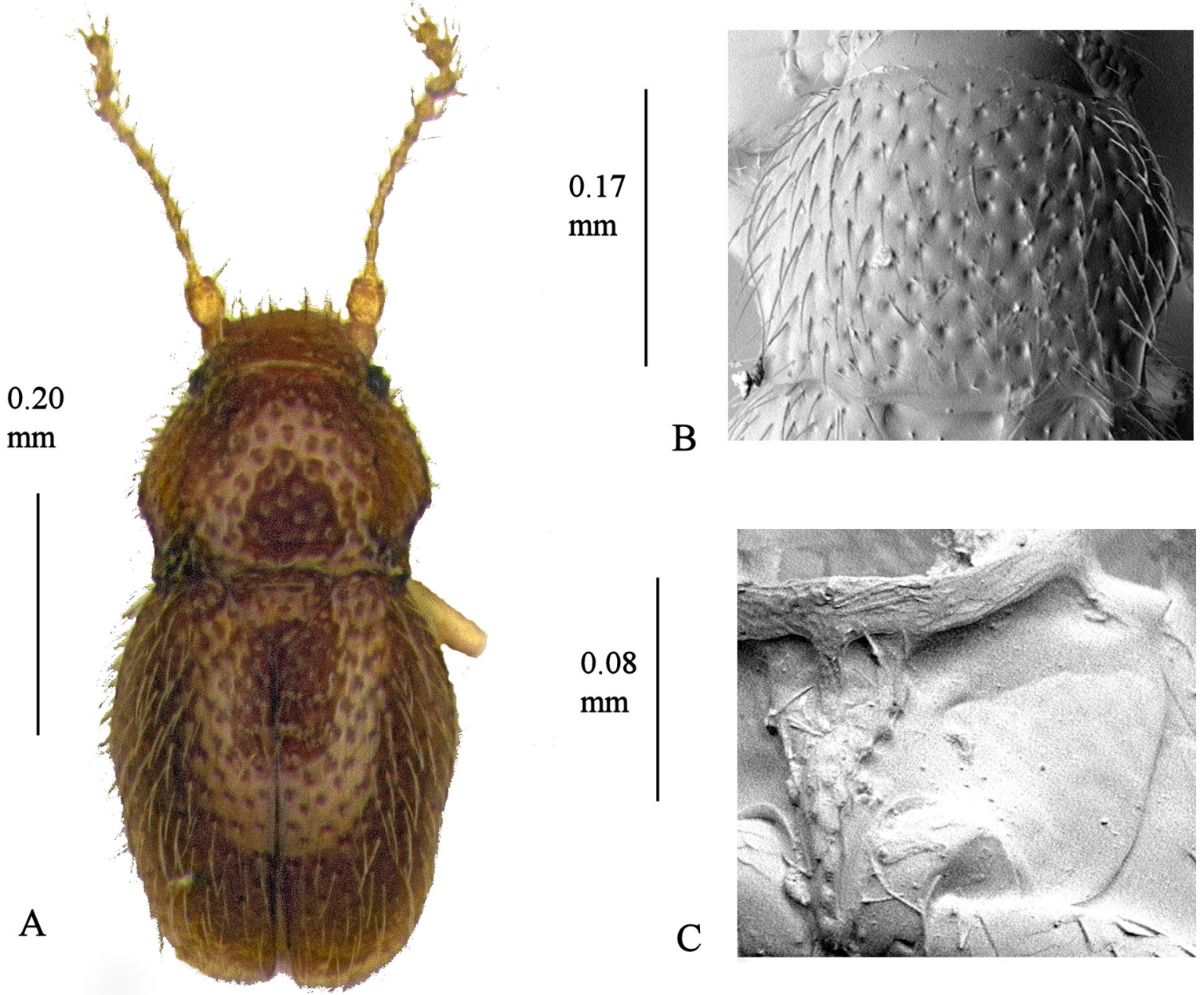

Fig. 58. Cissidium nomurai Sawada, 2008. A. Habitus. B. Pronotum, $\times 600$. C. Mesoventrite showing median extension of collar, mid-keel, keel and lateral margin, $\times 630$. 
NE of Mt Terukubi; 290 m a.s.1.; 21.x.1987; Y. Nishikawa leg.; YS • + 20 further ex. from various locations in Japan; YS.

\section{Supplementary description}

The following description amplifies the type description of Sawada (2008) in order to conform with the entries in the present paper.

Size. Habitus (Fig. 58A), length $0.55 \mathrm{~mm}$.

Colour. Reddish brown to dark brown, antennae, legs and pubescence dusky yellow.

HEAD. With a transverse row of indistinctly formed foveolae between the eyes; width across the eyes $0.16 \mathrm{~mm}$.

Pronotum. Length $0.17 \mathrm{~mm}$, width $0.24 \mathrm{~mm}$, densely pubescent and distinctly foveolate throughout; side margins rounded to concave before rectangular hind angles, narrowly bordered, the border continuing for a short distance along the side of the posterior margin which is with an almost imperceptible emargination opposite the scutellum (Fig. 58B).

ELYTRA. Length $0.34 \mathrm{~mm}$, width $0.27 \mathrm{~mm}$, pubescent, more widely distributed than pronotum shallowly foveolate contrasting with the pronotum.

Mesoventrite. Median extension of collar parallel sided; mid-keel widest anteriorly tapering posteriorly to junction with keel; keel setose and strongly sculpted, terminating below the mid-point of the mesocoxae; mesoventral lateral margins curved strongly posteriorly; humeri toothed (Fig. 58C).

Metaventrite. Foveolate on disc which is slightly depressed, length $0.11 \mathrm{~mm}$, distance across spines $0.09 \mathrm{~mm}$; mesocoxal posterior borders without serrations.

Genitalia. Male aedeagus as Fig. 6Fa-b, but beak not so strongly bent. Female spermatheca turbinate.

\section{Remarks}

This is one of three species in this group from Japan and differs from C. latum in being narrower and from $C$. itoi in the form of the female spermatheca.

Cissidium pauxillum Darby, 2019

Fig. 59

\section{Material examined}

\section{Holotype}

MALAYSIA • Sarawak, $4^{\text {th }}$ division, Gunung Mulu National Park; May-Aug. 1978; base comp, alluvial forest litter near laboratory; P.M. Hammond and J.E. Marshall leg., BM 1978-49; BMNH.

\section{Supplementary description}

The following description amplifies the type description of Darby (2019), by adding more details of the meso- and metaventral characters, in order to conform with the entries in the present paper.

Size. Habitus (Fig. 59A), length $0.68 \mathrm{~mm}$.

Colour. Yellow, antennae, legs and pubescence paler yellow. 
HeAd. Distance across eyes $0.18 \mathrm{~mm}$; antennomeres III-XI, length $0.25 \mathrm{~mm}$, III-IX, length $0.15 \mathrm{~mm}$, $\mathrm{X}-\mathrm{XI}$ length 0.10 ; mentum as Fig. 4A.

Pronotum. Length $0.17 \mathrm{~mm}$, width $0.27 \mathrm{~mm}$, densely foveolate and pubescent throughout, without foveae; side margins evenly curved to rectangular hind angles, lateral margins continued along base to the angulate medial emargination opposite the scutellum (Fig. 59B).

ELYTRA. Length $0.37 \mathrm{~mm}$, width $0.30 \mathrm{~mm}$, foveolate and pubescent throughout.

Mesoventrite. Short, collar without reticulation though with a little medial coarse sculpturing, medial extension broadening posteriorly; mid-keel short, anterior angles almost reaching collar, posterior angles not reaching mesocoxal anterior borders, setose before junction with keel; keel tapering then narrow and parallel-sided before pointed termination at interruption of mesocoxal margins; humeri with sharply projecting teeth; mesoventral lateral margins serrate (Fig. 59C).

Metaventrite. With scattered pubescence, length $0.11 \mathrm{~mm}$, disc simple, width across spines $0.09 \mathrm{~mm}$, spines long, sharply pointed.

\section{Remarks}

This is the only species from Malaysia in this group which has strongly concave margins to the mesoventral mid-keel. The genitalia have not been dissected.
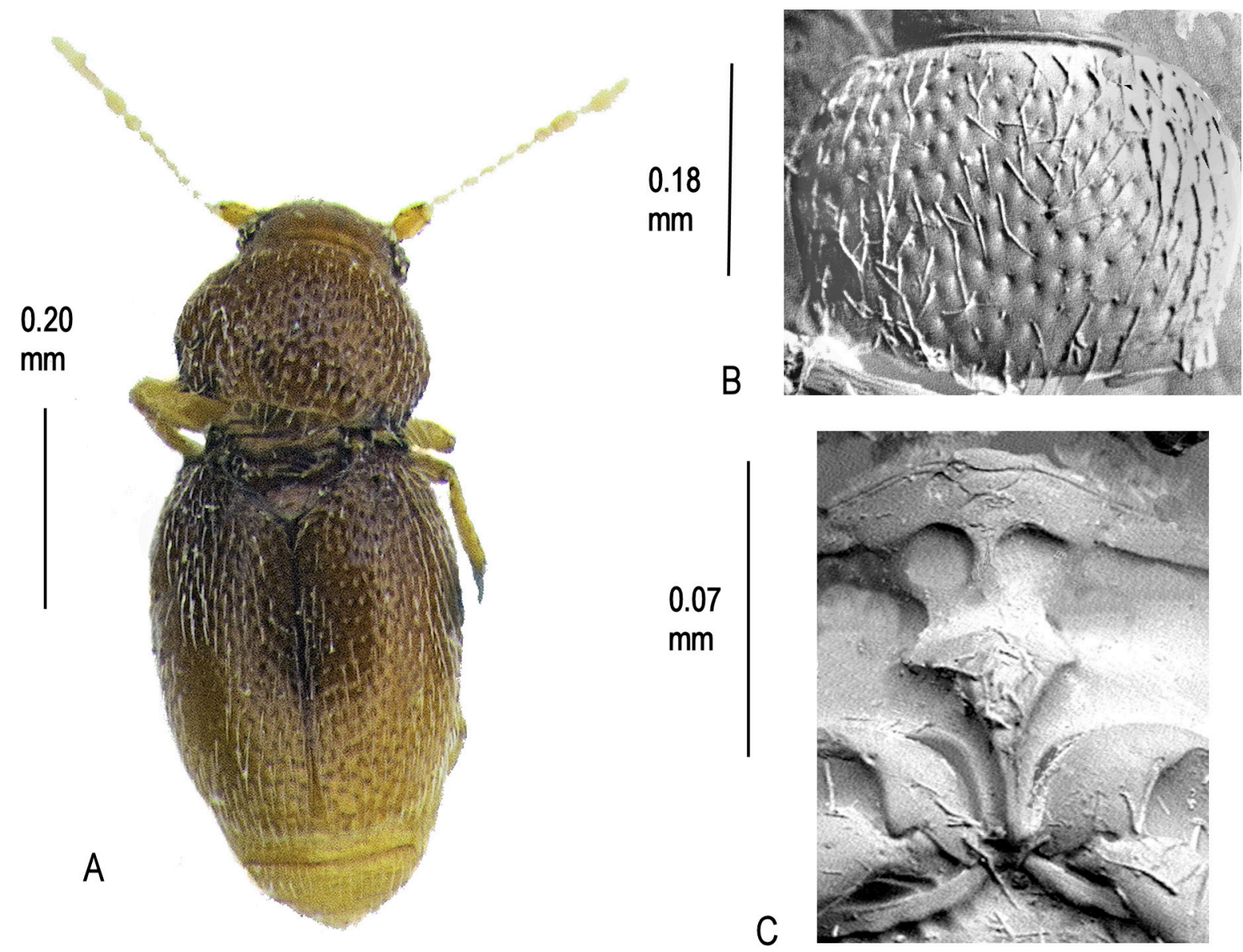

Fig. 59. Cissidium pauxillum Darby, 2019. A. Habitus. B. Pronotum, $\times 590$. C. Mesoventrite showing median process of collar, mid-keel and keel, $\times 810$. 


\section{Cissidium pilosellum sp. nov.}

urn:Isid:zoobank.org:act:433CB5E1-67B0-4A5E-AF3B-C58A68CADDE5

Figs $4 \mathrm{~F}, 60$

\section{Etymology}

Named after the Latin adjective 'pilosus', meaning 'hairy'.

\section{Material examined}

\section{Holotype}

SRI LANKA • + ; Central, Makgala; 1780-1800 m a.s.1.; 23 Jan. 1970; Musard, Besuchet and Löbl leg.; MMUE.

\section{Paratypes}

SRI LANKA • $2 \hat{\partial} \hat{\partial}, 1$ 9 ; same collection data as for holotype; $1 \hat{\jmath}$ mounted verso; MMUE, BMNH.

\section{Description}

Size. Habitus (Fig. 60A), length $1.00 \mathrm{~mm}$.
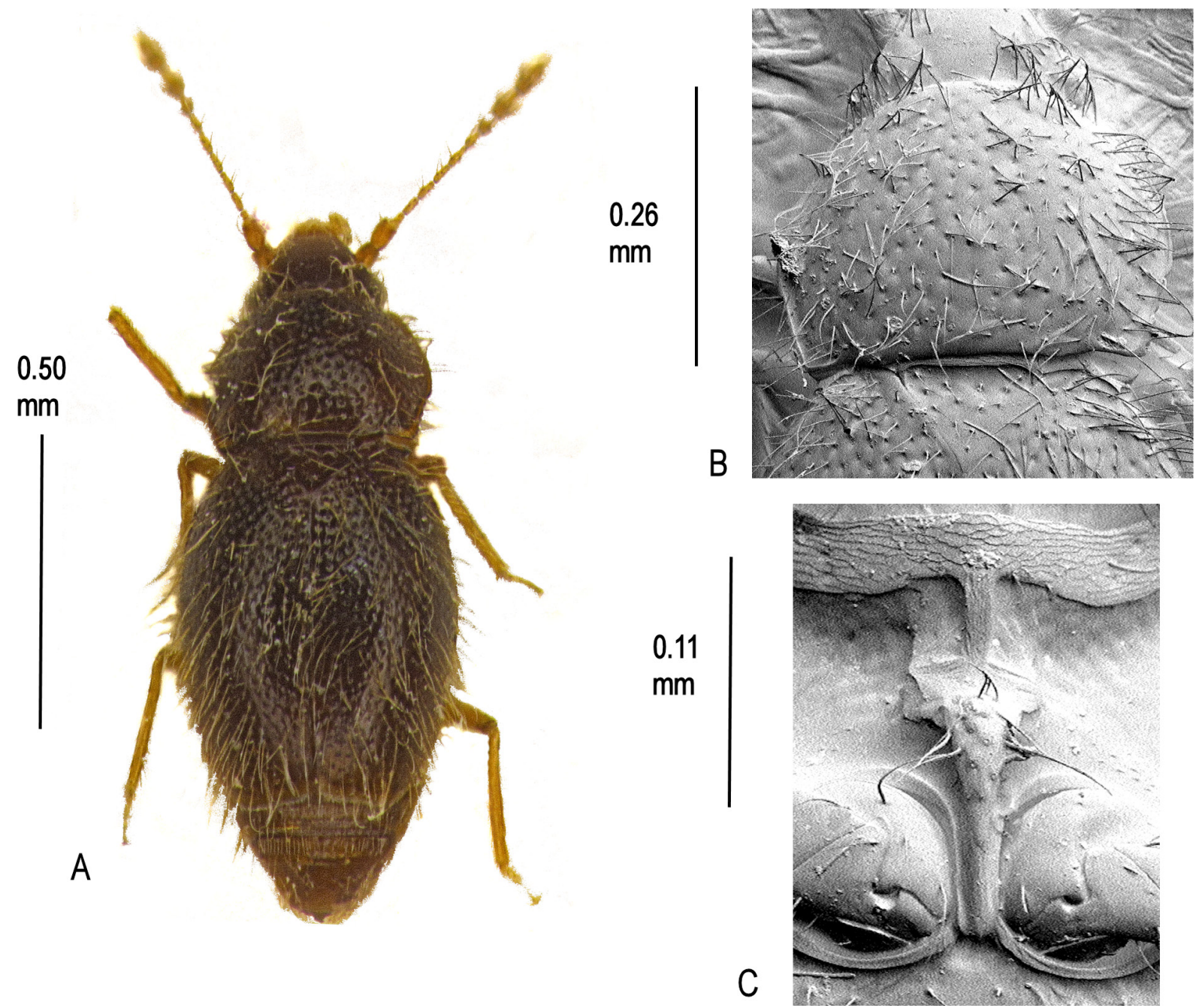

Fig. 60. Cissidium pilosellum sp. nov. A. Habitus. B. Pronotum, $\times$ 495. C. Mesoventrite showing median process of collar, mid-keel and keel, $\times 605$. 
CoLour. Very dark, almost black, antennae, legs and pubescence dusky yellow.

HEAD. Antennomeres III-XI length $0.43 \mathrm{~mm}$, III-IX length $0.20 \mathrm{~mm}, \mathrm{X}-\mathrm{XI}$ length $0.23 \mathrm{~mm}$; width across eyes $0.24 \mathrm{~mm}$; mentum triangular (Fig. $4 \mathrm{~F}$ ).

Pronotum. Length $0.29 \mathrm{~mm}$, width $0.40 \mathrm{~mm}$, densely covered with long pubescence and foveolae; sides slightly crenulate and angled, straightening before rectangular hind angles and obtuse anterior angles, bordered, the border continuing for a short distance along the posterior margin then recursive, emargination opposite scutellum present only as a slight insinuation (Fig. 60B).

Elytra. Length $0.59 \mathrm{~mm}$, width $0.45 \mathrm{~mm}$, densely pubescent and foveolate as pronotum. Proventrum. Wide in front of procoxae, with 8 stout setae in two pairs of four.

Mesoventrite. Collar with a long parallel-sided median extension; mid-keel short, widest anteriorly, the angles effaced before the rounded (misshapen) hind angles; keel long, with \pm eleven setae, tapering to point at base of mesocoxae; humeri sharply toothed (Fig. 60C).

Metaventrite. Pubescent, disc simple, length 0.17 width between spines $0.11 \mathrm{~mm}$; margins of mesocoxal cavities not serrate.

WingS. Micropterous.

GenitALiA. Male aedeagus as Fig. 6Ia-b. Female spermatheca globular.

\section{Remarks}

One of the only two species of Cissidium from Sri Lanka in this group. Distinguished from C. mahleri sp. nov. by the longer and narrower median extension of the mesoventral collar.

Cissidium puncticolle sp. nov.

urn:1sid:zoobank.org:act:A871108B-C662-4087-A519-031E0CD92BEE

Fig. 61

\section{Etymology}

Johnson ms name after the dense foveolae on the dorsum.

\section{Material examined}

Holotype

NEPAL - O $^{\top}$ Ulleri; $83^{\circ} 44^{\prime}$ E, $28^{\circ} 21^{\prime} \mathrm{N}$; 6000-7000ft a.s.1.; 18 May 1954; dry soil in deciduous forest;

K.H. Hyatt leg.; BMNH.

\section{Paratypes}

NEPAL $\bullet 1$, same collection data as for holotype; MMUE $\bullet 4$ ex.; Barahbise geg, Ting-Sang-La; H. Franz leg.; MMUE, BMNH.

There is also a slide of the genitalia of a male in the BMNH: "NEPAL, Sikha, $83^{\circ} 40^{\prime} \mathrm{E} 28^{\circ} 26^{\prime} \mathrm{N}, 24$ 26.v.1954, 8000ft".

\section{Description}

Size. Habitus (Fig. 61A), length $0.59 \mathrm{~mm}$.

CoLour. Yellow brown, antennae, legs and pubescence yellow. 
HeAD. Antennomeres III-XI length $0.30 \mathrm{~mm}$, III-IX length $0.15 \mathrm{~mm}, \mathrm{X}-\mathrm{XI}$ length $0.15 \mathrm{~mm}$; width across eyes $0.21 \mathrm{~mm}$; mentum as Fig. 4A.

Pronotum. Length $0.16 \mathrm{~mm}$, width $0.24 \mathrm{~mm}$, densely pubescent and foveolate the foveolae less pronounced medially at base and one or two enlarged almost foveae; lateral margins rounded straightening to obtuse hind angles, bordered, the border continuing along the posterior margin to the angulate medial emargination opposite the scutellum (Fig. 61B).

ELYTRA. Length $0.42 \mathrm{~mm}$, width $0.33 \mathrm{~mm}$, pubescent and foveolate as pronotum.

Mesoventrite. With a narrow, parallel-sided median extension; mid-keel with two carinae anteriorly joining collar to create two large depressions, collar at this point not reticulate, widening slightly posteriorly, hind angles meeting mesocoxal anterior borders; keel tapering to a sharp point just below interruption of mesocoxal margins; mesoventral lateral margins without serrations; humeri with large prominent teeth (Fig. 61C).

Metaventrite. Sparsely pubescent, disc simple, length 0.15 width between spines $0.11 \mathrm{~mm}$; margins of posterior mesocoxal cavities serrate.
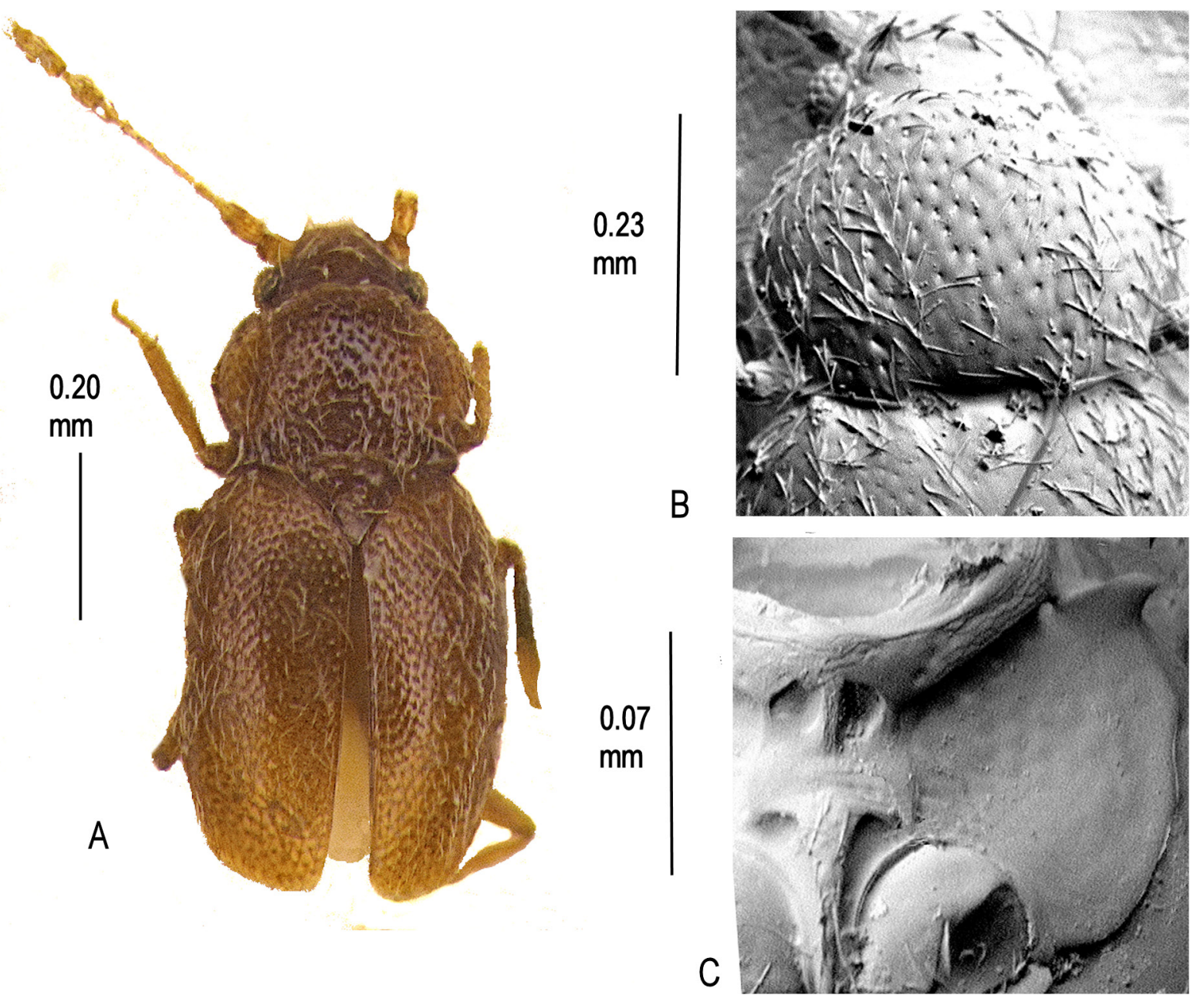

Fig. 61. Cissidium puncticolle sp. nov. A. Habitus. B. Pronotum, $\times$ 425. C. Mesoventrite showing median process of collar, mid-keel, keel and lateral margin with very protuberant humerus, $\times 660$. 
WINGs. Male apterous? No trace of wings found in dissection. Female macropterous.

Genitalia. Male aedeagus as Fig. 6Fa-b.

\section{Remarks}

The only species of Cissidium recorded from Nepal in this group.

Cissidium werneri sp. nov. urn:Isid:zoobank.org:act:7F7CA60C-3DA3-4EB2-9B12-9D3F0D01A04B

Fig. 62

\section{Etymology}

Named after the collector, Dr Floyd G. Werner.

\section{Material examined}

Holotype

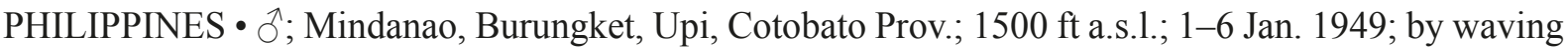
fine meshed net over forest floor in late afternoon; F.M. Werner leg.; (HD) \# 47; FMNH.

\section{Description}

Size. Habitus (Fig. 62A), length $0.72 \mathrm{~mm}$.

CoLour. Dark red brown, pubescence antennae and legs dusky yellow.

HeAD. Strongly foveolate with a setose linear depression between eyes, width across eyes $0.22 \mathrm{~mm}$; antennomeres III-XI length $0.27 \mathrm{~mm}$, III-IX length $0.13 \mathrm{~mm}, \mathrm{X}-\mathrm{XI}$ length $0.14 \mathrm{~mm}$.

Pronotum. $0.18 \mathrm{~mm}$ long, 0.31 wide; pubescent, strongly foveolate throughout, without basal foveae; lateral margins rounded then shallowly concave to rectangular hind angles, sides conspicuously bordered, the border continued along the lateral margin to the sinuous median emargination opposite the scutellum (Fig. 62B).

ELYTRA. Length $0.51 \mathrm{~mm}$, width $0.41 \mathrm{~mm}$; pubescent with shallow foveolae contrasting strongly with the pronotum.

Mesoventrite. Median process of collar onto mid-keel broad, widening posteriorly; mid-keel wide, sides concave, anterior margin slightly wider than posterior which has well marked flat carinae joining the mesocoxal margins, raised medially to a point before the keel; keel with \pm four setae, tapering to a rounded point at the interruption of the mesocoxal border; mesoventral lateral margins serrate; humeri toothed (Fig. 62C).

Metaventrite. Length $0.13 \mathrm{~mm}$, disc simple, distance across spines $0.07 \mathrm{~mm}$; posterior margins of mesocoxae serrate.

Wings. Macropterous.

Genitalia. Male aedeagus as Fig. 6 Ia-b. Females unknown. 


\section{Remarks}

One of the only two species of Cissidium in this group from the Philippines. Distinguished from C. mindanao sp. nov. by the less densely foveolate pronotum.
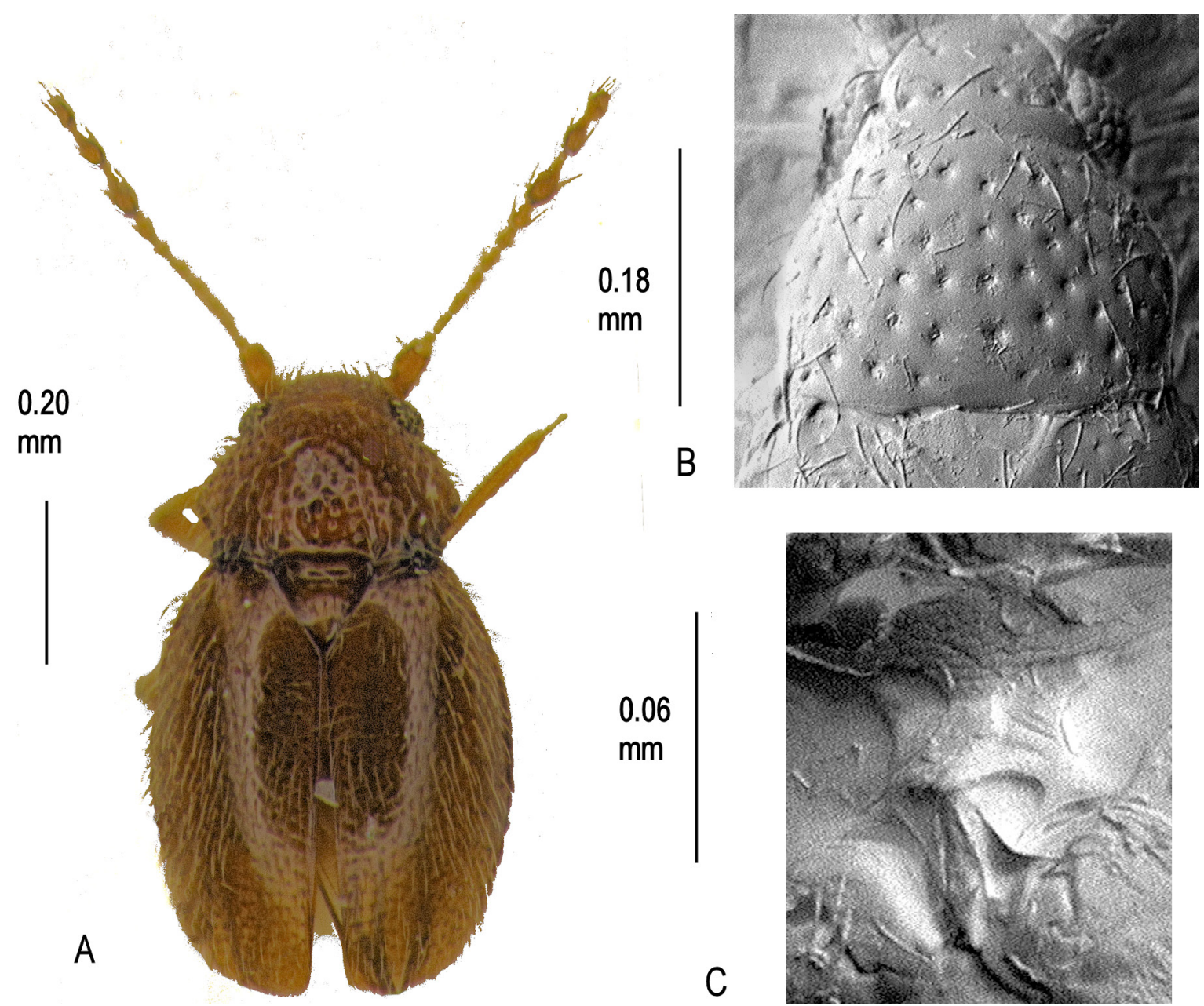

Fig. 62. Cissidium werneri sp. nov. A. Habitus. B. Pronotum, $\times$ 570. C. Mesoventrite showing median process of collar, mid-keel and keel, $\times 640$.

\section{Species group 4a: pronotum without either foveae or distinct foveolae, sides rounded}

\section{Key to Cissidium species in group $4 \mathrm{~A}$}

1. Species with longitudinal linear depressions on the pronotum .................................................... 2

- Species without linear depressions on the pronotum..................................................................... 4

2. Linear depressions very faint (best seen with side lighting).................................... trangse sp. nov.

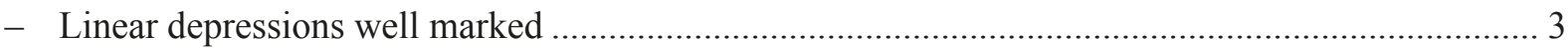

3. Linear depressions long almost reaching mid-point of pronotum, pronotum more densely pubescent C. bilineatum sp. nov.

- Linear depressions shorter, pronotum more sparsely pubescent C. arcuatum sp. nov. 
4. Mentum triangular

C. triangulum Darby, 2019

- Mentum not triangular

5. Head small, pronotum domed, sides almost parallel before hind angles, base of pronotum wider than elytra

- Pronotum not so domed, not wider than elytra, head larger in proportion

6. Pronotal hind angles acute, projected rearwards

C. seditiosum sp. nov.

- Pronotal hind angles rounded, not projected rearward

C. insulare sp. nov.

7. Pronotum cordate, posterior margin same width as distance across the eyes, elytra almost parallelsided, very small species.

C. besucheti sp. nov.

- Larger species, pronotal posterior margin clearly wider than distance across eyes

8. Posterior margins of pronotum almost parallel-sided

- Posterior margins of pronotum clearly concave before hind angles.

9. Mesoventral lateral margins serrate

- Mesoventral lateral margins without serrations.

10. Mid-keel rounded/tapering posteriorly, without projecting hind angles.

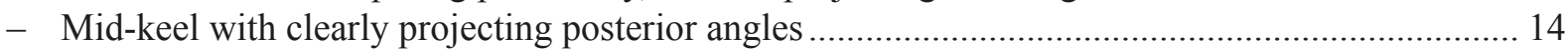

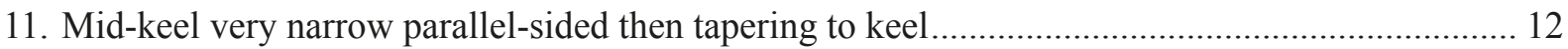

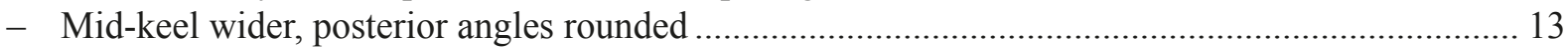

12. Mid-keel tapering to keel from end of the very narrow medial process of the collar

- Mid-keel parallel-sided for most of its length before tapering to join keel

C. visendum sp. nov.

C. plaumanni sp. nov.

13. Mesoventral collar with two short posteriorly directed processes either side of the medial process

C. opacum sp. nov.

- Collar without processes either side of the medial process C. steeli sp. nov.

14. Mesoventral lateral borders effaced in posterior half. 15.

- Mesoventral lateral borders distinct to mesocoxae. 16.

15. Pronotum widest in basal half, pubescence sparser.

C. luctuosum sp. nov.

- Pronotum widest medially pubescence denser C. faustum sp. nov.

16. Sides of mid-keel straight to posterior angles.

C. obscurum sp. nov.

- Sides of mid-keel not straight concave or slightly convex

17. Sides of mid keel slightly concave same width as the median extension of the collar anteriorly and strongly widening posteriorly

C. elongatum Sawada, 2008

- Mid-keel sides concave

18. Mid keel sides more pronouncedly concave, narrower at termination of the medial extension of the collar, chaetotaxy of male abdominal ventrites distinctive.

C. petri Darby, 2015

- Mid keel sides less pronouncedly concave wider at termination of the medial extension of the collar 
19. Posterior border of pronotum well-marked to emargination opposite the scutellum .

- Posterior border of pronotum very short reaching only half way to emargination opposite the scutellum C. eciton sp. nov.

20. Tip of keel sharply pointed.

- Tip of keel blunt/rounded.

21. Pronotal posterior border very narrow

C. sueae sp. nov.

- Pronotal posterior border wider, clearly distinct C. subfaustum sp. nov.

22. Medial extension of collar tapering to a blunt point. C. flavum sp. nov.

- Medial extension of collar parallel-sided 23

23. Pronotum wider, lateral margins more sharply rounded

- Pronotum narrower, sides more smoothly rounded C. ecuadoriense sp. nov. C. angusi sp. nov.

Cissidium angusi sp. nov. urn:1sid:zoobank.org:act:A1B4A3E6-D811-4560-87A1-D36B12D2391B Fig. 63

\section{Etymology}

Named after my colleague Dr Robert Angus.

\section{Material examined}

\section{Holotype}

BRAZIL • P; Bocaiuva, Parana; Dec. 1963; F. Plaumann leg.; FMNH.

\section{Paratypes}

BRAZIL • 4 우; same collection data as for holotype; one mounted verso, one mounted as a slide; MMUE, BMNH.

\section{Description}

Size. Habitus (Fig. 63A), length $0.95 \mathrm{~mm}$.

CoLour. Yellow brown, head slightly darker, pubescence, legs and antennae slightly paler.

HEAD. With a clearly marked linear depression behind the eyes, width across eyes $0.23 \mathrm{~mm}$; antennomeres III-XI length $0.42 \mathrm{~mm}$, III-IX length $0.25 \mathrm{~mm}, \mathrm{X}-\mathrm{XI}$ length $0.17 \mathrm{~mm}$; mentum as Fig 4E though sides slightly more sinuous.

Pronotum. Length $0.24 \mathrm{~mm}$, width $0.32 \mathrm{~mm}$, pubescent, without foveae; side margins rounded and then concave to acute hind angles, bordered, the border extending along the posterior margin to the medial emargination opposite the scutellum (Fig. 63B).

ELYTRA. Length $0.55 \mathrm{~mm}$, width $0.47 \mathrm{~mm}$, pubescent, length of setae as pronotum.

Mesoventrite. Medial extension of collar widening posteriorly; anterior margin of mid-keel wider than posterior, posterior margin not reaching anterior margin of mesocoxal cavities; keel with a series of \pm eight setae tapering to point above the interruption of the mesocoxal borders; mesoventral lateral margins without serrations; humeri toothed (Fig. 63C). 
MetaVentrite. Length $0.17 \mathrm{~mm}$, width across spines $0.13 \mathrm{~mm}$, with scattered setae, disc simple; posterior margins of mesocoxal cavities not serrate.

WINGs. Macropterous.

Genitalia. Female spermatheca globular. Male not known.

\section{Remarks}

One of the three Brazilian species in this group, and distinguished by the parallel-sided median extension of the mesoventral keel together with the wide anterior angles of the mid-keel and the long tapering keel.
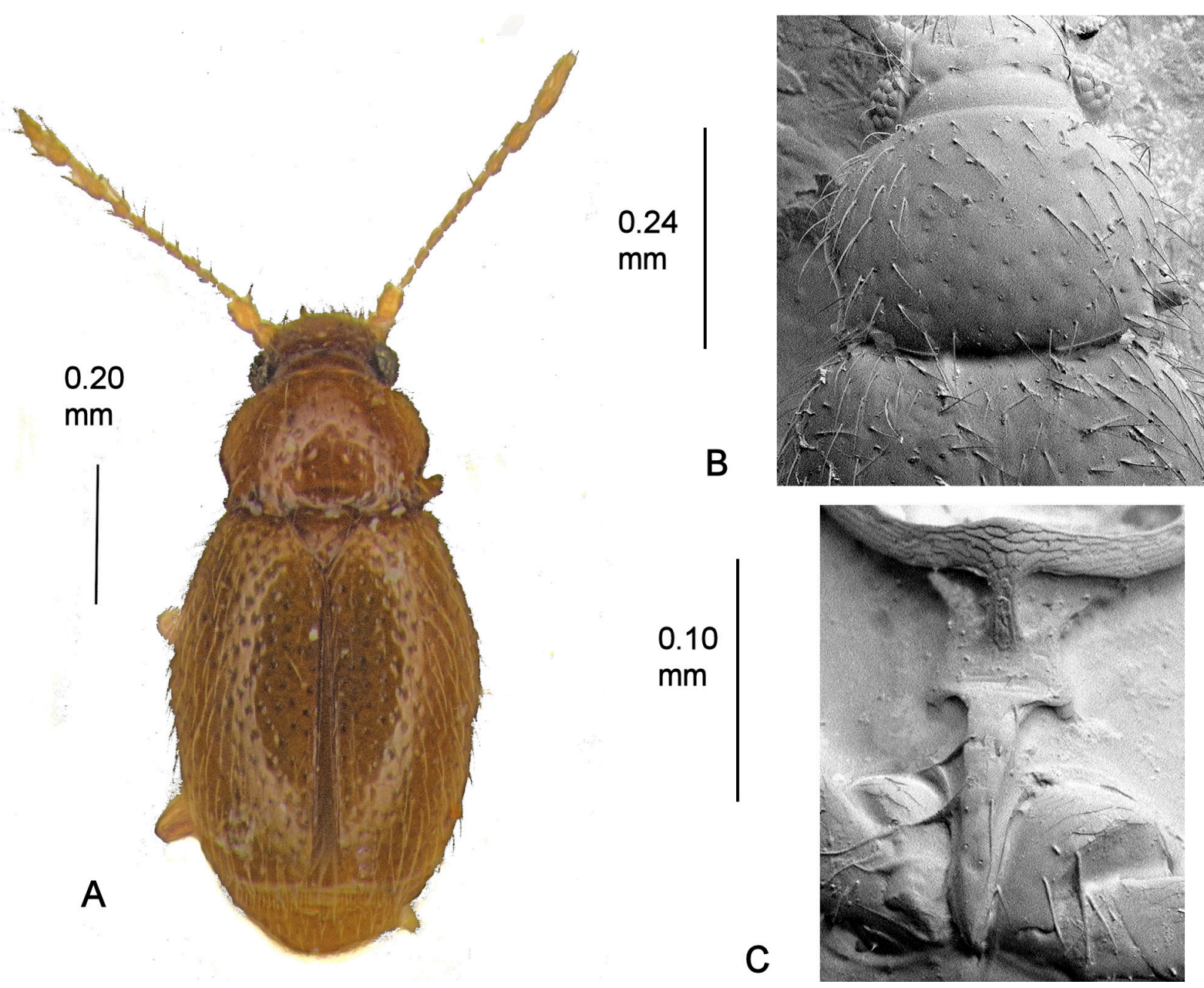

Fig. 63. Cissidium angusi sp. nov. A. Habitus. B. Pronotum, $\times$ 520. C. Mesoventrite showing median process of collar, mid-keel and keel, $\times 1040$. 
Cissidium arcuatum sp. nov.

urn:1sid:zoobank.org:act:990BE6BE-B990-4332-91A4-11B17CD39C1B

Figs 6D, 64

\section{Etymology}

Johnson ms name, presumed to be after the shape of the pronotal lateral margins.

\section{Material examined}

\section{Holotype}

VIETNAM • क; Tonkin, Hoabinh; A.de Cooman leg.; BM.1940-13; BMNH.

\section{Paratype}

VIETNAM • 1 ; ; same collection data as for holotype; mounted verso; MMUE,

\section{Description}

SizE. Habitus (Fig. 64A), length $0.67 \mathrm{~mm}$.

Colour. Dark brown, pubescence, legs and antennae yellow.

HEAD. With a shallow linear depression behind the eyes, width across eyes $0.21 \mathrm{~mm}$; antennomeres IIIXI length $0.36 \mathrm{~mm}$, III-IX length $0.20 \mathrm{~mm}$, X-XI length $0.16 \mathrm{~mm}$; mentum as Fig. 4A.

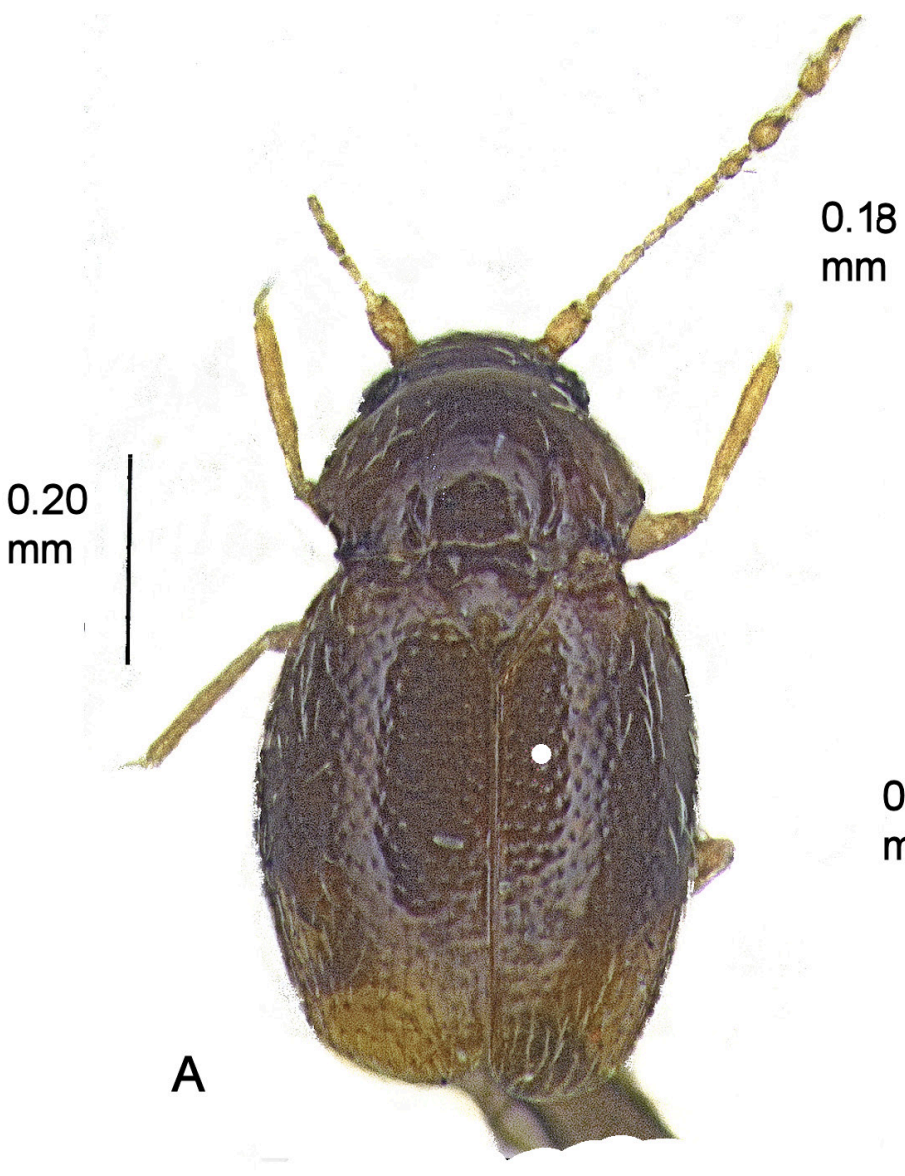

B

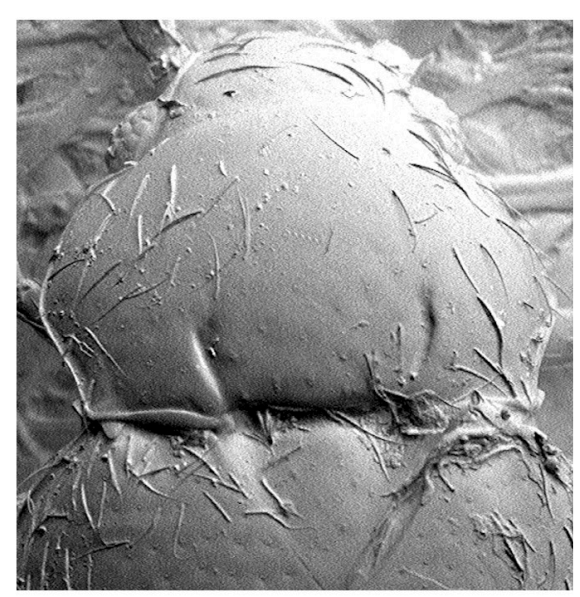

\begin{tabular}{l|}
0.08 \\
$\mathrm{~mm}$
\end{tabular}

C

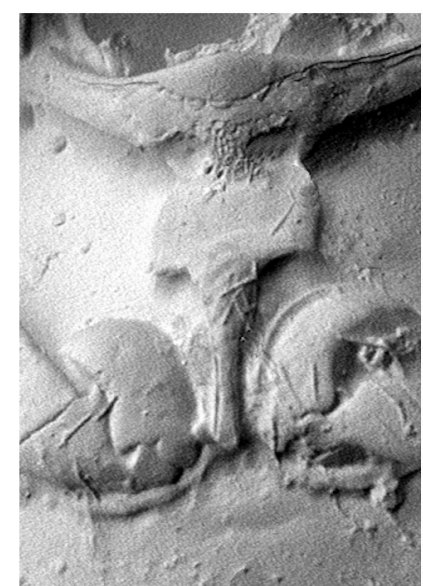

Fig. 64. Cissidium arcuatum sp. nov. A. Habitus. B. Pronotum, $\times 425$. C. Mesoventrite showing median process of collar, mid-keel and keel, $\times 550$. 
Pronotum. Length $0.18 \mathrm{~mm}$, width $0.30 \mathrm{~mm}$, with scattered pubescence and two short linear depressions converging posteriorly to base at sides of emargination opposite scutellum; lateral margins rounded and then sinuate to obtuse hind angles, bordered, the border extending along the posterior margin to the medial emargination (Fig. 64B).

ELYTRA. Length $0.47 \mathrm{~mm}$, width $0.39 \mathrm{~mm}$, pubescent, shallowly foveolate, length of setae as pronotum.

MesoventRITE. Collar with wide medial area on the anterior margin without reticulation; medial extension of collar short, wide, coarsely sculpted; mid-keel parallel-sided with two concave insertions anteriorly, hind angles not reaching anterior margins of mesocoxal borders; keel with a series of \pm eight setae broadest anteriorly then narrowing with slightly concave margins to a rounded tip at the interruption of the mesocoxal borders; mesoventral lateral margins serrate; humeri strongly toothed (Fig. 64C).

Metaventrite. Length $0.17 \mathrm{~mm}$, width across spines $0.11 \mathrm{~mm}$, with scattered setae, disc simple. Posterior margins of mesocoxal cavities not serrate.

Wings. Macropterous.

Genitalia. Female spermatheca Fig. 6D; male aedeagus as Fig. 6Fa-b, but length $0.10 \mathrm{~mm}$.

\section{Remarks}

Distinguished from C. aristophanousi sp. nov. by the two elongate foveae on the pronotum.

Cissidium besucheti sp. nov. urn:1sid:zoobank.org:act:7F5ED7E5-78EA-4BED-8512-F61581F1569C

Fig. 65

\section{Etymology}

Johnson ms name after the collector Claude Besuchet.

\section{Material examined}

\section{Holotype}

SRI LANKA • 3 ; North Central, Alut Oya, river edge on damp sand; 3 Feb. 1970; Mussard, Besuchet and Löbl leg.; MMUE.

\section{Paratypes}

SRI LANKA • $1 \hat{\jmath}, 2$ 우; same collection data as for holotype; $1 \hat{\jmath}, 1$ q mounted verso, latter missing antennae; MMUE, BMNH.

\section{Description}

Size. Habitus (Fig. 65A), length $0.54 \mathrm{~mm}$.

Colour. Dusky yellow.

HEAD. With a barely marked linear depression behind the eyes, width across eyes $0.16 \mathrm{~mm}$; antennomeres III-XI length $0.20 \mathrm{~mm}$, III-IX length $0.12 \mathrm{~mm}, \mathrm{X}-\mathrm{XI}$ length $0.08 \mathrm{~mm}$, constriction in antennomere XI obscured by setae; mentum as Fig. 4A. 
Pronotum. Densely pubescent; length $0.16 \mathrm{~mm}$, width $0.19 \mathrm{~mm}$, with shallow foveolae in basal half; sides rounded, hind angles obtuse, bordered, the border also on the posterior margin up to the corners of the sinuous emargination opposite the scutellum (Fig. 65B).

ELYTRA. Densely pubescent; length $0.34 \mathrm{~mm}$, width $0.24 \mathrm{~mm}$, appearing more parallel-sided than other species, pubescence a little shorter than on pronotum, foveolate.

Mesoventrite. Medial extension of collar onto mid-keel parallel-sided, rounded posteriorly; mid-keel margins narrowing anteriorly to join collar extension, posterior margin not reaching anterior margin of mesocoxal borders; keel narrow, tapering to a sharp point below the midpoint of the mesocoxae; mesoventral lateral margins serrate; humeri bluntly toothed (Fig. 65C).

Metaventrite. Length $0.13 \mathrm{~mm}$, pubescent except in anterior corners, width across spines $0.07 \mathrm{~mm}$, disc simple; posterior margins of mesocoxal cavities not serrate.

WINGS. Macropterous.

Genitalia. Male aedeagus as Fig. 6Ia-b. Female spermatheca not detected in the dissection.

\section{Remarks}

One of the only two species of Cissidium from Sri Lanka in this group. Distinguished from C. loebli sp. nov. by its smaller size, shorter antennae, more parallel elytra and paler colouration.
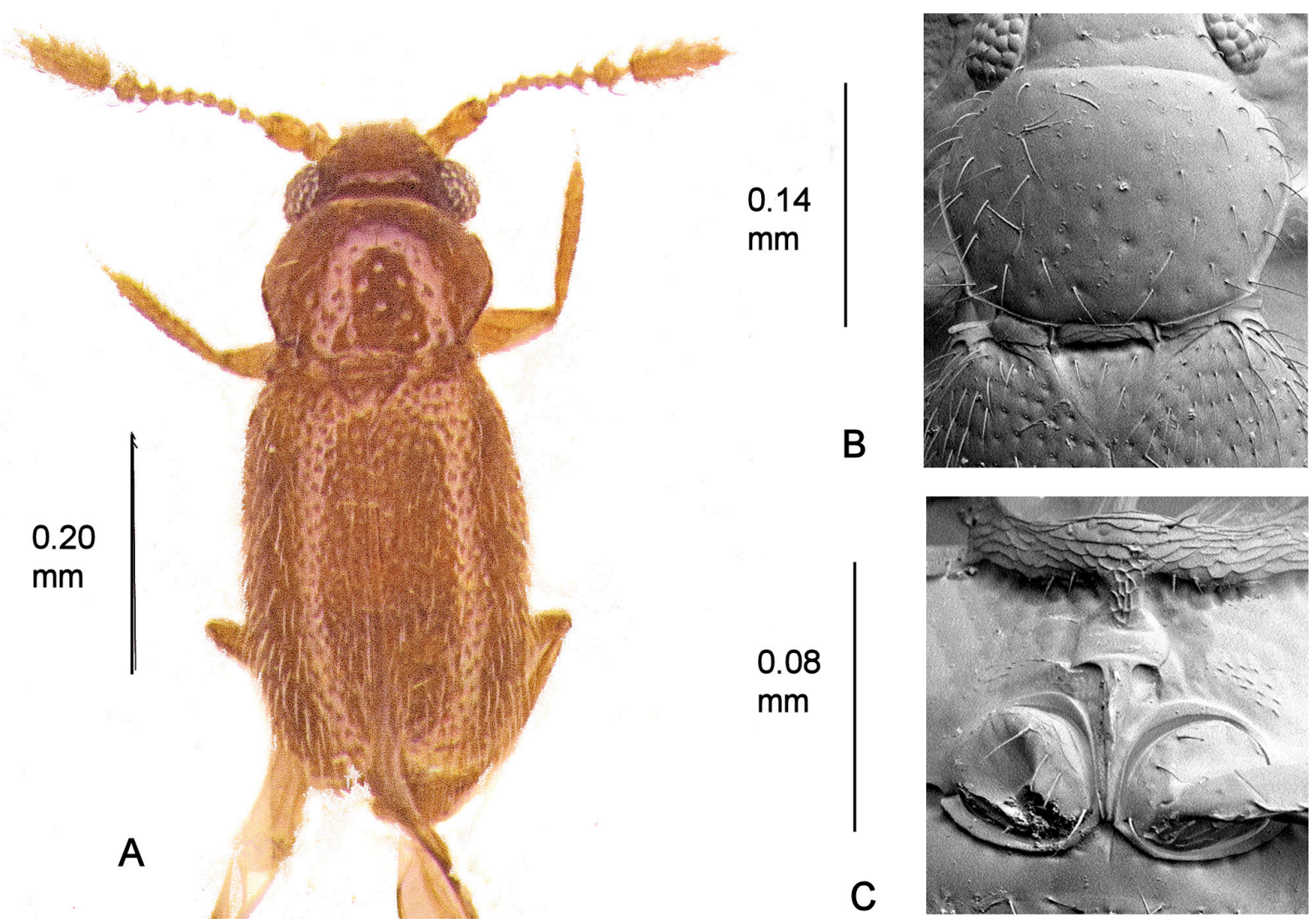

Fig. 65. Cissidium besucheti sp. nov. A. Habitus. B. Pronotum, $\times$ 755. C. Mesoventrite showing median process of collar, mid-keel and keel, $\times 1140$. 
Cissidium bilineatum sp. nov.

urn:1sid:zoobank.org:act:E3934680-B3BE-4C64-87A4-FE0BEEF8896F

Figs $3 \mathrm{H}, 6 \mathrm{~A}, 66$

\section{Etymology}

Named after the linear depressions on the pronotum

\section{Material examined}

\section{Holotype}

MALAYSIA • ○’; E Johore Sedili, Jason's Bay, coastal swamp forest; 13 Oct. 1963, very wet litter; D.H. Murphy leg.; No 82; FM(HD) \# 50.34; FMNH.

\section{Paratypes}

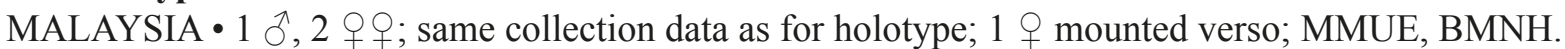

\section{Additional material}

MALAYSIA • 1 ô; Sabah, Sandakan Distr., Sapagaya Forest Res.; 27 Jul. 1980; logged dipterocarp forest; R.F. Inger and D.D. Davis leg.; lacking antennae and with one elytron re-attached; MMUE. This specimen, not listed as a paratype, may be this species. It is much darker than the type series but in all
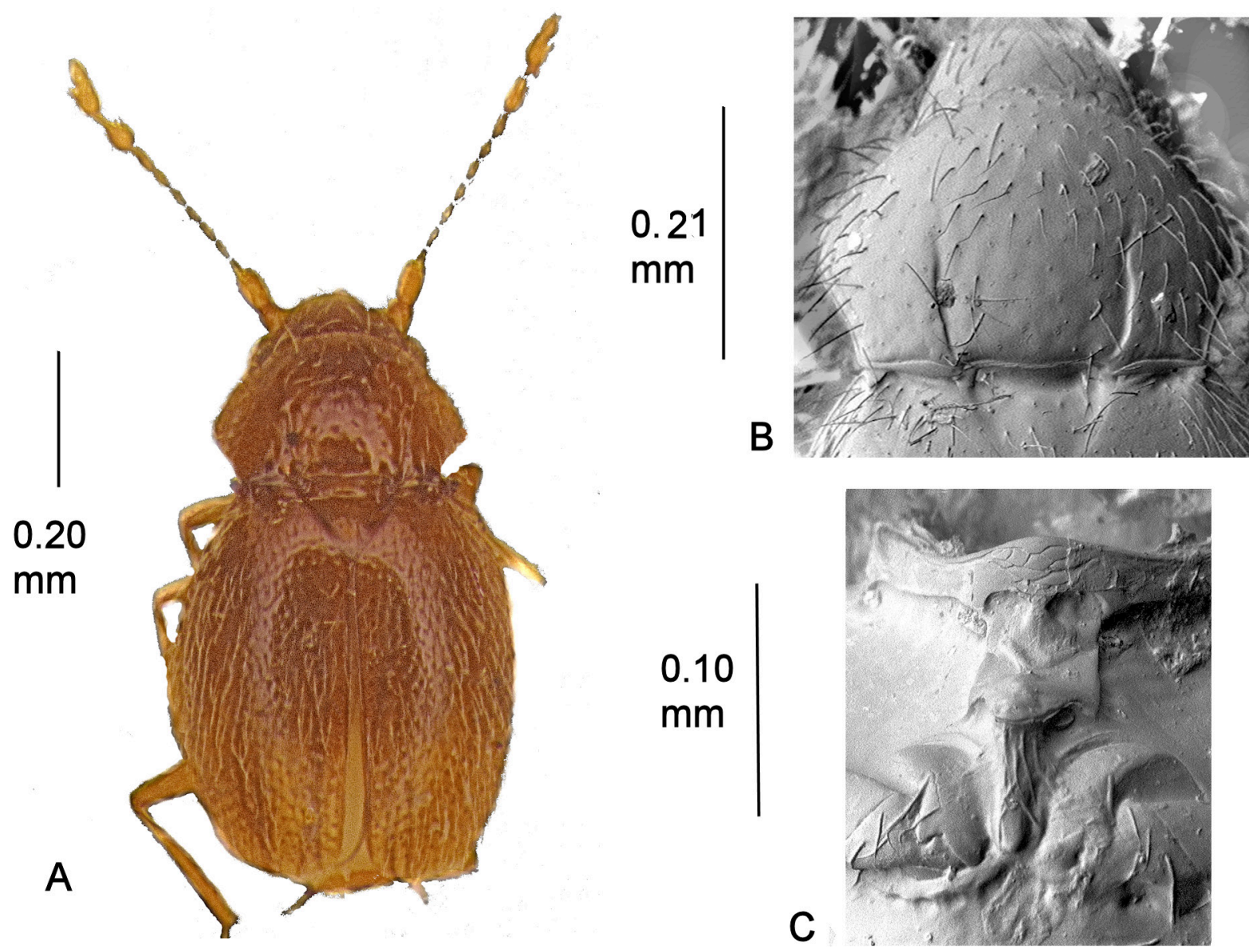

Fig. 66. Cissidium bilineatum sp. nov. A. Habitus. B. Pronotum, $\times$ 395. C. Mesoventrite showing median process of collar, mid-keel and keel, $\times 1140$. 
other respects similar, particularly in having a very setose head and patches on the mesoventral collar without reticulation.

\section{Description}

Size. Habitus (Fig. 66A), length $0.68 \mathrm{~mm}$.

CoLour. Yellow brown, pubescence, legs and antennae slightly paler

HEAD. Densely setose and foveolate (Fig. 3H); width across eyes $0.21 \mathrm{~mm}$; antennomeres III-XI length $0.33 \mathrm{~mm}$, III-IX length $0.21 \mathrm{~mm}, \mathrm{X}-\mathrm{XI}$ length $0.12 \mathrm{~mm}$ globular; mentum as Fig. 4A.

Pronotum. Length $0.21 \mathrm{~mm}$, width $0.31 \mathrm{~mm}$, pubescence more outstanding than on elytra, with two linear depressions reaching almost to the midpoint of the sclerite; side margins \pm sharply angled then sinuate to obtuse hind angles, bordered, the border extending along the entire posterior margin including the emargination opposite the scutellum (Fig. 66B).

ELYTRA. Length $0.44 \mathrm{~mm}$, width $0.40 \mathrm{~mm}$, more densely pubescent than pronotum, pubescence slightly shorter.

MESOVENTRITE. Medial extension of collar narrow either side of semi-circular impressions in collar then widening posteriorly; mid-keel posterior corners not reaching anterior margin of mesocoxal borders; keel with a series of \pm nine setae, almost parallel to a rounded tip between the mesocoxae; mesoventral lateral margins serrate in posterior half; humeri strongly toothed (Fig. 66C).

Metaventrite. Length $0.16 \mathrm{~mm}$, width across spines $0.10 \mathrm{~mm}$, with scattered setae, disc plain; posterior margins of mesocoxal cavities serrate.

Wings. Macropterous.

Genitalia. Male aedeagus as Fig. 6Fa-b. Female spermatheca (Fig. 6A).

\section{Remarks}

Distinguished from C. visendum sp. nov., the only other Cissidium recorded from Malaya in this group, by the presence of the linear depressions on the pronotum.

\section{Cissidium eciton sp. nov. urn:1sid:zoobank.org:act:96EE6F6D-EB77-47FB-84A1-AE55DA4C1971}

Figs $3 \mathrm{G}, 67$

\section{Etymology}

Johnson ms name. Eciton, a genus of ants, is used as a noun in apposition.

\section{Material examined}

\section{Holotype}

PANAMA • $O$; "B[arro] C[olorado] I[sland] C.Z., debris from abandoned bivouac of Eciton burchelli, Berlese, CNHM"; 25.i.1959; "3cRu, FMNH (HD) 59.284(6 [another character at this point is indecipherable]"; H.S. Dybas leg.; FMNH.

\section{Paratype}

PANAMA • 1 § ; Chiriqui Prov., Castita Alta, Finca Larida, nr Boquete; 7750 ft a.s.1.; 17 Mar. 1959; forest floor litter under palms etc., H.S. Dybas leg.; FM(HD) \# 59.257; MMUE. Fragments of a third specimen are also pinned with this specimen. 


\section{Description}

Size. Habitus (Fig. 67A), length $0.67 \mathrm{~mm}$.

CoLour. Dark yellow brown, shining, pubescence, antennae and legs paler.

HEAD. With a deep transverse depression behind the eyes (Fig. 3G), width across eyes $0.19 \mathrm{~mm}$; antennomeres III-XI length $0.38 \mathrm{~mm}$, III-IX length $0.22 \mathrm{~mm}, \mathrm{X}-\mathrm{XI}$ length $0.16 \mathrm{~mm}$; mentum as Fig. 4A.

Pronotum. Length $0.19 \mathrm{~mm}$, width $0.27 \mathrm{~mm}$, pubescent, without either foveolae or foveae; lateral margins rounded and narrowly bordered, the borders extending a short distance along the posterior margin, hind angles acute, emargination opposite the scutellum sinuous (Fig. 67B).

ELYTRA. Length $0.42 \mathrm{~mm}$, width $0.37 \mathrm{~mm}$, pubescent, setae same length as pronotum, without foveolae.

MesoventRITE. Collar with a narrow medial extension; mid-keel narrow, anterior corners almost obliterated before reaching collar, posterior corners not joining mesocoxal anterior borders, slightly raised at junction with keel; keel with \pm four setae, long, narrow, pointed at termination between
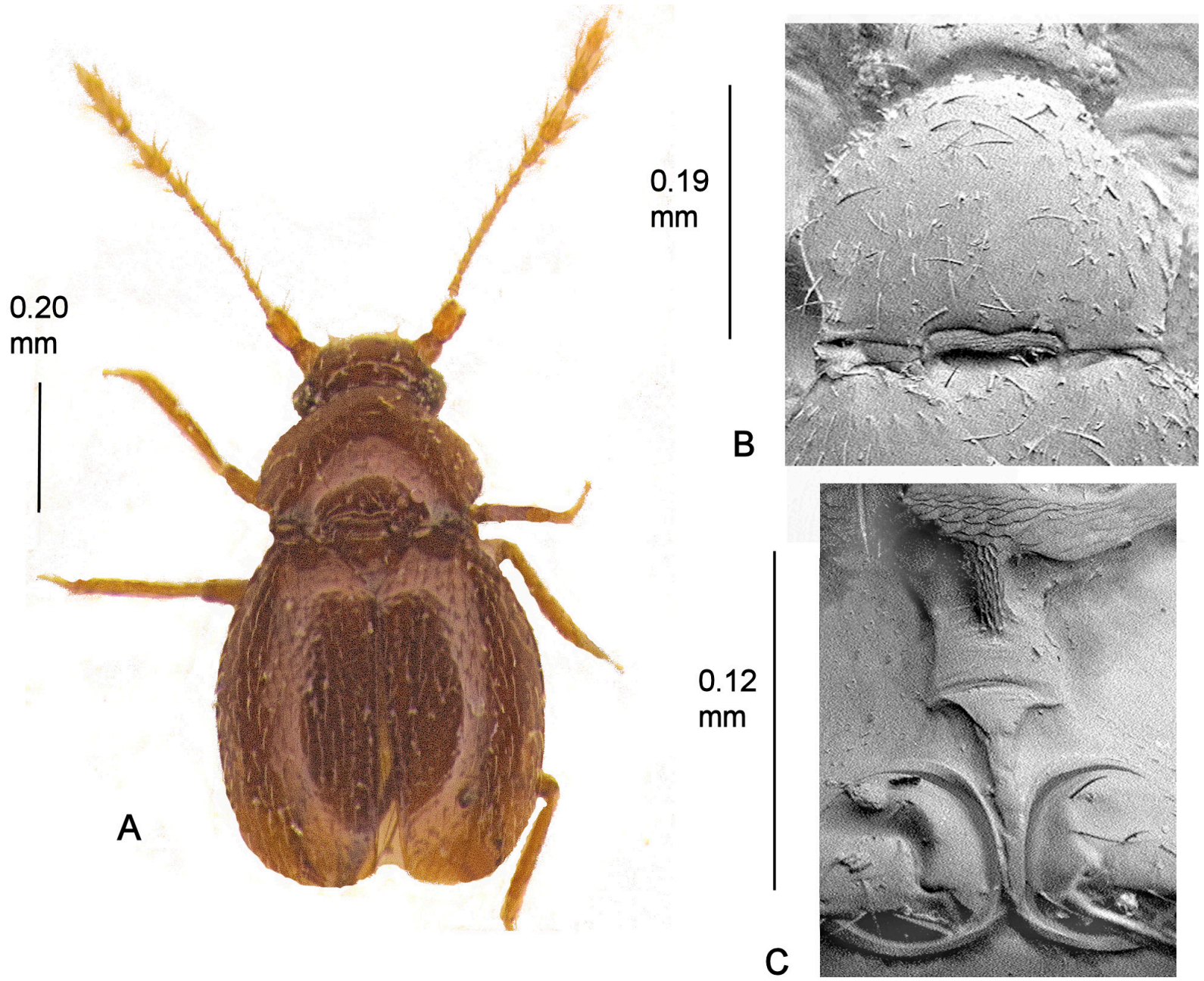

Fig. 67. Cissidium eciton sp. nov. A. Habitus. B. Pronotum, $\times$ 305. C. Mesoventrite showing median process of collar, mid-keel and keel, $\times 790$. 
the mesocoxae; mesoventral lateral margins partially obliterated, without serrations; humeri toothed (Fig. 67C).

Metaventrite. Length $0.15 \mathrm{~mm}$, sparsely pubescent, female disc plain, male with a median depression, width across spines $0.09 \mathrm{~mm}$; posterior margins of mesocoxal cavities without serrations.

Wings. Macropterous.

Genitalia. Female spermatheca globular.

\section{Remarks}

One of the five Panamanian species in this group. Distinguished by the short, effaced borders on the posterior margin of the pronotum.

\section{Cissidium ecuadoriense sp. nov. urn:lsid:zoobank.org:act:4387F4E8-31A2-4780-9822-C6FCDDA1FA29}

Fig. 68

\section{Etymology}

Named after the country where the insect was found.

\section{Material examined}

\section{Holotype}

ECUADOR • +; Ingenio San Carlos, Bguayoquil; Aug. 1975; H. Franz leg.; MMUE.

\section{Paratypes}

ECUADOR • 2 ex.; same collection data as for holotype; one mounted verso; MMUE, BMNH.

\section{Description}

Size. Habitus (Fig. 68A), length $0.71 \mathrm{~mm}$.

Colour. Dark yellow brown, shining, pubescence, antennae and legs paler.

HEAD. Frons behind the eyes obscured; width across eyes $0.19 \mathrm{~mm}$; antennomeres III-XI length $0.28 \mathrm{~mm}$, III-IX length $0.13 \mathrm{~mm}, \mathrm{X}-\mathrm{XI}$ length $0.15 \mathrm{~mm}$; mentum and prementum obscured.

Pronotum. Length $0.20 \mathrm{~mm}$, width $0.29 \mathrm{~mm}$, pubescent, without either foveolae or foveae; lateral margins rounded and sinuate before rectangular hind angles, narrowly bordered, the borders extending along the posterior margin to the ends of the emargination opposite the scutellum (Fig. 68B).

ELYTRA. Length $0.41 \mathrm{~mm}$, width $0.39 \mathrm{~mm}$, pubescent, setae same length as pronotum, without foveolae.

Mesoventrite. Collar with a long, narrow, pointed medial extension; mid-keel anterior corners almost obliterated before reaching collar, posterior corners not joining mesocoxae, slightly raised at junction with keel; keel with \pm eleven setae, long, narrow, parallel-sided to termination below interruption of mesocoxal margins; mesoventral lateral margins without serrations; humeri toothed (Fig. 68C).

MetaVentrite. Length $0.15 \mathrm{~mm}$, sparsely pubescent, disc plain, width across spines $0.08 \mathrm{~mm}$; posterior margins of mesocoxal cavities without serrations. 
WINGS. Macropterous.

GeNitALIA. Female spermatheca globular. Males not known.

\section{Remarks}

The only species of Cissidium to have been described from Ecuador.
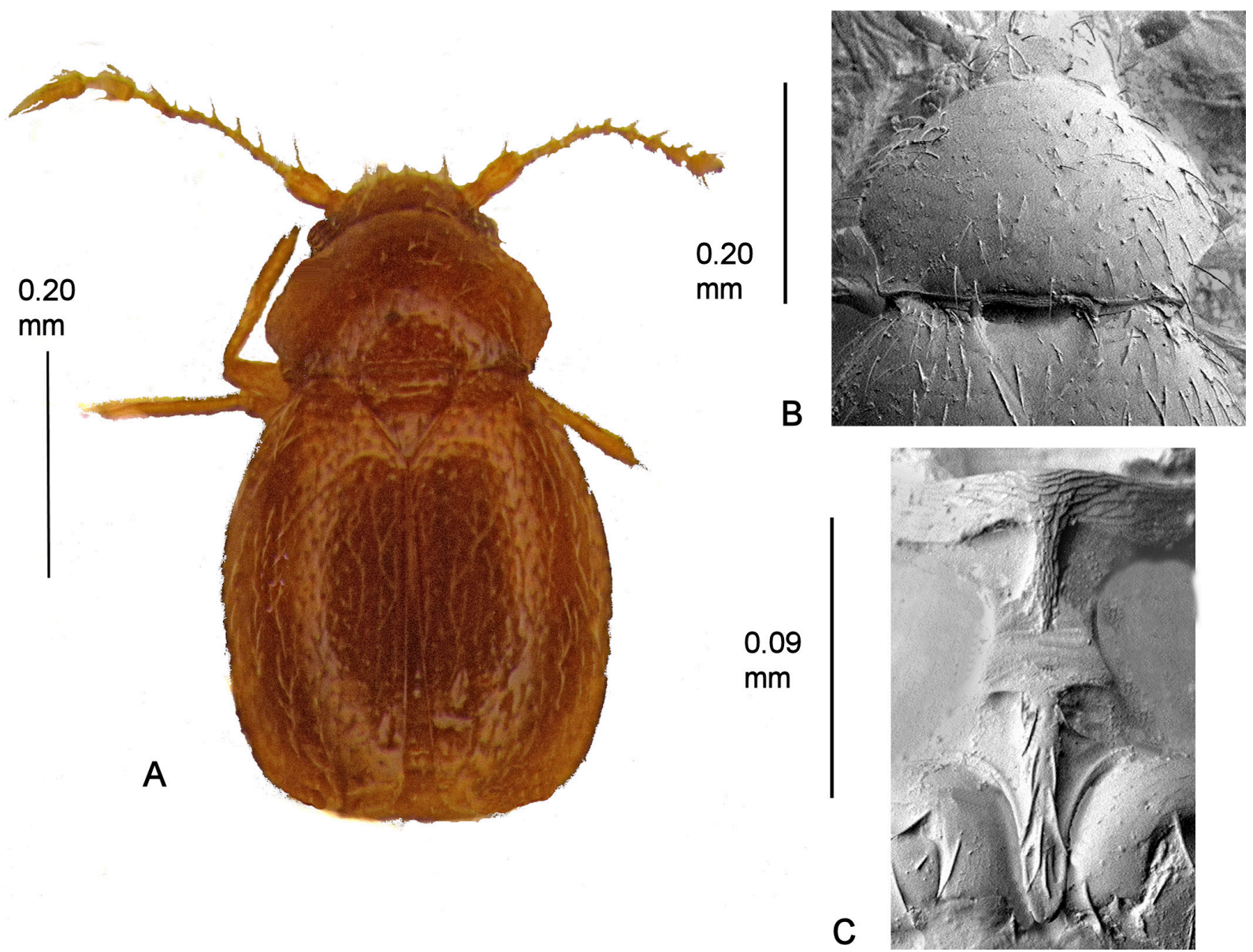

Fig. 68. Cissidium ecuadoriense sp. nov. A. Habitus. B. Pronotum, $\times 400$. C. Mesoventrite showing median process of collar, mid-keel and keel, $\times 1020$.

Cissidium elongatum Sawada, 2008

Fig. 69

\section{Material examined}

Paratypes

JAPAN • 5 ex.; Mt Ichifusa, Kumamoto Pref.; 13 May 1985; S. Nomura leg.; YS • 1 ○’; Kawakami-mura, Nara Pref.; 29 Jan. 1995; K. Ikeuchi leg.; BMNH • 1 ð̊; Mt Kumosou, Tokushima Pref.; 18 Aug. 1988; M. Sakai leg.; YS • 1 đ̊; Nakanoshima Is. Tokara Isls., Kagoshima Pref.; 2 May 1987; S. Nomura leg.; BMNH $\bullet 5$ ô; Hatsuno, Amami-Oshima Is., Kagoshima Pref.; 13 Oct. 1988; Y. Nishikawa leg.; YS, BMNH • 1 đ̊; Haneji, Mt. Tanodake, Okinawa Pref.; 25 Oct. 1987; Y. Nishikawa leg.; YS. 


\section{Supplementary description}

The following description amplifies the type description of Sawada (2008) in order to conform with the entries in the present paper.

Size. Habitus (Fig. 69A), length $0.72 \mathrm{~mm}$.

Colour. Reddish brown to light brown, antennae, legs and pubescence dusky yellow. HEAD. With a deep transverse depression behind the eyes, width across eyes $0.21 \mathrm{~mm}$.

Pronotum. Length $0.19 \mathrm{~mm}$, width $0.29 \mathrm{~mm}$, pubescent and shallowly foveolate; side margins rounded to obtuse hind angles, narrowly bordered, the border continuing along the posterior margin to the sinuous emargination opposite the scutellum (Fig. 69B).

ELYTRA. Length $0.45 \mathrm{~mm}$, width $0.38 \mathrm{~mm}$, more densely pubescent basally than pronotum, without foveolae.

Mesoventrite. Median extension of keel very broad; mid-keel anteriorly same width as collar extension then with concave sides to hind angles not reaching anterior borders of the mesocoxae; keel tapering to point below mid-point of the mesocoxae; mesoventral lateral borders evenly rounded and serrate in posterior half; humeri toothed (Fig. 69C).
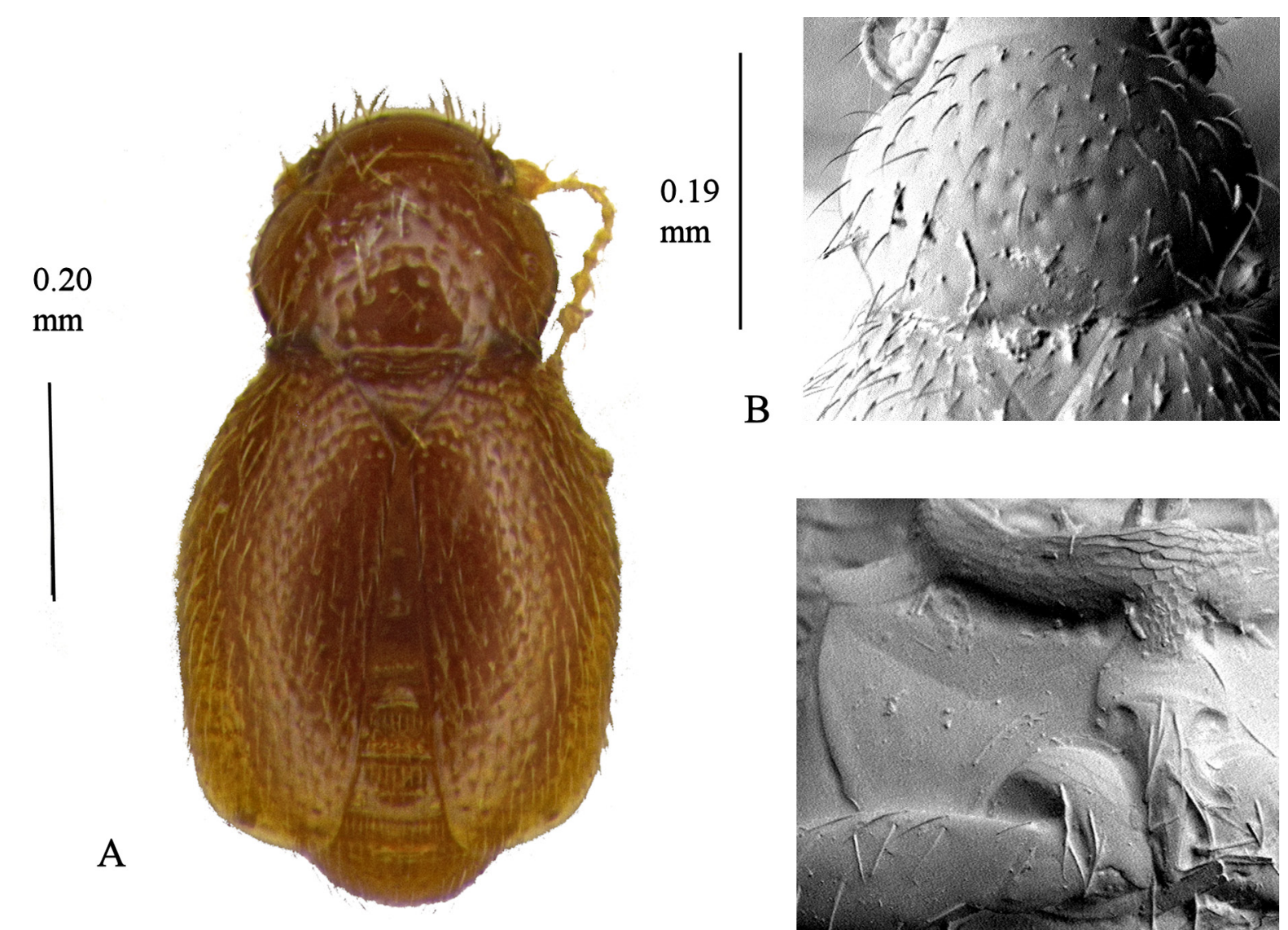

$\mathrm{B}$

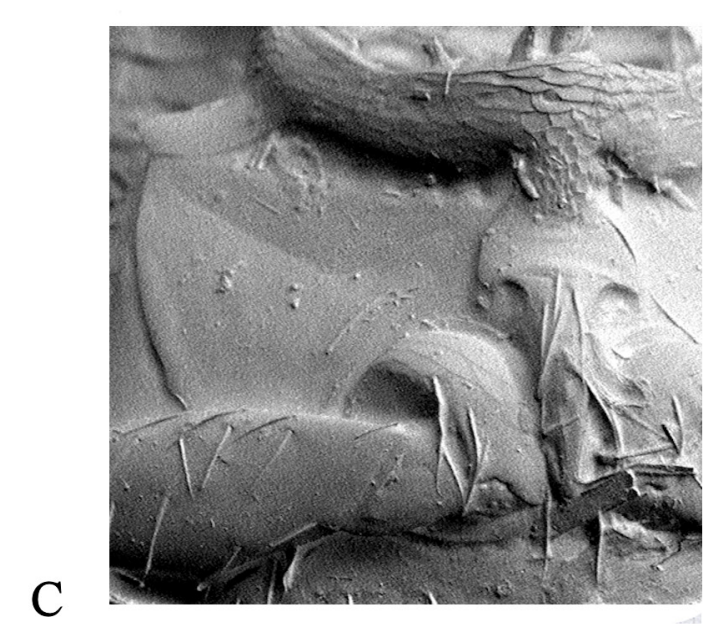

Fig. 69. Cissidium elongatum Sawada, 2008. A. Habitus. B. Pronotum, $\times 525$ C. Mesoventrite showing median process of collar, mid-keel, keel and lateral margin, $\times 665$. 
Metaventrite. Sparsely pubescent; length $0.15 \mathrm{~mm}$; disc simple, distance across spines $0.11 \mathrm{~mm}$; mesocoxal posterior borders serrate.

Genitalia. Male aedeagus very short as Fig. 6Ia-b. Female spermatheca ovoid.

\section{Remarks}

The only Japanese species in this group.

Cissidium faustum sp. nov. urn:1sid:zoobank.org:act:F12FEC5C-CB83-4AB9-9871-E24D1C6429BD

Fig. 70

\section{Etymology}

Named after the Latin adjective 'faustus', meaning 'auspicious' and referring to the likelihood of more Cissidium being recorded in the future from Mexico.

\section{Material examined}

Holotype

PANAMA • + ; Chiriqui Prov., Castita Alta, Finca Larida nr Boquete; 17 Mar. 1959; $7750 \mathrm{ft}$ a.s.1.; forest floor litter under palms etc.; H.S. Dybas leg.; FM(HD) \#59.257; FMNH.

\section{Paratypes}

PANAMA $\bullet 1$ ${ }^{\lambda}$; same collection data as for holotype; MMUE.

MEXICO • 1 q; ver. 1.2 miles S of Huatusco; 1244 m a.s.l.; cloud forest litter; 2 Aug. 1969; S. and J. Peck leg.; BMNH.

\section{Description}

Size. Habitus (Fig. 70A), length $0.67 \mathrm{~mm}$.

CoLour. Dark yellow brown, shining, pubescence, antennae and legs paler.

HEAD. With a transverse depression behind the eyes, width across eyes $0.19 \mathrm{~mm}$; antennomeres III-XI length $0.32 \mathrm{~mm}$, III-IX length $0.18 \mathrm{~mm}, \mathrm{X}-\mathrm{XI}$ length $0.14 \mathrm{~mm}$; mentum as Fig.4A.

Pronotum. Length $0.20 \mathrm{~mm}$, width $0.29 \mathrm{~mm}$, pubescent, without both foveolae and foveae; lateral margins rounded and narrowly bordered, the borders extending a short distance along the posterior margin, hind angles rectangular, emargination opposite scutellum sinuous (Fig.70B).

ELYTRA. Length $0.44 \mathrm{~mm}$, width $0.37 \mathrm{~mm}$, pubescent, setae same length as pronotum, without foveolae.

MesoventRITE. Collar with strongly arched medial extension; mid-keel narrow, anterior corners almost obliterated before reaching collar, posterior corners not joining mesocoxal anterior borders, raised at junction with keel; keel with \pm nine setae, long, narrow, pointed at termination below interruption of mesocoxal margins; mesoventral lateral margins without clear serrations; humeri sharply toothed (Fig. 70C).

MetaVentrite. Length $0.15 \mathrm{~mm}$, sparsely pubescent, disc simple in female, male with a medial depression, width across spines $0.08 \mathrm{~mm}$; posterior margins of mesocoxal cavities without serrations. 
Wings. Macropterous.

Genitalia. Female spermatheca globose with a sinuous duct.

\section{Remarks}

The only species of Cissidium to have been described from Mexico. One of the five Panamanian species in this group. Distinguished by the median extension of the mesoventral collar almost reaching to the lateral margins of the mid-keel anteriorly.
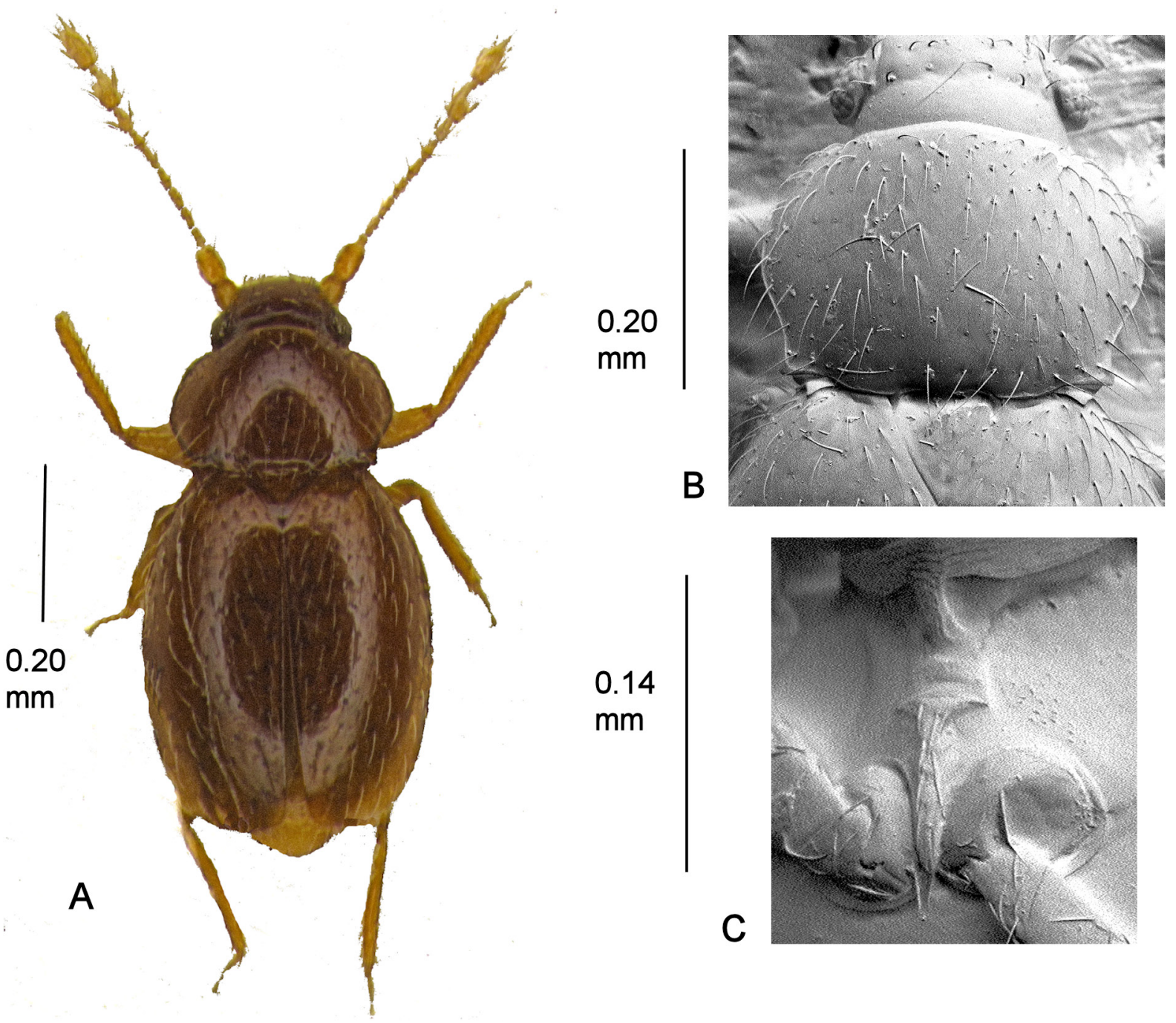

Fig. 70. Cissidium faustum sp. nov. A. Habitus. B. Pronotum, $\times$ 695. C. Mesoventrite showing median process of collar, mid-keel and keel, $\times 590$. 
Cissidium flavum sp. nov.

urn:1sid:zoobank.org:act:A36CD579-8C69-473F-B1FA-2CACDF167FBB

Fig. 71

\section{Etymology}

Johnson ms name, after the yellow colour of the specimen.

\section{Material examined}

\section{Holotype}

BRAZIL • + ; Tainhas R.G. de Sul; 1 May 1959; specimen mounted as a disarticulated slide; F. Plaumann leg.; FMNH.

\section{Description}

Size. Habitus (Fig. 71A), length $0.62 \mathrm{~mm}$.

CoLour. Yellow.
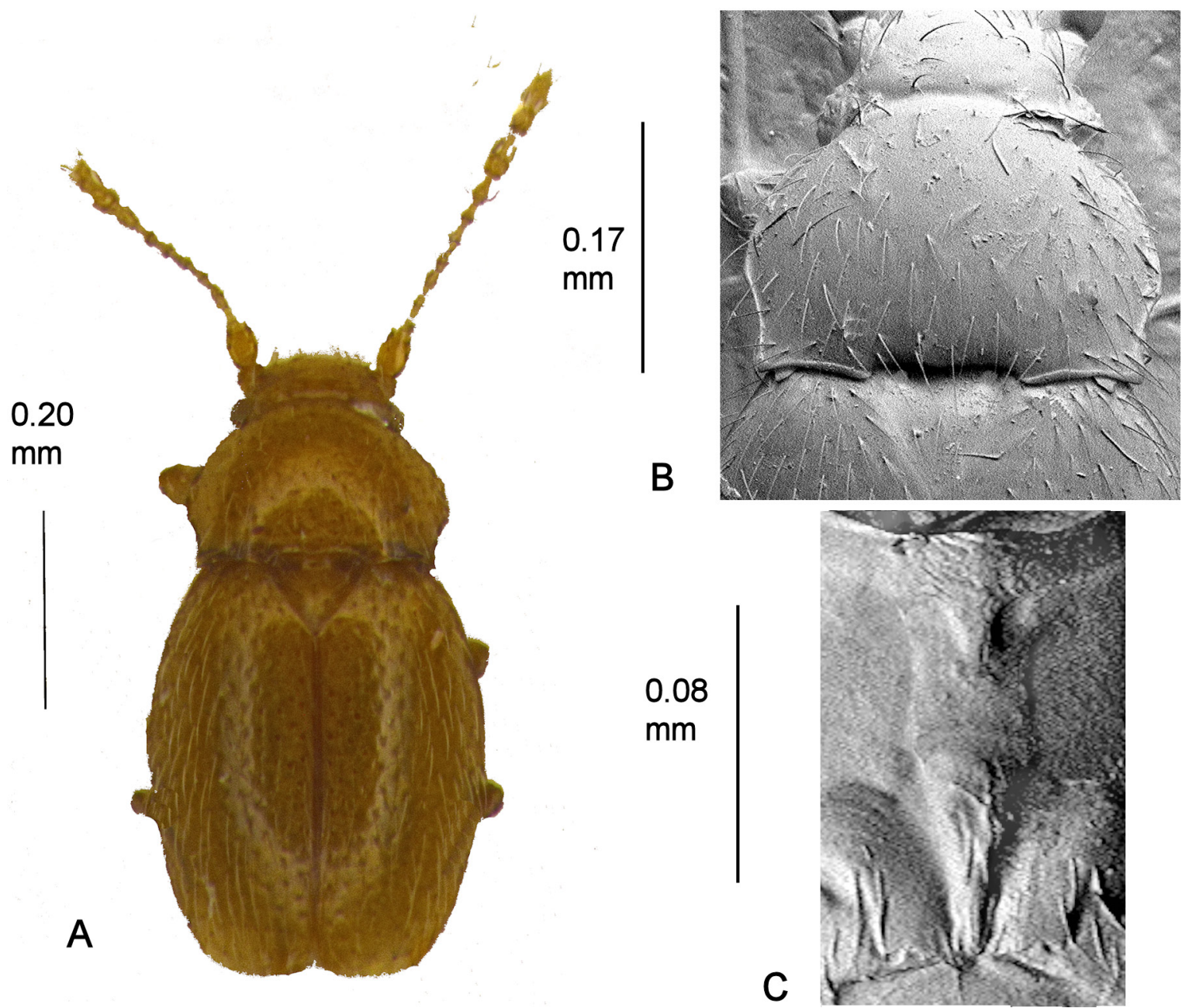

Fig. 71. Cissidium flavum sp. nov. A. Habitus. B. Pronotum, $\times$ 585. C. Mesoventrite showing median process of collar, mid-keel and keel, $\times 530$. 
HEAD. With a transverse depression behind the eyes, width across eyes $0.19 \mathrm{~mm}$; mentum and prementum obscured; antennomeres III-XI length $0.31 \mathrm{~mm}$, III-IX length $0.19 \mathrm{~mm}, \mathrm{X}-\mathrm{XI}$ length $0.12 \mathrm{~mm}$ globular.

Pronotum. Length $0.17 \mathrm{~mm}$, width $0.27 \mathrm{~mm}$, pubescent, without foveolae and foveae; lateral margins shallow angled, narrowly bordered, the borders extending along the posterior margin to the angulate medial emargination opposite the scutellum, hind angles sharp, acute (Fig. 71B).

ELYTRA. Length $0.42 \mathrm{~mm}$, width $0.35 \mathrm{~mm}$, pubescent, setae same length as pronotum, without foveae and foveolae.

MesoventRite. Collar with tapering medial extension; mid-keel narrow, anterior corners almost obliterated before reaching collar, posterior corners not joining mesocoxal anterior borders, raised at junction with keel; keel with \pm nine setae, broad at base and tapering to bluntly pointed termination at mesocoxal hind margins; mesoventral lateral margins without clear serrations; humeri toothed (Fig. 71C).

Metaventrite. Length $0.12 \mathrm{~mm}$, sparsely pubescent, disc simple, width across spines $0.08 \mathrm{~mm}$, spines short; posterior margins of mesocoxal cavities without serrations.

WINGS. Macropterous.

Genitalia. Female spermatheca globular. Male not known.

\section{Remarks}

One of the three Brazilian species in this group. Distinguished by the pointed median extension of the mesoventral keel together with the partially parallel- sided mid-keel.

Cissidium globosum Darby, 2015

Figs $2 \mathrm{G}, 72$

\section{Material examined}

\section{Holotype}

BOLIVIA • ; ; Santa Cruz Dep., Espejillos; 1754'04" S, 63²6'16" E; 536 m a.s.1.; 1 Dec. 2013; sifting under palms; Winkler app. extrac.; P. Baňař leg.; UASC.

\section{Supplementary description}

The following description amplifies the type description of Darby (2015), in particular by adding more details of the meso- and metaventral characters, in order to conform with the entries in the present paper.

SizE. Habitus (Fig. 72A), length $0.61 \mathrm{~mm}$.

CoLour. Brownish yellow, legs and antennae paler.

HEAD. With a linear depression between the eyes, distance across the eyes $0.19 \mathrm{~mm}$; antennomeres IIIXI $0.26 \mathrm{~mm}$ long, terminal antennomeres globose (Fig. 2G).

Pronotum. $0.25 \mathrm{~mm}$ wide, $0.17 \mathrm{~mm}$ long (Fig. 72B).

ELyTRA. $0.41 \mathrm{~mm}$ long, $0.35 \mathrm{~mm}$ wide, foveolae deeper than those on pronotum. 
Mesoventrite. Medial extension of collar broad; mid-keel with concave lateral margins, the anterior corners wider than the posterior corners which do not reach the mesocoxal anterior borders, shallowly raised before keel with \pm six setae from concave foveolae; keel short, pointed, terminating close to rear margin of mesocoxae; lateral margins of mesoventrite without serrations (Fig. 72C).

Metaventrite. Posterior margins of mesocoxae partially serrate, spines long.

GenitaLia. Female spermatheca globular. Males not known.

\section{Remarks}

Separable from the six other Bolivian Cissidium by its small size, the strongly arched median extension of the mesoventral collar and the parallel sided mid-keel.
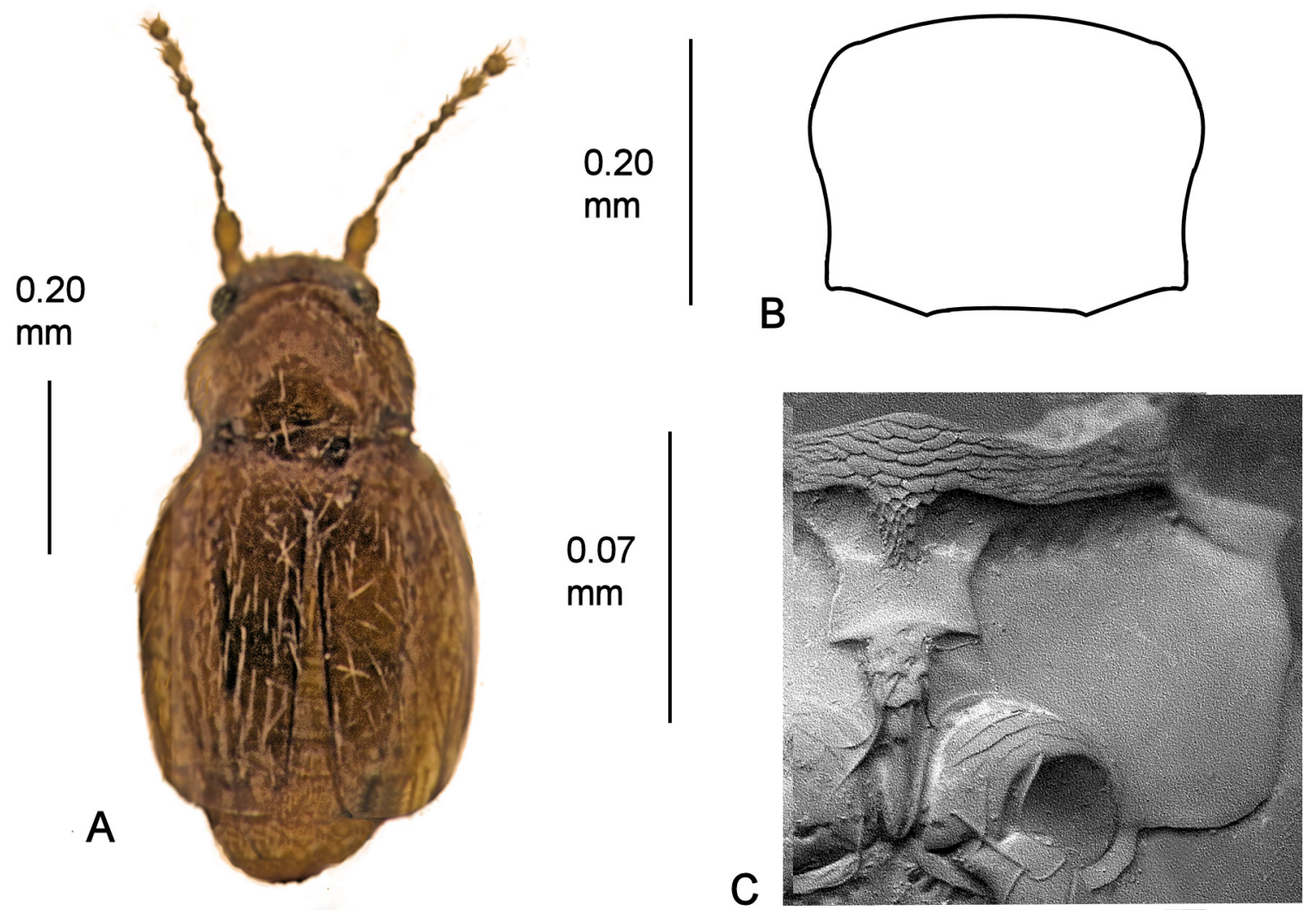

Fig. 72. Cissidium globosum Darby, 2015. A. Habitus. B. Pronotum. C. Mesoventrite showing median process of collar, lateral margin, mid-keel and keel, $\times 1000$. 
Cissidium insulare sp. nov.

urn:1sid:zoobank.org:act:D36570BE-5CC4-4B8B-9D43-06E6A02D87F1

Fig. 73

\section{Etymology}

Johnson ms name, after the discovery of the species on an island (Jamaica).

\section{Material examined}

\section{Holotype}

JAMAICA • + ; Blue Mountains, near Hardwar Gap; 20 Nov. 1968; forest litter; H. Franz leg.; MMUE.

\section{Paratype}

JAMAICA $•$; ; same collection data as for holotype; mounted verso; MMUE.

\section{Additional material}

Two indet. specimens mounted as slides without data except 'Jamaica' in MMUE may be associated with these specimens.

\section{Description}

Size. Habitus (Fig. 73A), length $0.84 \mathrm{~mm}$.
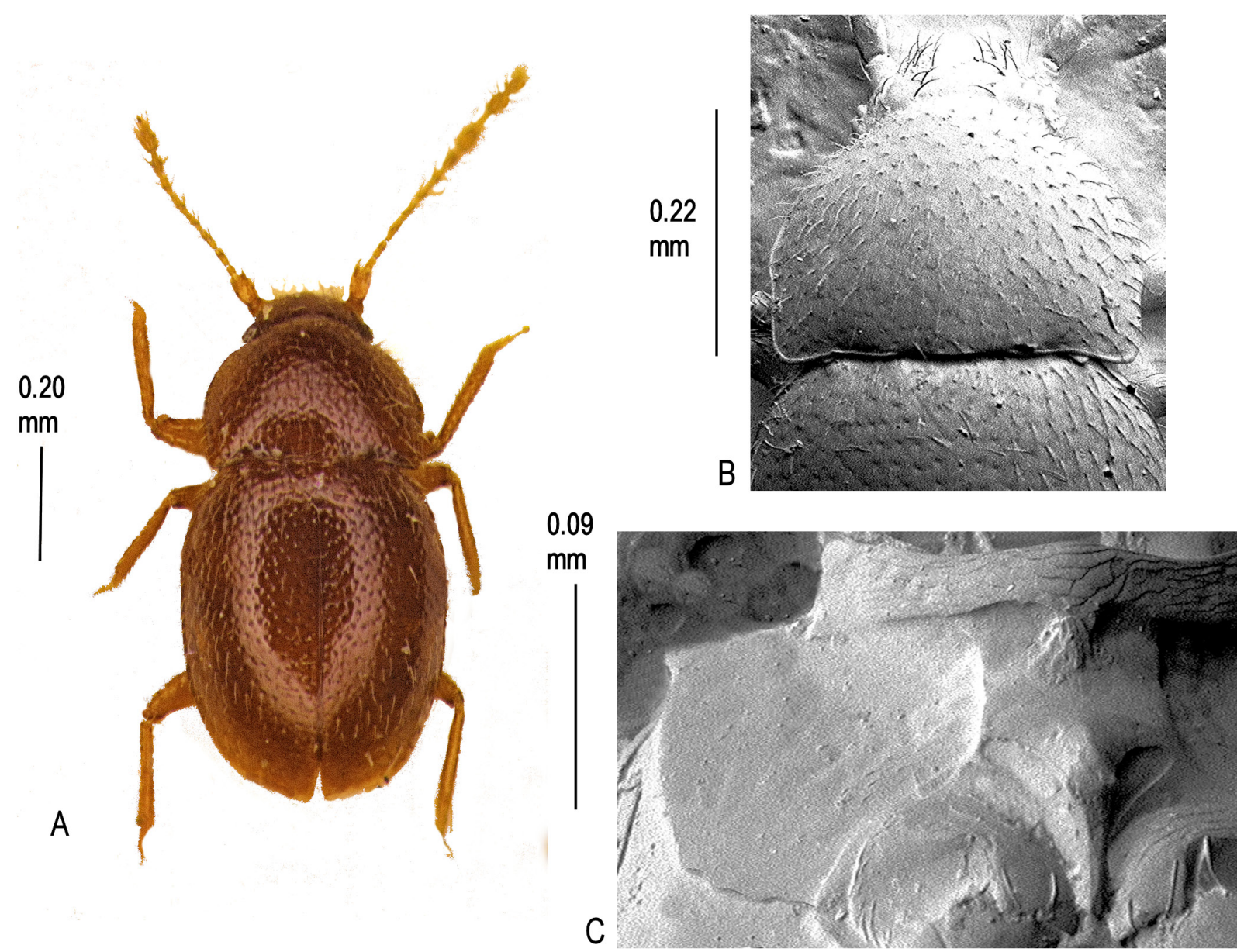

Fig. 73. Cissidium insulare sp. nov. A. Habitus. B. Pronotum, $\times 315$. C. Mesoventrite showing median process of collar, lateral margin, mid-keel and keel, $\times 595$. 
CoLour. Dark brown, shining, pubescence and antennae dusky yellow.

HEAD. With a linear depression behind the eyes, width across eyes $0.22 \mathrm{~mm}$; antennomeres III-XI length $0.40 \mathrm{~mm}$, III-IX length $0.25 \mathrm{~mm}, \mathrm{X}-\mathrm{XI}$ length $0.25 \mathrm{~mm}$; mentum and prementum obscured.

Pronotum. Length $0.22 \mathrm{~mm}$, width $0.38 \mathrm{~mm}$, densely pubescent, without foveae and only very faint foveolae; lateral margins rounded, almost parallel posteriad, hind angles rounded, narrowly bordered, the border continuing onto the posterior margin but absent opposite the scutellum, emargination opposite the scutellum absent (Fig. 73B).

ELYTRA. Length $0.56 \mathrm{~mm}$, width $0.45 \mathrm{~mm}$, densely pubescent and faintly foveolate as pronotum.

MesoventRITE. Collar medial extension short, pointed; mid-keel almost parallel-sided, posterior corners with short carinae reaching mesocoxal anterior borders, raised medially at junction with keel; keel, narrow, long, with pointed termination mid-way between mesocoxae; mesoventral lateral margins serrate in posterior half; humeri toothed (Fig. 73C).

Metaventrite. Length $0.13 \mathrm{~mm}$, male with a deep triangular, shallowly foveolate depression with a sharply marked emargination in the posterior margin (as Fig 7E); posterior borders of mesocoxae not serrate.

Wings. Female apterous. Male macropterous.

GENITALIA. Female spermatheca globular. Male aedeagus narrow and sharply pointed.

\section{Remarks}

Distinguished from C. seditiosum sp. nov., the only other species of Cissidium reported from Jamaica, by the rounded as opposed to acute hind angles of the pronotum.

Cissidium loebli sp. nov. urn:1sid:zoobank.org:act:F65097B6-D4E1-4050-942B-779A54F243D3

Fig. 74

\section{Etymology}

Named after the distinguished Czech entomologist Dr Ivan Löbl, one of the collectors of the specimens.

\section{Material examined}

\section{Holotype}

SRI LANKA • ○’; Central, Hakgala; 1200-1800 m a.s.1.; 28 Jan. 1970; Mussard, Besuchet and Löbl leg.; MMUE.

\section{Paratypes}

SRI LANKA • 2 $\uparrow+, 1 \AA$; same collection data as for holotype; $1 q$ and $1 \lesssim$ mounted verso; MMUE.

\section{Description}

Size. Habitus (Fig. 74A), length $0.58 \mathrm{~mm}$.

CoLour. Yellow brown, pubescence and antennomeres slightly paler. 
HEAD. With several shallow foveae behind the eyes, not forming a distinct linear depression, eyes small, width across $0.16 \mathrm{~mm}$; antennomeres III-XI length $0.34 \mathrm{~mm}$, III-IX length 0.20, X-XI length $0.11 \mathrm{~mm}$; mentum as Fig. 4B.

Pronotum. Length $0.14 \mathrm{~mm}$, width $0.24 \mathrm{~mm}$, reticulate, densely pubescent, without foveae; sides rounded, then almost parallel before slightly obtuse hind angles, narrowly bordered, the border continuing for a short distance only along the posterior margin, medial emargination opposite the scutellum sinuous (Fig. 74B).

ELYTRA. Length $0.36 \mathrm{~mm}$, breadth $0.32 \mathrm{~mm}$, reticulation and pubescence as pronotum.

MESOVEnTRITE. Almost imperceptibly reticulate, without setae; median process of collar broad, widening posteriorly; mid-keel with two narrow carinae anteriorly forming semi-circular depressions; mid-keel parallel-sided, very short, posterior angles with carinae reaching mesocoxal anterior borders, slightly raised before joining keel; keel long, with \pm ten setae, tapering to a point just past the mid-point of the mesocoxae; mesoventral lateral margins serrate in posterior third (Fig. 74C).
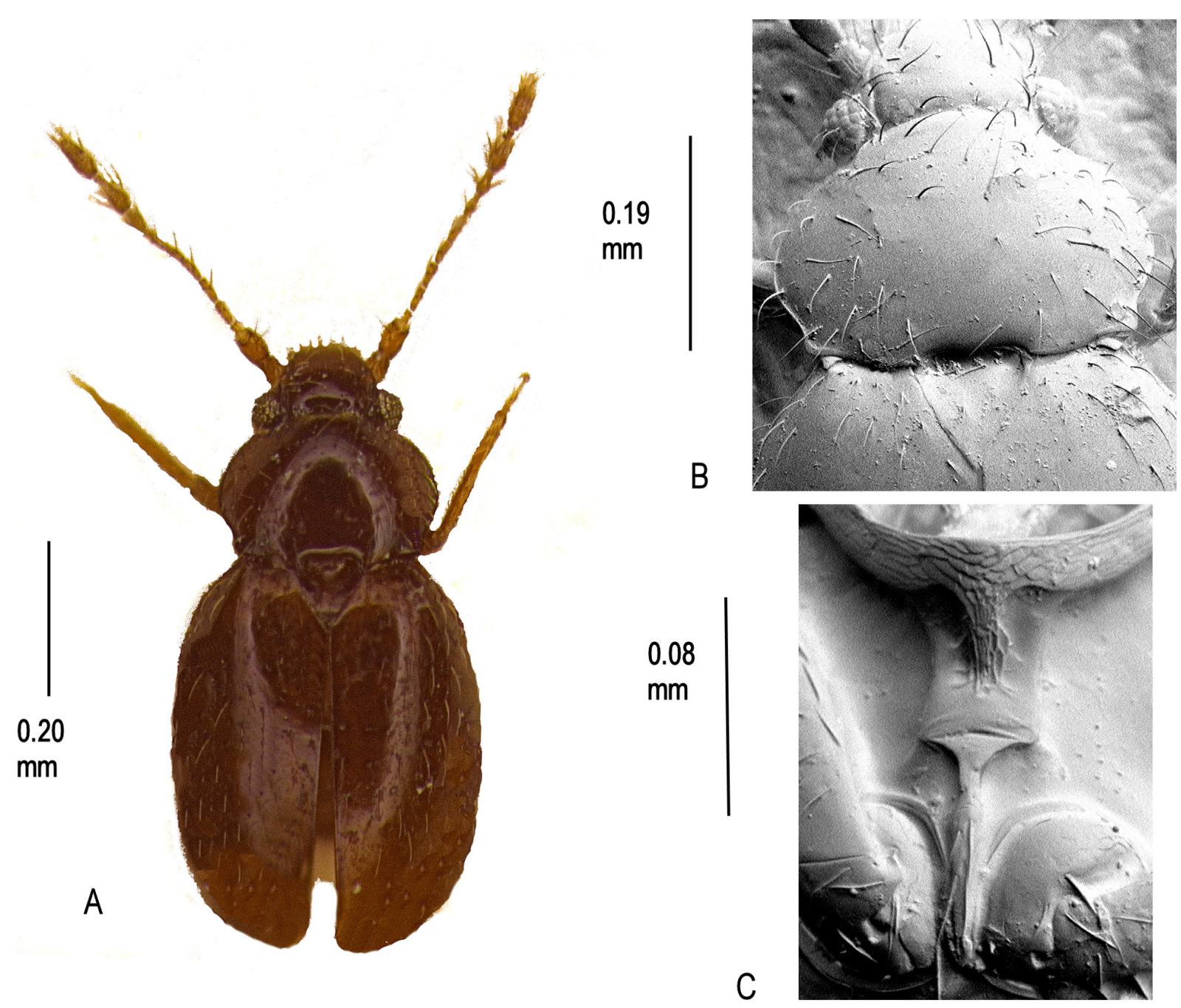

Fig. 74. Cissidium loebli sp. nov. A. Habitus. B. Pronotum, $\times$ 670. C. Mesoventrite showing median process of collar, lateral margin, mid-keel and keel, $\times 1160$. 
Metaventrite. Reticulate, most obvious on the disc, and pubescent, length $0.13 \mathrm{~mm}$, width across spines $0.09 \mathrm{~mm}$, disc simple.

Genitalia. Not dissected.

Cissidium luctuosum sp. nov.

urn:1sid:zoobank.org:act:93ACA134-45EB-42F0-BE9E-CB51DAECDEBA

Fig. 75

\section{Etymology}

Johnson ms name. From the Latin adjective 'luctuosus', meaning 'sorrowful' or 'mourning' and presumably referring to the dark colour.

\section{Material examined}

\section{Holotype}

PANAMA • + ; N of Finca Palo Santo, nr Nueva California, Chiriqui Prov.; 9 Mar. 1959; $4900 \mathrm{ft}$ a.s.1.; Berlese floor litter in damp ravine; H.S. Dybas leg.; FMNH.
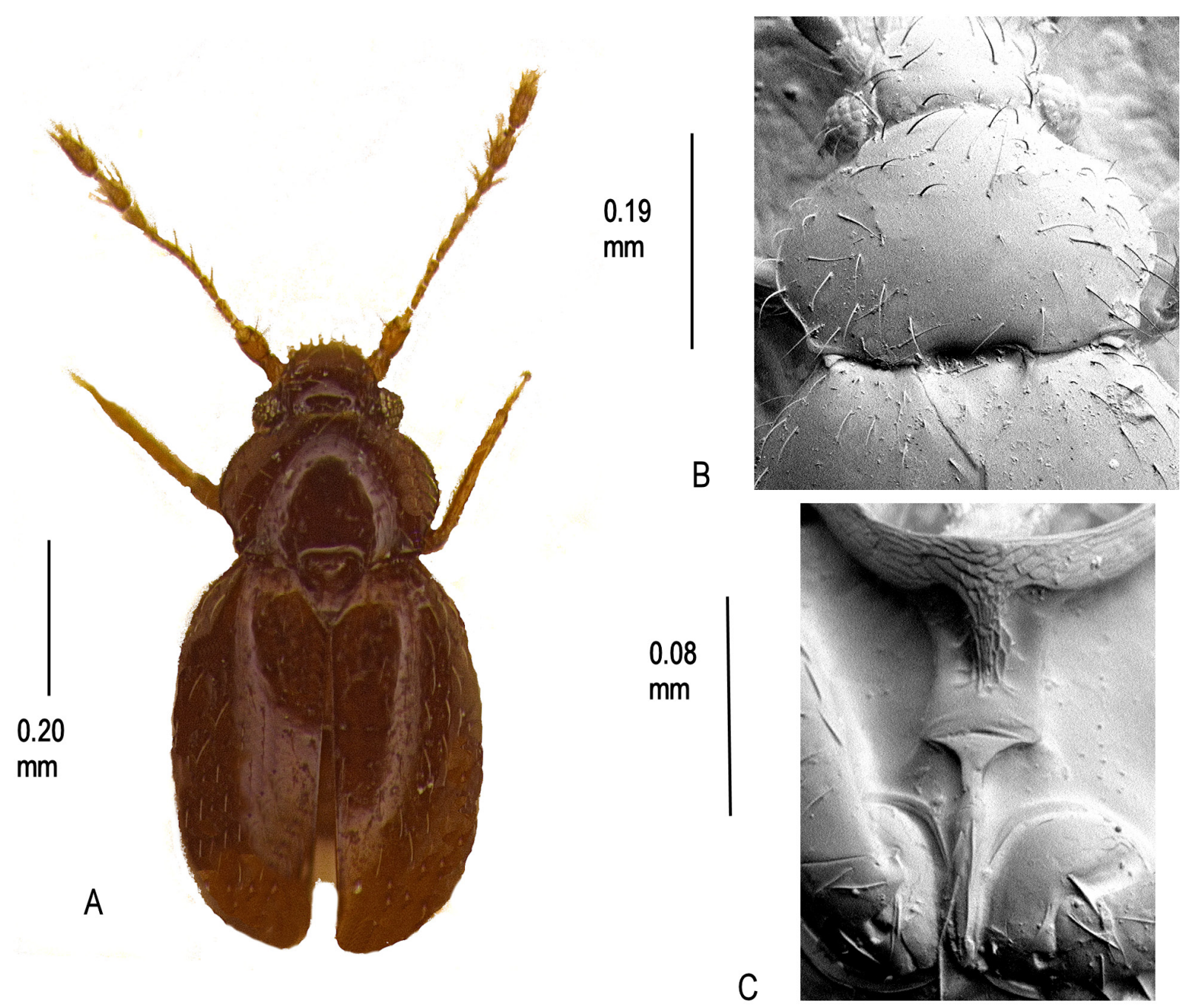

Fig. 75. Cissidium luctuosum sp. nov. A. Habitus. B. Pronotum, $\times$ 605. C. Mesoventrite showing median process of collar, mid-keel and keel, $\times 675$. 


\section{Description}

Size. Habitus (Fig. 75A), length $0.74 \mathrm{~mm}$.

CoLour. Dark brown, pubescence, antennae, and legs dusky yellow.

HEAD. With a linear depression behind the eyes, width across eyes $0.19 \mathrm{~mm}$; antennomeres III-XI length $0.33 \mathrm{~mm}$, III-IX length $0.21 \mathrm{~mm}, \mathrm{X}-\mathrm{XI}$ length $0.12 \mathrm{~mm}$; mentum obscured.

Pronotum. Length $0.19 \mathrm{~mm}$, width $0.28 \mathrm{~mm}$, pubescence confined mainly to margins, without either foveolae or foveae; sides evenly rounded to rectangular hind angles, bordered laterally, the border continuing along the posterior margin as far as the emargination opposite the scutellum (Fig. 75B).

ELYTRA. Length $0.47 \mathrm{~mm}$, width $0.38 \mathrm{~mm}$, sparsely pubescent throughout.

MESOVENTRITE. Median process of mesoventral collar parallel-sided, extending to mid-point of mid-keel; mid-keel almost parallel-sided, hind angles effaced before mesocoxal anterior borders, raised before joining keel; keel with \pm four setae, narrow, almost parallel-sided, terminating in a point past the midpoint of the mesocoxae; mesoventral lateral margins effaced, barely visible; humeri sharply toothed (Fig. 75C).

Metaventrite. Length $0.15 \mathrm{~mm}$, sparsely setose, disc simple, width across spines $0.10 \mathrm{~mm}$.

Wings. Macropterous.

Genitalia. Female spermatheca distinctive as Fig. 6E. Males not known.

\section{Remarks}

One of the five Panamanian species in this group. Distinguished by the disc of the pronotum lacking setae and by the setose posterior termination of the median extension of the mesoventral collar.

Cissidium obscurum sp. nov. urn:1sid:zoobank.org:act:88BE9D35-6C14-4FAB-AC3D-633634572195

Fig. 76

\section{Etymology}

Johnson ms name, from the Latin adjective 'obscurus', meaning 'dark, obscure'.

\section{Material examined}

\section{Holotype}

PANAMA - \; Bocas del Toro, Prov. Almirante, trail to Dam on Nigua Creek; 31 Mar. 1959; Berlese cortex of hollowed palm stump; H.S. Dybas leg.; FMNH.

\section{Description}

Size. Habitus (Fig. 76A), length $0.71 \mathrm{~mm}$.

CoLour. Dark brown, shining, antennae, legs and pubescence yellow.

HEAD. With a setose foveolate depression behind the eyes, width across eyes $0.20 \mathrm{~mm}$; antennomeres III-XI length $0.28 \mathrm{~mm}$, III-IX length $0.18 \mathrm{~mm}, \mathrm{X}-\mathrm{XI}$ length $0.10 \mathrm{~mm}$; mentum obscured. 
Pronotum. Length $0.20 \mathrm{~mm}$, width $0.30 \mathrm{~mm}$, densely pubescent, shallowly foveolate near base; sides evenly rounded to rectangular hind angles, front angles rounded, lateral borders continued along the basal margin to the sinuous medial emargination in front of the scutellum (Fig. 76B).

ElYTRA. Length $0.47 \mathrm{~mm}$, width $0.41 \mathrm{~mm}$, densely pubescent, not foveolate.

Mesoventrite. Collar with a long tapering median extension; mid-keel parallel-sided posterior angles not reaching mesocoxae, rising slightly at junction with keel; keel with \pm six setae, tapering to a point at base of mesocoxae; mesoventral lateral margins smoothly rounded without serrations; humeri toothed (Fig. 76C).

MetaVentrite. Length 0.16 , disc simple, width between spines $0.10 \mathrm{~mm}$; margins of mesocoxal cavities serrate.

WINGS. Macropterous.
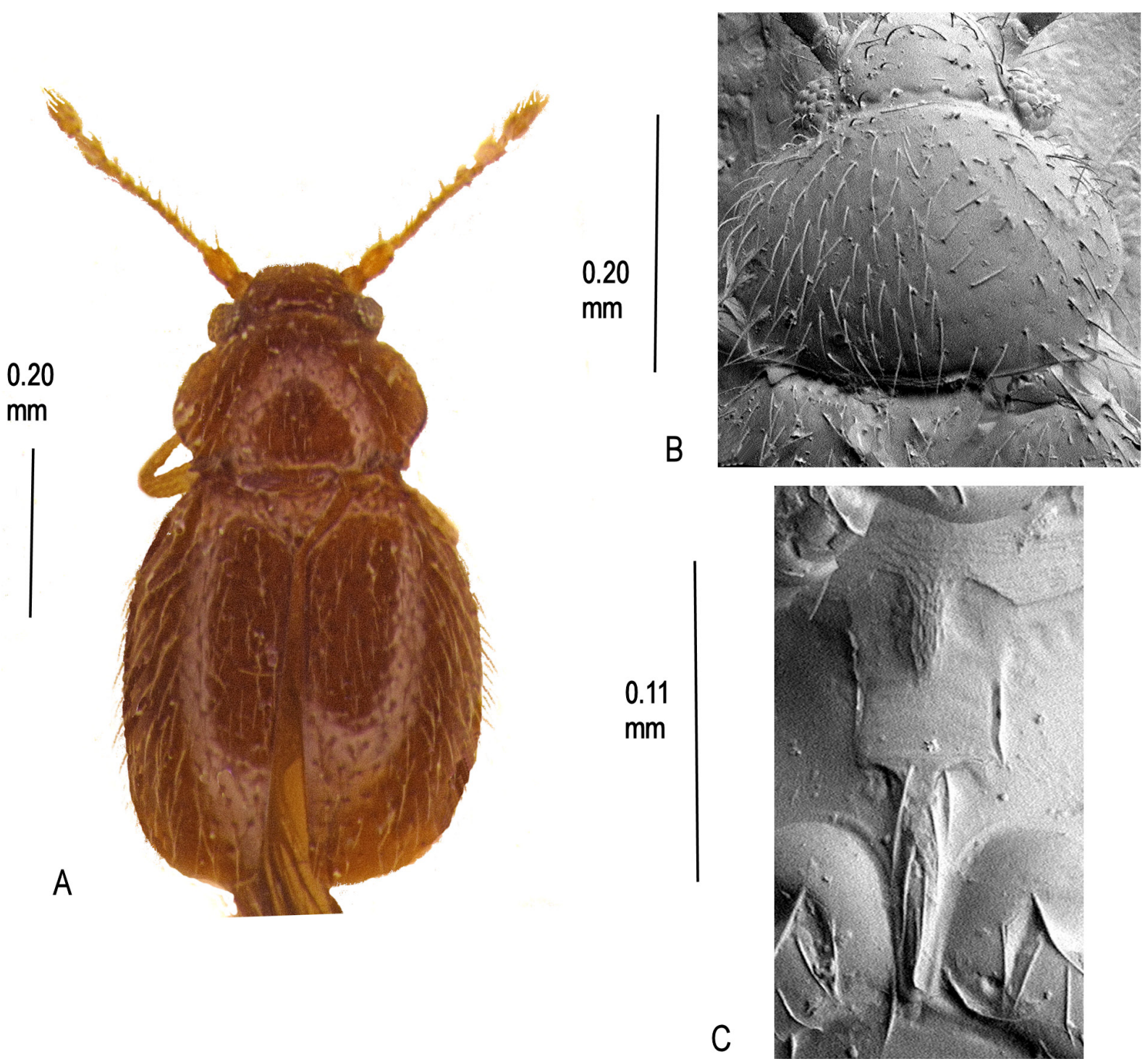

Fig. 76. Cissidium obscurum sp. nov. A. Habitus. B. Pronotum, $\times 560$. C. Mesoventrite showing median process of collar, mid-keel and keel, $\times 740$. 


\section{Remarks}

One of the five Panamanian species in this group. Distinguished by the length of the median extension of the mesoventral collar and of the mid-keel which is parallel sided.

\section{Cissidium opacum sp. nov.}

urn:1sid:zoobank.org:act:90BBF05F-D923-469D-9978-964396963C0F

Fig. 77

\section{Etymology}

Johnson ms name, from the Latin adjective 'opacus', meaning 'shady' or 'dark'.

\section{Material examined}

\section{Holotype}

SOUTH AFRICA • Cape Prov. Peninsula, Table Mt., Bats Cave, wood humus; Dec. 1960, N. Leleup leg.; ZA.43; MMUE.
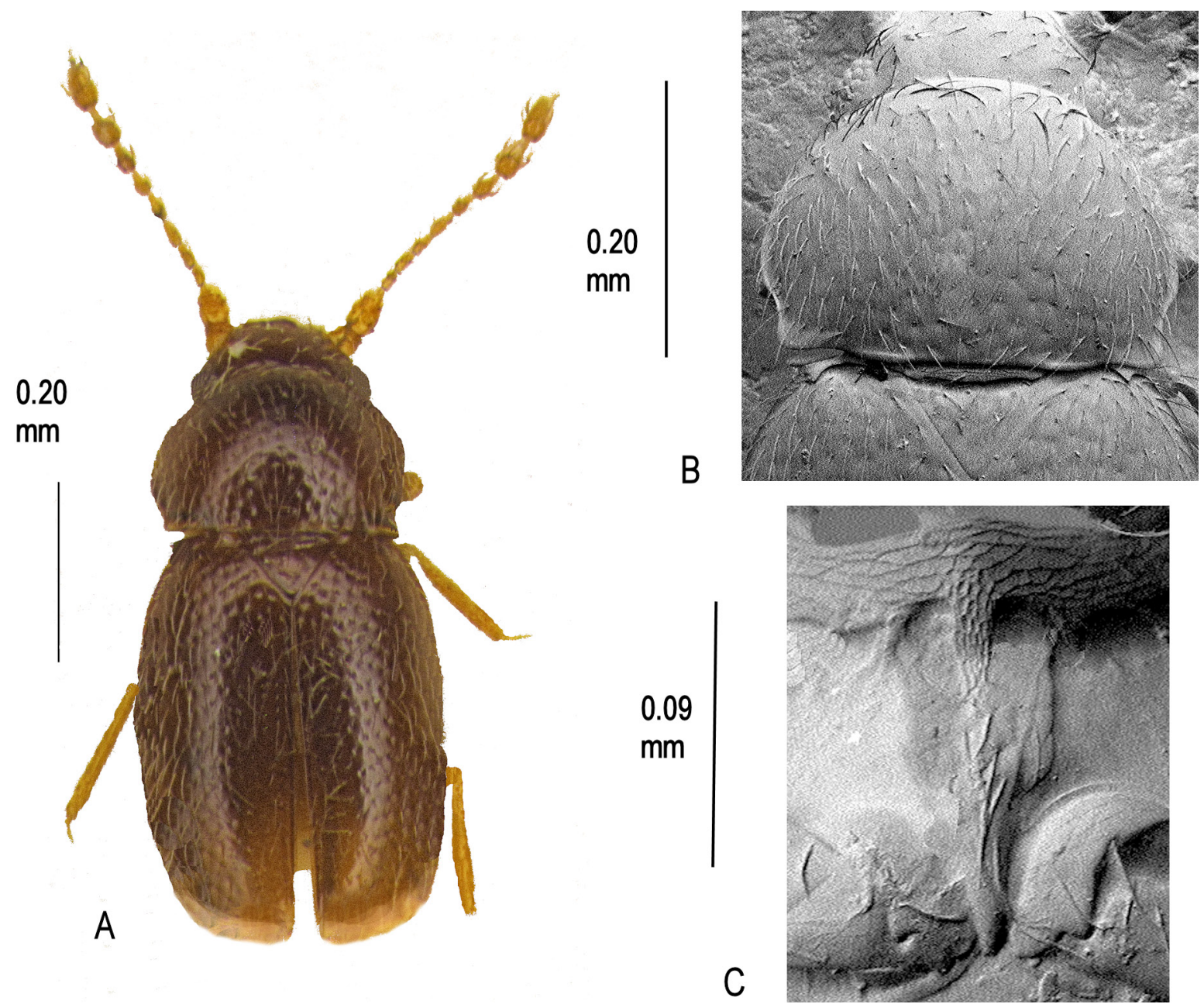

Fig. 77. Cissidium opacum sp. nov. A. Habitus. B. Pronotum, $\times$ 550. C. Mesoventrite showing median process of collar, mid-keel and keel, $\times 945$. 


\section{Description}

Size. Habitus (Fig. 77A), length $0.71 \mathrm{~mm}$.

Colour. Dark brown, shining, antennae, legs and pubescence yellow.

HEAD. With a narrow impressed line behind the eyes; width across eyes $0.21 \mathrm{~mm}$; antennomeres III-XI length $0.29 \mathrm{~mm}$, III-IX length $0.19 \mathrm{~mm}, \mathrm{X}-\mathrm{XI}$ length $0.10 \mathrm{~mm}$, antennomere XI without a median separation; mentum obscured.

Pronotum. Length $0.20 \mathrm{~mm}$, width $0.29 \mathrm{~mm}$, densely pubescent; sides angulate in posterior third, evenly rounded anteriorly, with short concave margins posteriorly before the rounded rectangular hind angles, sides narrowly margined the margins not continued along the base, base straight in front of scutellum without an emargination (Fig 77B).

ELYTRA. Length $0.45 \mathrm{~mm}$, width $0.34 \mathrm{~mm}$, densely pubescent, not foveolate.

Mesoventrite. Collar with a long tapering median extension; mid-keel parallel-sided posterior angles rounded, rising slightly at junction with keel; keel with \pm seven setae, tapering to a point at base of mesocoxae; mesoventral lateral margins smoothly rounded without serrations; humeri narrow, not noticeably toothed (Fig. 77C).

Metaventrite. Length $0.16 \mathrm{~mm}$, width between spines $0.09 \mathrm{~mm}$; margins of mesocoxal cavities serrate.

WINGs. Macropterous.

Sex not determined.

\section{Remarks}

The only species of Cissidium to have been described from South Africa.

Cissidium petri Darby, 2015

Figs 2H, 4A, 6F, 7F, 78

\section{Material examined}

\section{Holotype}

BOLIVIA - O; Cochabamba dep., Cristal Mayu River valley, ca $20 \mathrm{~km}$ W of Villa Tunari; ca $720 \mathrm{~m}$ a.s.1.; 24 Jun. 2013; sifting litter; Winkler app. extr.; P. Baňař leg.; UASC.

\section{Paratypes}

BOLIVIA $\bullet 1$ ô, 1 क; same collection data as for holotype; MMBC, BMNH.

\section{Supplementary description}

The following description amplifies the type description of Darby (2015), by adding more details of the meso- and metaventral characters, in order to conform with the entries in the present paper.

SizE. Habitus (Fig. 78A), length $0.68 \mathrm{~mm}$.

CoLour. Light brown, antennae and legs dusky yellow. 
HeAD. Antennomeres, 3-11 length $0.33 \mathrm{~mm}$, III-IX length $0.19 \mathrm{~mm}, \mathrm{X}-\mathrm{XI}$ length $0.14 \mathrm{~mm}$ (Fig. 2Hab); distance across eyes $0.19 \mathrm{~mm}$; mentum as Fig. 4A.

Pronotum. $0.26 \mathrm{~mm}$ wide, $0.19 \mathrm{~mm}$ long, sparsely pubescent, sides rounded, concave to rectangular hind angles, anterior angles obtuse, bordered, the border continuing along the posterior margin to the medial emargination in front of the scutellum (Fig. 78B).

ELYTRA. $0.40 \mathrm{~mm}$ long, $0.35 \mathrm{~mm}$ wide; pubescent, foveolate contrasting with the pronotum.

Mesoventrite. Median extension parallel-sided; mid-keel sides concave, anterior angles slightly wider than posterior angles which are effaced before mesocoxal anterior borders, slightly raised before meeting keel; keel with \pm ten setae, strongly tapering to point close to base of mesocoxae; mesoventral lateral margins effaced (Fig. 78C).

Metaventrite. Pubescent, disc simple, length $0.16 \mathrm{~mm}$, distance between spines $0.09 \mathrm{~mm}$; posterior margin of metacoxae without serrations.

Genitalia. Male aedeagus (Fig. 6Fa-b), terminal abdominal ventrites (Fig. 7F). Female spermatheca globular.
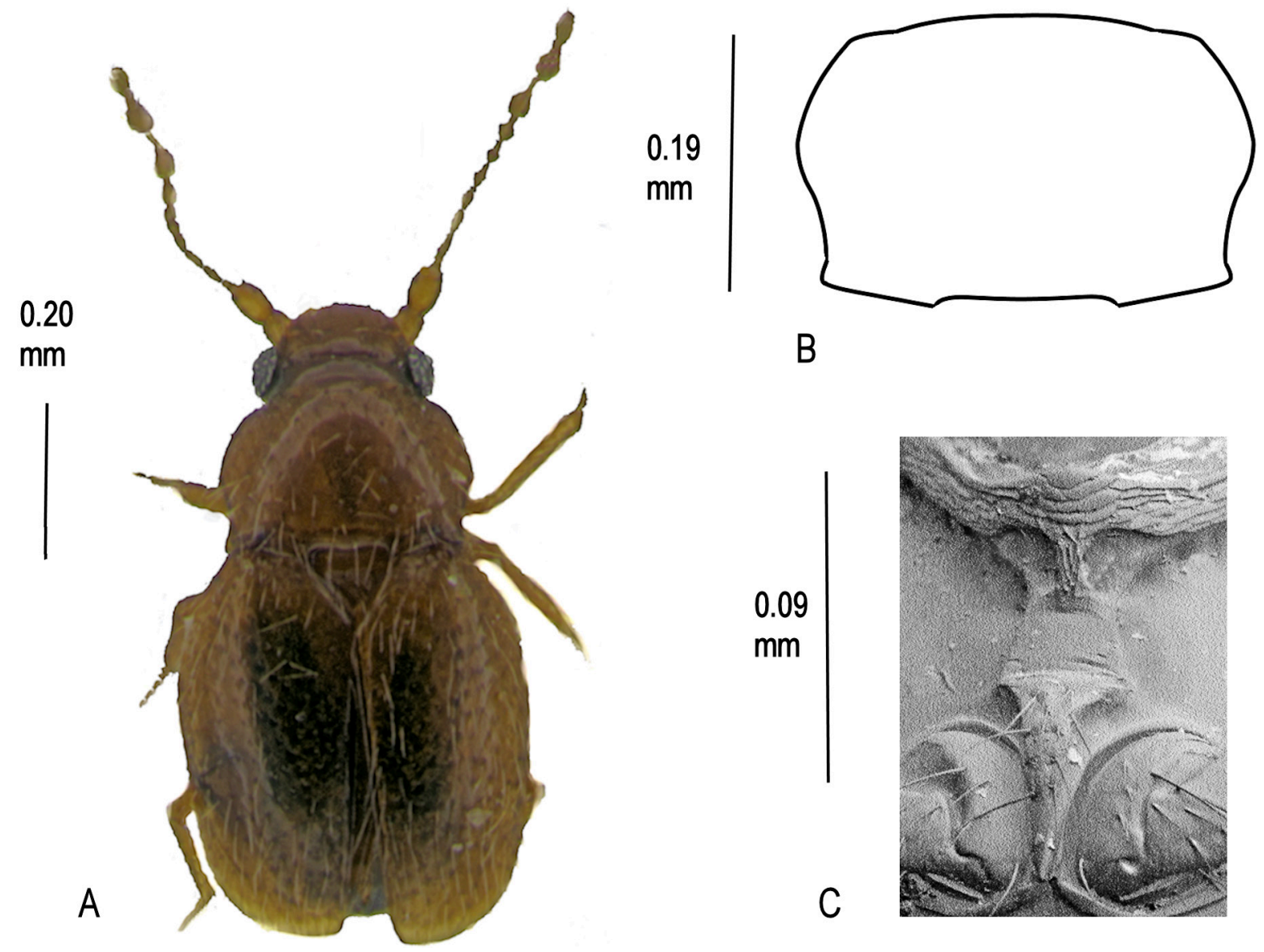

$\mathrm{B}$

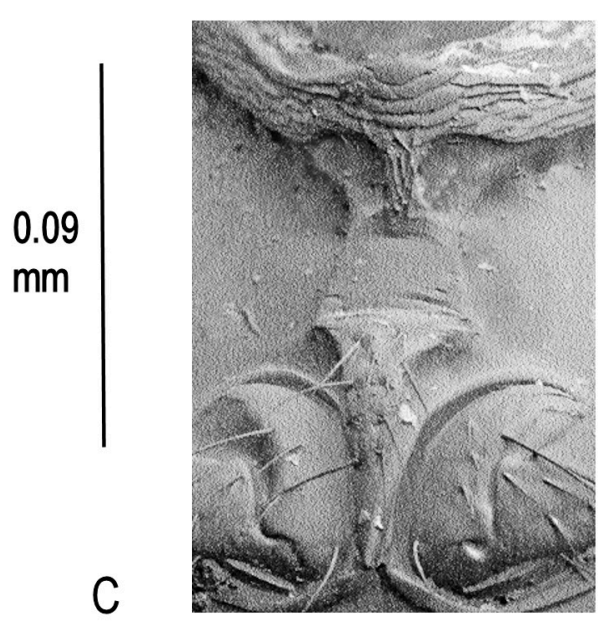

Fig. 78. Cissidium petri Darby, 2015. A. Habitus. B. Pronotum. C. Mesoventrite showing median process of collar, mid-keel and keel, $\times 705$. 
Cissidium plaumanni sp. nov.

urn:1sid:zoobank.org:act:42B630C8-C99C-4238-AA11-0ECF0C0D6E13

Figs $7 \mathrm{~B}, 79$

\section{Etymology}

Johnson ms name, after the collector Fritz Plaumann.

\section{Material examined}

\section{Holotype}

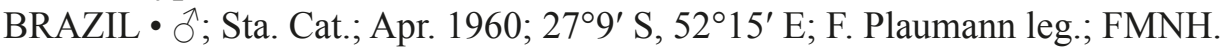

\section{Paratypes}

BRAZIL - 12 ex.; same collection data as for holotype; 1 mounted verso, 4 mounted as slides; FMNH, MMUE, BMNH.

\section{Description}

Size. Habitus (Fig. 79A), length $0.59 \mathrm{~mm}$.

Colour. Yellow brown, antennae, legs and pubescence yellow.
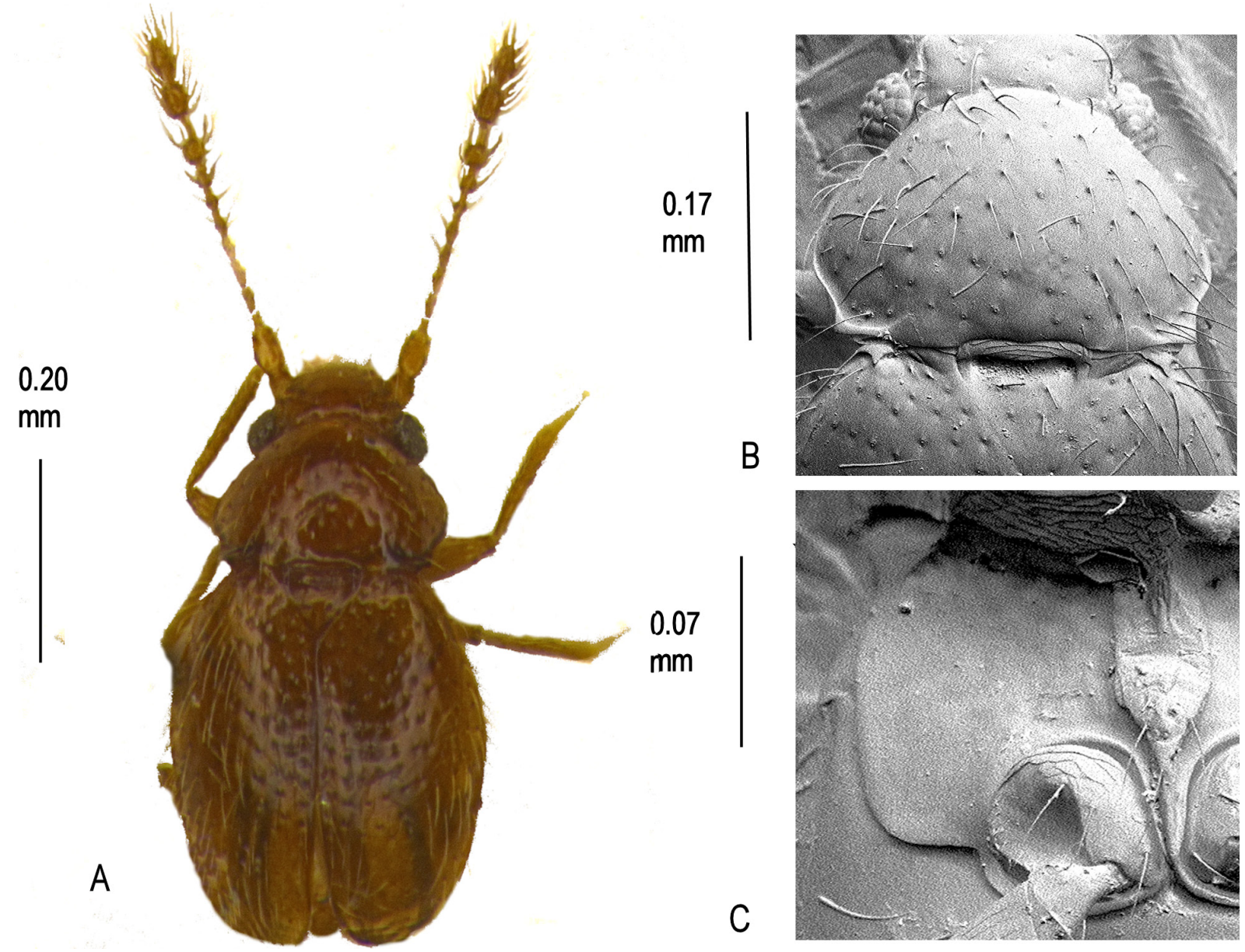

Fig. 79. Cissidium plaumanni sp. nov. A. Habitus. B. Pronotum, $\times 590$. C. Mesoventrite showing median process of collar, lateral margin, mid-keel and keel, $\times 740$. 
HeAd. Antennomeres III-XI length $0.32 \mathrm{~mm}$, III-IX length $0.18 \mathrm{~mm}, \mathrm{X}-\mathrm{XI}$ length $0.14 \mathrm{~mm}$; width across eyes $0.19 \mathrm{~mm}$; mentum as Fig. 4A.

Pronotum. Length $0.17 \mathrm{~mm}$, width $0.24 \mathrm{~mm}$, pubescent, the setal insertion points slightly raised, without foveae and foveolae; lateral margins rounded to hind angles, bordered, the border rectangular at the hind angles and continued for a short distance along the hind margin then recursive, medial emargination opposite scutellum clearly defined (Fig. 79B).

ElYTRA. Length $0.37 \mathrm{~mm}$, width $0.33 \mathrm{~mm}$ pubescent as pronotum.

Mesoventrite. Collar with a parallel-sided median extension; mid-keel narrow, parallel-sided, without anterior and posterior projections; keel very narrow tapering to a sharp point just below the interruption point of the mesocoxal margins; mesoventral lateral margins without serrations, humeri with large teeth (Fig. 79C).

Metaventrite. Sparsely pubescent, disc simple, length $0.13 \mathrm{~mm}$, width between spines $0.08 \mathrm{~mm}$, spines long, sharply pointed (Fig. 7B); mesocoxal posterior margins not serrate. WINGS. Macropterous.

GenitALiA. Male aedeagus as Fig. 6Fa-b; female spermatheca globular.

\section{Remarks}

Distinguished from the other species of Cissidium from Brazil in this group by the recursive terminations of the posterior borders of the pronotum.

Cissidium steeli sp. nov. urn:lsid:zoobank.org:act:86C4969A-78B4-4DD6-A2BB-443588CDFCD0

Fig. 80

\section{Etymology}

Johnson ms name, after W. Steel, the well-known UK Coleopterist.

\section{Material examined}

Holotype

TRINIDAD • +; Tamana; leaf litter; Aug. 1969; J. Darlington leg.; MMUE.

\section{Description}

Size. Habitus (Fig. 80A), length $0.71 \mathrm{~mm}$.

CoLour. Dark brown, shining, pubescence, legs and antennae dusky yellow.

HEAD. With a foveolate shallow linear depression behind the eyes, width across eyes $0.20 \mathrm{~mm}$; mentum as Fig. 4A; antennomeres III-XI, length $0.31 \mathrm{~mm}$, III-IX length $0.20 \mathrm{~mm}, \mathrm{X}-\mathrm{XI}$ length $0.11 \mathrm{~mm}$.

Pronotum. $0.19 \mathrm{~mm}$ long, $0.30 \mathrm{~mm}$ wide, sparsely pubescent without either foveolae or foveae; lateral margins evenly rounded to slightly acute hind angles, narrowly bordered, the border running along the entire posterior margin though narrower in the sinuous medial emargination in front of the scutellum (Fig. 80B).

ELYTRA. $0.45 \mathrm{~mm}$ long, $0.35 \mathrm{~mm}$ wide, pubescent as pronotum, shallowly foveolate. 
Mesoventrite. Medial extension of collar tapering posteriorly then parallel-sided; mid-keel broadest anteriorly then slightly concave to rounded posterior angles; keel with \pm eight setae, long, parallel to pointed termination posterior to the interruption point of the mesocoxal margins; mesoventral lateral margins straight to rounded rectangular angles, without serrations; humeri toothed (Fig. 80C).

Metaventrite. Sparsely pubescent, length $0.15 \mathrm{~mm}$, disc simple, width across spines $0.12 \mathrm{~mm}$; posterior margin of mesocoxae serrate.

Wings. Macropterous.

Genitalia. Female spermatheca globular. Male not known.

\section{Remarks}

The only species of Cissidium to have been described from Trinidad.
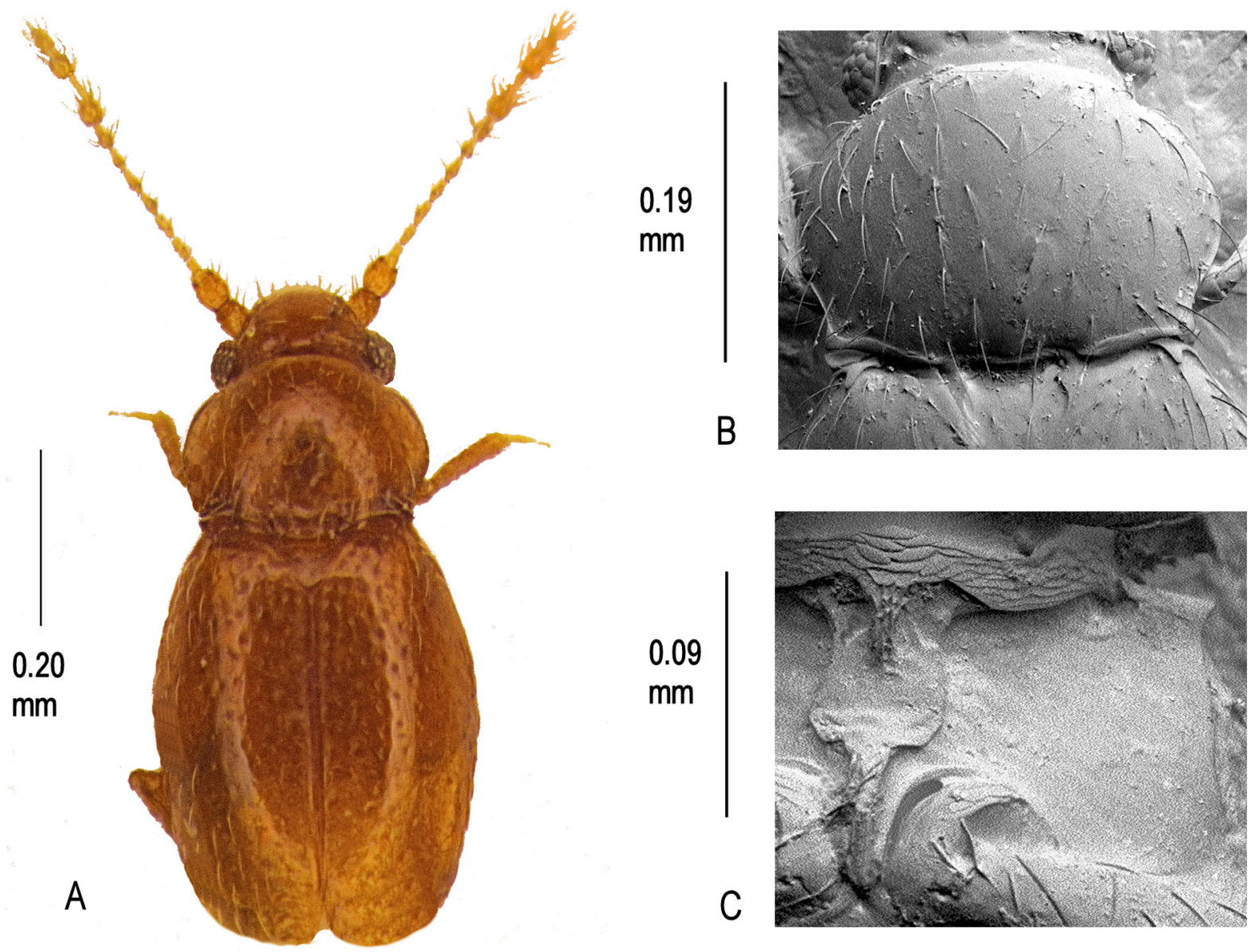

Fig. 80. Cissidium steeli sp. nov. A. Habitus. B. Pronotum, $\times 680$. C. Mesoventrite showing median process of collar, mid-keel and keel, $\times 785$. 
Cissidium subfaustum sp. nov.

urn:Isid:zoobank.org:act:E204C76D-EAD4-4C6E-BDCA-DDDED90DD366

Fig. 81

\section{Etymology}

Johnson ms name referring to similarity of the species to C. faustum sp. nov.

\section{Material examined}

\section{Holotype}

PANAMA • + ; W of Finca Palo Santo, nr. Nueva California, Chirique Prov.; 4900 ft a.s.l.; 9 Mar. 1959; Berlese floor litter in damp ravine; H.S. Dybas leg.; FMNH.

\section{Description}

Size. Habitus (Fig. 81A), length $0.71 \mathrm{~mm}$.

CoLour. Dark brown, pubescence, legs and antennae dusky yellow.
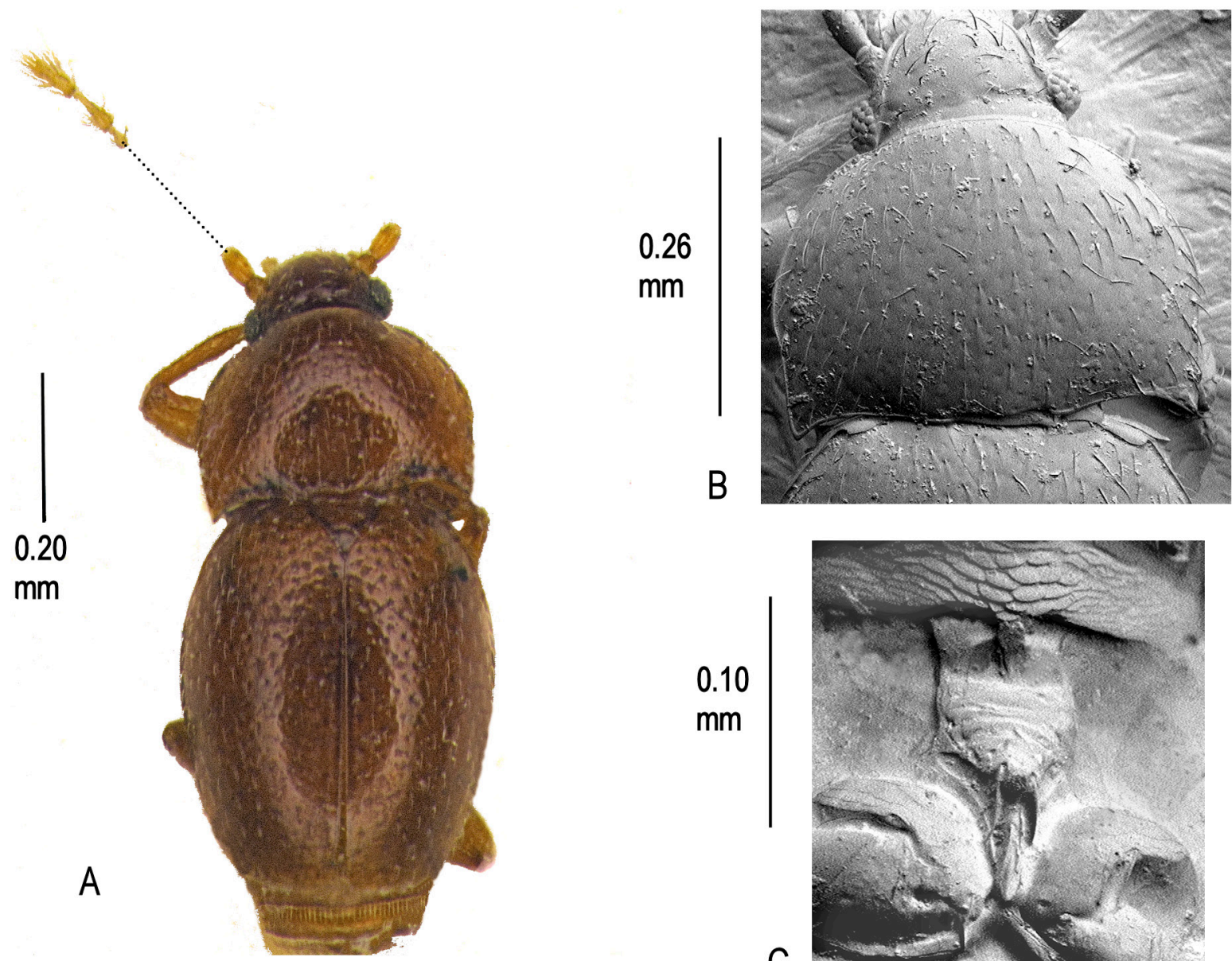

Fig. 81. Cissidium subfaustum sp. nov. A. Habitus. B. Pronotum, $\times 410$. C. Mesoventrite showing median process of collar, mid-keel and keel, $\times 1280$. 
HeAD. With a shallow foveolate and setose linear depression behind the eyes, width across eyes $0.17 \mathrm{~mm}$; mentum as Fig. 4A; antennomeres III-XI, length $0.34 \mathrm{~mm}$, III-IX length $0.15 \mathrm{~mm}, \mathrm{X}-\mathrm{XI}$ length $0.19 \mathrm{~mm}$.

Pronotum. $0.20 \mathrm{~mm}$ long, $0.25 \mathrm{~mm}$ wide, pubescent with shallow foveolae in basal half; lateral margins evenly rounded to acute hind angles, narrowly bordered, the borders continuing along the posterior margin to the angulate medial emargination opposite the scutellum (Fig. 81B).

ELytRa. $0.39 \mathrm{~mm}$ long, $0.34 \mathrm{~mm}$ wide, pubescent and shallowly foveolate.

Mesoventrite. Medial extension of collar sharply pointed; mid-keel anterior angles effaced before reaching collar, posterior angles stopping well short of mesocoxae; keel long, with \pm six setae, tapering to a sharp point near the base of the mesocoxae; mesoventral lateral margins effaced, without serrations; humeri toothed (Fig. 81C).

MetaventRite. Sparsely pubescent, length $0.12 \mathrm{~mm}$, disc simple, width across spines $0.08 \mathrm{~mm}$; posterior margin of mesocoxae not serrate.

Wings. Apterous.

Genitalia. Female spermatheca globular. Male not known.

\section{Remarks}

One of the five Panamanian species in this group. Distinguished by the sharp borders along the posterior margin of the pronotum.

Cissidium seditiosum $\mathrm{sp}$. nov. urn:1sid:zoobank.org:act:5C7FCA79-8952-4E1D-8999-DE7915F58095

Fig. 82

\section{Etymology}

Johnson ms name, presumably from the Latin 'seditiosus', meaning 'mutinous' or 'fractious'.

\section{Material examined}

\section{Holotype}

JAMAICA - \; St. Ann Parish, 2.5 miles S of Moncague; $2250 \mathrm{ft}$ a.s.1.; 3 Apr. 1968; forest floor litter;

S. Peck and R. Fiske leg.; parts of antennae missing; FMNH.

\section{Paratype}

JAMAICA $\bullet \overbrace{}^{\top}$; same collection data as for holotype; aedeagus glued to card, antennae missing; MMUE.

\section{Description}

Size. Habitus (Fig. 82A), length $0.83 \mathrm{~mm}$.

CoLour. Yellow brown, head darker, pubescence, legs and antennae dusky yellow.

HEAD. With a shallow linear depression behind the eyes, width across eyes $0.21 \mathrm{~mm}$; mentum parallelsided; antennomeres III-XI, length $0.39 \mathrm{~mm}$, III-IX length $0.22 \mathrm{~mm}, \mathrm{X}-\mathrm{XI}$ length $0.17 \mathrm{~mm}$. (Note; one antennomere missing, the other missing antennomeres III-IX, X-XI remaining pasted to the card). 
Pronotum. $0.26 \mathrm{~mm}$ long, $0.37 \mathrm{~mm}$ wide, densely pubescent, the hairs barely overlapping, and foveolate, without basal foveae; sides rounded, becoming almost parallel to acute hind angles, bordered, the border continuing along the posterior margin to the short and angulate median emargination in front of the scutellum (Fig. 82B).

ELYTRA. $0.49 \mathrm{~mm}$ long, $0.40 \mathrm{~mm}$ wide, pubescent and foveolate contrasting with the pronotum.

Mesoventrite. Medial extension of collar short, parallel-sided then becoming effaced; mid-keel parallelsided hind angles with short flat carinae to mesocoxal anterior borders, rising medially with transverse foveolate sculpturing and \pm eight setae (missing from holotype) to a point above the keel; keel with \pm six setae, short, terminating in a point at the mid-point of the mesocoxae; mesoventral lateral margins evenly rounded, without serrations; humeri toothed (Fig. 82C).

Metaventrite. Length $0.15 \mathrm{~mm}$, reticulate at sides, depressed disc with crescent-shaped foveolae and mixture of setae and elongate scales, distance across spines $0.12 \mathrm{~mm}$.

Wings. Apterous.
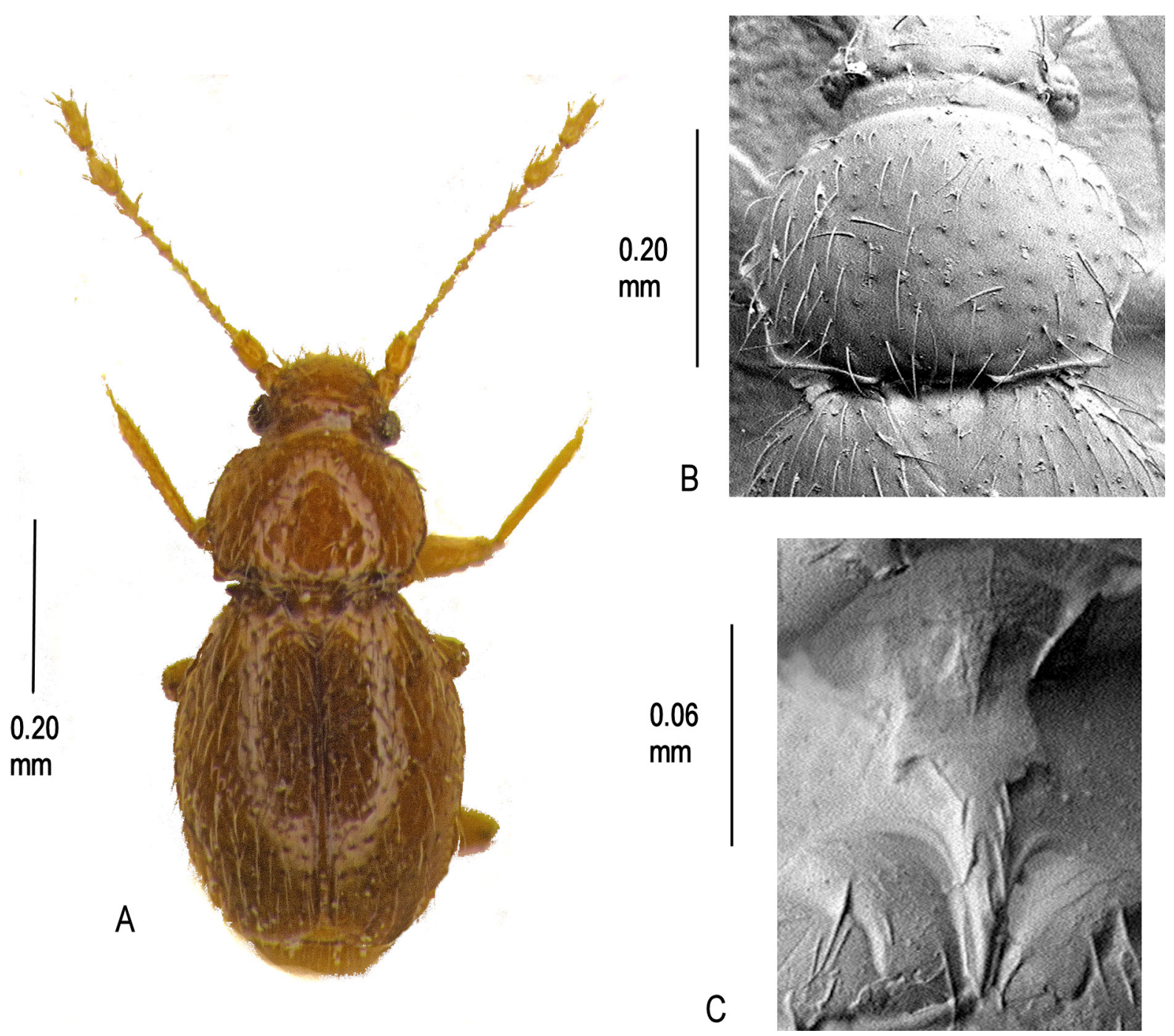

Fig. 82. Cissidium seditiosum sp. nov. A. Habitus. B. Pronotum, $\times 470$. C. Mesoventrite showing median process of collar, mid-keel and keel, $\times 695$. 
Genitalia. Male aedeagus pointed, lateral margins broadening towards tip.

\section{Remarks}

Distinguished from C. insulare sp. nov., the only other Cissidium reported from Jamaica, by the acute hind angles of the pronotum.

Cissidium sueae sp. nov.

urn:1sid:zoobank.org:act:662078AF-F3BB-49B4-A366-AAB095BF7D06

Figs 3B, 83

\section{Etymology}

I have the pleasure in naming this species after my sister Susan Allen.

\section{Material examined}

\section{Holotype}

BRAZIL • P; Santo Caterinay, Chapecosino; Jan. 1950; F. Plaumann leg.; H.F. Dybas \# 58-36; FMNH.

\section{Description}

Size. Habitus (Fig. 83A), length $0.86 \mathrm{~mm}$.
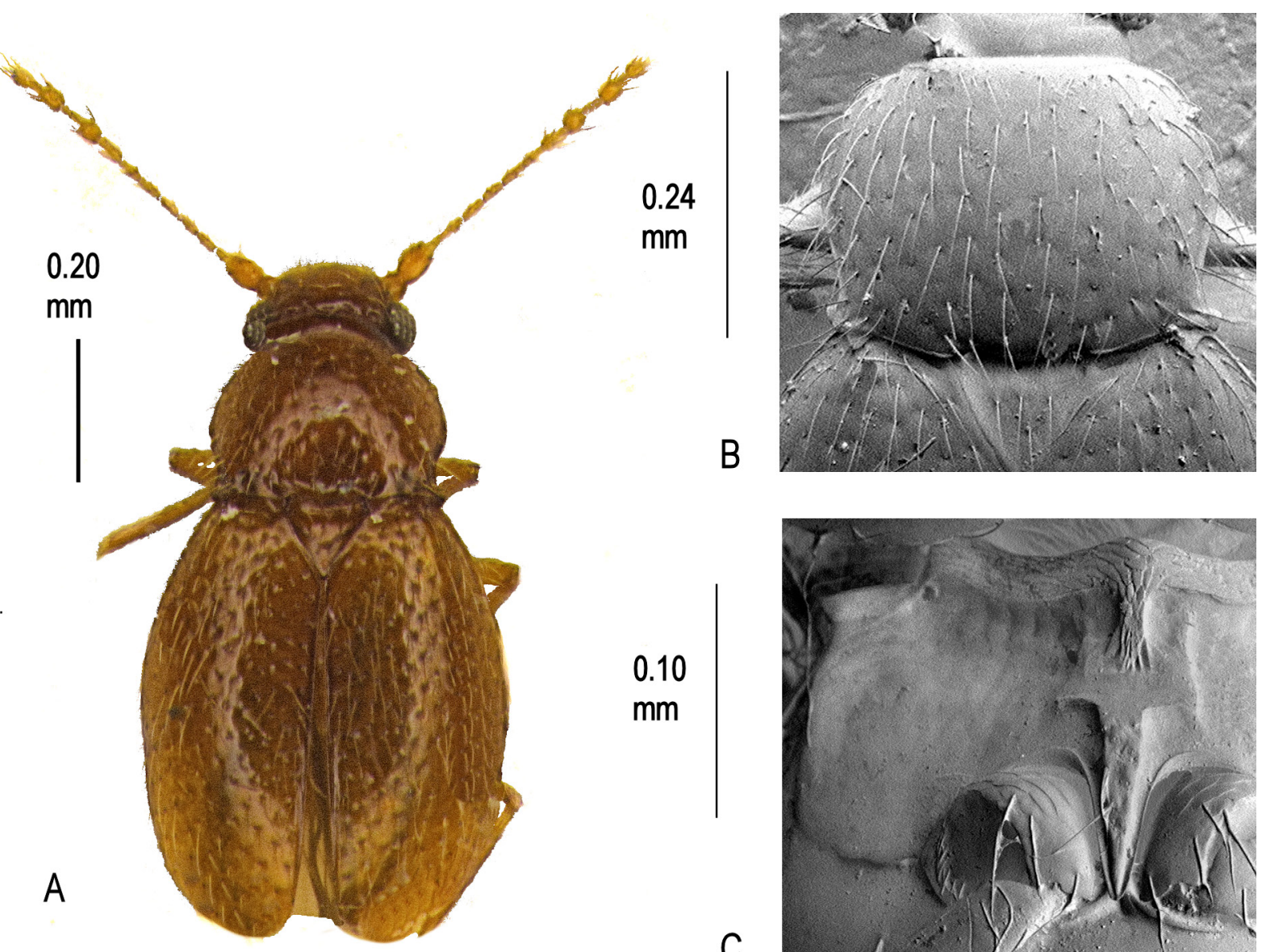

B

$\mathrm{mm}$

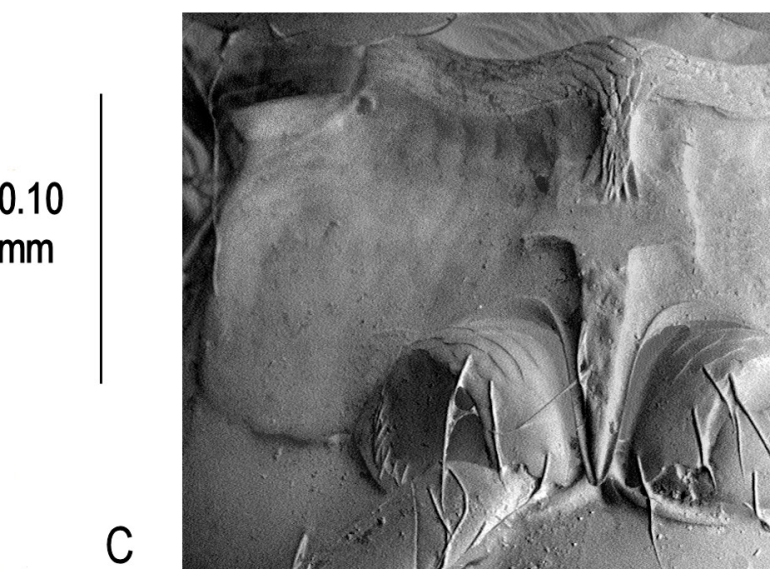

Fig. 83. Cissidium sueae sp. nov. A. Habitus. B. Pronotum, $\times$ 345. C. Mesoventrite showing median process of collar, lateral margin, mid-keel and keel, $\times 750$. 
CoLour. Yellow brown, pubescence, legs and antennae dusky yellow.

HEAD. With a shallow foveolate and setose linear depression behind the eyes (Fig. 3B), width across eyes $0.17 \mathrm{~mm}$; mentum as Fig 4A; antennomeres III-XI, length $0.42 \mathrm{~mm}$, III-IX length $0.22 \mathrm{~mm}, \mathrm{X}-\mathrm{XI}$ length $0.20 \mathrm{~mm}$.

Pronotum. $0.24 \mathrm{~mm}$ long, $0.32 \mathrm{~mm}$ wide, pubescent with shallow foveolae in basal half; lateral margins evenly rounded to acute hind angles, narrowly bordered, the borders continuing along the posterior margin to the angulate medial emargination in front of the scutellum (Fig. 83B).

ELYTRA. $0.54 \mathrm{~mm}$ long, $0.47 \mathrm{~mm}$ wide, pubescent and shallowly foveolate.

Mesoventrite. Medial extension of collar with terminal fringe of short setae; mid keel effaced before collar, hind angles stopping well short of the mesocoxal anterior borders; keel long, setose, tapering to a sharp point near the base of the mesocoxae; mesoventral lateral margins rounded, without serrations; humeri toothed (Fig. 83C).

Metaventrite. Sparsely pubescent, length $0.14 \mathrm{~mm}$, disc simple, width across spines $0.12 \mathrm{~mm}$; posterior margin of mesocoxae not serrate.

Wings. Macropterous.

Genitalia. Female spermatheca globular. Male not known.

\section{Remarks}

One of the five Brazilian species in this group. Distinguished by the setose posterior margin of the median extension of the mesoventral keel.

\section{Cissidium trangse sp. nov. urn:1sid:zoobank.org:act:E9F8435B-868D-4989-A272-ADA87C244DB4}

Fig. 84

\section{Etymology}

Johnson ms name after Trang in the SW of Thailand where the insect was collected.

\section{Material examined}

\section{Holotype}

THAILAND • o; S., Kachong Exp. Stat b. Trang; Franz leg.; one antenna lost in SEM; MMUE.

\section{Additional material}

A teneral specimen in MMUE taken at the same time may be this species.

\section{Description}

Size. Habitus (Fig. 84A), length $0.58 \mathrm{~mm}$.

CoLour. Yellow brown, pubescence, legs and antennae dusky yellow.

HEAD. With a shallow foveolate and setose linear depression behind the eyes; width across eyes $0.18 \mathrm{~mm}$; mentum as Fig. 4A; antennomeres III-XI, length $0.30 \mathrm{~mm}$, III-IX length $0.14 \mathrm{~mm}, \mathrm{X}-\mathrm{XI}$ length $0.16 \mathrm{~mm}$. 
Pronotum. $0.18 \mathrm{~mm}$ long, $0.24 \mathrm{~mm}$ wide, pubescent with shallow foveolae in basal half where there are traces of two short linear foveae; lateral margins evenly rounded before shallow concave sinuations to bluntly rectangular hind angles, narrowly bordered, the borders continuing along the posterior margin becoming wider towards the angulate medial emargination in front of the scutellum (Fig. 84B).

ELYTRA. $0.38 \mathrm{~mm}$ long, $0.33 \mathrm{~mm}$ wide, pubescent, without foveolae.

MesoventRITE. Medial extension of collar slightly tapering; mid-keel anterior angles widening before collar, posterior angles rounded; keel narrow, densely setose, tapering then parallel-sided to termination just past the interruption point of the mesocoxal margins; mesoventral lateral margins serrate in posterior half; humeri toothed (Fig. 84C).

MetaVentrite. Sparsely pubescent, length $0.10 \mathrm{~mm}$, disc simple, width across spines $0.08 \mathrm{~mm}$; posterior margin of mesocoxae serrate.

WINGS. Macropterous.
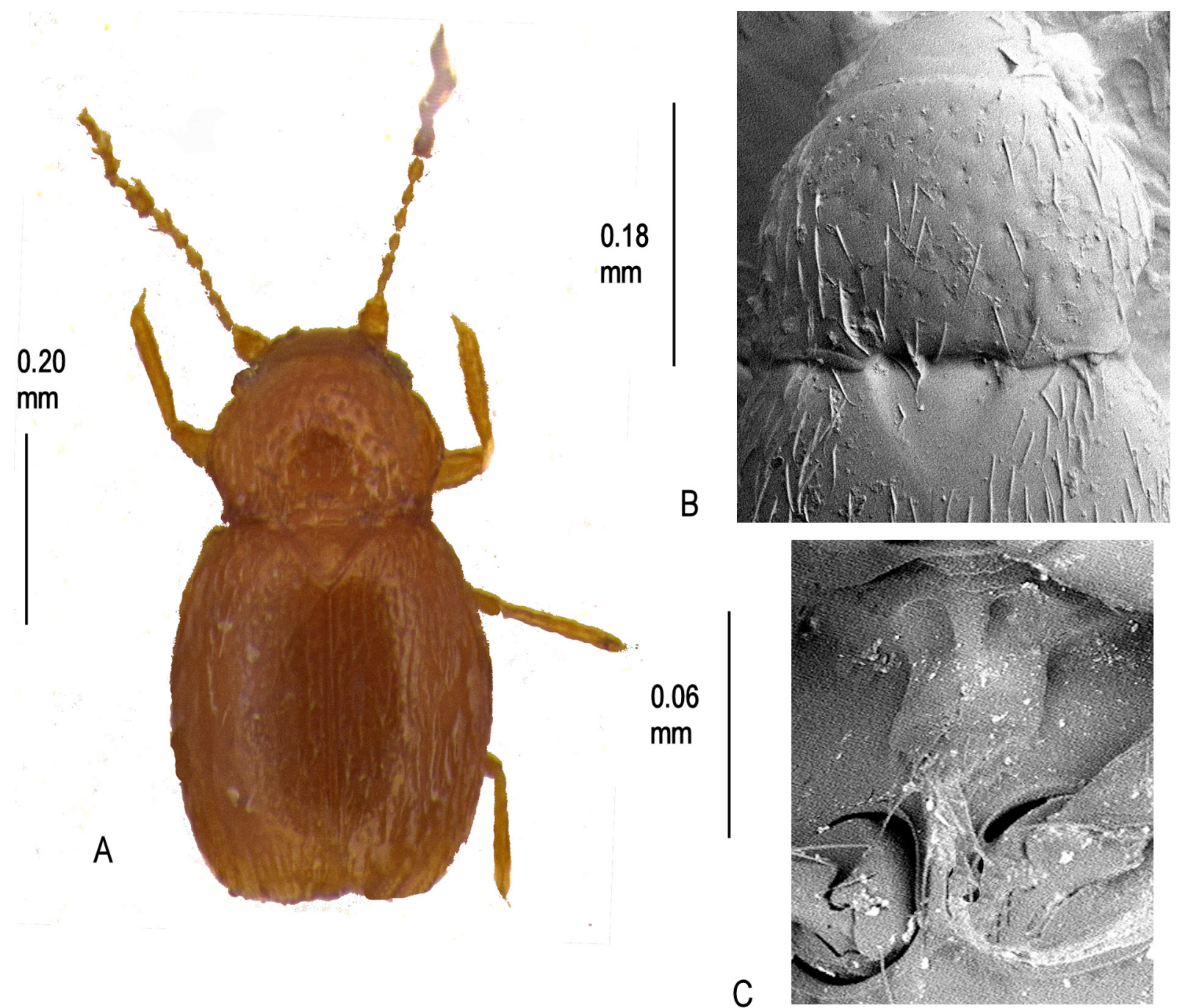

Fig. 84. Cissidium trangse sp. nov. A. Habitus. B. Pronotum, $\times 480$. C. Mesoventrite showing median process of collar, mid-keel and keel, $\times 670$. 
GenitaLia. Female spermatheca globular. Males not known.

\section{Remarks}

The only species of Cissidium to have been described from Thailand.

Cissidium triangulum Darby, 2019

Figs 4E, 85

\section{Material examined}

\section{Holotype}

MALAYSIA - Sarawak, Mulu; pitfalls in alluvial forest; Mar. 1978; N.M. Collins leg.; genitalia not dissected; BMNH.

\section{Supplementary description}

The following description amplifies the type description of Darby (2019), in particular by adding more details of the meso- and metaventral characters, in order to conform with the entries in the present paper.

Size. Habitus (Fig. 85A), length $0.79 \mathrm{~mm}$.

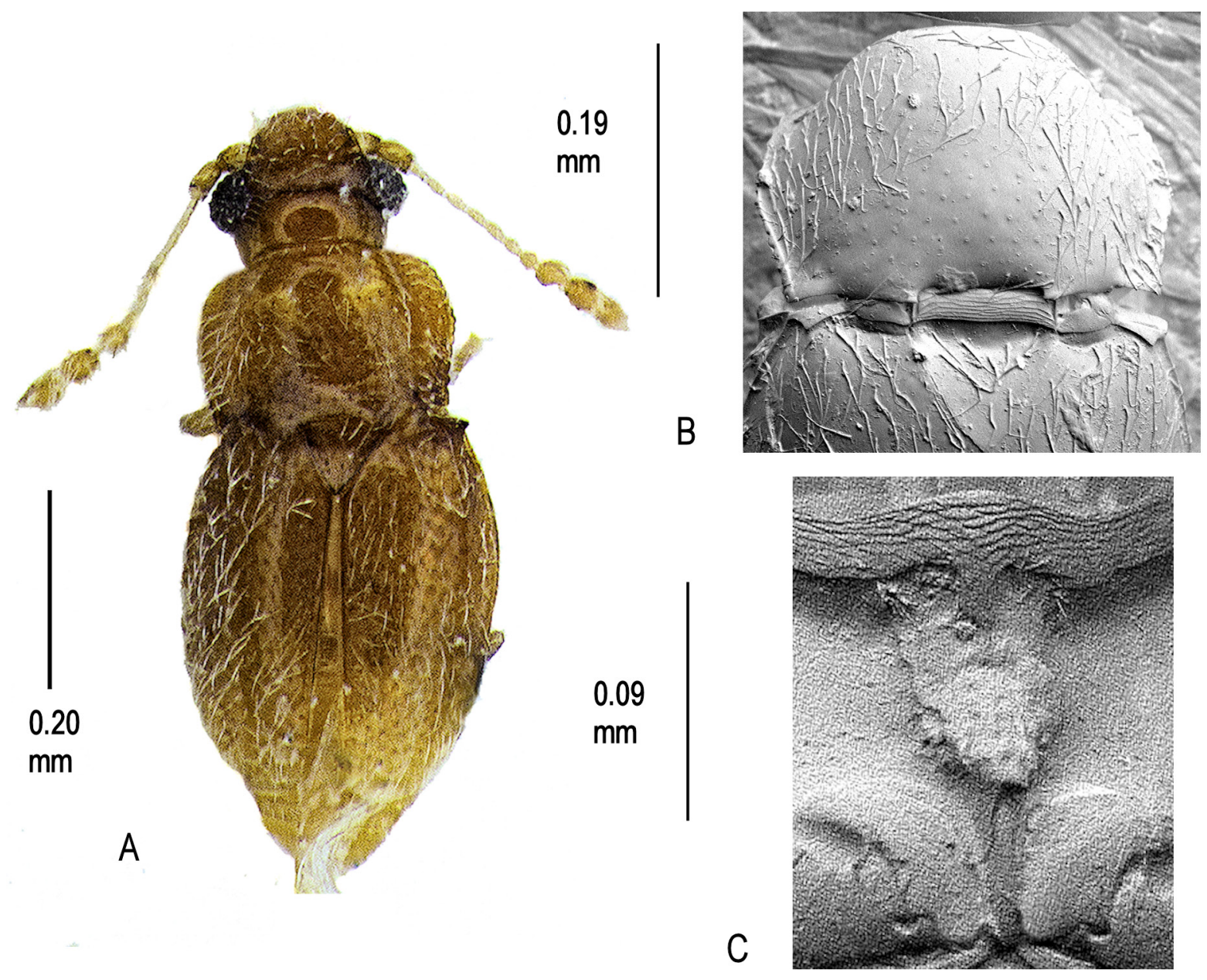

Fig. 85. Cissidium triangulum Darby, 2019. A. Habitus. B. Pronotum, $\times 555$. C. Mesoventrite showing median process of collar, mid-keel and keel, $\times 575$. 
CoLour. Yellow brown, antennae, legs, and pubescence yellow.

HEAD. Distance across eyes $0.22 \mathrm{~mm}$; antennomeres III-XI, length $0.31 \mathrm{~mm}$; mentum triangular the anterior margin much longer than the basal, stipes also triangular, broadest at base (Fig. 4E).

Pronotum. Length $0.19 \mathrm{~mm}$, width $0.28 \mathrm{~mm}$, pubescent, shallowly foveolate; sides rounded then straight before rectangular hind angles, border crenulate, not continuing along posterior margin, median emargination angulate (Fig. 85B).

ELYTRA. Length $0.41 \mathrm{~mm}$, width $0.34 \mathrm{~mm}$, pubescent, the pubescence slightly longer than on the pronotum, shallowly foveolate.

Mesoventrite. Median extension of collar parallel-sided, short, mid-keel setose and rugose before keel; keel narrow, tapering to a point at the base of the mesocoxae; mesoventral lateral margins almost straight before turning to meet mesocoxae, then obscured; humeri barely toothed (Fig. 85C).

METAVENTRITE. With scattered pubescence throughout, disc plain, length $0.14 \mathrm{~mm}$, distance across spines $0.08 \mathrm{~mm}$; mesocoxal posterior margins without serrations.

\section{Remarks}

The only species of Cissidium from Sarawak in this group.

Cissidium visendum sp. nov. urn:1sid:zoobank.org:act:83CA11DD-21D9-49F7-9B48-41BDDBB3FFCD

Fig. 86

\section{Etymology}

Named after the Latin adjective 'visendus', meaning 'worth seeing'.

\section{Material examined}

\section{Holotype}

MALAYSIA • ○; Selangor, Gombak; FMNH.

No other collection data are present, but it is likely that the specimen was taken in the vicinity of University of Malaya Field Station, by D.H. Murphy (see C. modestum sp. nov.). A determination label in Johnson's hand stating 'adustipenne' is attached to the specimen but it is clearly not that species (see

C. adustipenne).

\section{Description}

Size. Habitus (Fig. 86A), length $0.64 \mathrm{~mm}$.

Colour. Yellow.

HEAD. With a shallow linear depression behind the eyes; width across eyes $0.20 \mathrm{~mm}$ antennomeres IIIXI length $0.29 \mathrm{~mm}$, III-IX length $0.15 \mathrm{~mm}, \mathrm{X}-\mathrm{XI}$ length $0.14 \mathrm{~mm}$; mentum as Fig. 4A.

Pronotum. Length $0.18 \mathrm{~mm}$, width $0.29 \mathrm{~mm}$, pubescent without foveae; side margins evenly rounded to rectangular hind angles, bordered, border not extending onto posterior margin which has an emargination opposite the scutellum (Fig. 86B). 
ELYTRA. Length $0.40 \mathrm{~mm}$, width $0.35 \mathrm{~mm}$, pubescent, shallowly foveolate most noticeably in basal area.

Mesoventrite. Medial extension of collar long, narrow and parallel-sided, mid-keel tapering seamlessly into parallel-sided keel, setose; keel long, extending past mesocoxal border interruption; humeri barely toothed; mesoventral lateral margins smoothly rounded, without serrations (Fig. 86C).

Metaventrite. Length $0.12 \mathrm{~mm}$, width across spines $0.08 \mathrm{~mm}$, with a densely setose, almost square, medial depression, the setae stouter than on the rest of the metaventrite; posterior margins of mesocoxal cavities without serrations.

WINGS. Macropterous.

\section{Remarks}

Distinguished from C. bilineatum sp. nov., the only other species from Malaya recorded in this group, by the absence of the linear depressions on the pronotum.
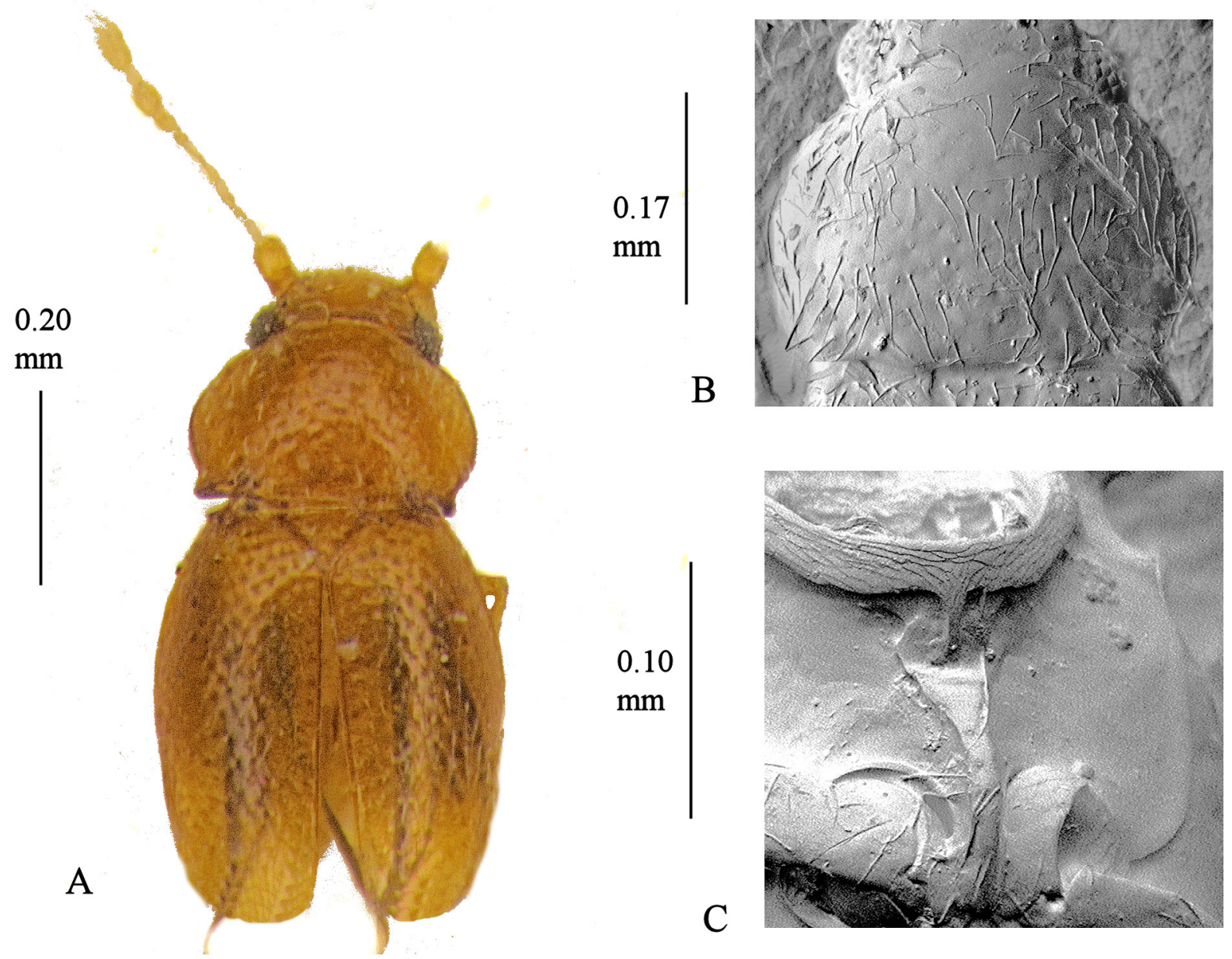

Fig. 86. Cissidium visendum sp. nov. A. Habitus. B. Pronotum, $\times$ 555. C. Mesoventrite showing median process of collar, lateral margin, mid-keel and keel, $\times 362$. 


\section{Species group 4B pronotum without foveae and distinct foveolae, sides angulate}

\section{Key to species group 4B}

1. Mesoventral lateral margins serrate 2

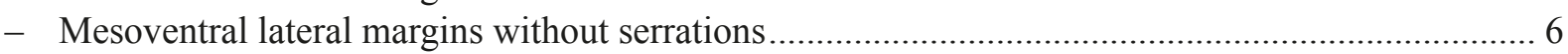

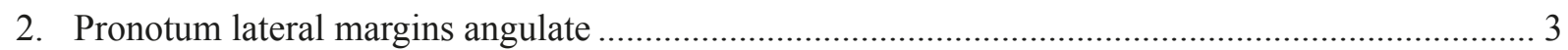

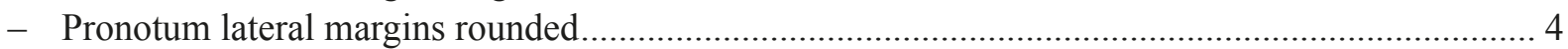

3. Pronotum lateral margins less strongly angled, almost parallel-sided before hind angles, wider than the elytral base

C. cryptophagoides sp. nov.

- Pronotal base narrower with two linear depressions, sides strongly angled

C. shibatai Sawada, 2008

4. Elytra narrow, pronotum lateral margins almost parallel-sided base without linear depressions........

C. sakaii Sawada, 2008

- Elytra rounded 5

5. Mid-keel wider anteriorly

C. nishikawai Sawada, 2008

- Mid-keel wider posteriorly

C. elongatum Sawada, 2008

6. Mesoventral lateral margins partly or completely effaced

- Mesoventral lateral margins distinct to mesocoxal borders.

7. Mesoventral collar without a median extension.

C. obsoletum sp. nov.

- Mesoventral collar with a median extension 8

8. Mesoventrite lateral margins with a distinct concave bulge at the posterior angle 9

- Mesoventral lateral margins without a concave bulge.

9. Mid-keel not fusing with the posterior border of the mesoventral collar the anterior angles not interrupting the line of the posterior margin.

- Mid keel fusing with the posterior border of the mesoventral collar ......

10. Raised posterior margin before keel broad and strongly sculpted

C. ibicarense sp. nov.

- Raised posterior margin before keel narrower not sculpted ....

C. peruviense sp. nov.

11. Larger species $\pm 0.90 \mathrm{~mm}$.

C. orami sp. nov.

- Smaller species $\pm 0.65-0.70 \mathrm{~mm}$.

12 Mesoventral lateral margin hind angle sharp the concave extrusion very small.

C. dybasi sp. nov.

- Mesoventral lateral margin hind angle more rounded

13. Mid-keel broad, short, mesoventral collar extension short

C. reitteri (Matthews, 1889)

- Mid keel narrower, longer, mesoventral collar extension longer

C. bomjesus sp. nov.

14. Mid-keel very much reduced almost absent, keel strongly sculpted

C. losbanos sp. nov.

- Keel narrow before joining keel, less strongly sculpted C. sawadai Darby, 2015

15. Keel very broad, flat, with rounded tip C. similatum sp. nov.

- Keel narrower 
16. Mid-keel sides strongly widened anteriorly

- Mid-keel sides not so widened anteriorly, sides concave ................................................................. 19

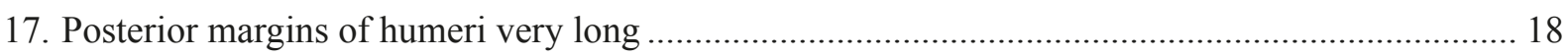

- Posterior margins of humeri shorter, mid-keel with concave sides

18. Longer species, mid-keel wider.

C. lisae Darby, 2015

- Shorter species, mid keel shorter, keel much narrower

19. Mid-keel hind angles rounded

C. obscenum sp. nov.

- Mid-keel hind angles not rounded, extending towards mesocoxal posterior border.

20. Mesoventral collar without a medial extension C. dividuum sp. nov.

- Mesoventral collar with a medial extension.... 21

21. Mesoventral median extension long, with a splayed end, keel very long and narrow C. subangulatum sp. nov.

- Shorter species, mid-keel shorter, keel shorter and wider at base C. angulatum sp. nov.

Cissidium angulatum sp. nov. urn:1sid:zoobank.org:act:0A8C4F42-155C-4326-B4D9-097A0AB57637

Fig. 87

\section{Etymology}

Named after the strongly angled lateral margins of the pronotum.

\section{Material examined}

\section{Holotype}

PANAMA • ㅇ; B.C.I. [Barro Colorado Island]; 7 Dec. 1938; 3cAu FM(HD) \#38.6; HD [Henry Dybas] leg.; FMNH.

\section{Paratype}

PANAMA • 1 ex., BCI., 21 Jul. 1938; 3cAEu; FM(HD) \#38.10; mounted verso; MMUE.

\section{Description}

Size. Habitus (Fig. 87A), length $0.67 \mathrm{~mm}$.

CoLour. Dark brown, elytra dusky yellow where translucent, pubescence, legs and antennae dusky yellow.

HEAD. With a clearly marked linear depression behind the eyes, width across eyes $0.19 \mathrm{~mm}$; antennomeres III-XI length $0.33 \mathrm{~mm}$, III-IX length $0.22 \mathrm{~mm}, \mathrm{X}-\mathrm{XI}$ length $0.11 \mathrm{~mm}$; mentum narrowed towards base then parallel-sided towards anterior margin, front angles obtuse.

Pronotum. Length $0.19 \mathrm{~mm}$, width $0.28 \mathrm{~mm}$, sparsely pubescent length of setae $0.05 \mathrm{~mm}$, without foveae; side margins strongly bordered, sharply angled, border not extending onto posterior margin which has an emargination opposite the scutellum, hind angles acute (Fig 87B).

ELYTRA. Length $0.42 \mathrm{~mm}$, width $0.37 \mathrm{~mm}$, sparsely pubescent, length of setae as pronotum. 
Mesoventrite. Medial extension of collar short; mid-keel posterior margin reaching anterior margin of mesocoxal cavities, keel with a series of \pm six setae arising from scale-like, overlapping cells then tapering to point between mesocoxae; mesoventral humeri sharply toothed with strongly sinuate posterior border, lateral margins without serrations (Fig. 87C).

Metaventrite. Length $0.13 \mathrm{~mm}$, width across spines $0.10 \mathrm{~mm}$, with scattered setae and a shallow medial depression, disc simple; posterior margins of mesocoxal cavities serrate.

WINGS. Macropterous.

Genitalia. Female spermatheca globular. Males unknown.

\section{Remarks}

Only likely to be confused with $C$. dividuum sp. nov. in this group of Cissidium from Panama on dorsal characteristics but distinguished from that species by the longer mesoventral mid-keel and presence of a median extension of the collar.
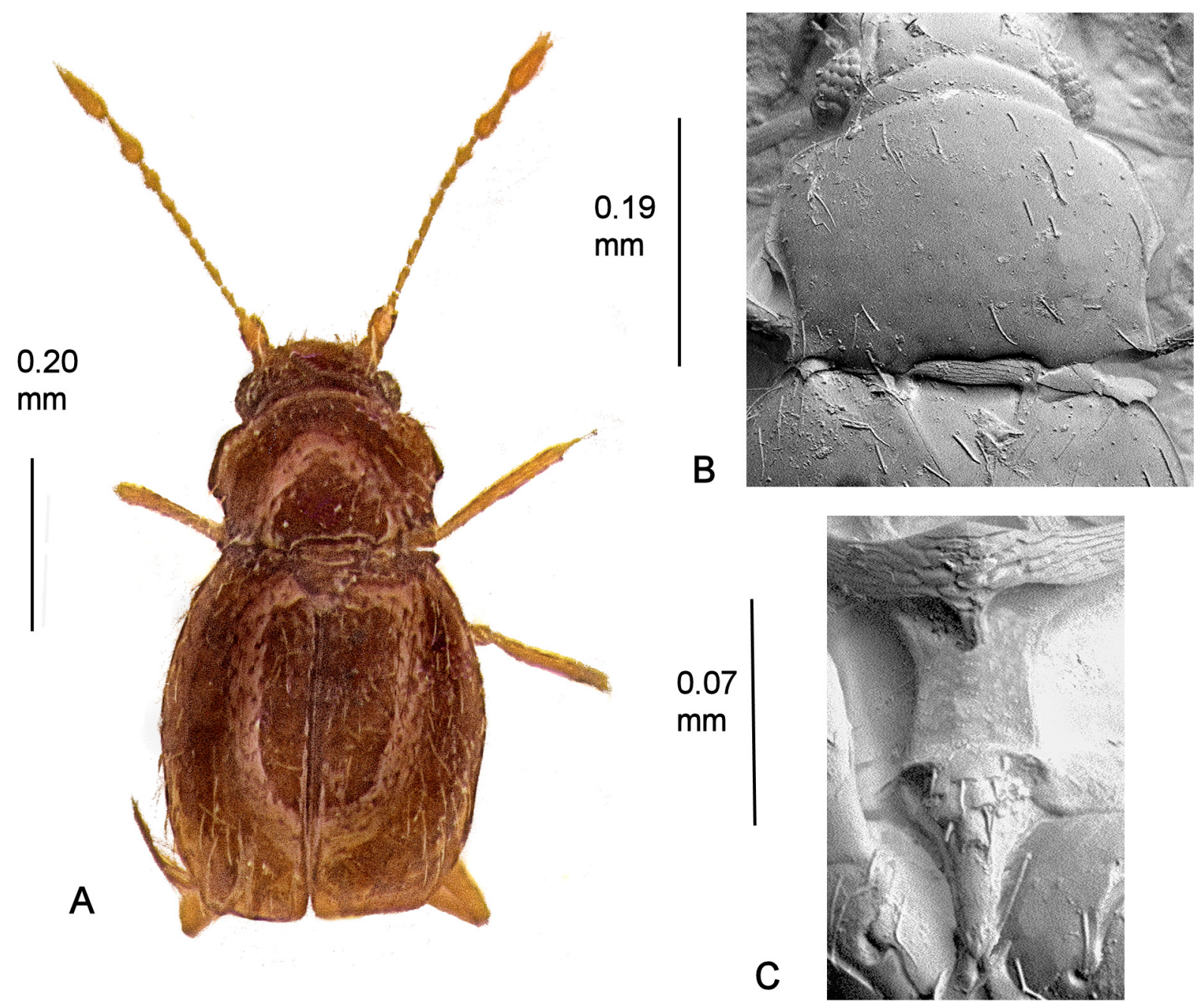

Fig. 87. Cissidium angulatum sp. nov. A. Habitus. B. Pronotum, $\times 590$. C. Mesoventrite showing median process of collar, mid-keel and keel, $\times 1000$. 
Cissidium basale Motschulsky, 1855

Figs $3 \mathrm{E}, 88$

\section{Material examined}

PANAMA - O; Barro Colorado Is; Berlese leaves and drift among rocks of stream bed; 25 Jan. 1950; H.S. Dybas 8-147 leg.; the specimen also bears a label stating "Cissidium basale Mots. det C. Johnson 1971 cf with 2 syntypes"; MMUE.

\section{Supplementary description}

Size. Habitus (Fig. 88A), length $0.76 \mathrm{~mm}$.

CoLour. Dark brown shining, pubescence, legs and antennae yellow.

HEAD. With a sharp linear depression interrupted medially by a fovea behind the eyes (Fig. 3E), width across eyes $0.23 \mathrm{~mm}$; antennomeres III-XI length $0.49 \mathrm{~mm}$, III-IX length $0.25 \mathrm{~mm}$, X-XI length $0.24 \mathrm{~mm}$; mentum difficult to make out, submentum with two very long setae.
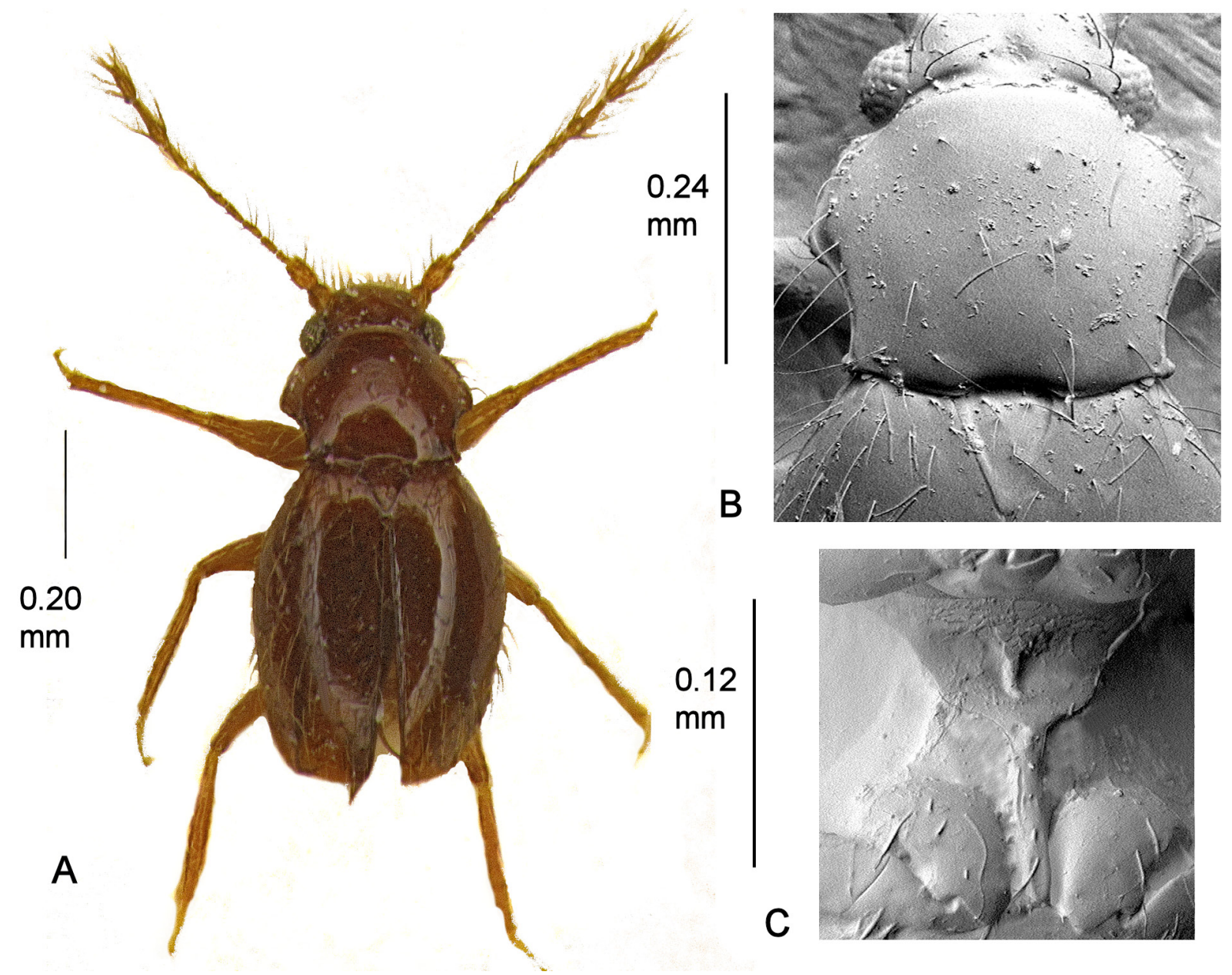

Fig. 88. Cissidium basale Motschulsky, 1855. A. Habitus. B. Pronotum, $\times 385$. C. Mesoventrite showing median process of collar, mid-keel and keel, $\times 710$. 
Pronotum. Length $0.24 \mathrm{~mm}$, width $0.30 \mathrm{~mm}$, with scattered pubescence on disc and along lateral margins; lateral margins strongly bordered, sharply angled medially, anterior corners obtusely angled, posterior corners rectangular, border on posterior margin obscured laterally and along emargination in front of the scutellum (Fig. 88B).

ElYTRA. Length $0.48 \mathrm{~mm}$, width $0.39 \mathrm{~mm}$, sparsely pubescent, length of setae as pronotum.

Mesoventrite. Medial extension of collar pointed; anterior margin of mid-keel wide, tapering with sinuous lateral margins directly to keel, without a clear posterior margin; keel long, parallel-sided with five setae, terminating past the midpoint of the mesocoxae; mesoventral lateral margins effaced; humeri toothed, posterior margins sinuous, long (Fig. 88C).

MetaVentRite. Length $0.12 \mathrm{~mm}$, width across spines $0.08 \mathrm{~mm}$, with scattered setae, disc simple; posterior margins of mesocoxal borders without serrations.

WINGs. Macropterous.

\section{Remarks}

One of the three Panamanian species in this group. Distinguished by the very broad anterior margin of the mesoventral mid-keel together with the short and sharply pointed median extension of the collar.

Cissidium bomjesus sp. nov.

urn:1sid:zoobank.org:act:82221C1C-A852-4E0B-99FF-B24A65B2040A

Fig. 89

\section{Etymology}

Named after the place of capture, noun in apposition.

\section{Material examined}

Holotype

BRAZIL• ○’; Bom Jesus; 2840’ E, 50¹2' S; 1200 m a.s.1.; Dec. 1962; F. Plaumann leg.; FMNH.

\section{Description}

Size. Habitus (Fig. 89A), length $0.68 \mathrm{~mm}$.

Colour. Yellow brown, pubescence, legs and antennae dusky yellow.

HEAD. Linear depression behind the eyes with a row of foveolae, width across eyes $0.20 \mathrm{~mm}$; antennomeres III-XI length $0.33 \mathrm{~mm}$, III-IX length $0.24 \mathrm{~mm}, \mathrm{X}-\mathrm{XI}$ length $0.11 \mathrm{~mm}$ globular; mentum as Fig. 4D.

Pronotum. Length $0.21 \mathrm{~mm}$, width $0.28 \mathrm{~mm}$, without either foveae or foveolae; lateral margins \pm sharply angled then concave to rectangular hind angles, bordered, the border not extending along the posterior margin which has an emargination opposite the scutellum (Fig. 89B).

ELYTRA. Length $0.44 \mathrm{~mm}$, width $0.37 \mathrm{~mm}$, pubescent, setae same length as those on pronotum.

MesoventRITE. Medial extension of collar broad; mid-keel widest anteriorly then tapering posteriorly before rising sharply to junction with keel, posterior corners reaching anterior margin of mesocoxal borders; keel without setae, almost parallel to a rounded tip at midpoint of the mesocoxae; mesoventral 
lateral margins not serrate, almost rectangular before meeting mesocoxal borders; humeri bluntly toothed (Fig. 89C).

Metaventrite. Length $0.15 \mathrm{~mm}$, width across spines $0.09 \mathrm{~mm}$, with sparse pubescence medially, disc simple; posterior margins of mesocoxal cavities serrate.

Wings. Macropterous.

Genitalia. Male aedeagus as Fig. 6Fa-b. Females not known.

\section{Remarks}

One of the five Brazilian species in this group. Only likely to be confused with C. reitteri (Matthews, 1889) but distinguished by the less angulate pronotal sides and the narrower and longer mid-keel.

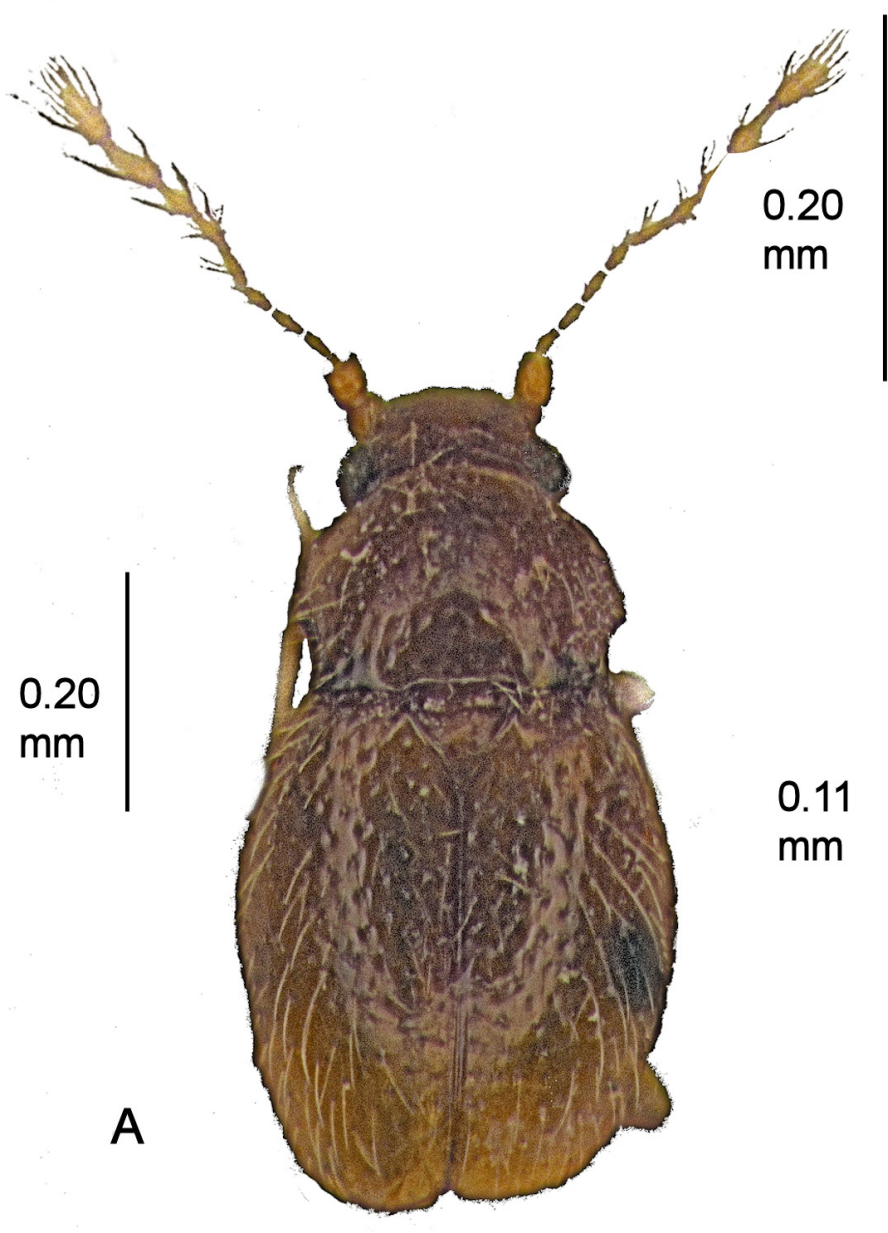

B

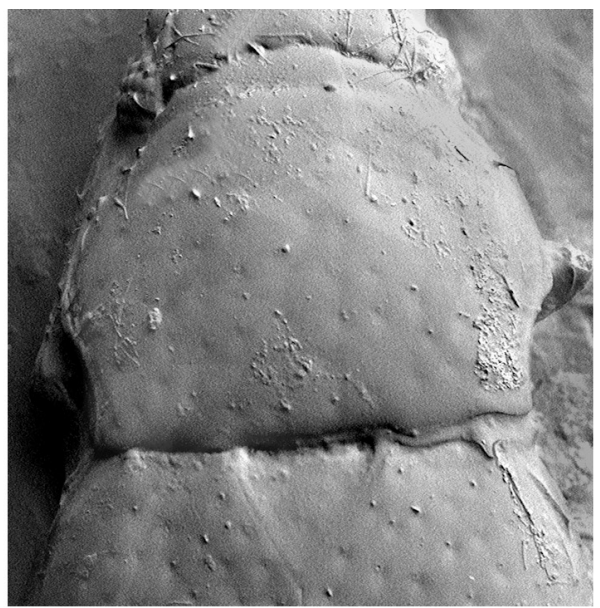

C

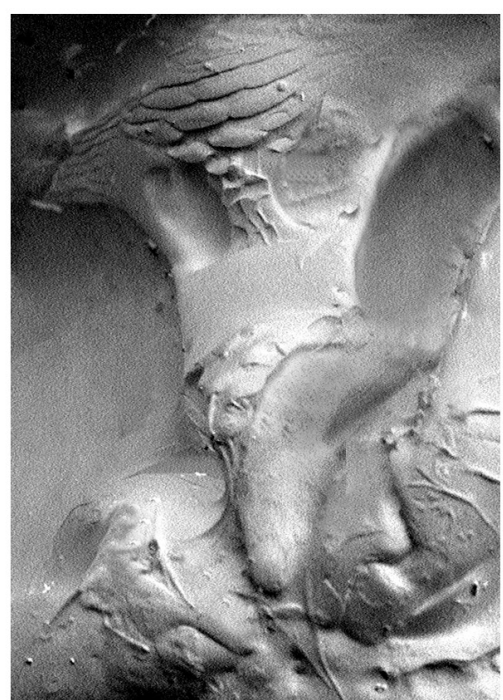

Fig. 89. Cissidium bomjesus sp. nov. A. Habitus. B. Pronotum, $\times 570$. C. Mesoventrite showing median process of collar, mid-keel and keel, $\times 1320$. 
Cissidium cryptophagoides sp. nov.

urn:1sid:zoobank.org:act:28447343-05AE-485D-9AB3-F713DF6FC22A

Fig. 90

\section{Etymology}

Johnson ms name.

\section{Material examined}

\section{Holotype}

PANAMA • O; B[arro] C[olorado] I[sland]; 14 Jul. 1938; FM(HD) \#38-7, 1c Au; FMNH.

\section{Paratype}

PANAMA $・ 1$; ; same collection data as for holotype; FMNH Chicago leg.; the specimen is mounted verso; MMUE.

\section{Description}

Size. Habitus (Fig. 90A), length $0.80 \mathrm{~mm}$.

Colour. Yellow.
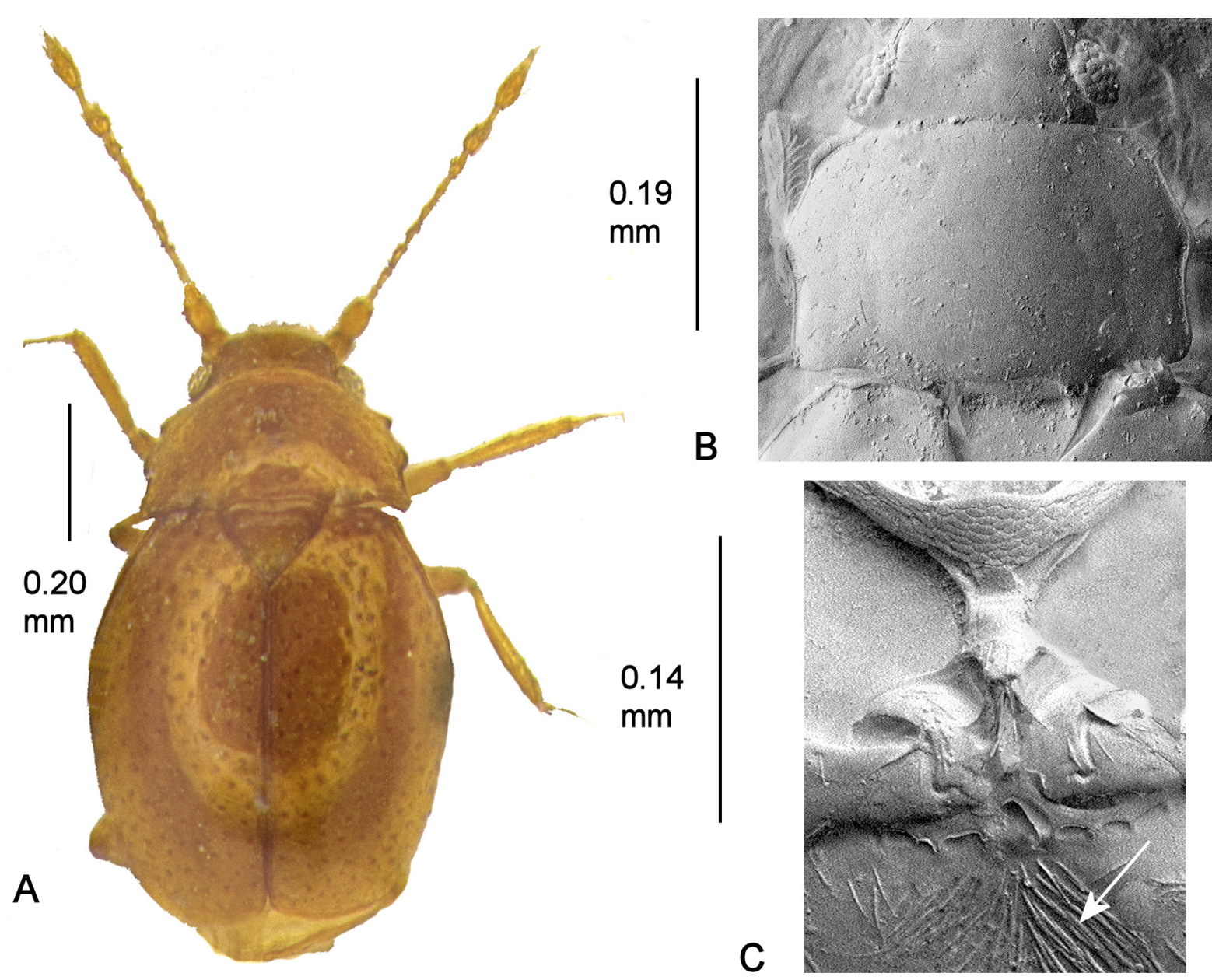

Fig. 90. Cissidium cryptophagoides sp. nov. A. Habitus. B. Pronotum, $\times 475$ C. Mesoventrite showing median process of collar, mid-keel and keel, $\times 1100$. 
HEAD. With a shallow median depression between the eyes, width across eyes $0.24 \mathrm{~mm}$; antennomeres III-XI length $0.41 \mathrm{~mm}$; mentum as Fig. 4A.

Pronotum. Length $0.19 \mathrm{~mm}$, width $0.36 \mathrm{~mm}$, very sparsely pubescent, without foveolae or foveae; lateral margins sharply angled medially, almost parallel-sided to rectangular (rounded) hind angles, anterior angles marked by a swelling of the lateral border, border not extending onto the posterior margin which has an emargination opposite the scutellum (Fig. 90B).

ELYTRA. Length $0.54 \mathrm{~mm}$, width $0.48 \mathrm{~mm}$, pubescent, shallowly foveate.

Mesoventrite. Medial extension of collar wide almost as wide as mid-keel at termination; mid-keel lateral margins concave, strongly widened anteriorly before joining collar and posteriorly with carinae joining mesocoxal anterior borders, sharply raised medially before keel; keel with \pm four setae parallelsided to a blunt termination beyond the interruption point of the mesocoxal margins; mesoventral lateral margins serrate in posterior half, deep pits present at junction between collar and humeri which may be perforations; humeri wide, sharply toothed (Fig. 90C).

Metaventrite. Length $0.13 \mathrm{~mm}$, female with disc simple, male with distinctive pattern of radiating setae in triangular, medially depressed area, distance across short triangular spines $0.11 \mathrm{~mm}$; posterior margins of mesocoxal cavities serrate.

WiNGS. Micropterous.

Genitalia. Female spermatheca globular. Male aedeagus not found in dissection.

\title{
Remarks
}

One of the three Brazilian species in this group. Distinguished by the almost parallel-sided lateral margins of the pronotum before the hind angles and by the setae on the metaventrite of the male.

\author{
Cissidium dividuum sp. nov. \\ urn:1sid:zoobank.org:act:5D646C8C-1C66-47ED-A68B-731F740CAD61
}

Fig. 91

\section{Etymology}

Johnson ms name, derivation not clear.

\section{Material examined}

Holotype

PANAMA • 9 ; Chiriqui Prov., Castita Alta, Finca Larida nr Boquete; 18 Mar. 1959; $6900 \mathrm{ft}$ a.s.1.; berlese (543), cont. floor debris in deep ravine; H.S. Dybas leg.; FM(HD) \#59.261; FMNH.

\section{Description}

Size. Habitus (Fig. 91A), length $0.72 \mathrm{~mm}$.

CoLour. Dark brown, shining, pubescence, antennae and legs paler, head darker.

HEAD. With a linear depression behind the eyes, width across eyes $0.19 \mathrm{~mm}$; antennomeres III-XI length $0.32 \mathrm{~mm}$, III-IX length $0.17 \mathrm{~mm}, \mathrm{X}-\mathrm{XI}$ length $0.15 \mathrm{~mm}$; mentum and prementum obscured. 
Pronotum. Length $0.20 \mathrm{~mm}$, width $0.28 \mathrm{~mm}$, pubescent, shallowly foveolate in basal half; lateral margins sharply angled and strongly bordered, the borders with prominent rounded angles at the anterior corners and running a short distance along the posterior margin, hind angles markedly acute, posterior margin with an emargination opposite the scutellum (Fig. 91B).

ELYTRA. Length $0.47 \mathrm{~mm}$, width $0.41 \mathrm{~mm}$, pubescent, setae same length as pronotum, without foveolae.

Mesoventrite. Collar without a medial extension; mid-keel narrow, posterior corners clearly joining mesocoxal anterior margins, sharply raised at junction with keel, with \pm two setae; keel with \pm four setae, parallel-sided to bluntly pointed termination below the mesocoxae; mesoventral lateral margins almost obliterated, without serrations; humeri toothed (Fig. 91C).

Metaventrite. Length $0.17 \mathrm{~mm}$ sparsely pubescent, with shallow medial depression, disc simple, width across spines $0.11 \mathrm{~mm}$, posterior margins of mesocoxal borders without serrations.

Wings. Macropterous.

GenitaLia. Female spermatheca globular. Males not known.

\section{Remarks}

One of the three Brazilian species in this group. Only likely to be confused with $C$. cryptophagoides sp. nov. if the mesoventral characters are studied, but unlike that species the pronotal lateral borders are concave and the hind angles sharply acute.
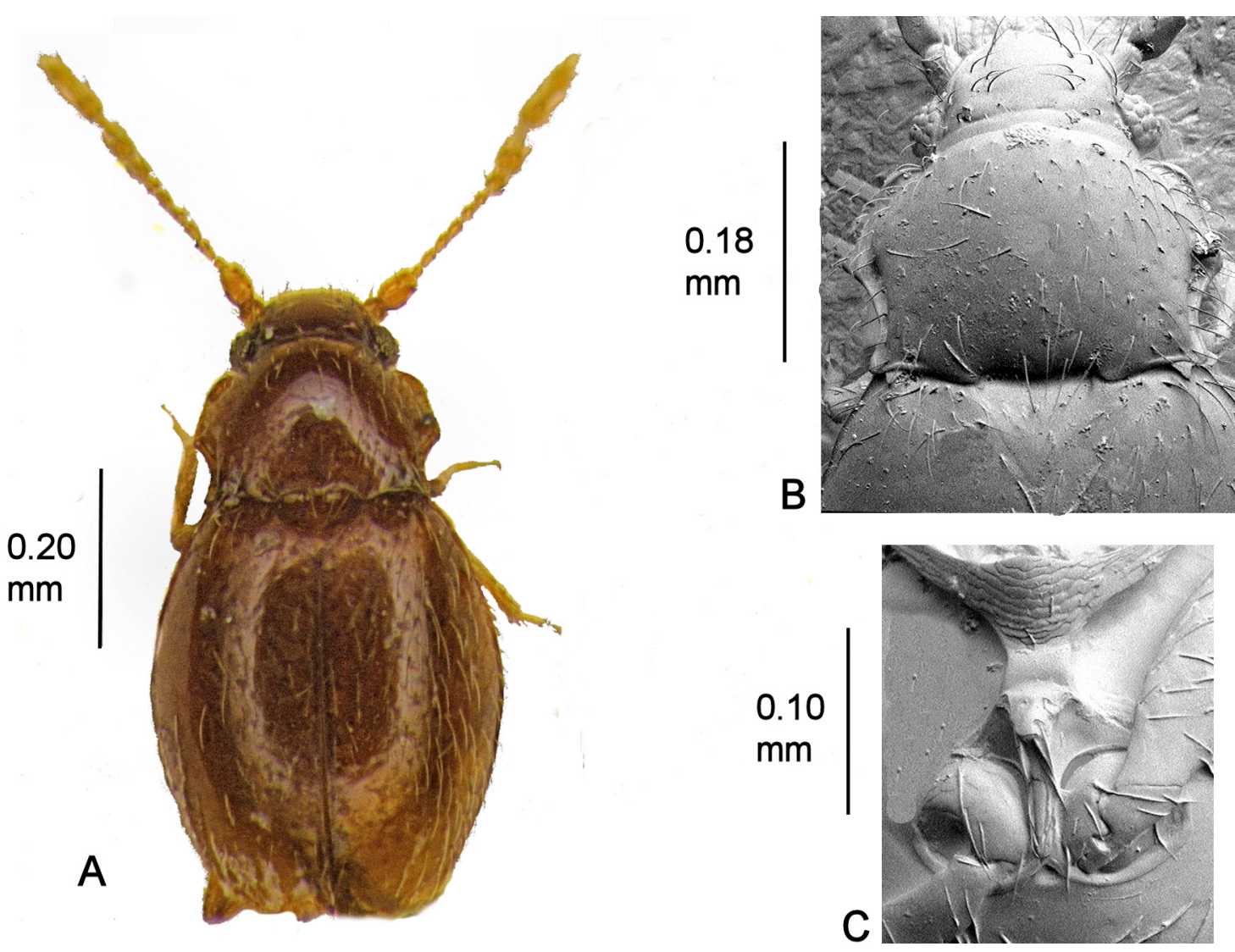

Fig. 91. Cissidium dividuum sp. nov. A. Habitus. B. Pronotum, $\times$ 495. C. Mesoventrite showing median process of collar, mid-keel and keel, $\times 695$. 


\section{Cissidium dybasi sp. nov.}

urn:lsid:zoobank.org:act:3195ABA5-F6E4-40D9-9C2F-F9816155C8F6

Fig. 92

\section{Etymology}

Named after the late Henry Dybas who did so much to further our knowledge of the Ptiliidae through his work at the Field Museum, Chicago, and who was very encouraging to the present author.

\section{Material examined}

\section{Holotype}

BRAZIL • đ̇; Santa Catarinay, Chapesonisho; Jan. 1958; F. Plaumann leg.; H.F. Dybas \#58-36; FMNH.

\section{Description}

Size. Habitus (Fig. 92A), length $0.66 \mathrm{~mm}$.

CoLour. Dusky yellow.
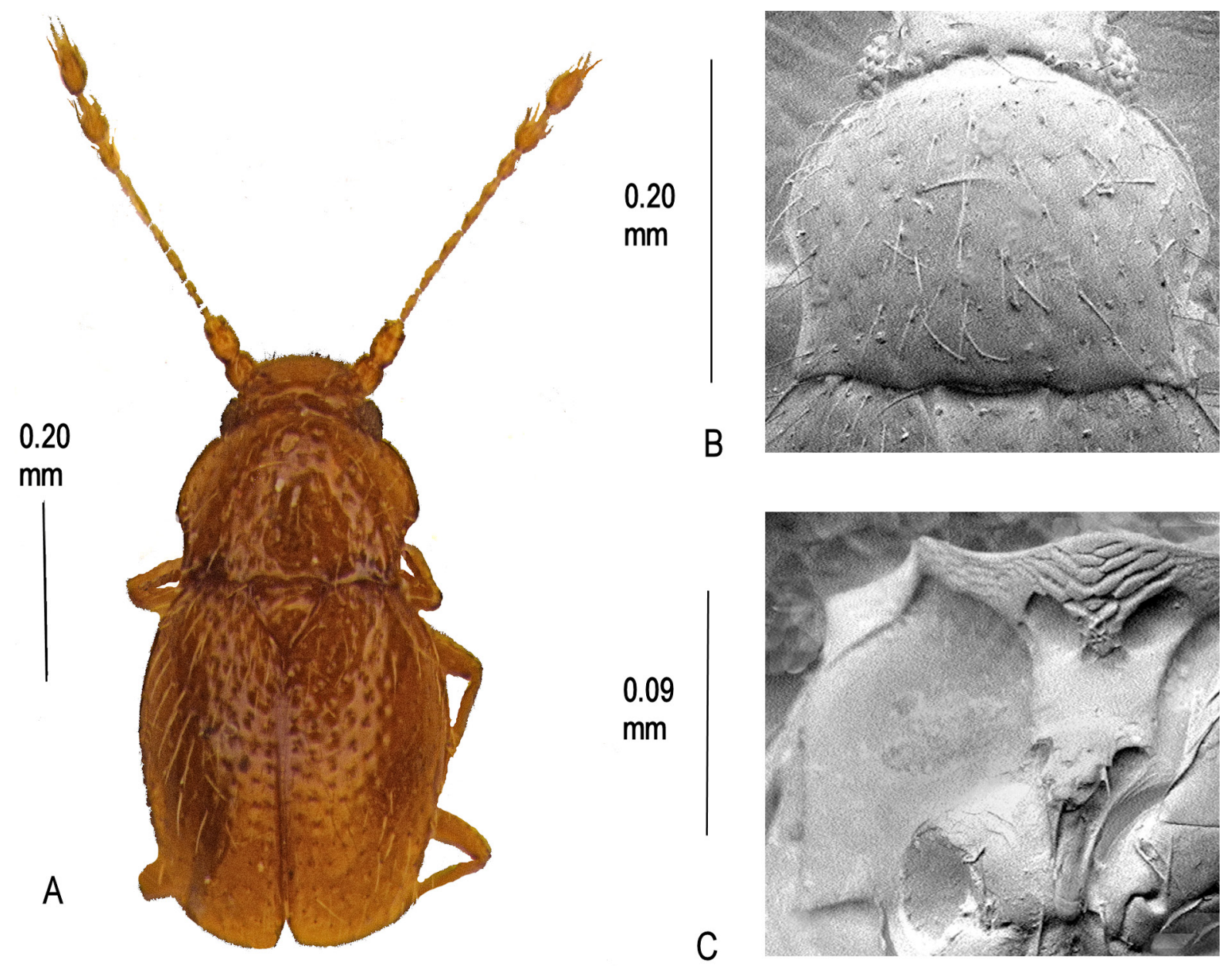

Fig. 92. Cissidium dybasi sp. nov. A. Habitus. B. Pronotum, $\times$ 370. C. Mesoventrite showing median process of collar, lateral margin, mid-keel and keel, $\times 1360$. 
HEAD. With a clearly marked foveate depression between the eyes, width across eyes $0.18 \mathrm{~mm}$; antennomeres III-XI length $0.36 \mathrm{~mm}$; mentum and prementum obscured.

Pronotum. Length $0.20 \mathrm{~mm}$, width $0.28 \mathrm{~mm}$, shallowly foveolate in basal half, pubescent; lateral margins rounded, then concave to acute hind angles, bordered, border not extending onto the posterior margin which has a sinuous emargination opposite the scutellum (Fig. 92B).

ELYTRA. Length $0.41 \mathrm{~mm}$, width $0.34 \mathrm{~mm}$, pubescent, setae same length as pronotum, without foveolae.

MesoventRITE. Medial extension of collar broad; mid-keel lateral margins widening anteriorly before joining collar and defining two large foveae, posterior corners not joining mesocoxal anterior borders, medially with a short, broad, posteriorly rounded, setose termination before the keel, the setae arising from well-marked elongate sculpture; keel tapering to blunt termination between the mesocoxae; mesoventral lateral margins acutely angled, without serrations; humeri bluntly toothed with strongly sloping posterior margins (Fig. 92C).

MetaVentrite. Sparsely pubescent, with shallow medial depression; posterior margins of mesocoxal borders not serrate.

WINGs. Macropterous.

Genitalia. Male aedeagus as Fig. 6Fa-b. Females not known.

\section{Remarks}

One of the five Brazilian species in this group. Separable by the slightly acute angles of the mesoventrite lateral sides and the sharply sloping posterior borders of the humeri.

Cissidium ibicarense sp. nov. urn:lsid:zoobank.org:act:2C9DAF49-AA1D-4D25-9365-428C13EAB2CC

Figs $3 F$, 93

\section{Etymology}

Johnson ms name, after Ibicare, a municipality in Santa Catarina in the South region of Brazil, where the insect was found.

\section{Material examined}

Holotype

BRAZIL • P; Ibicare; 600 m a.s.1.; Sep. 1960; F. Plaumann leg.; FMNH.

\section{Paratypes}

BRAZIL 10 ex.; same collection data as for holotype; one mounted verso; FMNH, MMUE, BMNH.

\section{Description}

Size. Habitus (Fig. 93A), length $0.78 \mathrm{~mm}$.

CoLour. Yellow brown, shining, pubescence and antennae slightly paler.

HEAD. With a depression behind the eyes composed of foveae of different shapes, interrupted medially (Fig. 3F), width across eyes $0.22 \mathrm{~mm}$; antennomeres III-XI length $0.38 \mathrm{~mm}$, III-IX length $0.24 \mathrm{~mm}$, 
$\mathrm{X}-\mathrm{XI}$ length $0.14 \mathrm{~mm}$; mentum and prementum as Fig. 4B, base of mentum with a row of differently shaped foveolae interrupted by a narrow transverse depression.

Pronotum. Length $0.23 \mathrm{~mm}$, width $0.34 \mathrm{~mm}$, pubescent, without foveae, shallowly foveolate; lateral margins strongly bordered and sharply angled, concavely rounded to base, borders not continuing along posterior margin, hind angles sharply acute, posterior margin with emargination opposite the scutellum (Fig. 93B).

ELYTRA. Length $0.54 \mathrm{~mm}$, width $0.40 \mathrm{~mm}$, pubescent, setae same length as pronotum, foveolate the foveolae more strongly marked in basal half.

Mesoventrite. Collar with a median parallel-sided extension; mid-keel widest anteriorly, posterior corners effaced before reaching mesocoxal anterior borders, sharply raised at junction with keel with \pm three setae from concave foveolae; keel tapering to pointed termination between the mesocoxae; mesoventral lateral margins rectangular without serrations; humeri toothed, posterior margins long and sinuous (Fig. 93C).

Metaventrite. Length $0.16 \mathrm{~mm}$, setose, disc simple, width across spines $0.11 \mathrm{~mm}$, spines long, sharply pointed; posterior margins of mesocoxae serrate.
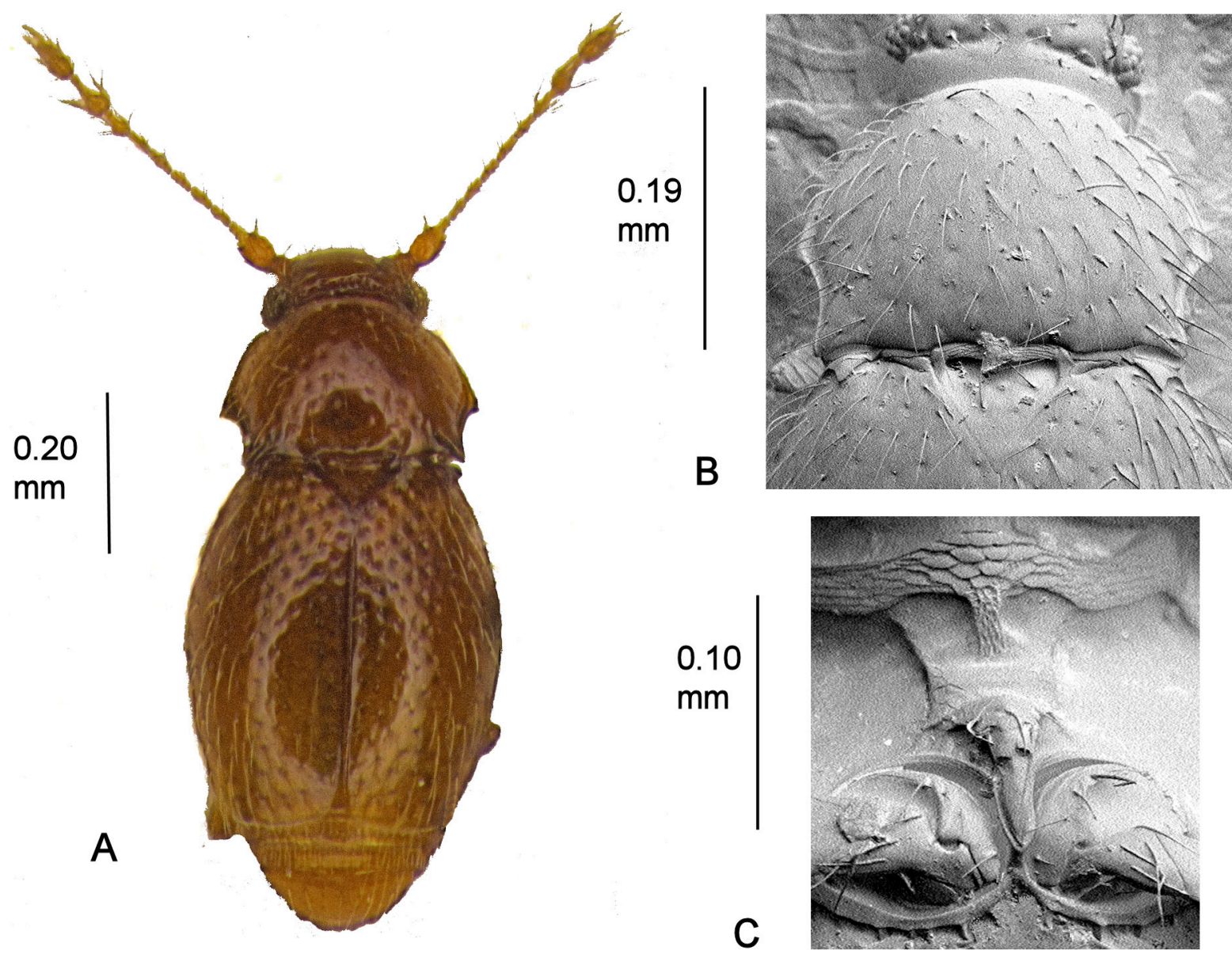

Fig. 93. Cissidium ibicarense sp. nov. A. Habitus. B. Pronotum, $\times$ 505. C. Mesoventrite showing median process of collar, mid-keel and keel, $\times 1380$. 
Wings. Macropterous.

GeNitALIA. Female spermatheca globular. Males not known.

\section{Remarks}

One of the five Brazilian species in this group. Distinguished by the anterior angles of the mesoventral mid-keel which do not fuse with the collar.

\section{Cissidium lisae Darby, 2015}

Figs 2F, 5F, 94

\section{Material examined}

\section{Holotype}

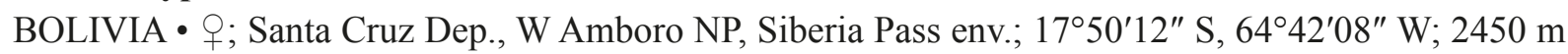
a.s.1.; 28 Nov. 2013; sifting litter; Winkler app. extr.; P. Baňar̆ leg.; UASC.

\section{Paratypes}

BOLIVIA 1 1 ; same collection data as for holotype; MMBC $\bullet 1$; ; Santa Cruz Dep., W of Amboro

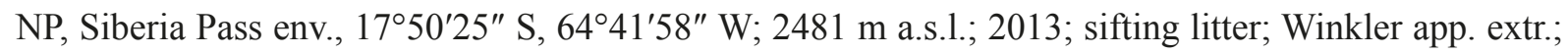
P. Baňař leg.; BMNH.

\section{Supplementary description}

The following description amplifies the type description of Darby (2015), by adding more details of the meso- and metaventral characters, in order to conform with the entries in the present paper.

SizE. Habitus (Fig. 94A), length $0.80 \mathrm{~mm}$.

CoLour. Yellow brown, antennae and legs dusky yellow.

HeAD. Width across eyes $0.22 \mathrm{~mm}$; antennomeres 3-11 length $0.45 \mathrm{~mm}$ long (Fig. 2F); mentum as Fig. 4B.

Pronotum. Length $0.19 \mathrm{~mm}$, width $0.28 \mathrm{~mm}$, sparsely pubescent and foveolate; lateral margins sharply angled, strongly concave posteriad to rectangular hind angles, less markedly concave anteriorly to distinct obtusely rounded front angles (Fig. 94B).

ElytRA. $0.55 \mathrm{~mm}$ long, $0.41 \mathrm{~mm}$ wide, pubescence a little shorter and more decumbent than on the pronotum.

MESOVENTRITE. Median process of the very narrow collar pointed; mid-keel strongly widened anteriorly, hind angles with carinae to mesocoxal anterior borders, bluntly raised medially before junction with keel; keel with \pm five setae, parallel-sided to rounded termination at base of mesocoxae (Fig. 5F); humeri toothed with flat, sharply pointed carinae reaching posteriorly to mid-point of mesoventrite, mesoventral lateral margins entirely effaced, present as apodemes (Fig. 94C).

MetaVentrite. Spines very small.

Genitalia. Female spermatheca globular. Males not known. 


\section{Remarks}

Differs from the other Bolivian Cissidium, except C. sawadai Darby, 2015, by the long and narrow elytra and distinguishable from that species by the strongly tapering mid-keel.
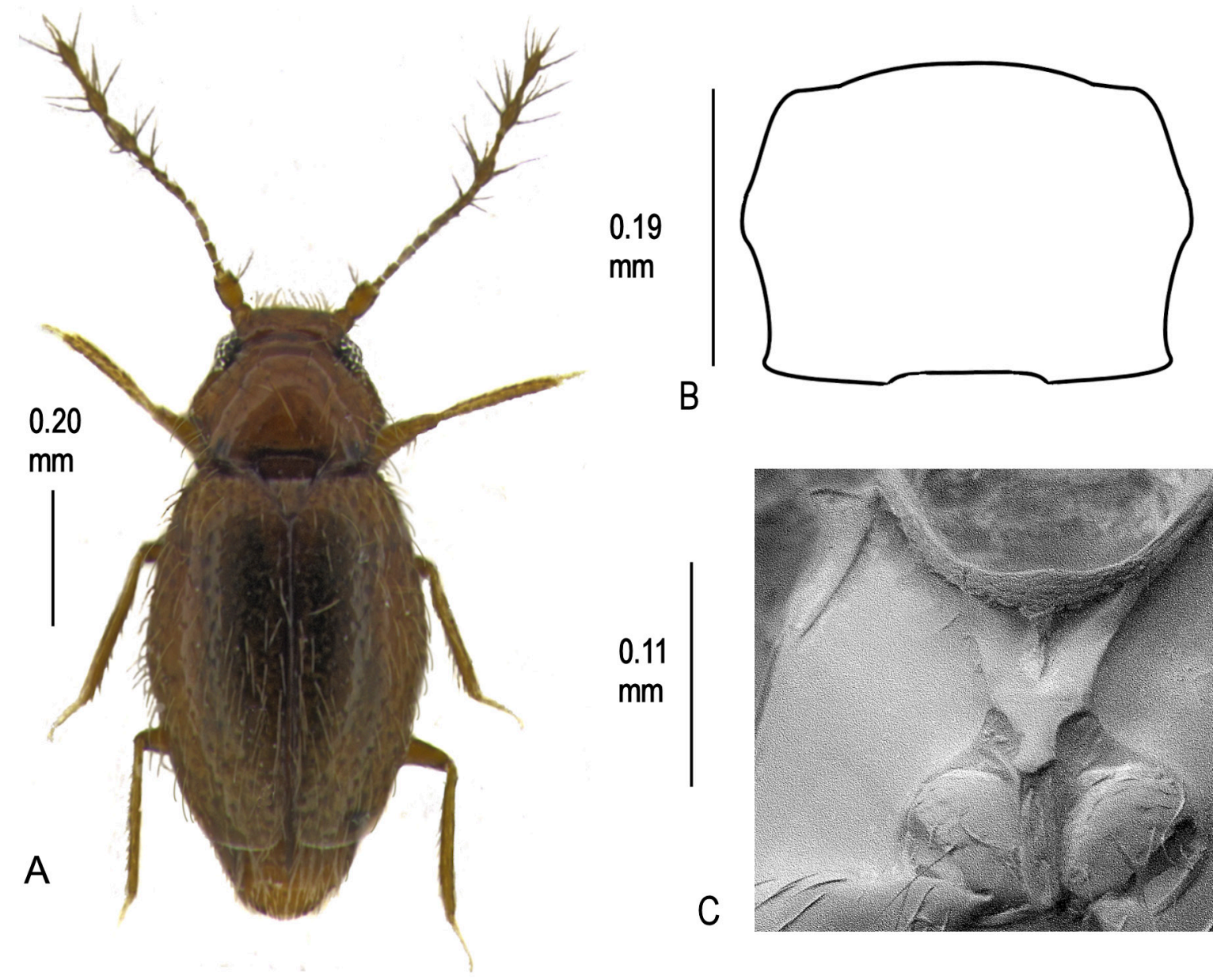

Fig. 94. Cissidium lisae Darby, 2015. A. Habitus. B. Pronotum, C. Mesoventrite showing median process of collar, mid-keel and keel, $\times 550$.

Cissidium losbanos sp. nov.

urn:lsid:zoobank.org:act:A843A921-A7D6-460C-8D0E-143329B50207

Figs 4D, 95

\section{Etymology}

Named after the Mount Makiling National Reserve, in the Municipality of Los Banos, in Laguna Province of the Philippines, where the insects were collected. Noun in apposition.

\section{Material examined}

\section{Holotype}

PHILIPPINES • O; Los Banos, Makiling Forest; 27-28 Sep. 1981; in rotten wood; M. Darby leg.; BMNH. 
Paratypes

PHILIPPINES • 7 ex.; same collection data as for holotype; two mounted verso; BMNH.

\section{Description}

Size. Habitus (Fig. 95A), length $0.94 \mathrm{~mm}$.

CoLour. Yellow brown, antennae, legs and pubescence paler.

HEAD. With a sharply defined transverse depression behind the eyes, width across eyes $0.27 \mathrm{~mm}$; antennomeres III-XI length $0.46 \mathrm{~mm}$, III-IX length $0.30 \mathrm{~mm}, \mathrm{X}-\mathrm{XI}$ length $0.16 \mathrm{~mm}$ globular; mentum and prementum with distinctive sculpturing (Fig. 4D).

Pronotum. Length $0.28 \mathrm{~mm}$, width $0.44 \mathrm{~mm}$, densely pubescent, without foveolae and foveae; lateral margins shallowly angled, bordered, the borders extending narrowly along the entire posterior margin, hind angles sharp, acute, posterior border without emargination opposite the scutellum (Fig. 95B).

ELYTRA. Length $0.58 \mathrm{~mm}$, width $0.49 \mathrm{~mm}$, pubescent, foveolate contrasting with the pronotum.
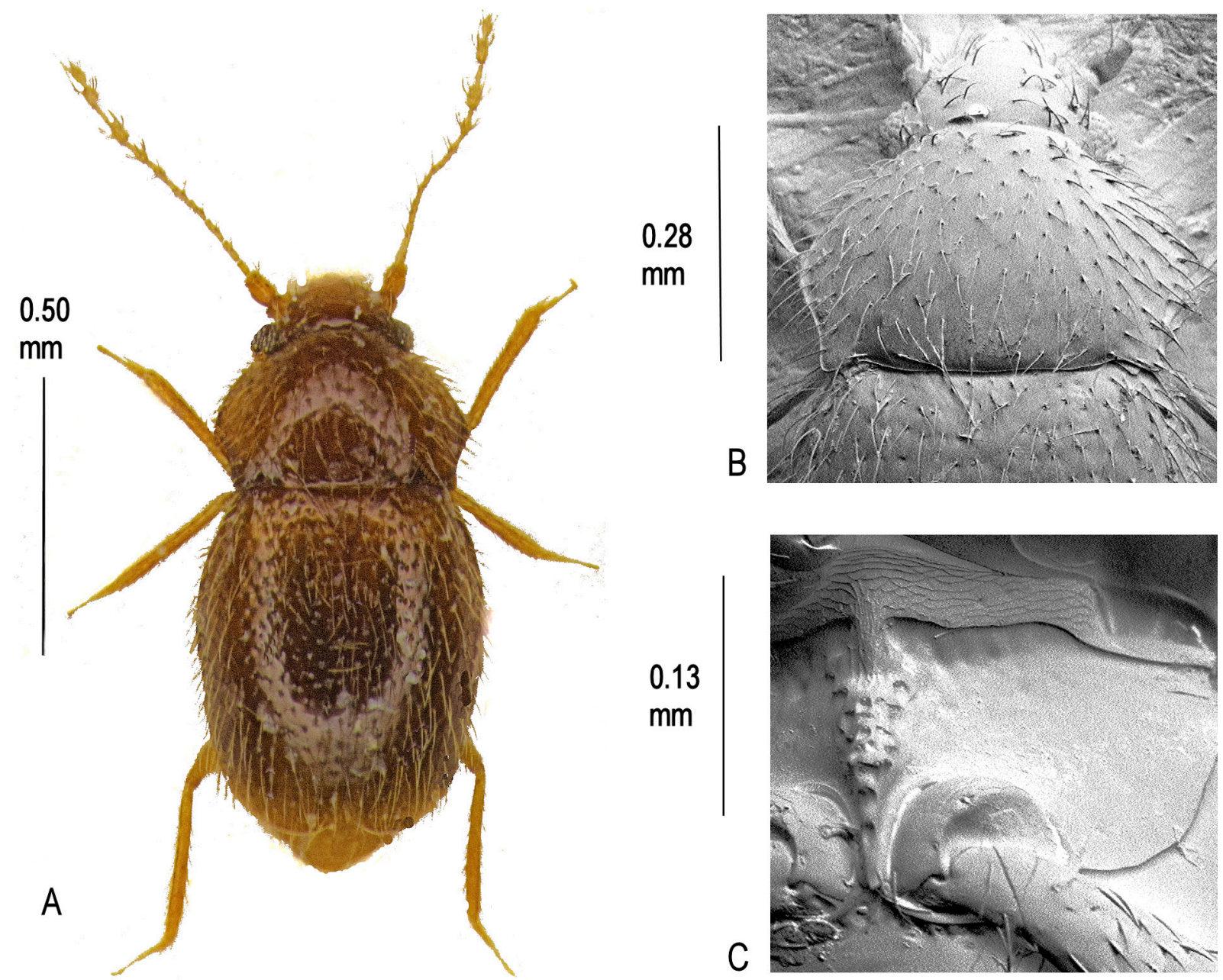

Fig. 95. Cissidium losbanos sp. nov. A. Habitus. B. Pronotum, $\times 350$. C. Mesoventrite showing median process of collar, mid-keel and keel, $\times 325$. 
Mesoventrite. Collar with tapering medial extension onto mid-keel; mid-keel and keel fused without projecting anterior and posterior corners, strongly and coarsely sculptured, tapering to a point posterior to the mid-point of the mesocoxae; mesoventral lateral margins evenly rounded in posterior half without serrations; humeri a clear extension of the collar, narrow, barely toothed (Fig. 95C).

MetaVentrite. Length $0.18 \mathrm{~mm}$, sparsely pubescent, disc simple, width across spines $0.14 \mathrm{~mm}$; posterior margins of mesocoxal borders without serrations.

WINGS. Macropterous.

Genitalia. Female spermatheca globular. Male aedeagus as Fig. 6 Ia-b.

\section{Remarks}

The only species of Cissidium in this group from the Philippines.

Cissidium nishikawai Sawada, 2008

Fig. 96

\section{Material examined}

Paratype

JAPAN • 1 \%; Gaji-rindo, Kunigami-son, Okinawa Pref.; 21 Oct. 1987; Y. Nioshikawa leg.; YS. The specimen is thickly covered with glue and the details are difficult to make out, no attempt was made to turn it over to inspect the underside. Figure 96C is copied from Sawada (2008).

\section{Supplementary description}

The following description amplifies the type description of Sawada (2008) to conform with the entries in the present paper.

Size. Habitus (Fig. 96A), length $0.69 \mathrm{~mm}$.

CoLour. Reddish brown, antennae, legs and pubescence dusky yellow.

HEAD. With a transverse depression behind the eyes, width across eyes $0.18 \mathrm{~mm}$; antennomeres III-XI, length $0.29 \mathrm{~mm}$ terminally globular.

Pronotum. Length $0.19 \mathrm{~mm}$, width $0.28 \mathrm{~mm}$, shallowly foveolate and sparsely pubescent; side margins rounded to rectangular hind angles, bordered, the border continuing along the entire posterior margin including the emargination in front of the scutellum (Fig. 96B).

ELYTRA. Length $0.45 \mathrm{~mm}$, width $0.41 \mathrm{~mm}$, pubescent.

Mesoventrite. Lateral margins serrate; humeri toothed (Fig. 96C).

MetaVentrite. Mesocoxal posterior borders serrate

GeNitALia. Female spermatheca globular. Males not known.

\section{Remarks}

This is the only Japanese species in this group apart from C. shibatai Sabada, 2008. It may be distinguished from that species by the much wider pronotal base. 

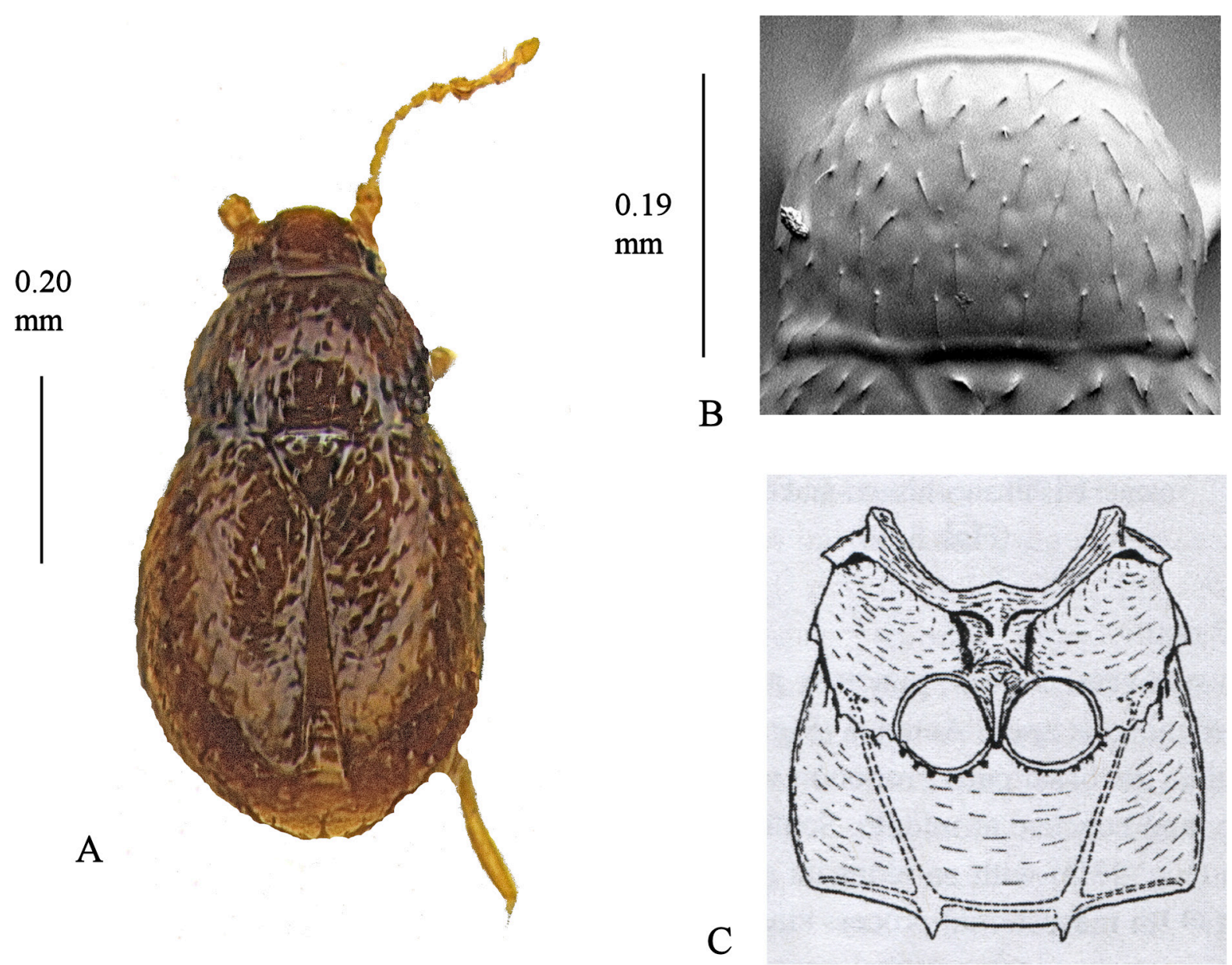

Fig. 96. Cissidium nishikawai Sawada, 2008. A. Habitus. B. Pronotum, $\times 600$. C. Meso- and metaventrite from Sawada (2008).

Cissidium obscenum sp. nov.

urn:lsid:zoobank.org:act:83CD06F2-2E72-4AE2-9841-AF1D5238BA59

Figs $7 \mathrm{E}, 97$

\section{Etymology}

Johnson ms name (as obscoenum) from the Latin adjective 'obscenus' and probably relating to the large size.

\section{Material examined}

\section{Holotype}

PERU • Õ; "E PERU”, road from Tarapoto to Yurimagua; forest litter on mountain slope; H. Franz leg.; MMUE.

\section{Description}

SizE. Habitus (Fig 97A), length $1.00 \mathrm{~mm}$. 
CoLour. Yellow brown, shining, antennae, legs and pubescence dusky yellow.

HEAD. Without a clear transverse depression behind the eyes; width across eyes $0.27 \mathrm{~mm}$; antennomeres III-XI length $0.46 \mathrm{~mm}$, III-IX length $0.29 \mathrm{~mm}, \mathrm{X}-\mathrm{XI}$ length $0.17 \mathrm{~mm}$; mentum as Fig. 4A.

Pronotum. Length $0.29 \mathrm{~mm}$, width $0.43 \mathrm{~mm}$, pubescent, shallowly foveolate near base; sides sharply angled then almost parallel-sided to rounded rectangular hind angles, front angles rounded, lateral borders continued along the basal margin to the angulate medial emargination opposite the scutellum (Fig. 97B).

ELYTRA. Length $0.65 \mathrm{~mm}$, width $0.51 \mathrm{~mm}$, pubescent, not foveolate, obliquely truncate.

Mesoventrite. Collar with a parallel-sided median extension widening slightly anteriorly and with rounded posterior corners, posterior margin not raised continuing directly into the keel; keel long, with \pm six setae, tapering to rounded tip at base of mesocoxae; mesoventral lateral margins rounded, effaced posteriorly without obvious serrations; humeri toothed (Fig. 97C).

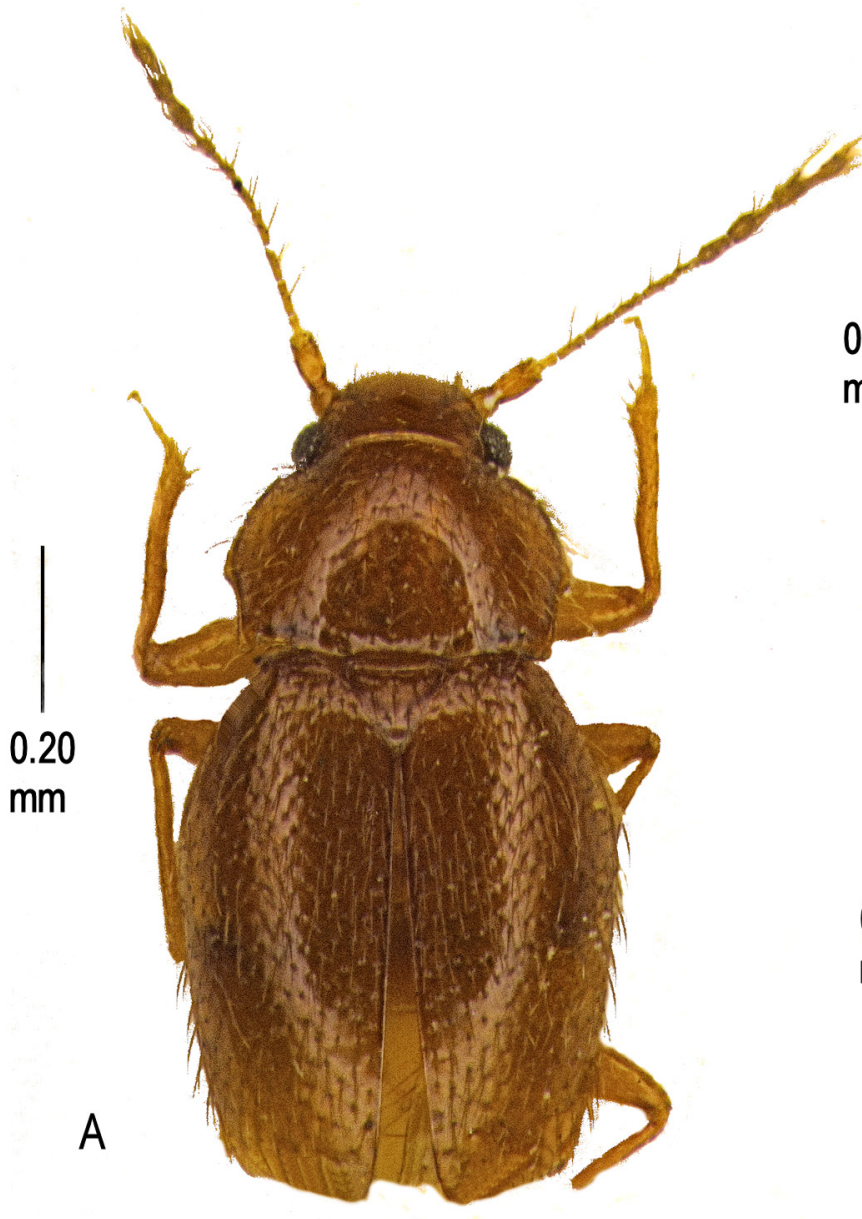

0.29
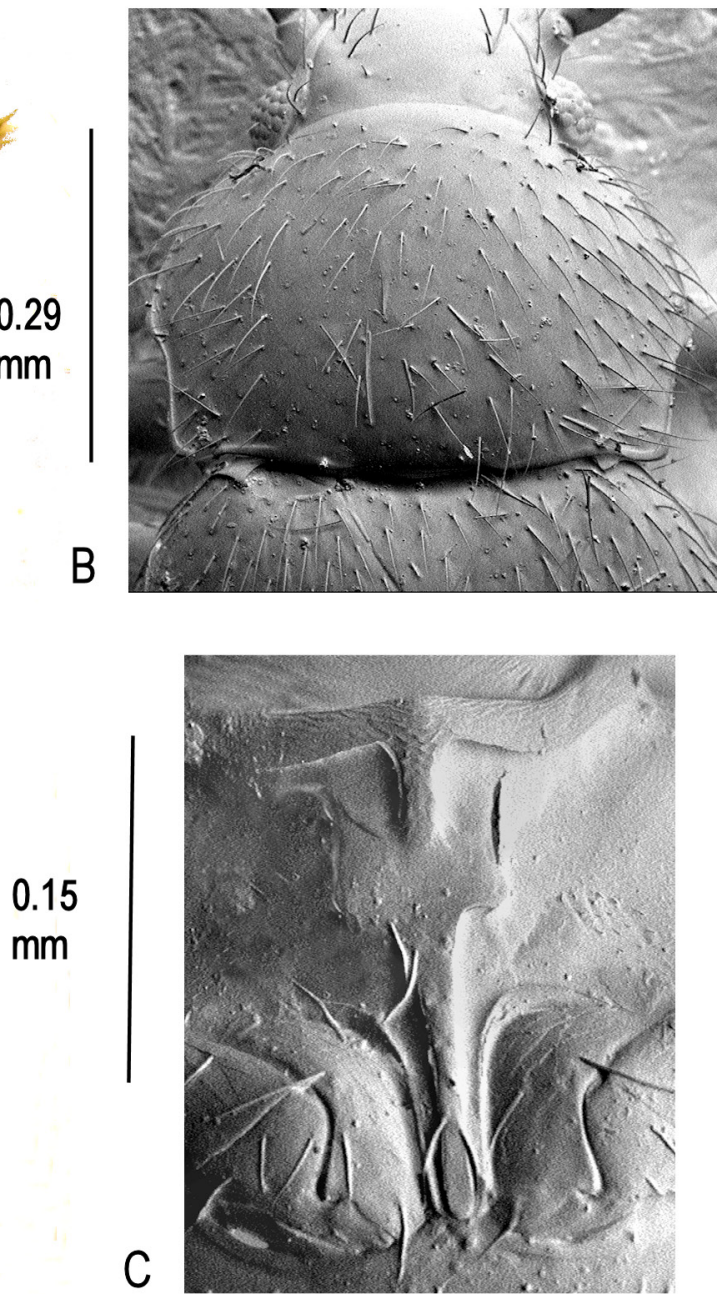

Fig. 97. Cissidium obscenum sp. nov. A. Habitus. B. Pronotum, $\times$ 460. C. Mesoventrite showing median process of collar, mid-keel and keel, $\times 545$. 
Metaventrite. With a setose depression medially, the setae confined to the borders (Fig. 7E), spines not visible, length $0.16 \mathrm{~mm}$, width between metacoxae $0.12 \mathrm{~mm}$; mesocoxal borders not serrate.

WINGs. Macropterous.

Genitalia. Male aedeagus long as Fig. 6K but without the terminal hook. Females not known.

\section{Remarks}

The three Peruvian species of Cissidium all fall into this group, this is distinguished from the others by its large size.

Cissidium obsoletum sp. nov. urn:1sid:zoobank.org:act:3D695B00-2863-4F4B-BDCA-C24906A26BBB

Fig. 98

\section{Etymology}

Johnson ms name, from the Latin adjective 'obsoletus', meaning 'worn out' or 'shabby' and probably referring to the poor condition of the insect.

\section{Material examined}

\section{Holotype}

ZIMBABWE • ;; "N. RHODESIA", Mwinilunga District, Helenga, nr. Kalene, Zambesi Rapids; 3 May 1963; MV light trap; E. Pinhey leg.; BM 1963-742; BMNH. The specimen was found damaged, with one antenna and one elytron missing, and mesoventrite broken.

\section{Description}

Size. Habitus (Fig. 98A), length $0.65 \mathrm{~mm}$.

CoLour. Yellow brown, shining, antennae, legs and pubescence yellow.

HEAD. Without an impressed line behind the eyes, width across eyes $0.21 \mathrm{~mm}$; antennomeres III-XI length $0.31 \mathrm{~mm}$, III-IX length $0.16 \mathrm{~mm}, X-X I$ length $0.17 \mathrm{~mm}$, antennomere XI without a median constriction; mentum obscured.

Pronotum. Length $0.20 \mathrm{~mm}$, width $0.29 \mathrm{~mm}$, sparsely pubescent; sides evenly rounded anteriorly, slightly sinuate posteriorly before the rectangular hind angles, sides bordered, the borders continuing along the posterior margin where they are enlarged with convex anterior margins before terminating at the median emargination opposite the scutellum (Fig. 98B).

ELYTRA. Length $0.45 \mathrm{~mm}$, width $0.34 \mathrm{~mm}$, sparsely pubescent, barely foveolate.

Mesoventrite. Anteriorly too damaged to make out clearly; keel wide, parallel-sided, termination unclear; mesoventral lateral margins strongly angled, without serrations; humeri with small tooth (Fig. 98C).

Metaventrite. Length $0.18 \mathrm{~mm}$, scattered sparse pubescence, disc simple, width between spines $0.10 \mathrm{~mm}$; margins of mesocoxal borders not serrate.

WINGS. Macropterous.

Genitalia. Female spermatheca globular. Males not known. 


\section{Remarks}

The only species of Cissidium to have been described from Zimbabwe (given as Northern Rhodesia).
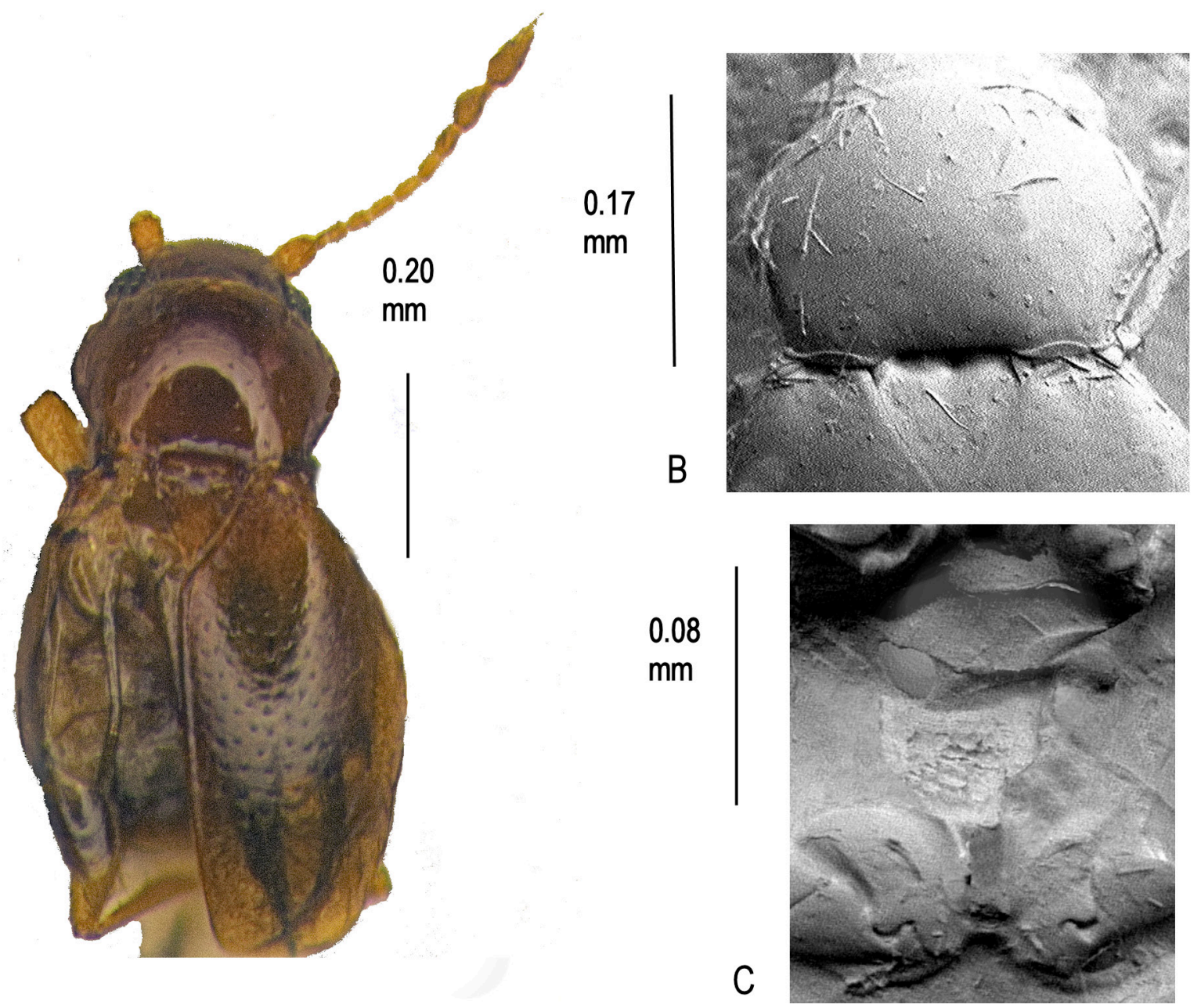

Fig. 98. Cissidium obsoletum $\mathrm{sp}$. nov. A. Habitus. B. Pronotum, $\times$ 435. C. Mesoventrite showing median process of collar, mid-keel and keel, $\times 610$.

Cissidium orami sp. nov.

urn:Isid:zoobank.org:act:FB3A63B0-4A4B-4AE9-B1FF-613DAB219E74

Fig. 99

\section{Etymology}

I have pleasure in naming this species after my colleague Dr David Oram.

\section{Material examined}

\section{Holotype}

BRAZIL・ + ; Tainhas, R[io] G[rande] do Sul; Apr. 1959; F. Plaumann leg.; FMNH. 
Paratypes

BRAZIL • 5 우; same collection data as for holotype; one mounted verso; MMUE, BMNH.

\section{Description}

Size. Habitus (Fig. 99A), length $0.92 \mathrm{~mm}$.

CoLour. Dark yellow brown, shining, antennae, legs and pubescence yellow.

HEAD. Linear depression behind the eyes with a small median interruption, width across eyes $0.24 \mathrm{~mm}$; antennomeres III-XI length $0.44 \mathrm{~mm}$, III-IX length $0.21 \mathrm{~mm}, \mathrm{X}-\mathrm{XI}$ length $0.23 \mathrm{~mm}$; mentum as Fig. 4B.

Pronotum. Length $0.24 \mathrm{~mm}$, width $0.35 \mathrm{~mm}$, sparsely pubescent, shallowly foveolate at base, without foveae; sides sharply angled, concave to acute hind angles, straight to rounded front angles, strongly bordered the border not continuing along the posterior margin, emargination opposite scutellum with sinuous angles (Fig. 99B).

ELYTRA. Length $0.59 \mathrm{~mm}$, width $0.45 \mathrm{~mm}$, pubescence a little denser than pronotum.
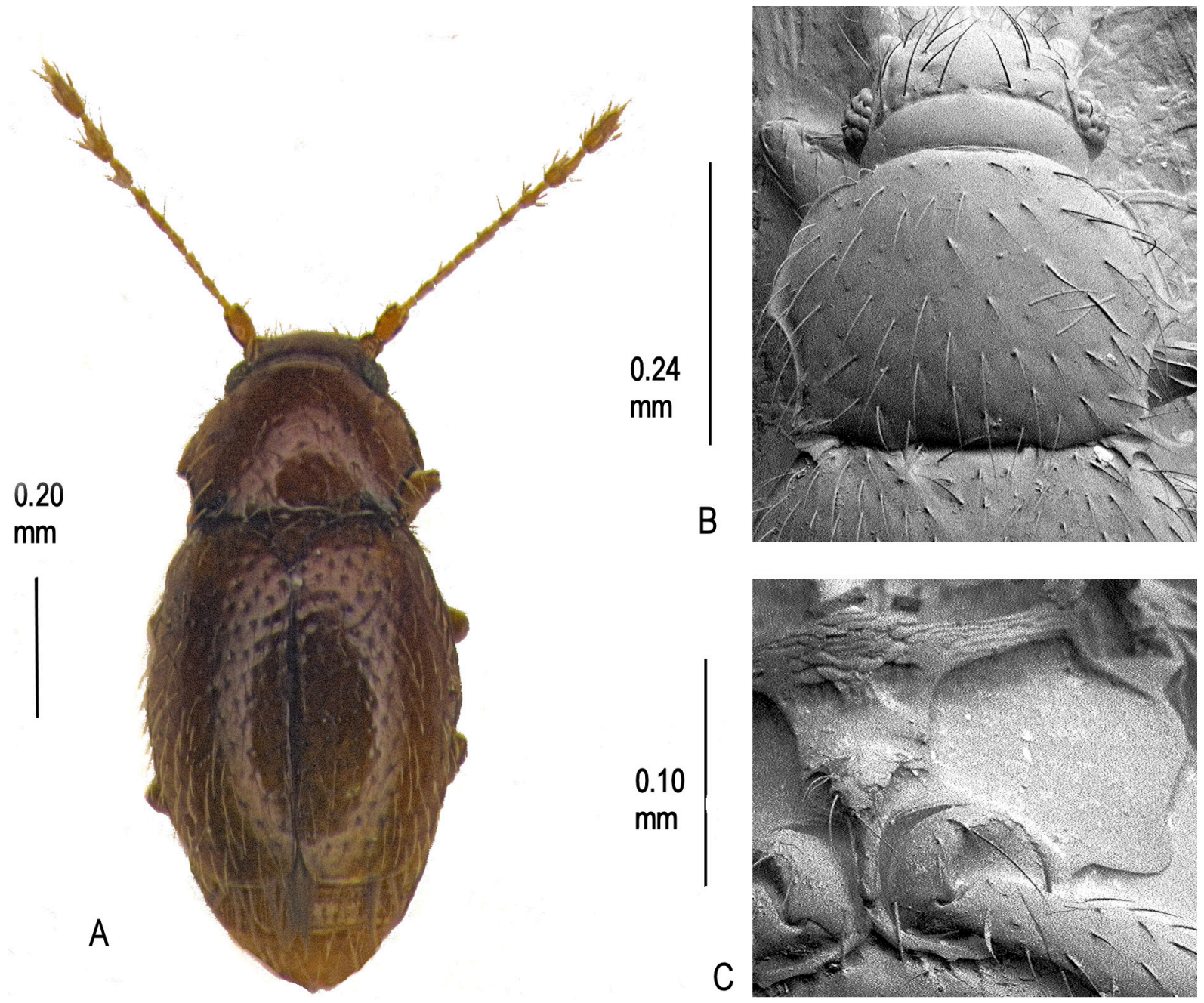

Fig. 99. Cissidium orami sp. nov. A. Habitus. B. Pronotum, $\times$ 550. C. Mesoventrite showing median process of collar, mid-keel and keel, $\times 660$. 
MesoventRite. Collar with a short broad median extension; mid-keel short, widest anteriorly, the angles joining with the collar to form two irregular depressions, the hind angles not reaching the mesocoxal anterior borders, raised medially with a strongly sculpted extension bearing \pm eight setae; keel narrow, parallel-sided with rounded termination between the mesocoxae; mesoventral lateral margins with rounded convex extrusion at the posterior angle, without serrations; humeri sharply toothed (Fig. 99C).

MetaVentrite. Length $0.17 \mathrm{~mm}$, disc simple, width between spines $0.11 \mathrm{~mm}$; margins of mesocoxal borders serrate.

WINGS. Macropterous.

GeNiTALia. Female spermatheca globular slightly distorted.

\section{Remarks}

One of the five Brazilian species in this group. Distinguished by the bulbous angle of the mesoventral lateral margins.

Cissidium peruviense sp. nov. urn:1sid:zoobank.org:act:B8474470-95D2-499D-AC25-C85C29FB795D

Fig. 100

\section{Etymology}

Named after the country where the specimens were collected.

\section{Material examined}

\section{Holotype}

PERU - 9 ; Cusco Dept, Villa Carmen Field Station, $1.7 \mathrm{~km}$ west of cafeteria research transect; 12.89250 S, 71.41917 W; 555 m a.s.1.; 21-22 May 2011; D.J.Bennett and E. Razuri leg.; MUSM.

\section{Paratypes}

PERU • 3 ex.; same collection data as for holotype; one mounted verso, one missing elytron, one missing both elytra; MUSM, SEMC, BMNH 11 ex., same collection data as for holotype but flight intercept trap; 26-28 May 2011; mounted verso; BMNH 1 ex., same collection data as for holotype as for preceding but 22-24 May 2011; missing elytron; BMNH.

\section{Description}

SizE. Habitus (Fig. 100A), length $0.70 \mathrm{~mm}$.

CoLour. Yellow brown, shining, antennae, legs and pubescence yellow.

HEAD. With a shallow setose depression behind the eyes, width across eyes $0.20 \mathrm{~mm}$; antennomeres III-XI length $0.31 \mathrm{~mm}$, III-IX length $0.17 \mathrm{~mm}, \mathrm{X}-\mathrm{XI}$ length $0.14 \mathrm{~mm}$; mentum as Fig 4B.

Pronotum. Length $0.19 \mathrm{~mm}$, width $0.26 \mathrm{~mm}$, sparsely pubescent, without either foveae or foveolae; sides angulate concave to rectangular hind angles, straight to rounded front angles, strongly bordered the border not continuing along the posterior margin, emargination opposite scutellum sinuate (Fig. 100B).

ELYTRA. Length $0.42 \mathrm{~mm}$, width $0.36 \mathrm{~mm}$, pubescence a little denser than pronotum, shallowly foveolate most noticeable in anterior half. 
MesoventRITE. Collar with a short broad medial extension; mid-keel with concave sides, the hind angles with carinae reaching the mesocoxal borders, sharply raised medially with \pm three setae; keel tapering to parallel-sided before a pointed tip at interruption point of mesocoxal borders; mesoventral lateral margins angulate with rounded convex extrusion at the angle, without serrations; humeri sharply toothed (Fig. 100C).

MetaVentrite. Length $0.15 \mathrm{~mm}$, with scattered pubescence, female disc simple, male medially depressed, width between spines $0.12 \mathrm{~mm}$; margins of mesocoxal cavities serrate.

WINGs. Macropterous.

Genitalia. Female spermatheca globular.

\section{Remarks}

Distinguished from the other species of smaller Peruvian Cissidium by a clearly marked median extension of the mesoventral collar.

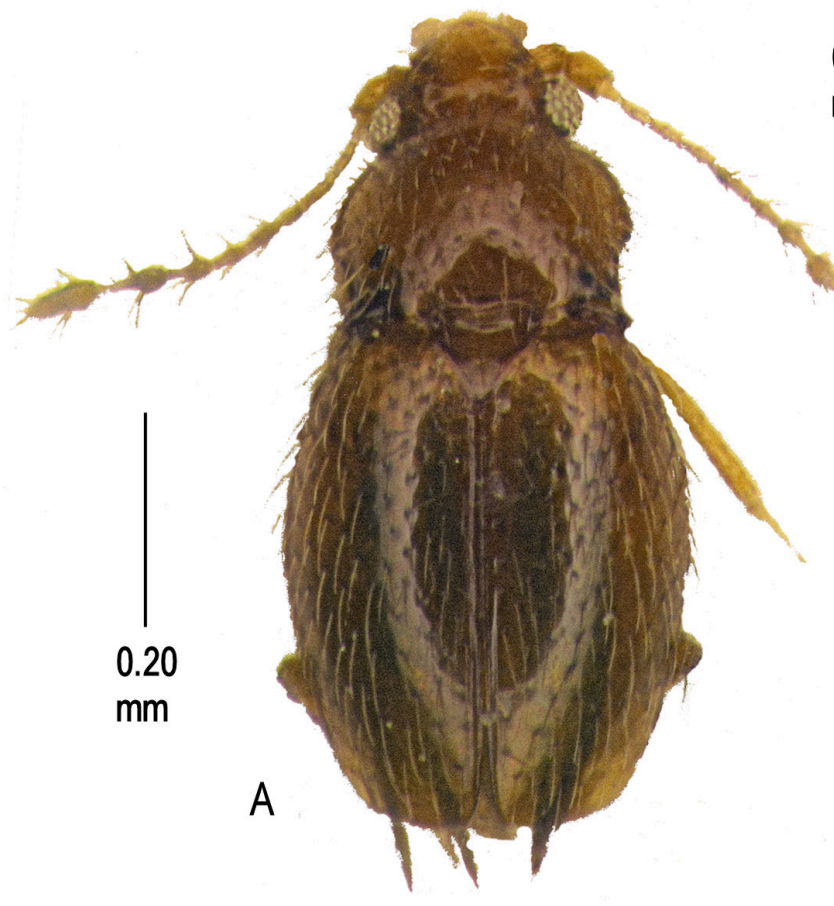

0.09 $\mathrm{mm}$

B

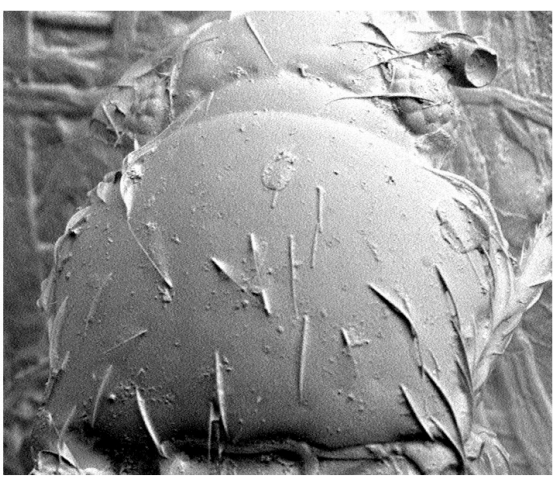

0.12 $\mathrm{mm}$

C

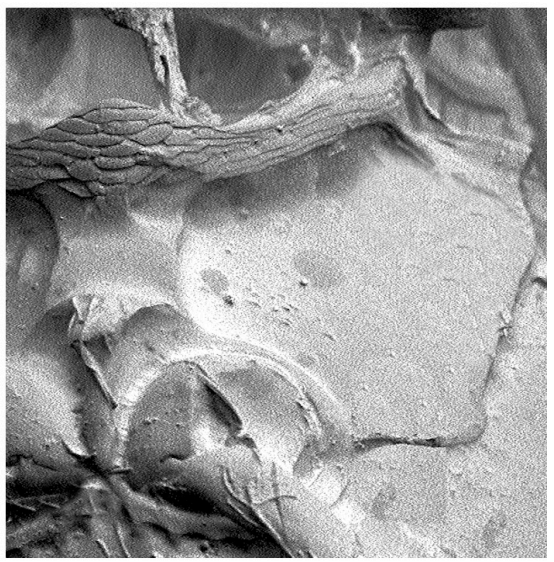

Fig. 100. Cissidium peruviense sp. nov. A. Habitus. B. Pronotum, $\times 625$. C. Mesoventrite showing median process of collar, mid-keel and keel, $\times 715$. 
Cissidium reitteri (Matthews, 1889)

Fig. 101

\section{Material examined}

\section{Holotype}

BRAZIL • +; 1146; Matthews coll. 1904-120; BMNH.

The specimen bears an orange label in Matthews' hand Dimorphella Reitteri and has been remounted. Matthews original mount is preserved on the pin.

\section{Additional material}

Fragments mounted as a slide labelled Dimorphella, "all parts, 1886", and on an orange label "Reitterella", apparently in Matthews' hand, are in the BMNH Matthews coll.1904-120. Only 2 legs and a globular spermatheca are possible to make out.

BRAZIL • Bom Jesus; 2840' S, 50¹2' W, 1200 m a.s.1.; Dec. 1962; F. Plaumann leg.; C. Johnson det.; MMUE.

There are also a further 14 specimens of this species in the MMUE and BMNH.

\section{Supplementary description}

The following description amplifies the type description of Matthews (1889, as Dimorphella, synonymy established by Johnson 1982), by adding more details of the meso- and metaventral characters, in order to conform with the entries in the present paper.

Size. Habitus (Fig. 101A), length $0.63 \mathrm{~mm}$.

CoLour. Yellow brown, antennae, legs and pubescence yellow.

HEAD. With a well-marked linear depression behind the eyes, width across eyes $0.19 \mathrm{~mm}$; antennomeres III-XI length $0.42 \mathrm{~mm}$, III-IX length $0.29 \mathrm{~mm}, \mathrm{X}-\mathrm{XI}$ length $0.13 \mathrm{~mm}$; mentum as Fig. 4B.

Pronotum. Length $0.19 \mathrm{~mm}$, width $0.27 \mathrm{~mm}$, pubescent, without foveae and foveolae; lateral margins sharply angled in posterior half, thence concave to acute hind angles and shallowly rounded to obtuse front angles, lateral margins bordered, the border not continued along the posterior margin, emargination opposite the scutellum sinuate (Fig. 101B).

ELYTRA. Length $0.40 \mathrm{~mm}$, width $0.35 \mathrm{~mm}$ pubescence slightly denser than pronotum and foveolae more marked.

Mesoventrite. Medial extension of collar broad, short, flanked by two smaller pointed extensions, collar reticulation missing at their base; mid-keel wide basally becoming parallel-sided before strongly sculpted raised medial extension to keel, posterior corners with narrow carinae to mesocoxal borders; keel narrow, slightly tapering to between the mesocoxae; mesoventral lateral margins convex behind humeri then almost straight to rectangular angle before mesocoxae, without serrations; humeri strongly toothed (Fig. 101C).

MetaVentrite. Sparsely pubescent, disc simple, length $0.16 \mathrm{~mm}$ width between spines $0.12 \mathrm{~mm}$; margins of mesocoxal borders serrate.

Wings. Macropterous. 
Genitalia. Female spermatheca globular. Male aedeagus as Fig. 6Fa-b.

\section{Remarks}

One of the five Brazilian species in this group. Only likely to be confused with C. bomjesus sp. nov. but distinguished from that species by the more angulate pronotal sides and the broader and shorter midkeel.
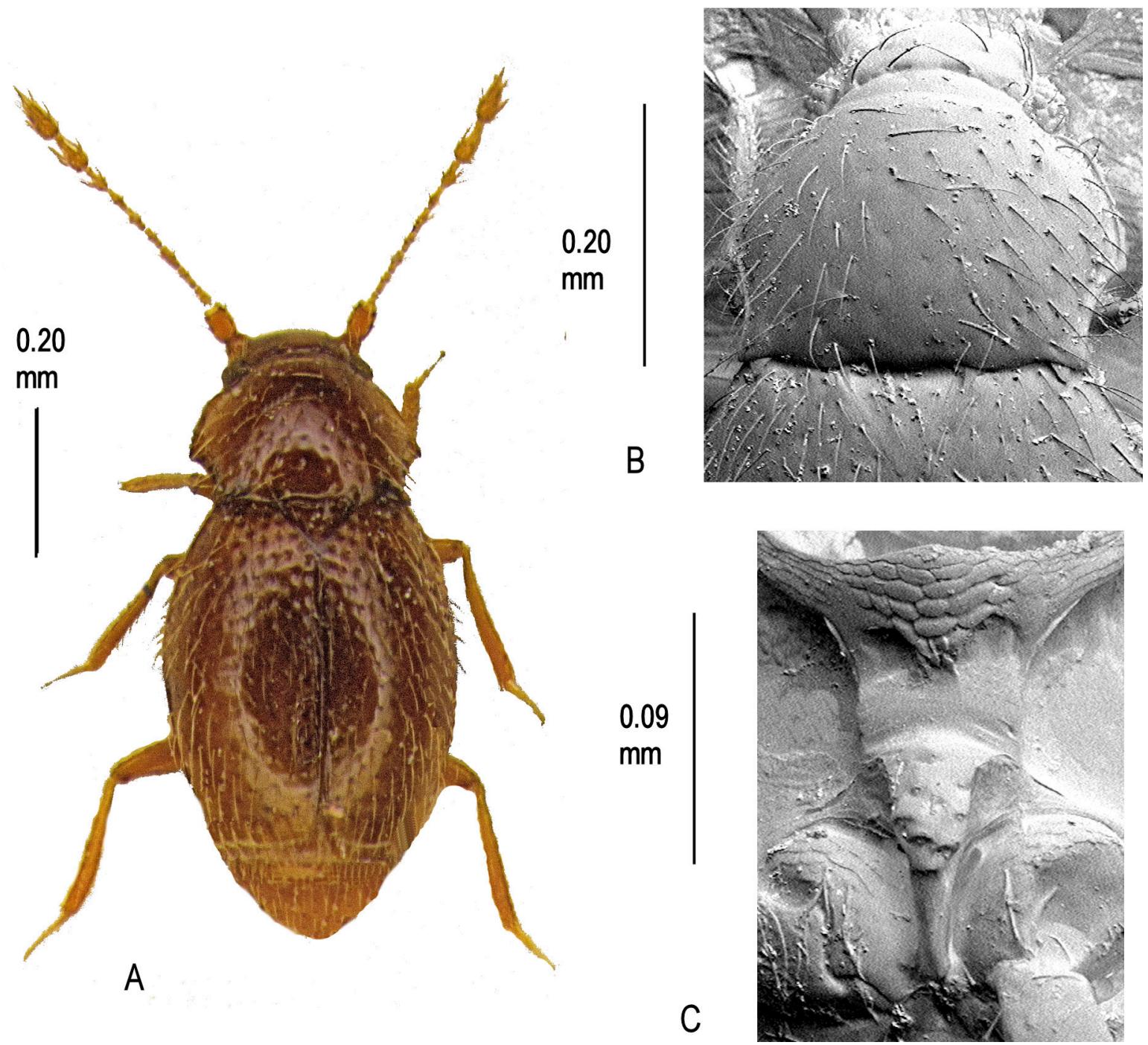

Fig. 101. Cissidium reitteri (Matthews, 1889). A. Habitus. B. Pronotum, $\times 330$. C. Mesoventrite showing median process of collar, mid-keel and keel, $\times 450$. 
Cissidium sawadai Darby, 2015

Figs 5E, 6C, 102

\section{Material examined}

\section{Holotype}

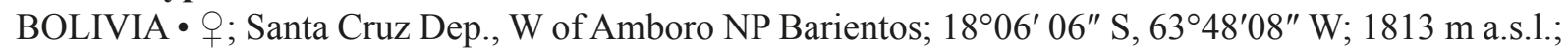
29 Nov. 2013; sifting litter; Winkler app. extr.; P. Baňař leg.; UASC.

\section{Paratype}

BOLIVIA • 1 क; Santa Cruz Dep., W of Amboro NP, Barientos; $18^{\circ} 06^{\prime} 00^{\prime \prime} \mathrm{S}, 63^{\circ} 48^{\prime} 05^{\prime \prime} \mathrm{W} ; 1817 \mathrm{~m}$ a.s.1.; 29 Nov. 2013; sifting litter; Winkler app. extr.; P. Baňař leg.; MMBC.

\section{Supplementary description}

The following description amplifies the type description of Darby (2015), by adding more details of the meso- and metaventral characters in order to conform with the entries in the present paper.

Size. Habitus (Fig. 102A), length $0.84 \mathrm{~mm}$.

CoLour. Yellowish brown, legs and antennae lighter.
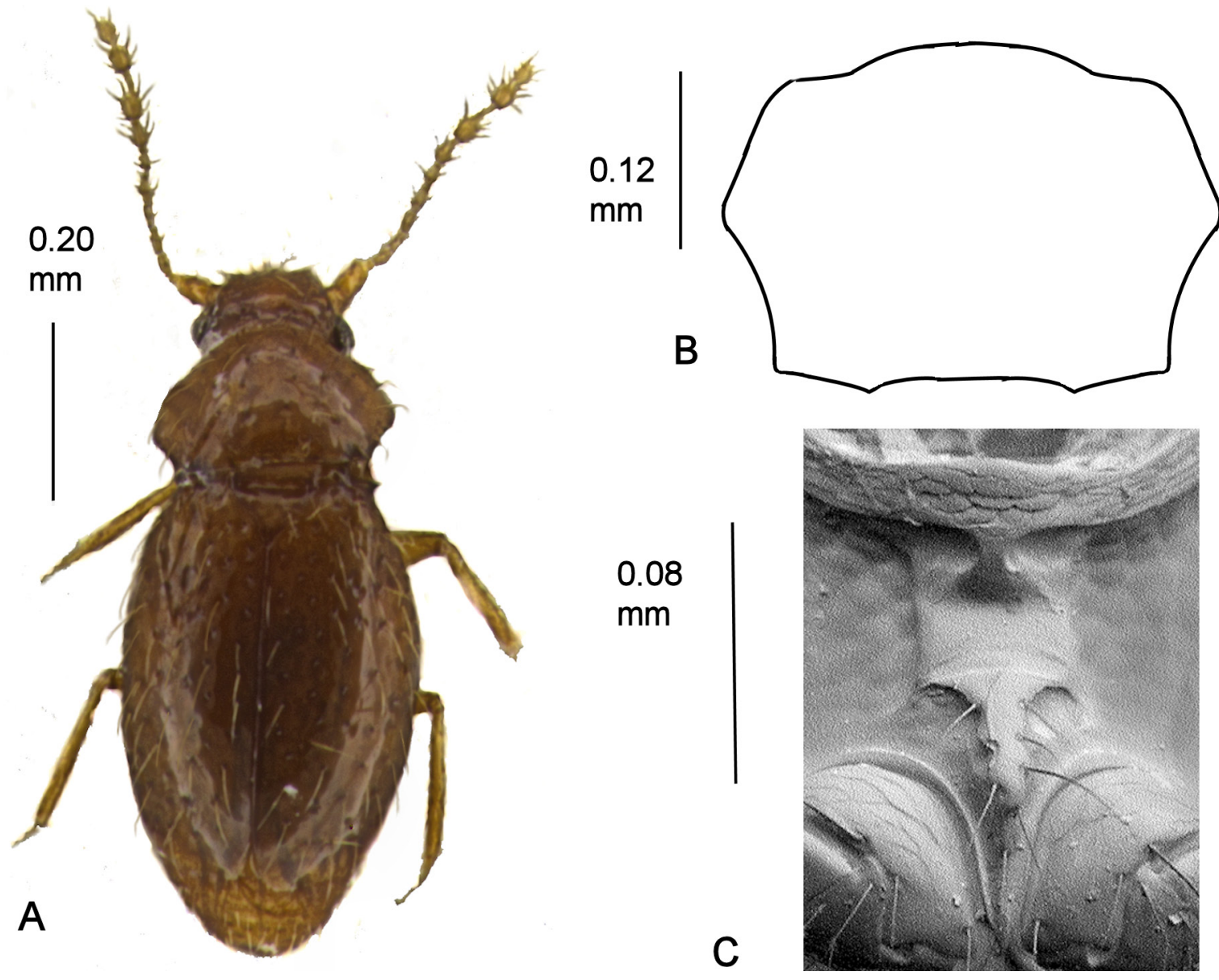

Fig. 102. Cissidium sawadai Darby, 2015. A. Habitus. B. Pronotum, C. Mesoventrite showing median process of collar, mid-keel and keel, $\times 610$. 
Head. Antennomeres III-XI 0.37 mm long, III-IX 23 mm long, X-XI 0.14 mm long.

Pronotum. $0.34 \mathrm{~mm}$ wide, $0.22 \mathrm{~mm}$ long, with scattered pubescence and shallow foveolae; lateral margins angulate thence almost straight to obtuse anterior angles and concave to rectangular hind angles (Fig. 102B).

ELYTRA. $0.55 \mathrm{~mm}$ long, $0.4 \mathrm{~mm}$ wide, more strongly and densely foveolate than the pronotum.

Mesoventrite. Medial process of collar short, widening with concave sides onto the mid-keel; mid-keel parallel-sided after widening anteriorly immediately before the collar, posterior corners not extending to the mesocoxal anterior borders, medial extension to keel with \pm six setae; keel with a single seta, narrow, barely tapering to point below mid-point of the mesocoxae (Fig. 5E); mesoventral lateral margins without serrations; humeri strongly toothed (Fig. 102C).

Metaventrite. Length $0.13 \mathrm{~mm}$, sparsely pubescent, disc simple, points long tapering to setal width, distance across points $0.11 \mathrm{~mm}$; posterior margins of mesocoxae without serrations.

Genitalia. Female spermatheca elongate (Fig. 6C).

\section{Remarks}

The largest of the six Bolivian Cissidium, except for C. lisae, from which it may be separated by the shape of the mesoventral keel.

Cissidium shibatai Sawada, 2008

Fig. 103

\section{Material examined}

\section{Paratypes}

JAPAN • 4 o $q$; Ryukyus, Mt. Omotodake, Ishigaki Is. Okinawa Pref.; 11 Apr. 1986; S. Nomura leg.; YS, BMNH • 1 ex.; same locality as for preceding; 8 May 1998; Y.Sawada leg.; YS, BMNH • 1 q; same locality as for preceding; 2 Aug. 1999, Y. Nishikawa leg.; YS • 1 q; Kanpire, Iriomote Is., Okinawa Pref.; 14 Apr. 1986; S.Nomura leg.; YS • 3 우; Toyokawa Iriomote Is., Okinawa Pref.; 16 May 1994; T. Hanatani leg.; YS, BMNH.

\section{Supplementary description}

The following description amplifies the type description of Sawada (2008) in order to conform with the entries in the present paper.

Size. Habitus (Fig. 103A), length $0.75 \mathrm{~mm}$.

CoLour. Reddish brown, antennae, legs and pubescence dusky yellow.

HEAD. With a deep transverse depression behind the eyes. Distance across the eyes $0.23 \mathrm{~mm}$; antennomeres III-XI $0.33 \mathrm{~mm}$ long, III-IX $0.19 \mathrm{~mm}$ long, X-XI $0.14 \mathrm{~mm}$ long; mentum obscured.

Pronotum. Length $0.22 \mathrm{~mm}$, width $0.35 \mathrm{~mm}$, sparsely pubescent, foveolate and with two distinct longitudinal foveae extending from basal margin at corners of the angulate emargination opposite the scutellum; side margins strongly angulate, almost straight to obtuse hind angles, bordered, the border continuing along the posterior margin (Fig. 103B). 
ELYTRA. Length $0.52 \mathrm{~mm}$, width $0.46 \mathrm{~mm}$, pubescence denser than on the pronotum.

Mesoventrite. Median process of collar broad, short; mid-keel almost parallel sided slightly wider posteriorly, hind angles with carinae reaching to mesocoxal anterior borders, setose before junction with keel; keel narrow, parallel-sided becoming slightly wider posteriorly between the mesocoxae with \pm three setae; mesoventral lateral borders serrate in posterior half; humeri strongly toothed (Fig. 103C).

Metaventrite. Sparsely pubescent, length $0.16 \mathrm{~mm}$, disc simple, distance across spines $0.12 \mathrm{~mm}$; mesocoxal posterior borders serrate.

Genitalia. Male aedeagus, as Fig. 6Ia-b but beak bent to a right angle. Female spermatheca U-shaped as Fig. 6E.

\section{Remarks}

This is the only Japanese species in this group apart from C. nishikawai. It may be distinguished from that species by the much narrower pronotal base.
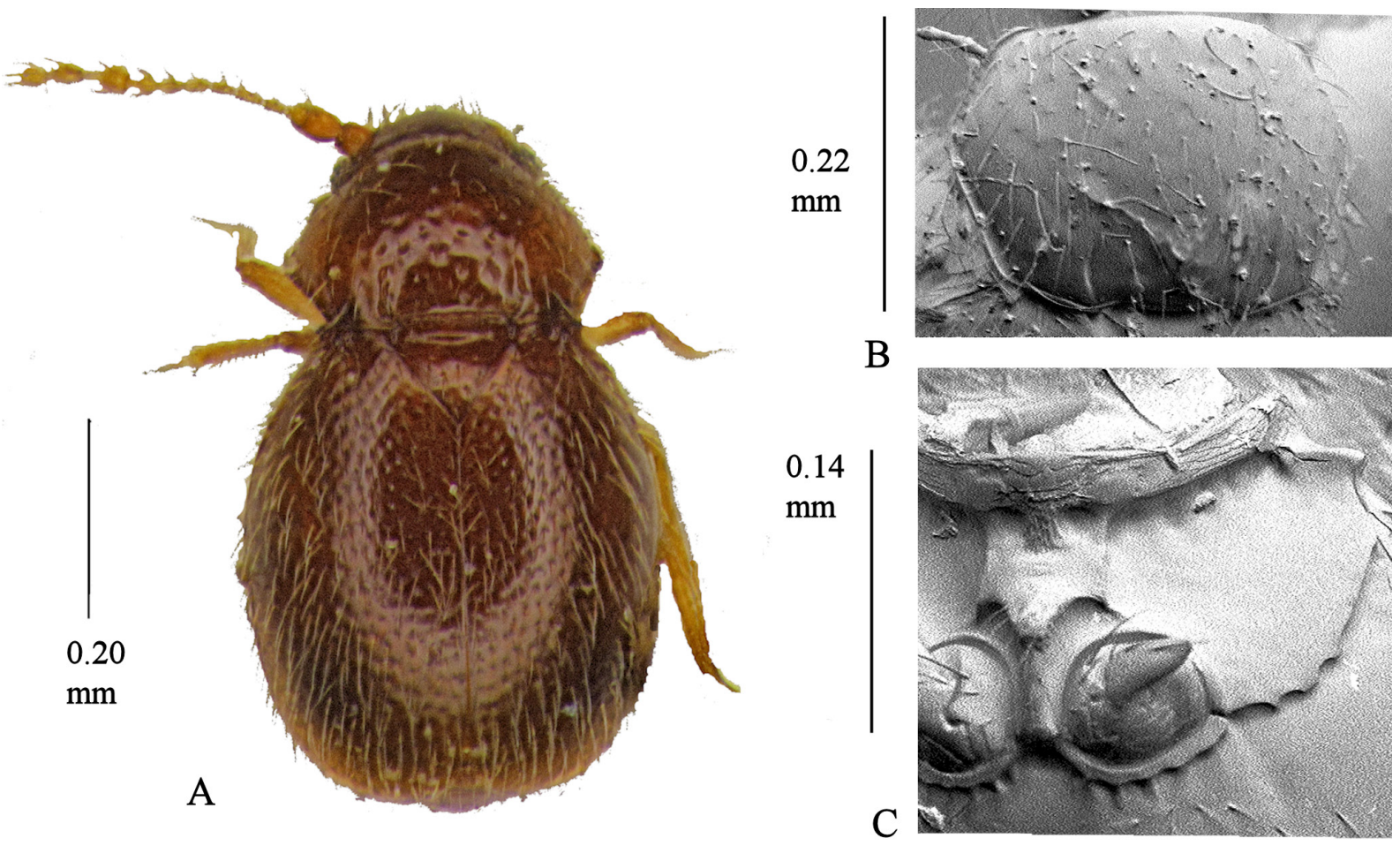

Fig. 103. Cissidium shibatai Sawada, 2008. A. Habitus. B. Pronotum, $\times 470$. C. Mesoventrite showing median process of collar, mid-keel, keel and lateral margin, $\times 465$. Meso-and metaventrite copied from Sawada (2008). 
Cissidium similatum sp. nov. urn:Isid:zoobank.org:act:936AB769-443E-464C-B40D-A911A6E69ABF

Fig. 104

\section{Etymology}

Johnson ms name.

\section{Material examined}

Holotype

PERU • O; surroundings of Tarapoto; Franz leg.; MMUE.

\section{Paratypes}

PERU • 5 ex.; same collection data as for holotype; 1 mounted verso; MMUE, BMNH.

\section{Description}

Size. Habitus (Fig. 104A), length $0.71 \mathrm{~mm}$.

CoLour. Dark brown, shining, pubescence, legs and antennae dusky yellow.

HEAD. With a series of linear foveae between the eyes interrupted medially, width across eyes $0.20 \mathrm{~mm}$; mentum parallel-sided; antennomeres III-XI, length $0.36 \mathrm{~mm}$, III-IX length $0.16 \mathrm{~mm}, \mathrm{X}-\mathrm{XI}$ length $0.20 \mathrm{~mm}$.

Pronotum. $0.19 \mathrm{~mm}$ long, $0.30 \mathrm{~mm}$ wide, sparsely pubescent and shallowly foveolate in basal half; lateral margins sharply angled then concave to acute hind angles, anterior angles strongly bordered and outstanding in dorsal view, lateral border not continuing along the basal margin, medial emargination opposite scutellum angulate (Fig. 104B).

ELYTRA. $0.47 \mathrm{~mm}$ long, $0.38 \mathrm{~mm}$ wide, pubescent as pronotum.

MesoventRite. Without a medial extension of collar; mid-keel with concave sides, anterior angles meeting collar, posterior angles effaced before mesocoxa anterior borders, with a short, broad, angled posterior margin; keel with \pm four setae, very wide tapering to a rounded termination close to base of mesocoxae; mesoventral lateral margins straight becoming effaced; humeri bluntly rounded (Fig. 104C).

MetaVentrite. Sparsely pubescent, length $0.17 \mathrm{~mm}$, disc simple, width across spines $0.13 \mathrm{~mm}$; posterior margin of mesocoxae serrate.

Wings. Macropterous.

GeNitALIA. Female spermatheca globular. Males not known.

\section{Remarks}

Distinguished from the other species of smaller Peruvian Cissidium by the absence of a median extension of the mesoventral collar. 

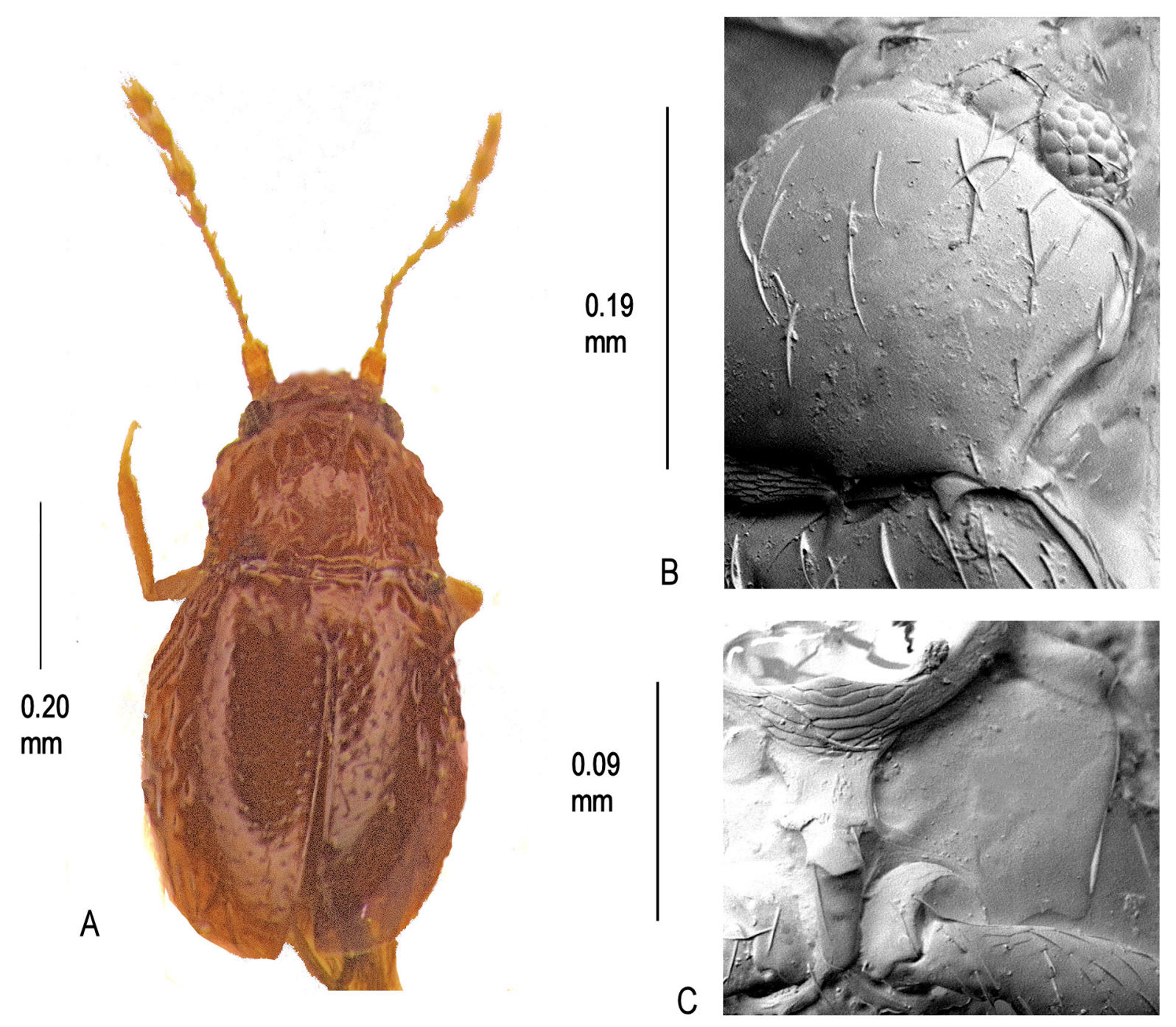

Fig. 104. Cissidium similatum sp. nov. A. Habitus. B. Pronotum, $\times 400$. C. Mesoventrite showing median process of collar, lateral margin, mid-keel and keel, $\times 470$.

Cissidium subangulatum sp. nov.

urn:1sid:zoobank.org:act:ED371CB6-DA3D-4967-B89B-96B19C80A15E

Fig. 105

\section{Etymology}

Johnson ms name.

\section{Material examined}

\section{Holotype}

PANAMA • + ; W of Finca Palo Santo, nr Nueva California, Chirique Prov.; 9 Mar. 1959; Berlese floor litter in damp ravine; $4900 \mathrm{ft}$ a.s.l.; H.S. Dybas leg.; FMNH.

\section{Description}

Size. Habitus (Fig. 105A), length 0.64 mm. 
CoLour. Dark brown, pubescence, legs and antennae brown.

HEAD. With a shallow foveolate linear depression behind the eyes, width across eyes $0.17 \mathrm{~mm}$; mentum as Fig. 4A; antennomeres III-XI, length $0.29 \mathrm{~mm}$, III-IX length $0.13 \mathrm{~mm}, \mathrm{X}-\mathrm{XI}$ length $0.16 \mathrm{~mm}$. [one antenna missing].

Pronotum. $0.17 \mathrm{~mm}$ long, $0.25 \mathrm{~mm}$ wide, pubescent without either foveolae or foveae; lateral margins sharply angled, strongly rounded to anterior angles, concave to acute posterior angles, strongly bordered, the border not continuing along the posterior margin, posterior medial emargination opposite the scutellum clearly marked (Fig. 105B).

ELYTRA. $0.41 \mathrm{~mm}$ long, $0.34 \mathrm{~mm}$ wide, pubescent as pronotum.

Mesoventrite. Medial extension of collar onto the mid-keel tapering then parallel-sided terminating in a fringe of setae which fan out across the mid-keel; mid-keel with concave sides, the anterior margin
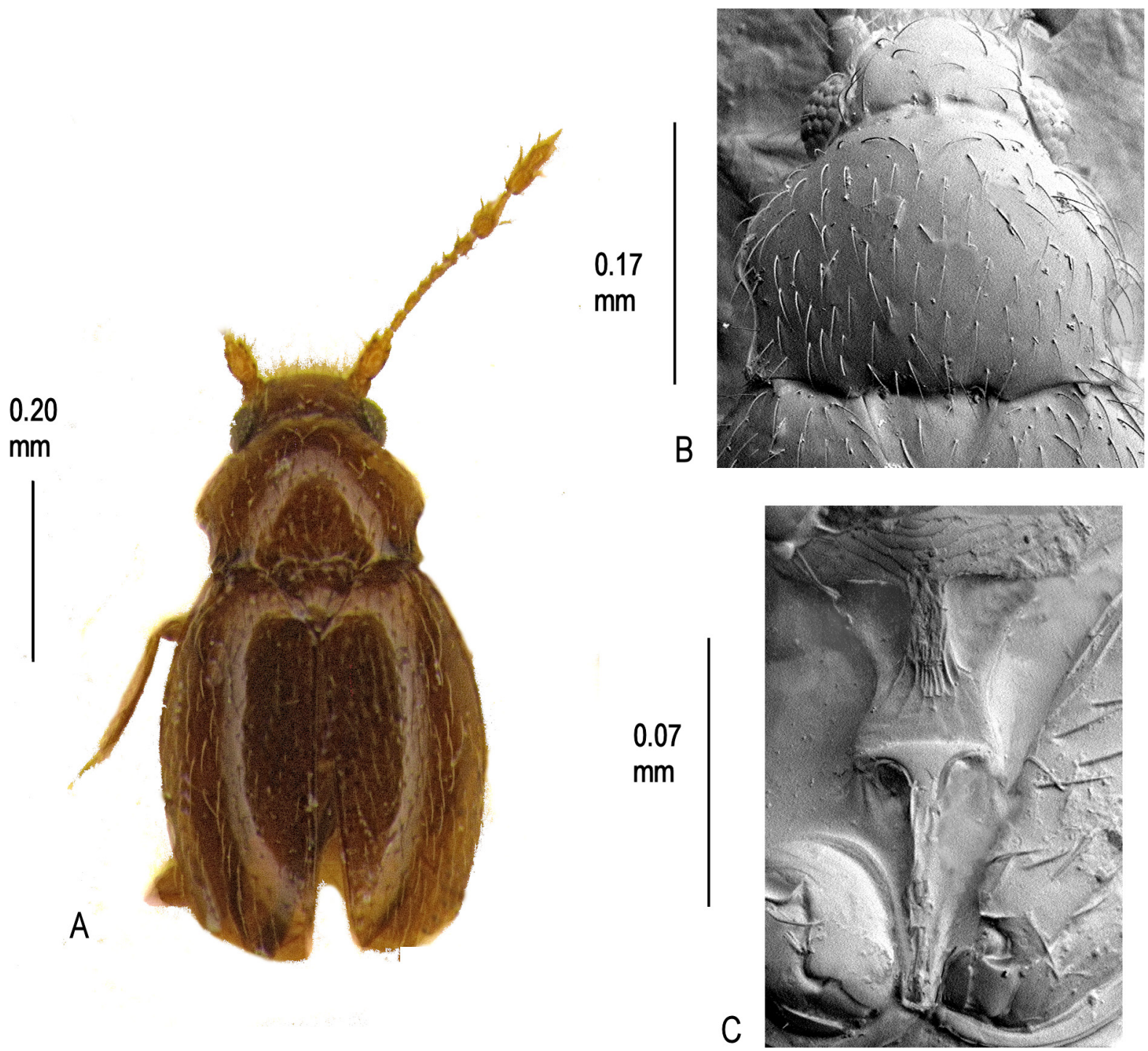

Fig. 105. Cissidium subangulatum sp. nov. A. Habitus. B. Pronotum, $\times 585$. C. Mesoventrite showing median process of collar, mid-keel and keel, $\times 1380$. 
slightly wider than the posterior, hind angles rounded stopping well short of the mesocoxal anterior borders and marked by some shallow radiating depressions in the mesoventrite; keel, long, narrow, parallel-sided and with \pm fourteen setae terminating close to base of mesocoxae; mesoventral lateral margins sinuous then effaced before joining mesocoxae, without serrations; humeri toothed (Fig. 105C).

Metaventrite. Sparsely pubescent, length $0.13 \mathrm{~mm}$, disc simple, width across spines $0.12 \mathrm{~mm}$; posterior margin of mesocoxae not serrate.

Wings. Macropterous.

Genitalia. Female spermatheca globular. Males not known.

\section{Remarks}

The only species of Cissidium from Panama in this category.

Cissidium tigrum Darby, 2015

Figs 2I, 4B, 5D, 6I, 106

\section{Material examined}

Holotype

BOLIVIA - O'; $^{\prime}$ cochabamba Dep., Cristal Mayu River valley ca $20 \mathrm{~km}$ W of Villa Tunari; $17^{\circ} 00^{\prime} 55^{\prime \prime} \mathrm{S}$, 65³7'48" W; 550 m a.s.1.; 24 Nov. 2013; sifting litter; Winkler app. extr.; P. Baňař leg.; UASC.

Paratype

BOLIVIA $・ 1$ ${ }^{\lambda}$; same collection data as for holotype; MMUC.

\section{Supplementary description}

The following description amplifies the type description of Darby (2015), by adding more details of the meso- and metaventral characters, in order to conform with the entries in the present paper.

Size. Habitus (Fig. 106A), length $0.63 \mathrm{~mm}$.

CoLour. Colour light brown, antennae and legs dusky yellow.

Head. Antennomeres III-XI $0.38 \mathrm{~mm}$ long, III-IX $17 \mathrm{~mm}$ long, X-XI $21 \mathrm{~mm}$ long (Fig. 2I); distance across eyes $0.21 \mathrm{~mm}$; mentum and submentum (Fig. 4B).

Pronotum. $0.25 \mathrm{~mm}$ wide, $0.16 \mathrm{~mm}$ long, sparsely pubescent; sharply angled in anterior half then concave to rectangular hind corners and slightly convex to obtuse anterior corners, bordered, the border not continuing along the posterior margin, emargination in front of scutellum well marked (Fig. 106B).

ElytRA. $0.39 \mathrm{~mm}$ long, $0.32 \mathrm{~mm}$ wide, area around scutellum more closely foveolate.

Mesoventrite. Medial extension of collar small, short, parallel-sided; mid-collar widest basally tapering strongly to base of keel with two small medial points not reaching mesocoxal anterior borders as carinae; keel parallel-sided with \pm three setae, bluntly terminating between the mesocoxae (Fig. 5D); mesoventral lateral margins effaced; humeri large, toothed with a long, strongly sloping posterior margin (Fig. 106C).

MetaVentrite. Length $0.13 \mathrm{~mm}$, disc simple, width across spines $0.10 \mathrm{~mm}$, spines short. 


\section{Remarks}

Distinguished from all other species of Cissidium in this paper by the shape of the male antennomere XI (Fig. 2I).

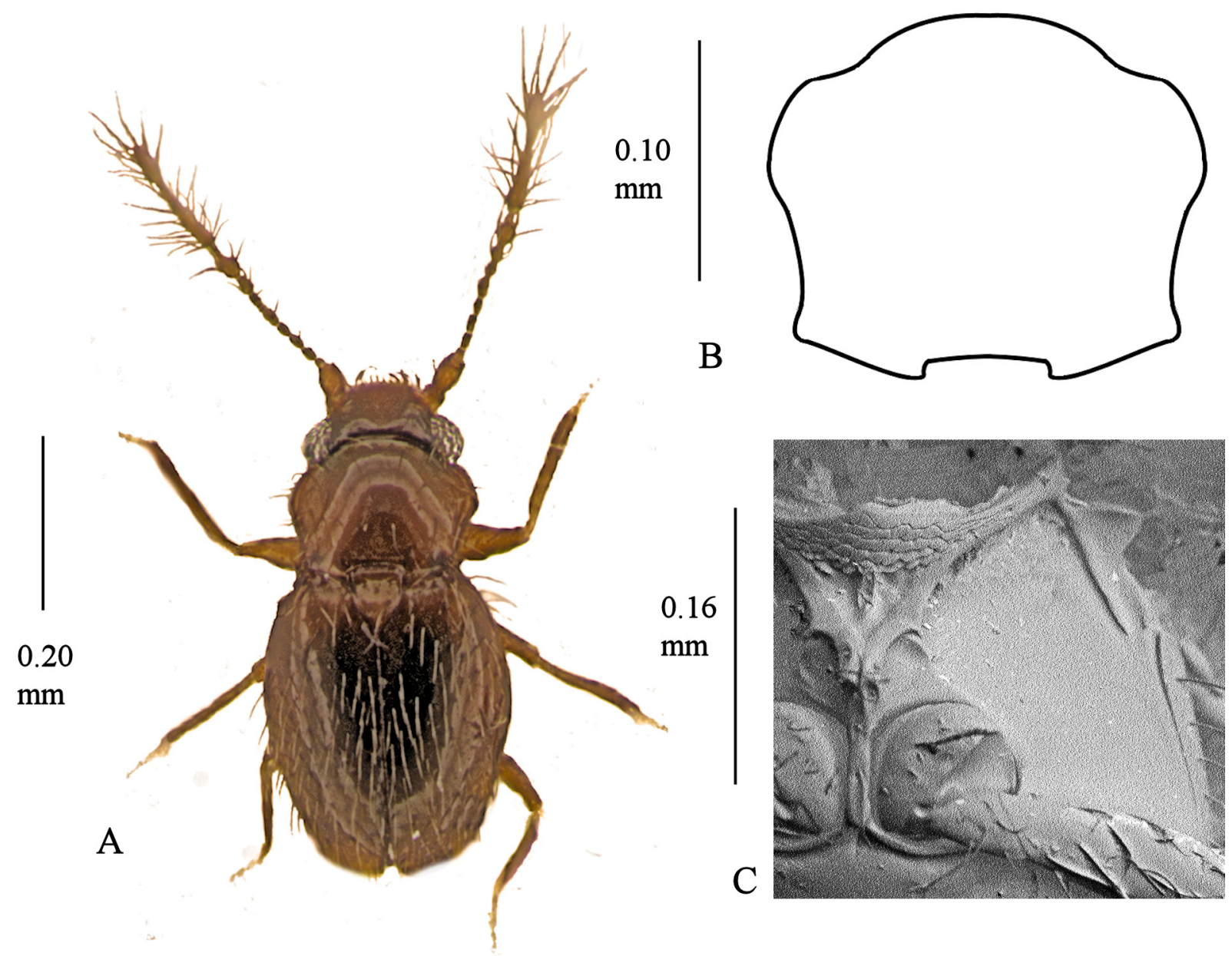

Fig. 106. Cissidium tigrum Darby, 2015. A. Habitus. B. Pronotum. C. Mesoventrite showing median process of collar, effaced lateral margin, mid-keel and keel, $\times 855$.

\section{Species group 5: pronotum with both foveae and foveolae}

\section{Key to species group 5}

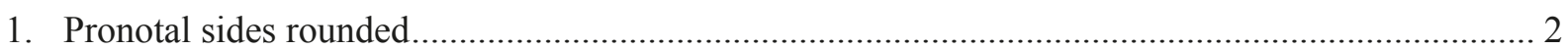

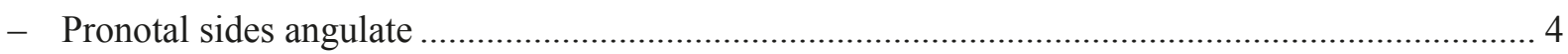

2. Pronotum base with a linear row of ten foveae in two pairs of five each, the medial two pairs being larger than the outer three pairs

C. modestum sp. nov.

- Foveae along pronotal base of the same size, more randomly arranged

3. Pronotum base with \pm seven foveae

- Pronotum base with \pm ten foveae. C. sakaii Sawada, 2008 
4. Head without a linear depression between the eyes

- Head with a linear depression between the eyes

C. fraternum sp. nov.

5. Sides of mid-keel straight

C. kolombangaricum sp. nov.

- Sides of mid-keel concave

6. Mid-keel short, anterior angles very wide

C. brachypterum sp. nov.

- Mid keel anterior angles narrower 7

7. Mid keel shorter and wider.

C. waginicum sp. nov.

- Mid keel narrower. C. apterum sp. nov.

Cissidium apterum sp. nov.

urn:1sid:zoobank.org:act:0CF1B47A-22B0-45A8-AE70-F24D484C01C5

Figs 6J, 107

\section{Etymology}

Johnson ms name, named after the apterous male.

\section{Material examined}

\section{Holotype}

SOLOMON ISLANDS • O'; Santa Ysobel, S.E., 1000 Ships Bay, opposite Lilihinia Is.; 20 Sep. 1965; forest litter; P.N. Lawrence leg.; BMNH.

\section{Paratypes}

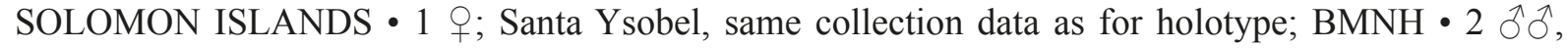
2 ㅇ; NE Tatamba, Raja; 30 Sep. 1965; forest litter; P.N. Lawrence leg.; MMUE, BMNH • 1 ○े; E Central San Jorge Is.; 24 Sep. 1965; forest litter; J.P. and P.N. Lawrence leg.; BMNH.

\section{Description}

Size. Habitus (Fig. 101A), length $0.63 \mathrm{~mm}$.

CoLour. Dark yellow brown, pubescence, legs and antennae dusky yellow.

HEAD. Without a clearly marked linear depression behind the eyes, width across eyes $0.22 \mathrm{~mm}$; antennomeres III-XI length $0.36 \mathrm{~mm}$, III-IX length $0.20 \mathrm{~mm}, \mathrm{X}-\mathrm{XI}$ length $0.16 \mathrm{~mm}$.

Pronotum. Length $0.18 \mathrm{~mm}$, width $0.32 \mathrm{~mm}$, pubescent, base with a series of four or five foveae on each side, these two series separated by distinct space opposite scutellum and with a few scattered, rather large, somewhat irregular foveolae in basal half; side margins sharply angled, concave before rectangular hind angles, sinuous before obtuse anterior angles, strongly bordered, border effaced laterally on posterior margin (Fig. 107B).

ElYTRA. Length $0.47 \mathrm{~mm}$, width $0.37 \mathrm{~mm}$, pubescence as pronotum, basal third sparsely covered with large foveolae.

Mesoventrite. Medial extension of collar short, pointed; anterior margin of mid-keel wider than posterior, corners of posterior margin reaching anterior margins of mesocoxal borders; keel sharply raised anteriorly then almost parallel-sided to termination between mesocoxae; mesoventral lateral margins serrate in posterior half; humeri barely toothed, sloping posteriorly (Fig. 107C). 
Metaventrite. Length $0.12 \mathrm{~mm}$, width across spines $0.12 \mathrm{~mm}$, with scattered setae, female disc simple, male disc depressed medially; posterior margins of mesocoxal cavities serrate.

Wings. Male macropterous. Female apterous.

Genitalia. Female spermatheca globular with small accessory knob. Male aedeagus with projecting hooked tip (Fig. 6J).

\section{Remarks}

Five of the ten species of Cissidium recorded from the Solomon Islands belong in this group and are difficult to separate on pronotal characters. The genitalia distinguish this species.
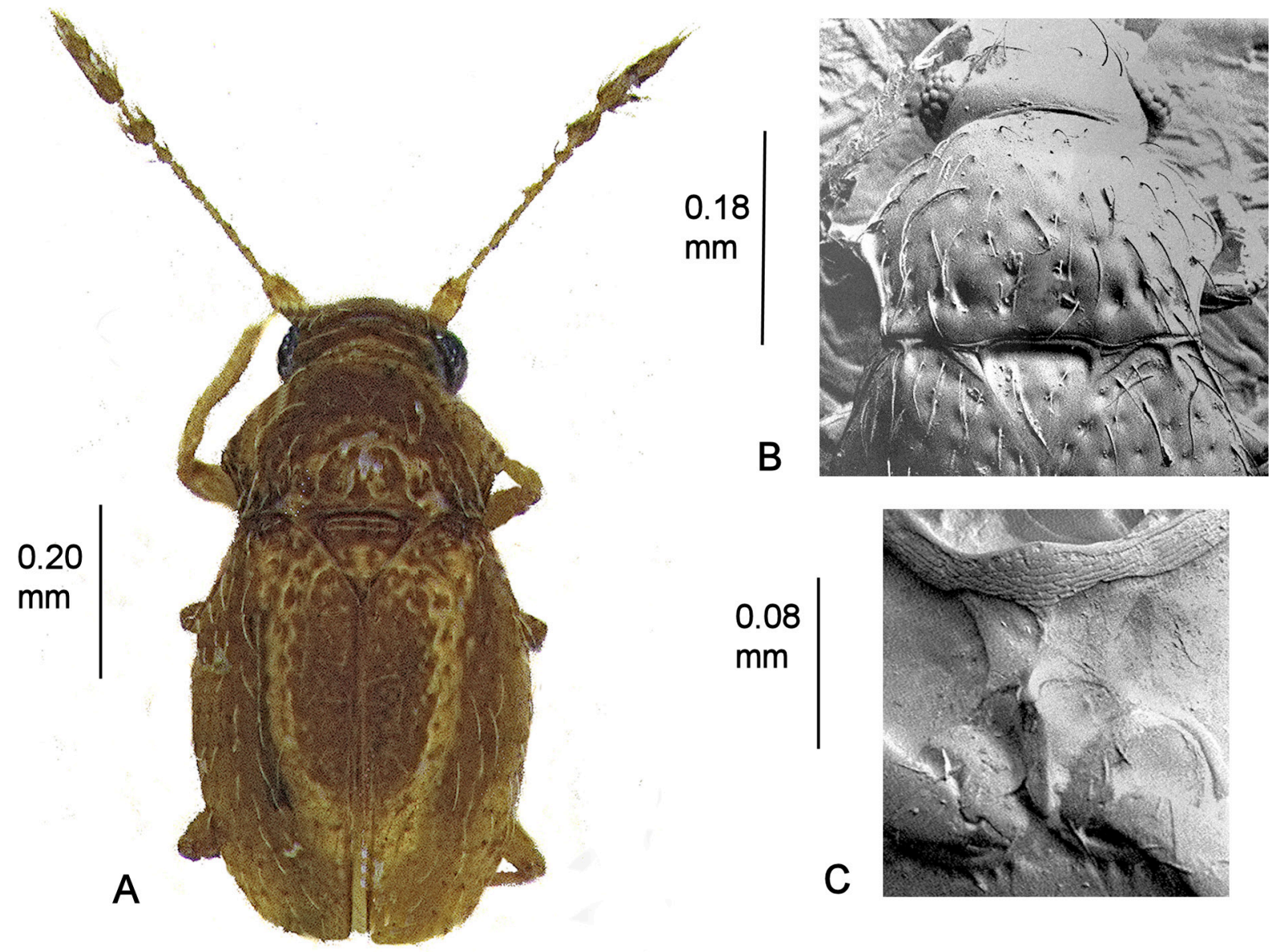

Fig. 107. Cissidium apterum sp. nov. A. Habitus. B. Pronotum, $\times 360$. C. Mesoventrite showing median process of collar, mid-keel and keel, $\times 470$. 
Cissidium brachypterum sp. nov.

urn:1sid:zoobank.org:act:407789E3-2648-4253-A802-7554E4F7C5A3

Figs 6K, 108

\section{Etymology}

Johnson ms name. Refers to the brachypterous female.

\section{Material examined}

Holotype

SOLOMON ISLANDS • O'; Nggela, Soso; 2 Dec. 1966; no. 21004; P. Greenslade leg.; BMNH.

\section{Paratypes}

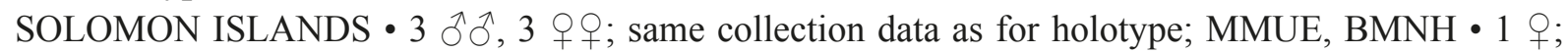
Guadalcanal, Popomanasiu; 5000 ft a.s.1.; Oct. 1965; litter sample 6, no. 20486; P. Greenslade leg.; MMUE • 1 क; Mt. Austen; 11 Mar. 1963; no. 849; P. Greenslade leg.; BMNH • 1 क; same collection data as for preceding but 10 Apr. 1963 ; no. $6415 ; \mathrm{BMNH} \bullet 1$ \% ; same collection data as for preceding but 25 Apr. 1963; no. 6289; BMNH • 1 §ิ, 2 ㅇ; ; same collection data as for preceding but Feb.-Mar. 1966; nos 21243/21336; MMUE, BMNH • 1 क; same collection data as for preceding but 10 Jul. 1966; 'road'; no.23465; MMUE.

\section{Additional material}

SOLOMON ISLANDS • 1 q; Kolombangara, near Kuzi; 50 ft a.s.1.; 8 Sep. 1965; valley litter no. 781800; P.N. Lawrence leg.; MMUE • 1 क; Russel Is., Yandina; 15 Aug. 1966; no. 23539; P. Greenslade leg.; BMNH.

\section{Description}

Size. Habitus (Fig. 108A), length $0.65 \mathrm{~mm}$.

CoLour. Yellow brown, head slightly darker, pubescence, legs and antennae dusky yellow.

HEAD. With a shallow linear depression behind the eyes, width across eyes $0.19 \mathrm{~mm}$; antennomeres IIIXI 0.29 mm long, III-IX 16 mm long, X-XI 13 mm long; mentum as Fig 4A.

Pronotum. Length $0.16 \mathrm{~mm}$, width $0.27 \mathrm{~mm}$, pubescent with a series of \pm eight foveolae along the posterior margin, and further foveolae on disc becoming obliterated towards the anterior margin; lateral margins sharply angled then sinuate posteriorly to rectangular hind angles, bordered, the border extending along the posterior margin to the medial emargination (Fig. 108B).

ELYTRA. Length $0.43 \mathrm{~mm}$, width $0.35 \mathrm{~mm}$, pubescent, length of setae as pronotum, basal half foveolate.

MesoventRITE. Medial extension of collar pointed, almost reaching keel; mid-keel very wide anteriorly, narrowing posteriorly, posterior corners almost reaching mesocoxal anterior borders, sharply raised medially before keel; keel with a series of \pm four setae tapering to a blunt termination almost level with hind margin of mesocoxae; mesoventral lateral margins serrate in posterior half; humeri toothed (Fig. 108C).

Metaventrite. Length $0.12 \mathrm{~mm}$, width across spines $0.12 \mathrm{~mm}$, sparsely pubescent, disc shallowly impressed; posterior margins of mesocoxal cavities serrate. 
Wings. Male macropterous, female brachypterous, wing hairs being limited to apical region of the membrane.

Genitalia. Male aedeagus elongate (Fig. 6K). Female spermatheca globular.

\section{Remarks}

Distinguished from the other species in the Solomon Islands group by the anterior width of the mesoventral mid-keel and the length of the keel.
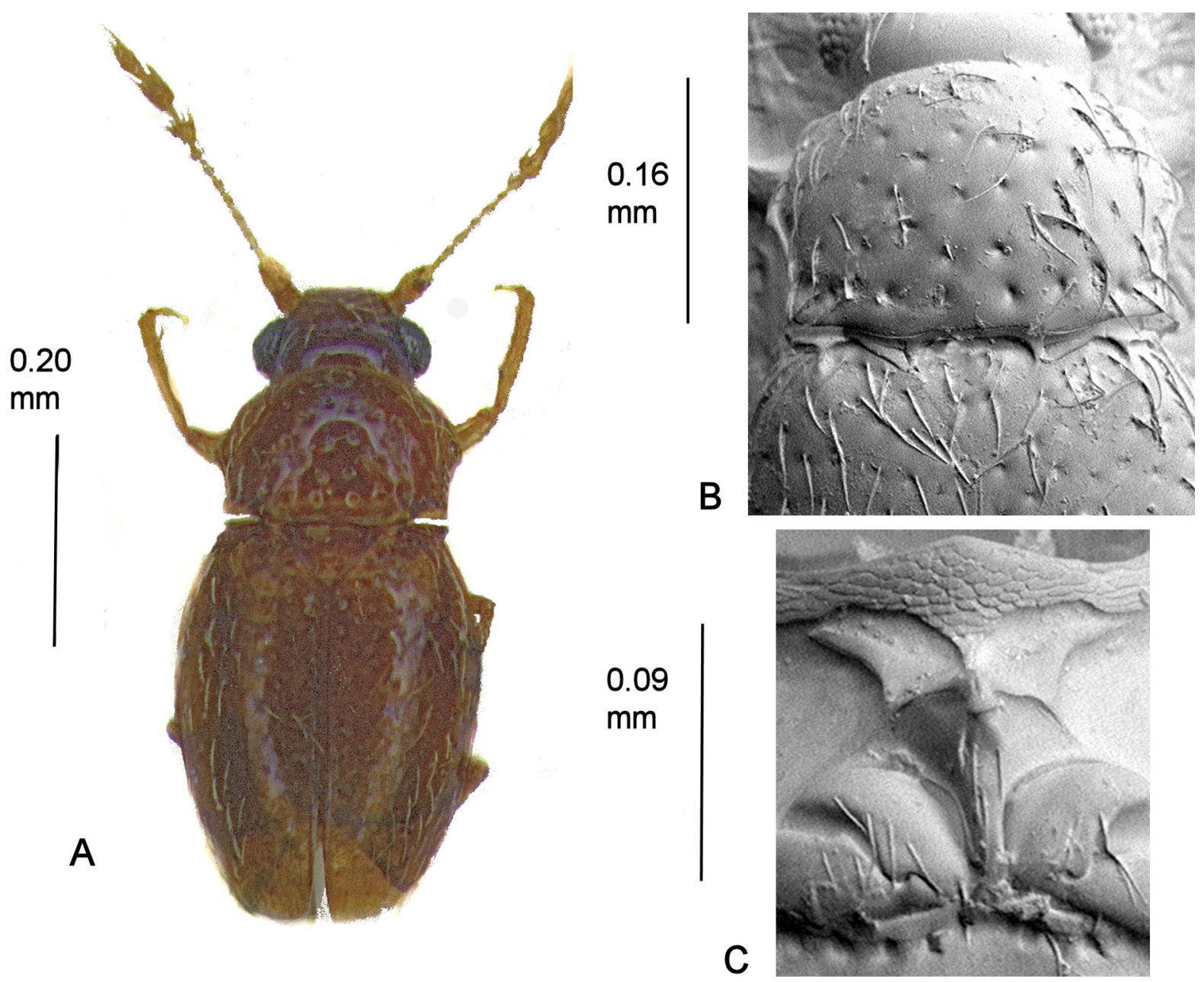

Fig. 108. Cissidium brachypterum sp. nov. A. Habitus. B. Pronotum, $\times 485$. C. Mesoventrite showing median process of collar, mid-keel and keel, $\times 560$. 
Cissidium fraternum sp. nov.

urn:lsid:zoobank.org:act:619FAB89-D53D-4C06-A2B0-3023099107E3

Figs $6 \mathrm{H}, 109$

\section{Etymology}

Johnson ms name, derivation unclear but presumably from the Latin adjective 'fraternus', meaning 'brotherly' and possibly referring to the similarity of this species to C. brachypterm sp. nov. and C. greensladei sp. nov., both also from the Solomon Islands.

\section{Material examined}

\section{Holotype}

SOLOMON ISLANDS • \} \text { ; Guadalcanal, Monitor Creek, Umosani River; } 8 \text { Jul. 1965; thicket litter, } matted roots; no. 85; P.N. Lawrence leg.; BMNH.

\section{Paratypes}

SOLOMON ISLANDS • 1 \%; Nuhu; 1000 ft a.s.1.; 31 May 1965; gully bottom litter; P. Naturaga leg.; MMUE • 1 क; Guadalcanal, Mt. Austen; Mar. 1966; no. 21336; P. Greenslade leg.; BMNH.

\section{Description}

Size. Habitus (Fig. 109A), length $0.60 \mathrm{~mm}$.

CoLour. Dusky yellow brown, antennae, legs and pubescence lighter.
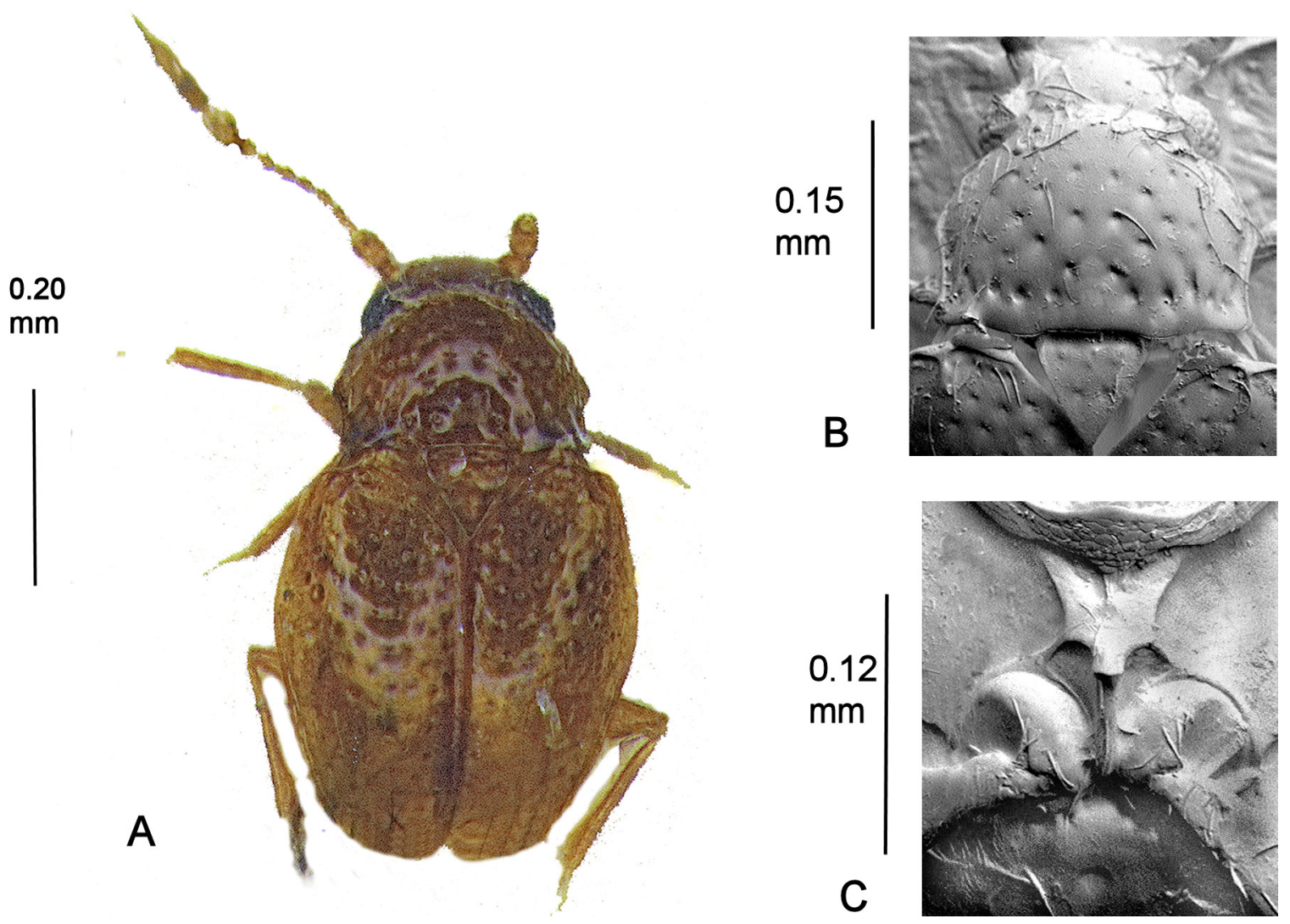

Fig. 109. Cissidium fraternum sp. nov. A. Habitus. B. Pronotum, $\times 415$. C. Mesoventrite showing median process of collar, mid-keel and keel, $\times 590$. 
HeAD. Width across eyes $0.20 \mathrm{~mm}$; antennomeres III-XI $0.30 \mathrm{~mm}$ long, III-IX $0.16 \mathrm{~mm}$ long, X-XI $0.14 \mathrm{~mm}$ long; mentum as Fig 4A.

Pronotum. Length $0.15 \mathrm{~mm}$, width $0.26 \mathrm{~mm}$; base with a series of four or five foveae on each side separated by distinct space opposite scutellum and a few scattered smaller foveae anterior to these; lateral margins sharply angled, concave to slightly acute hind angles, sinuous to obtuse front angles, bordered, the border along the posterior margin interrupted between the hind angles and the median emargination in front of the scutellum (Fig. 109B).

ELYTRA. Width $0.36 \mathrm{~mm}$; length. $0.4 \mathrm{~mm}$, basal half rather sparsely covered with large foveolae.

Mesoventrite. Collar barely extended medially onto mid-keel; mid-keel wider anteriorly than posteriorly, the posterior angles clearly joining the mesocoxal anterior border as two carinae, sharply raised medially to junction with keel; keel with \pm two setae, parallel-sided to blunt termination posterior to the interruption point of the mesocoxal margins; mesoventral lateral margins serrate in posterior half (Fig. 109C).

MetaVentrite. Sparsely pubescent, length $0.13 \mathrm{~mm}$, width across spines $0.13 \mathrm{~mm}$, with a triangularly impressed area medially and a small medial fovea posterior to the mesocoxae.

WINGS. Macropterous.

Genitalia. Female spermatheca globular. Male aedeagus distinctive (Fig. 6H).

\section{Remarks}

Compared with the other five Solomon Islands species in this group, $C$. fraternum $\mathrm{sp}$. nov. is very similar in size to C. brachypterum sp. nov., but with longer antennae. Compared to C. greensladei sp. nov., which it also much resembles, it is smaller and with shorter antennae. The aedeagus of the male provides decisive characters.

Cissidium kolombangaricum sp. nov. urn:1sid:zoobank.org:act:CAB500DC-351D-47A1-828B-C9207ADA4519

Figs $6 \mathrm{M}, 110$

\section{Etymology}

Johnson ms name, named after Kolombangara Island in the Solomon Islands where the specimens were collected.

\section{Material examined}

\section{Holotype}

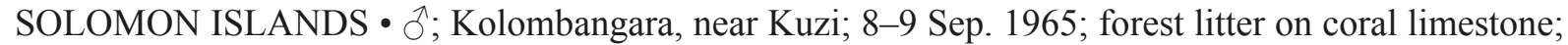
P.N. Lawrence leg.; BMNH.

\section{Paratype}

SOLOMON ISLANDS • 1 क; Kolombangara, north of Kuzi; $500 \mathrm{ft}$ a.s.1.; 6 Oct. 1965; forest litter; no.721-750; P.N. Lawrence leg.; MMUE.

\section{Description}

Size. Habitus (Fig. 110A), length $0.72 \mathrm{~mm}$. 
CoLour. Yellow brown, pubescence and antennomeres slightly paler.

HEAD. With a shallow transverse depression behind the eyes; eyes large, width across $0.21 \mathrm{~mm}$; antennomeres III-XI length $0.29 \mathrm{~mm}$, III-IX length $0.16 \mathrm{~mm}$, X-XI length $0.13 \mathrm{~mm}$; mentum sides slightly tapering posteriorly, front angles rounded.

Pronotum. Length $0.17 \mathrm{~mm}$, width $0.30 \mathrm{~mm}$, base with series of four or five foveae on each side, the two series hardly separated opposite scutellum; slightly smaller foveae anterior to these at sides of disc; lateral margins sharply angled, almost parallel to rectangular hind angles, front angles prominent, rounded, conspicuously bordered, borders not continued along the posterior margin, medial emargination in front of scutellum sinuous (Fig. 110B).

ELYTRA. Length $0.44 \mathrm{~mm}$, breadth $0.40 \mathrm{~mm}$, basal third rather sparsely foveate.

Mesoventrite. Median process of collar pointed; mid-keel widest anteriorly, sides straight to posterior angles with carinae to mesocoxal anterior borders, sharply raised with ridged top to junction with keel; keel foveolate and setose, parallel-sided to rounded termination beneath interruption point of mesocoxal margins; mesoventral lateral margins serrate (Fig. 110C).
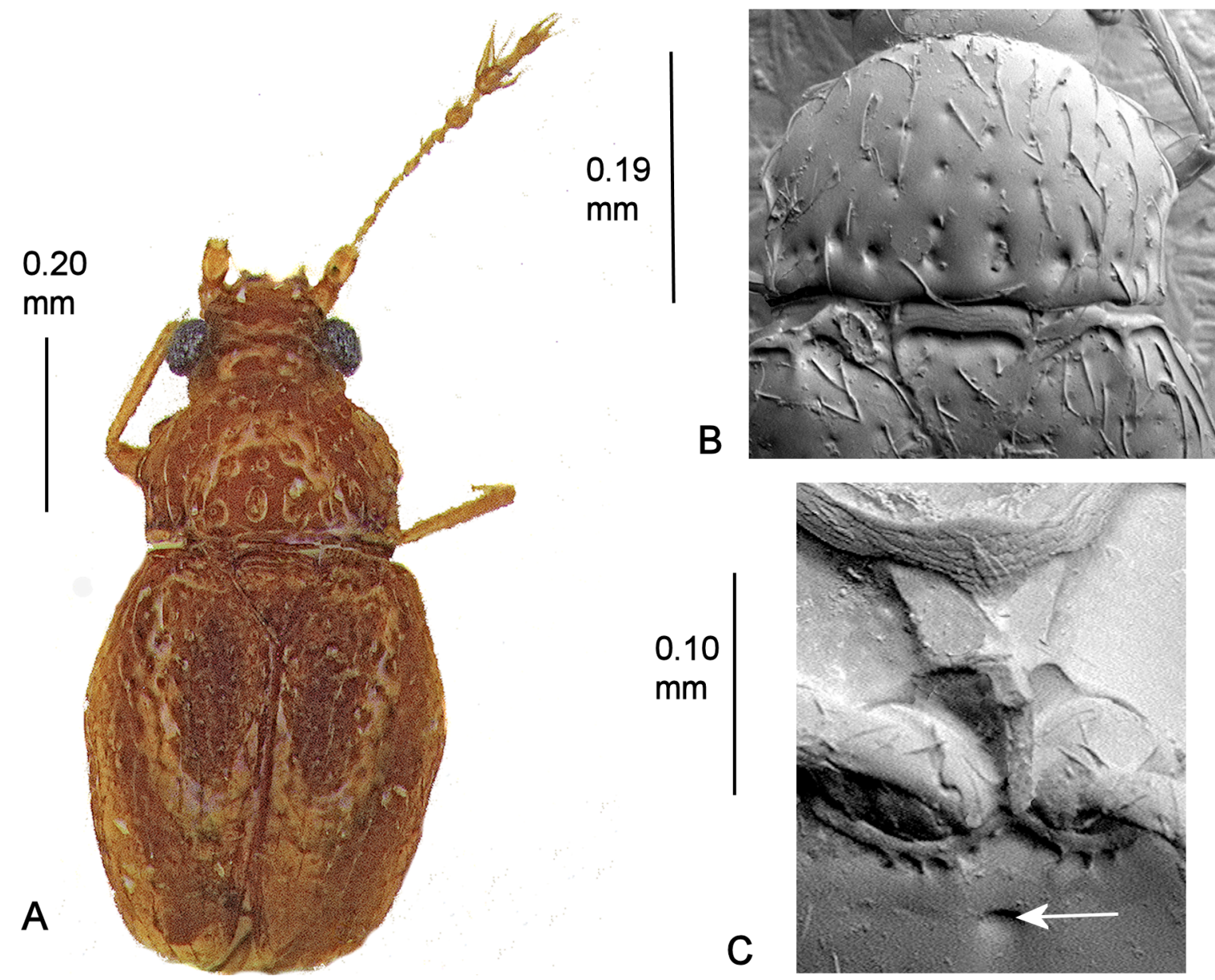

Fig. 110. Cissidium kolombangaricum sp. nov. A. Habitus. B. Pronotum, $\times$ 425. C. Mesoventrite showing median process of collar, mid-keel and keel, $\times 390$. 
MetaVentrite. Length $0.12 \mathrm{~mm}$, pubescence very sparse almost entirely confined to lateral borders, width across spines $0.11 \mathrm{~mm}$, disc strongly, triangularly depressed with a distinct medial fovea posteriad to mesocoxae.

Genitalia. Male aedeagus (Fig. 6M).

\section{Remarks}

The male aedeagus of this species separates it from the other Solomon Islands Cissidium.

Cissidium modestum sp. nov. urn:1sid:zoobank.org:act:54EC643C-B544-4F30-9B34-4C978304D294

Fig. 111

\section{Etymology}

Johnson ms name, after the Latin adjective modestus meaning sober, restrained.

\section{Material examined}

\section{Holotype}

MALAYSIA - ; Selangor, Gombak, vicinity of University of Malaya Field Station, $9^{\text {th }}$ mile; 9 Feb. 1967; D.H. Murphy leg.; FMNH.

\section{Description}

Size. Habitus (Fig. 111A), length $0.57 \mathrm{~mm}$.

CoLour. Dark red brown, pubescence, legs and antennae dusky yellow.

HEAD. With two slightly elongate setose foveolae inside eyes, width across eyes $0.18 \mathrm{~mm}$; antennomeres III-XI length $0.27 \mathrm{~mm}$, III-IX length $0.13 \mathrm{~mm}, \mathrm{X}-\mathrm{XI}$ length $0.14 \mathrm{~mm}$ globular; mentum and prementum obscured.

Pronotum. Length $0.15 \mathrm{~mm}$, width $0.22 \mathrm{~mm}$, sparsely pubescent with a row of ten foveae along the base and 3 or 4 smaller ones scattered on the disc; sides rounded, almost parallel-sided posteriad to rectangular hind angles, bordered, the border not continuing along the posterior margin, medial emargination in front of scutellum sinuous, barely marked (Fig. 111B).

ELYTRA. Length $0.37 \mathrm{~mm}$, width $0.28 \mathrm{~mm}$, pubescent and foveolate markedly contrasting with the pronotum.

MesoventRITE. Median process of mesoventral collar short; mid-keel widest anteriorly, the posterior angles stopping just short of the mesocoxal anterior borders, raised sharply to a medial blunt point before joining the keel; keel with \pm four setae, narrow anteriorly, wider and more rounded posteriorly, terminating below the mid-point of the mesocoxae; mesoventral lateral margins serrate posteriorly; humeri toothed (Fig. 111C).

Metaventrite. Length $0.11 \mathrm{~mm}$, setose, disc simple, width across spines $0.09 \mathrm{~mm}$ spines. WINGS. Macropterous.

Genitalia. Male aedeagus as Fig. 6Fa-b but slightly longer. Females not known. 


\section{Remarks}

This is the only species of Cissidium from Malaysia in this group.
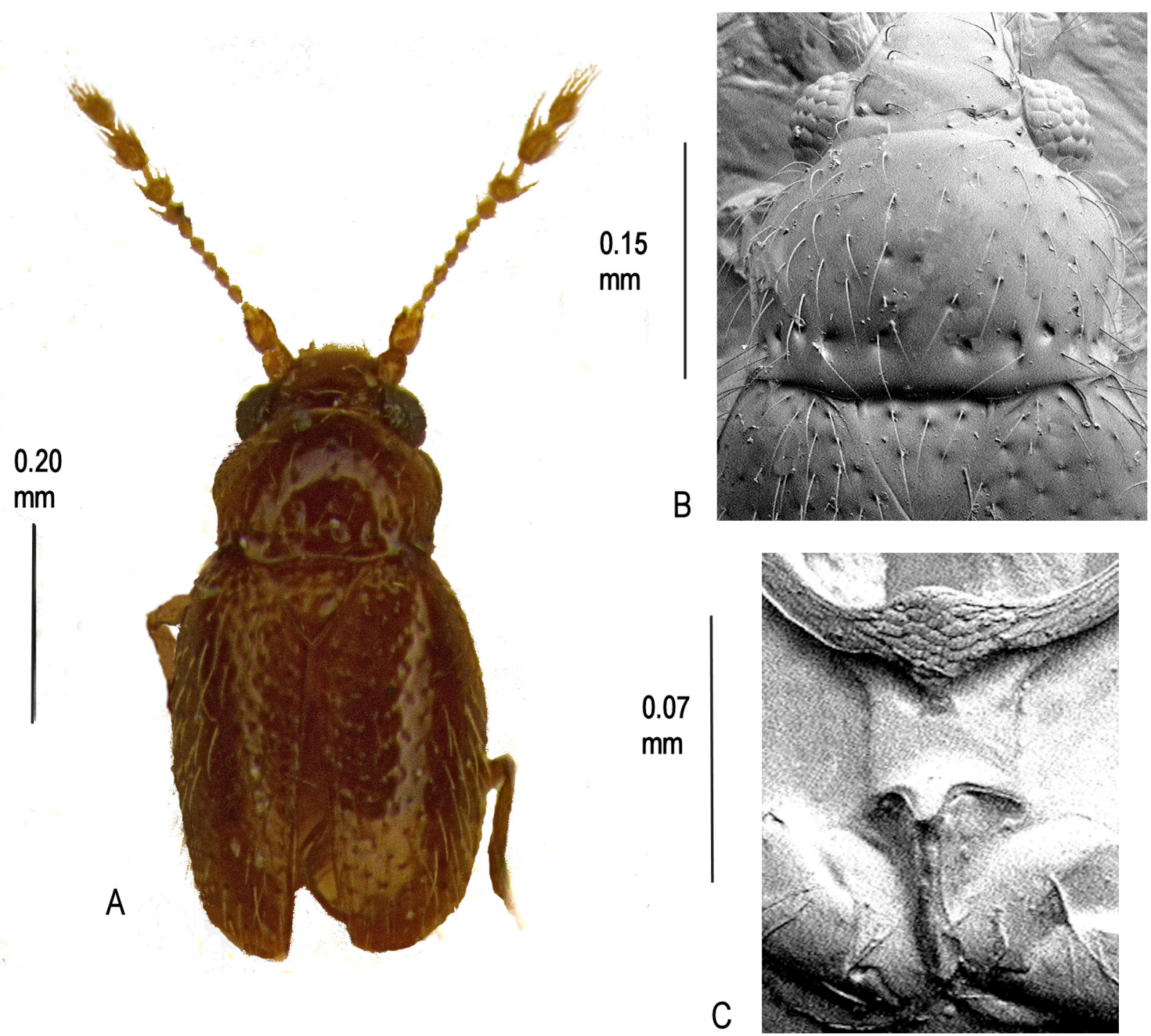

Fig. 111. Cissidium modestum sp. nov. A. Habitus. B. Pronotum, $\times$ 645. C. Mesoventrite showing median process of collar, mid-keel and keel, $\times 1380$.

Cissidium sakaii Sawada, 2008

Fig. 112

\section{Material examined}

\section{Paratypes}

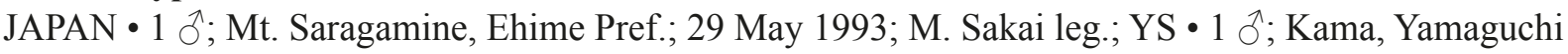
Pref.; 8 Aug. 1999; Y. Nishikawa leg.; BMNH 1 đ̊; Shirasuna, Komatsujima City, Tokushima Pref.; 4 Nov. 1993; M. Sakai leg. (BMNH); 10̄, Fall of Hiji, Kunigami-son, Okinawa Pref., 13 Apr. 1996, H. Hoshina leg.; YS. 


\section{Supplementary description}

The following description amplifies the type description of Sawada (2008) in order to conform with the entries in the present paper.

Size. Habitus (Fig. 112A), length $0.69 \mathrm{~mm}$.

Colour. Reddish brown, antennae, legs and pubescence dusky yellow. antennomeres III-XI $0.31 \mathrm{~mm}$ long.

HEAD. With a shallow uninterrupted transverse depression behind the eyes, width across the eyes $0.20 \mathrm{~mm}$.

Pronotum. Length $0.18 \mathrm{~mm}$, width $0.29 \mathrm{~mm}$, sparsely pubescent, foveolate and foveate in basal half, the foveae being almost the same size as the foveolae; side margins rounded to almost parallel-sided, narrowly bordered to slightly acute hind angles, the border continuing along the posterior margin to the sinuate emargination in front of the scutellum (Fig. 112B).

ELYTRA. Length $0.48 \mathrm{~mm}$, width $0.39 \mathrm{~mm}$, pubescent and foveolate.

Mesoventrite. Median extension of collar tapering from wide base almost to a point; mid-keel with concave sides, hind angles almost reaching anterior borders of mesocoxae; keel narrow, parallel-sided
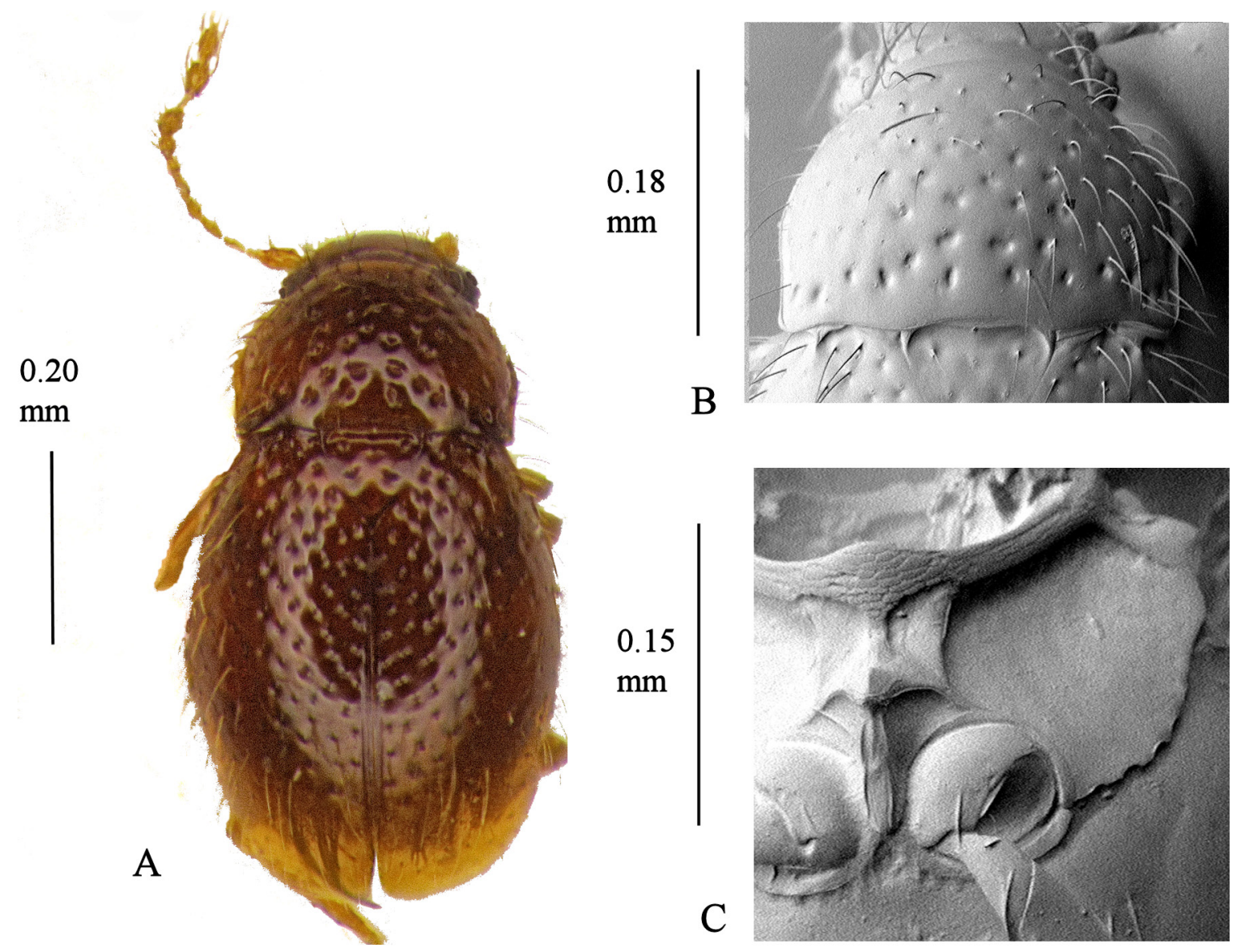

Fig. 112. Cissidium sakaii Sawada, 2008. A. Habitus. B. Pronotum, $\times 580$. C. Mesoventrite showing median process of collar, mid-keel, keel and lateral margin, $\times 505$. 
then tapering to between the mesocoxae; mesoventral lateral borders evenly rounded, serrate in posterior half; humeri toothed (Fig. 112C).

Metaventrite. Without pubescence, length $0.17 \mathrm{~mm}$, distance across spines $0.11 \mathrm{~mm}$, disc simple; mesocoxal posterior borders serrate.

GenITALIA. Male aedeagus as Fig. $6 \mathrm{Fa}-\mathrm{b}$ but beak more pointed and slightly raised at tip which is not so strongly bent. Females not known.

\section{Remarks}

This is the only Japanese species in this group.

Cissidium upiense $\mathrm{sp}$. nov.

urn:1sid:zoobank.org:act:5BE9BB51-1E41-4C45-8C89-4B3B15B91569

Figs 3A, 113

\section{Etymology}

Named after Upi, the municipality in the Province of Maguindanao, Philippines, where the insect was collected.

\section{Material examined}

\section{Holotype}

PHILIPPINES • ${ }^{\text {; }}$; Mindanao, Burungket, Upi, Cotobato Prov.; $1500 \mathrm{ft}$ a.s.1.; 1-6 Jan. 1949; by waving fine meshed net over forest floor in late afternoon; Werner leg.; FMNH.

\section{Description}

Size. Habitus (Fig. 113A), length $0.54 \mathrm{~mm}$.

CoLour. Yellow brown, pubescence, legs and antennae dusky yellow.

HEAD. With a shallow foveolate and setose linear depression behind the eyes (Fig. 3A), width across eyes $0.18 \mathrm{~mm}$; mentum and prementum obscured; antennomeres III-XI, length $0.29 \mathrm{~mm}$, III-IX length $0.16 \mathrm{~mm}, \mathrm{X}-\mathrm{XI}$ length $0.13 \mathrm{~mm}$.

Pronotum. $0.13 \mathrm{~mm}$ long, $0.23 \mathrm{~mm}$ wide, sparsely pubescent with \pm nine asymmetrically placed foveae in basal half, lateral margins evenly rounded to shallow concave sinuations before rectangular hind angles, strongly bordered, the borders not continuing along the posterior margin, medial emargination opposite the scutellum angulate (Fig. 113B).

ELYTRA. $0.39 \mathrm{~mm}$ long, $0.30 \mathrm{~mm}$ wide, pubescent, shallowly foveolate.

MesoventRITE. Medial extension of collar broadened posteriorly almost reaching lateral margins of midkeel; mid-keel sub parallel-sided, hind angles not reaching mesocoxae raised to blunt termination before keel; keel narrow with \pm four setae, tapering to a point at the base of the mesocoxae; mesoventral lateral margins serrate in posterior half; humeri toothed (Fig. 113C).

Metaventrite. Sparsely pubescent, length $0.13 \mathrm{~mm}$, disc simple, width across spines $0.08 \mathrm{~mm}$; posterior margin of mesocoxae serrate.

Wings. Macropterous. 
Genitalia. Male aedeagus small, pointed when viewed dorsally. Females not known.

\section{Remarks}

The only species of Cissidium in this group from the Philippines.
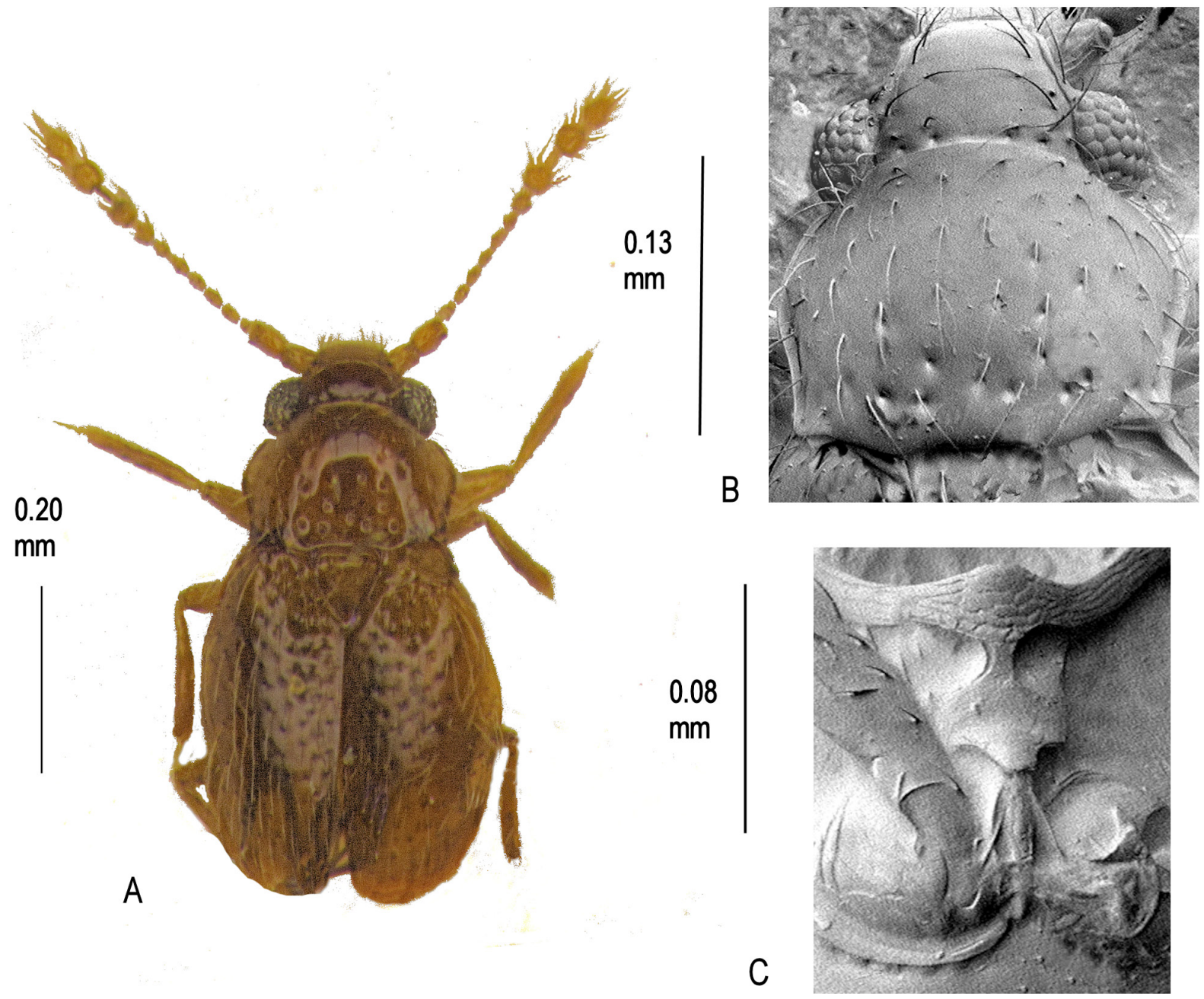

Fig. 113. Cissidium upiense sp. nov. A. Habitus. B. Pronotum, $\times 565$. C. Mesoventrite showing median process of collar, mid-keel and keel, $\times 585$.

Cissidium waginicum $\mathrm{sp}$. nov.

urn:Isid:zoobank.org:act:6DA410C3-BFCB-4D21-99B4-3CDC3D8B255E

Fig. 114

\section{Etymology}

Johnson ms name, after Wagina Island, where the specimen was collected.

\section{Material examined}

Holotype

SOLOMON ISLANDS • + ; Choiseul, Wagina Is.; 25 May 1966; no. 23078; P. Greenslade leg.; BMNH. 


\section{Description}

Size. Habitus (Fig. 114A), length $0.71 \mathrm{~mm}$.

CoLour. Yellow brown, pubescence antennae and legs dusky yellow.

HeAD. Width across eyes $0.22 \mathrm{~mm}$; antennomeres III-XI length $0.38 \mathrm{~mm}$, III-IX length $0.21 \mathrm{~mm}, \mathrm{X}-\mathrm{XI}$ length $0.17 \mathrm{~mm}$.

Pronotum. $0.18 \mathrm{~mm}$ long, $0.31 \mathrm{~mm}$ wide; sparsely covered with large, shallow and irregular foveolae, base with a series of four foveae on each side, the two series separated by a distinct space opposite scutellum; lateral margins sharply angled, thence narrowed in a weakly concave line to somewhat effaced but obtusely angled front angles visible in dorsal view, rearwards concave to slightly acute hind angles; sides conspicuously bordered, the border continued along the entire length of the posterior margin, median emargination opposite the scutellum sinuous, barely visible (Fig. 114B).

ELYTRA. $0.60 \mathrm{~mm}$ long, $0.41 \mathrm{~mm}$ wide, basal third sparsely covered with rather large foveolae.

MesoventRITE. Median process of collar short, pointed; mid-keel wide, sides concave, anterior margin slightly wider than posterior which has well marked flat carinae joining the mesocoxal anterior margins,
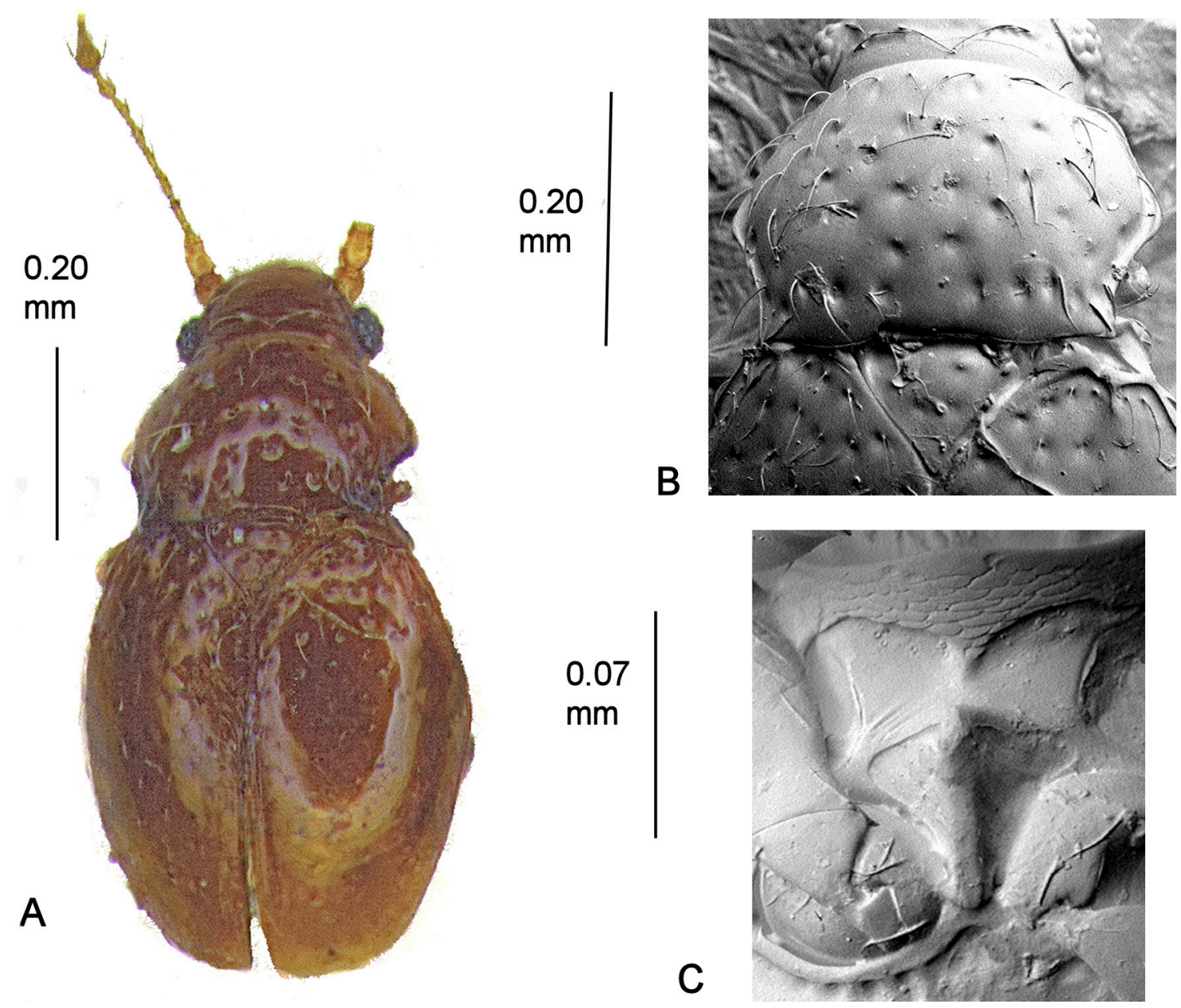

Fig. 114. Cissidium waginicum sp. nov. A. Habitus. B. Pronotum, $\times 455$. C. Mesoventrite showing median process of collar, mid-keel and keel, $\times 655$. 
raised medially to a point before the keel; keel parallel-sided with rounded termination just past the interruption point of the mesocoxal borders; mesoventral lateral margins serrate; humeri toothed (Fig. 114C).

Metaventrite. Length $0.14 \mathrm{~mm}$, disc simple, distance across spines $0.11 \mathrm{~mm}$; posterior borders of mesocoxae serrate.

Wings. Female apterous. Male unknown.

\section{Remarks}

Most likely to be confused with C. kolobangaricum sp. nov. in this group from the Solomon Islands, but distinguished by the wider mid-keel, and narrower pronotal base.

\section{Distributional data}

\section{Geographical distribution of species}

AUSTRALIA. C. deanei sp. nov., C. delicatum sp. nov., C. impressum sp. nov., C. lamington sp. nov., C. scutellare.

BOLIVIA. C. amboroense, C. globosum, C. lisae, C. petri, C. sawadai, C. tigrum.

BRAZIL. C. amazonicum sp. nov., C. angusi sp. nov., C. bomjesus sp. nov., C. dybasi sp. nov., C. flavum sp. nov., C. ibicarense sp. nov., C. orami sp. nov., C. plaumanni sp. nov., C. reitteri, C. sueae sp. nov.

CAMEROON. C. okuense.

ECUADOR. C. ecuadoriense sp. nov.

IVORY COAST. C. aristophanousi sp. nov.

JAMAICA. $C$. insulare sp. nov., $C$. seditiosum sp. nov.

JAPAN. C. ikeuchii, C. itoi, C. latum, C. ishigakiense, C. matthewsi, C. nishikawai, C. nomurai, C. elongatum, C. shibatai, C. sakaii.

MADAGASCAR. C. banari, C. bifoveolatum sp. nov., C. franzi sp. nov., C. glabratum sp. nov., C. semicalvum sp. nov.

MALAYSIA. Peninsular Malaysia: C. bilineatum sp. nov., C. modestum sp. nov., C. murphyi sp. nov., C. visendum sp. nov. Sabah: C. dewhurst sp. nov. Sarawak: C. globulum, C. longum, C. marshallae, C. pauxillum, C. subfoveolatum, C. triangulum.

MEXICO. C. faustum sp. nov.

NEPAL. C. logunovi sp. nov., C. puncticolle sp. nov.

NEW CALEDONIA. C. amieuense sp. nov., C. houailou sp. nov., C. inexspectatum sp. nov., C. misellum sp. nov., $C$. noumeae sp. nov., $C$. pinense sp. nov., $C$. riparium sp. nov.

NEW ZEALAND. C. crowsoni, C. foveolatum.

NIGERIA. C. yoruba sp. nov.

PANAMA. C. angulatum sp. nov., C. basale, C. cryptophagoides sp. nov., C. dividuum sp. nov., C. eciton sp. nov., C. faustum sp. nov. C. luctuosum sp. nov., C. obscurum sp. nov., C. subangulatum sp. nov., C. subfaustum sp. nov.

PERU. C. obscenum sp. nov., C. peruviense sp. nov., C. similatum sp. nov. 
PHILIPPINES. C. advena sp. nov., C. davaoense sp. nov., C. losbanos sp. nov., C. mindanao sp. nov., C. upiense sp. nov., C. werneri sp. nov.

RWANDA (as Ruanda). C. rogeri sp. nov.

SOLOMON ISLANDS. C. apterum sp. nov., C. brachypterum sp. nov., C. clareae sp. nov., C. fraternum sp. nov., $C$. greensladei sp. nov., $C$. kolombangaricum sp. nov., $C$. lawrencei sp. nov., $C$. lucidulum sp. nov., C. robustum sp. nov., C. waginicum sp. nov.

SOUTH AFRICA. C. opacum sp. nov.

SRI LANKA. C. besucheti sp. nov., C. ceylonicum sp. nov., C. loebli sp. nov., C. mahleri sp. nov., C. mussardi sp. nov., C. pilosellum sp. nov.

TANZANIA. C. montanum sp. nov.

THAILAND. C. trangse sp. nov.

TRINIDAD AND TOBAGO (Trinidad). $C$. steeli sp. nov.

VIETNAM (as Tonkin). C. arcuatum sp. nov.

ZIMBABWE (as Rhodesia). C. obsoletum sp. nov.

\section{Number of species represented in each species group}

(Numbers in brackets refer to numbers of species)

Species group 1. Madagascar (3) Solomon Isles (1)

Species group 2. Australia (5), Cameroon (1), Ivory Coast (1), Japan (2), Madagascar (2), New Caledonia (7), New Zealand (2), Nepal (1), Malaysia (1), Nigeria (1), Philippines (2), Rwanda (1), Solomon Islands (3), Sri Lanka (2).

Species group 3. Brazil (1), Bolivia (1), Japan (5), Malaysia (6), Nepal (1), Philippines (2), Sri Lanka (2).

Species group 4A. Bolivia (2), Brazil (5), Ecuador (1), Jamaica (2), Malaysia (4), Panama (4), South Africa (1), Sri Lanka (2), Thailand (1), Trinidad and Tobago (1), Vietnam (1)

Species group 4B. Bolivia (3), Brazil (5), Japan (5), Panama (5), Peru (3), Philippines (1), Solomon Islands (2), Tanzania (1), Zimbabwe (1)

Species group 5. Malaysia (1), Philippines (1), Solomon Islands (4)

\section{Species groups represented in each country}

Australia: 2.

Bolivia: 3, 4A, 4B.

Brazil: 3, 4A, 4B.

Cameroon: 2.

Ecuador: 4A.

Ivory Coast: 2

Jamaica: 4A.

Japan: 2, 3, 4B

Madagascar: 1, 2. 
Malaysia: 2, 3, 4A, 5 (Peninsula: 3, 4A, 5, Sabah: 3, Sarawak: 2, 3, 4A)

Mexico: 4A.

Nepal: 2, 3.

New Caledonia: 2.

New Zealand: 2.

Nigeria: 2.

Panama: 4A, 4B.

Peru: 4B.

Philippines: 2, 3, 4B, 5.

Rwanda: 1.

Solomon Islands: 1, 2, 4B, 5.

South Africa: 4A

Sri Lanka: 2, 3, 4A.

Tanzania: 4B.

Thailand: 4A.

Trinidad and Tobago: 4A.

Vietnam: 4A.

Zimbabwe: 4B.

\section{Discussion}

With representatives in 26 countries and five continents, this study shows Cissidium to be the second most widespread and speciose genus of Ptiliidae after Acrotrichis. Unlike Acrotrichis, however, it appears to be restricted to tropical and subtropical regions, the Nepalese and Japanese specimens being the furthest northern records to date. Another major difference is that while Acrotrichis are often found in large numbers, species of Cissidium are usually found only in single figures. It is worth noting that although the author examined more than 7600 specimens of Ptiliidae from litter samples collected by Dr Petr Baňař and his students in a wide range of Madagascan localities, the majority of which were Acrotrichis, no Cissidium were found although specimens in the Manchester collection show that the genus is known from the island. And amongst 2786 Ptiliidae collected by the same collector from similar habitats in Bolivia, again the majority of which were Acrotrichis, only 16 specimens of Cissidium were determined. In this respect there are parallels with species of Micridium, which are also recorded in extremely low numbers. Whether these low numbers are the result of genuine scarcity or a reflection of the collecting methods and habitats examined is unclear.

Unfortunately, our knowledge concerning the collection details of most of the species described in this paper is restricted to the information on the labels attached to the specimens. Since many different collectors were involved, the data is very inconsistent and important details are sometimes missing. There are, however, sufficient records from litter to indicate that this appears to be the favoured habitat, and this hypothesis is supported by the almost complete absence of records for under bark or in other saproxylic habitats. 
The long pubescence which is typical of many species may be a development to assist their ability to cope with damp situations (Crowson 1981). It is certainly the case that Cissidium bilineatum sp. nov., a densely foveolate species with long pubescence, was found in "very wet litter" in a coastal swamp forest, C. angulatum sp. nov. was found in a "damp pocket of leaves along stream side", C. riparium sp. nov. as its name implies in a riverine habitat, and there are other references to species being found in litter in gullies, valley bottoms and damp ravines. In opposition to that view, however, C. puncticolle sp. nov. and C. obscenum sp. nov., both with a similar vestiture as $C$. bilineatum sp. nov., are recorded from "dry soil in a deciduous forest" and "on a mountain slope", respectively. With the possible exception of Cissidium eciton sp. nov., found in an abandoned ants' nest, no species are recorded to have an association with ants or termites. Given the insects' long legs and large eyes it seems likely that they have an active lifestyle as scavengers bringing them into contact with a wide range of litter based environments. If that is true, the argument for rarity as opposed to limited collecting preferences seems to hold good, although wet litter is probably less frequently sampled than drier.

The large number of partially winged and apterous species supports the supposition that many species of Cissidium are endemics. This is particularly true of the species from the Solomon Islands, New Caledonia and Panama, where divergence and reproductive isolation have resulted in groups of morphologically similar species. The narrow geographical range of all the species - none have been recorded from more than one country - and the inability of many species to fly encourages the view of a genus once more common, but vulnerable to habitat degeneration, particularly to drying out, and now possibly in decline and surviving only in isolated pockets across the tropics.

\section{Acknowledgements}

I am very grateful to Dr Dmitri Logunov of Manchester Museum for entrusting me with the museum's material and for looking at my first draft. To Dr Yoshihiro Sawada I owe thanks for the loan of the specimens in his possession and for subsequently presenting some to the BMNH. Scientific research in Côte d'Ivoire was made possible thanks to the support of the African Natural History Research Trust (Leominster, UK) and Richard E.L. Smith. It was authorised by the Ministère de l'Enseignement Supérieur et de la Recherche Scientifique. The Office Ivoirien des Parcs et Réserves (OIPR) is thanked for authorising access and sampling of specimens in 2015 under permit no. 573, and exportation of specimens under permit no. 652. I am very grateful, as always, to Dr Alfred Newton for checking my new names and for his comments on the manuscript and to Colin Johnson's family I owe thanks for giving me access to his manuscript account of the Solomon Islands species. Finally, I owe a huge debt of gratitude to my colleague Maxwell Barclay for acting as my editor, reading through the manuscript and arranging publication, and despecially to Kristiaan Hoedemakers and staff for their meticulous editing.

\section{References}

Crowson R.A. 1981. The Biology of the Coleoptera. Academic Press, London and New York.

Darby M. 1986-on going. A Biographical Dictionary of British Coleopterists. Available from www.coleopterist.org.uk [accessed 4 Feb. 2020].

Darby M. 2013. Studies of Madagascan Ptiliidae (Coleoptera: Ptiliidae) 1: The Tribe Discheramocephalini including eighteen new species Zootaxa 3718 (3): 239-266. https://doi.org/10.11646/zootaxa.3718.3.2

Darby M. 2014. Studies of Madagascan Ptiliidae (Coleoptera) 4: The genus Bambara including eight new species and the first account of blindness and aptery in the genus. Zootaxa 3895 (2): 151-169. https://doi.org/10.11646/zootaxa.3895.2.1

Darby M. 2015. Studies of Bolivian Ptiliidae (Coleoptera) 1: The genus Cissidium Motschulsky with six new species. Zootaxa 3937 (1):179-190. https://doi.org/10.11646/zootaxa.3937.1.9 
Darby M. 2019. New Ptiliidae (Coleoptera) from Sarawak in the spirit collection of the Natural History Museum, London. European Journal of Taxonomy 512: 1-50. https://doi.org/10.5852/ejt.2019.512

Deane C. 1931. Trichopterygidae of Australia and Adjacent Islands. Descriptions of five new genera and twenty new species. Proceedings of the Linnean Society of New South Wales 227 (3): 227-242.

Grebennikov 2009. Discheramocephalini, a new pantropical tribe of featherwing beetles (Coleoptera: Ptiliidae): description of new taxa and phylogenetic analysis. Systematic Entomology 34: 113-136. https://doi.org/10.1111/j.1365-3113.2008.00444.x

Johnson C. 1982. An introduction to the Ptiliidae of New Zealand. New Zealand Journal of Zoology 9: 333-376.

Johnson C. 2004. Ptiliidae. In: Smetana I. \& Smetata A. (eds) Catalogue of Palaearctic Coleoptera, 2, Hydrophiloidea-Histeroidea-Staphylinoidea: 22-25, 122-131. Apollo Books, Stenstrup.

Johnson C. 2007. Studies on Ptiliidae (Col., ) from the Solomon Islands, 1. Entomologist's Monthly Magazine 143: 213-226.

Johnson C. ms 2010. Studies on Ptiliidae (Col) from the Solomon Islands 3. Unpublished typescript in the possession of Johnson's family, lacking figures.

Lawrence J.F. \& Ślipiński A. 2013. Australian Beetles, Volume 1 Morphology, Classification and Keys. Csiro Publishing, Collingwood, Australia.

Matthews A. 1872. Trichopterygia Illustrata et Descripta, A Monograph of the Trichopterygia. London, Janson.

Matthews A. 1884. Trichopterygidae found in Japan by Mr G. Lewis. Cistula Entomologica 3 (XXVIII): $77-84$.

Matthews A. 1889. New genera and species of Trichopterygidae. Annals and Magazine of Natural History (6) III: 188-195. Available from https://biodiversitylibrary.org/page/15621981 [accessed 4 Feb. 2020].

Matthews A. 1900. Trichopterygia Illustrata et Descripta, A monograph of the Trichopterygia. Supplement, O.E .Janson, London. https://doi.org/10.5962/bhl.title.9346

Motschulsky V. von. 1855. Voyages. Lettre de M. de Motschulsky à M. Ménétriés. No 2, au bord du bateau à vapeur United-States, 20 Mars 1854. Études entomologiques 4: 8-25.

Motschulsky V von. 1868. Enumeration des nouvelles espèces de Coléoptères rapportés de ses voyages par Victor Motschulsky. Bulletin de la Société mpériale des Naturalistes de Moscou XLI (3):170-192.

Sawada Y. 2008. A Revision of the Genus Cissidium (Coleoptera: Ptiliidae) in Japan. Special Publication 2: 101-126. Japan Coelopterological Society, Osaka.

Manuscript received: 16 May 2019

Manuscript accepted: 5 December 2019

Published on: 2 April 2020

Topic editor: Gavin Broad

Section editor: Max Barclay

Desk editor: Kristiaan Hoedemakers 
Printed versions of all papers are also deposited in the libraries of the institutes that are members of the EJT consortium: Muséum national d'histoire naturelle, Paris, France; Meise Botanic Garden, Belgium; Royal Museum for Central Africa, Tervuren, Belgium; Royal Belgian Institute of Natural Sciences, Brussels, Belgium; Natural History Museum of Denmark, Copenhagen, Denmark; Naturalis Biodiversity Center, Leiden, the Netherlands; Museo Nacional de Ciencias Naturales-CSIC, Madrid, Spain; Real Jardín Botánico de Madrid CSIC, Spain; Zoological Research Museum Alexander Koenig, Bonn, Germany; National Museum, Prague, Czech Republic. 